\title{
THE PERPETUATION OF SITE-SPECIFIC INSTALLATION ARTWORKS
}

IN MUSEUMS

Staging Contemporary Art

\author{
Tatja Scholte
}


The Perpetuation of Site-Specific

Installation Artworks in Museums 



\section{The Perpetuation of Site-Specific Installation Artworks in Museums}

Staging Contemporary Art

Tatja Scholte 
The publication of this book is made possible by a grant

Cover illustration: Notion Motion (2005) by Olafur Eliasson; collection Museum Boijmans Van Beuningen, Rotterdam (MBVB); detail of installation

Photo: Bob Goedewaagen; courtesy photographer and MBVB; @ S Studio Olafur Eliasson

Cover design: Arienne Boelens, Rotterdam

Lay-out: Crius Group, Hulshout

$$
\begin{array}{ll}
\text { ISBN } & 9789463723763 \\
\text { e-ISBN } & 9789048554546 \text { (pdf) } \\
\text { DOI } & 10.5117 / 9789463723763 \\
\text { NUR } & 658
\end{array}
$$

\section{(c) $(1) \Theta$}

Creative Commons License CC BY NC ND (http://creativecommons.org/licenses/by-nc-nd/3.o)

@ Tatja Scholte / Amsterdam University Press B.V., Amsterdam 2022

Some rights reserved. Without limiting the rights under copyright reserved above, any part of this book may be reproduced, stored in or introduced into a retrieval system, or transmitted, in any form or by any means (electronic, mechanical, photocopying, recording or otherwise). 


\section{Table of Contents}

List of Figures and Diagrams

1 The Problem of the Perpetuation of Site-Specific Installation Art 15 Introduction

$\begin{array}{llr}1.1 & \text { Research Question } & 19\end{array}$

1.2 Olafur Eliasson's Notion Motion 24

1.3 Biographical Approach 30

1.4 Typologies and Site-Specific Installations as Dynamic Networks 32

$\begin{array}{lll}1.5 & \text { Outline } & 35\end{array}$

2 Site-Specific Installation Art in Historical Perspective 41

2.1 The Rise of Site-Specific Installation Art: Criticism Towards the Established Art World $\quad 42$

2.2 Unmoveable or Moveable? The Case of Richard Serra's Tilted Arc $\quad 48$

2.3 The Extended Life of Richard Serra's Splashing 53

2.4 Site Specificity and the Viewer's Position in the Gallery Space 60

2.5 Robert Morris's Amsterdam Project 63

2.6 The Site of Production and the Site of Perception 66

2.7 Phil Collins's they shoot horses 69

$\begin{array}{ll}2.8 \text { Conclusion } & 71\end{array}$

3 A Conceptual Model for the Analysis of Site-Specific Installations 75 The Conceptual Model Part 1: Triadic Model for Analysing Site Specificity 77

3.1 Introducing Henri Lefebvre's Theory on Space 77

3.2 Lefebvre's Triad of Spatiality Applied to Site-Specific Instal$\begin{array}{ll}\text { lations } & 81\end{array}$

3.3 Analysing Cultural Phenomena "as Performance" 90

The Conceptual Model Part 2: Analysing Successive Iterations of Site-Specific Installation Artworks 92

3.4 Looking through the Lens of Conservation: Performativity of Site-Specific Installation Artworks 92

3.5 Site-Specific Installations as Networks "In Action" 98

3.6 Using the Script as an Analytical Tool 100 
3.7 A Short Analysis of Two Site-Specific Installations by Richard Serra

3.8 Conclusion

4 Ernesto Neto's Célula Nave

Extending the Lifespan of a Temporary, Site-Specific Installation in a Museum Context

4.1 The Spatial Design and Materiality of Célula Nave

122

4.2 The Functions of "Social Space" and "Representational Space" in Célula Nave

4.3 The Fabrication of Célula Nave and "Spaces of Production"

126

4.4 The Reinstallation of Célula Nave without the Presence of the Artist

4.5 Shifts in the Spatial Network of Célula Nave and Refinement of the Conceptual Model

4.6 We Fishing the Time: The Relocation of a Temporary Installation to the Permanent Collection of the Tate Modern

4.7 Option 1: Restoration of the Original Artwork

4.8 Option 2: Remake by a Textile Factory in Brazil and the Artist's Studio

4.9 Option 3: Remake by Another Fabricator Aiming at a More Durable Version

4.10 Conclusion

5 Jason Rhoades's SLOTO

Reactivating Site Specificity and the Social Space of Perpetuation and Care

5.1 The Spatial Design of The Secret Life of the Onion

5.2 Representational Site Specificity of The Secret Life of the Onion

5.3 Social Production Spaces of The Secret Life of the Onion 172

5.4 Summarizing the Spatial Network of the First Staging 174

5.5 A Curatorial Intervention with SLOTO's Second Staging 177

5.6 Comparison with Jason Rhoades's P.I.G. (Piece in Ghent) 183

5.7 The Spatial Network "In Flux" 186

$\begin{array}{ll}5.8 \text { Conclusion } & 191\end{array}$ 
The Perpetuation of an Installation Artwork Emerging from a

Site-Specific Project

6.1 The Project and the Installation Drifting Producers

6.2 The Spatial Network of the Initial Exhibition at the Art Sonje Center

6.3 Intercultural Exchange in the Production and Reception of Drifting Producers

6.4 The Trajectory of Drifting Producers

6.5 Site Specificity of Drifting Producers in the Van Abbemuseum

6.6 The Social Production Space of Drifting Producers

222

6.7 Comparative Case Study: Constant's New Babylon Project

228

6.8 Conclusion

7 Conclusion and Further Discussion

7.2 Site Specificity and the Ongoing Dialogue between Artists and Custodians

7.3 Museum Practices and the Expanded Performance Analogy 



\section{List of Figures and Diagrams}

Figures

Figure $1 \quad$ Yard (1961) by Allan Kaprow. Installation view Environments, Situations, Spaces, Sculpture Garden at Martha Jackson, Gallery, New York. Photo: Ken Heyman-Woodfin Camp. Courtesy photographer and Getty Research Institute, Los Angeles. (c) Gallery Hauser \& Wirth.

Figure 2 Yard (1961/2007) by Allan Kaprow. Collection Van Abbemuseum, Eindhoven (VAM). Installation view in Allan Kaprow. Art as Life in 2007. Photo: Peter Cox. Courtesy photographer and VAM.

Figure 3 Notion Motion (2005) by Olafur Eliasson. Collection Museum Boijmans Van Beuningen, Rotterdam (MBVB). Donation: Han Nefkens H+F Mecenaat. Photo: Hans Wilschut. Courtesy photographer and MBVB. (C) Studio Olafur Eliasson.

Figure 4 Notion Motion (2005) by Olafur Eliasson. Collection Museum Boijmans Van Beuningen, Rotterdam (MBVB). Donation: Han Nefkens H+F Mecenaat. Installation view 2016. Photo: Hans Wilschut. Courtesy photographer and MBVB. (C) Studio Olafur Eliasson.

Figure 5 Tilted Arc (1981, removed in 1989) by Richard Serra, Federal Plaza, New York City. Photo: Anne Chauvet. (c) c/o Pictoright Amsterdam.

Figure 6 Gutter Splash Two Corner Cast (1992/1998) by Richard Serra. Collection Museum De Pont, Tilburg. Photo: courtesy De Pont. (c) c/o Pictoright Amsterdam.

Figure 7 The Amsterdam Project. Specifications for a Piece with Combustible Materials (1969) by Robert Morris. Collection Stedelijk Museum Amsterdam. Installation view in Op losse schroeven. Situaties en cryptostructuren. Photo: courtesy Stedelijk Museum Amsterdam. (c) c/o Pictoright Amsterdam.

Figure 8 They shoot horses (2004) by Phil Collins. Collection Tate Galleries, London. Photo: Tate. (C) c/o Pictoright Amsterdam and Tate. 
Figure 9 Waxing Arcs (1980, second version 1999) by Richard Serra. Collection Museum Boijmans Van Beuningen, Rotterdam (MBVB). Donation: Stichting Fonds Willem van Rede. Photo: Nieuwe Beeldenmakers, Ernie Buts. Courtesy photographer and MBVB. (C) c/o Pictoright Amsterdam.

Figure $10 \quad$ In Constant Motion: Richard Serra's 'Waxing Arcs' (2013), multimedia presentation by IJsfontein in Museum Boijmans Van Beuningen, Rotterdam (MBVB). Courtesy IJsfontein/MBVB.

Figure $11 \quad U m$ Sagrado Lugar (A Sacred Place) (2017) by Ernesto Neto. Installation view at $57^{\text {th }}$ Venice Bienniale. Photo by the author. 118

Figure 12 Célula Nave. It happens in the body of time, where truth dances (2004) by Ernesto Neto. Collection Museum Boijmans Van Beuningen, Rotterdam (MBVB). Donation: Stichting Fonds Willem van Rede. Installation view in Perception of Space. Photo: Bob Goedewaagen. Courtesy photographer and MBVB. (C) Ernesto Neto.

Figure 13/13a Célula Nave. It happens in the body of time, where truth dances (2004) by Ernesto Neto. Collection Museum Boijmans Van Beuningen, Rotterdam (MBVB). Donation: Stichting Fonds Willem van Rede. Installation view in Perception of Space. Photo: Bob Goedewaagen. Courtesy photographer and MBVB. (C) Ernesto Neto.

Figure 14 Floor plan of Célula Nave by Studio Ernesto Neto. Image editing: Arienne Boelens. (C) Ernesto Neto.

Figure 15 Students and teachers of University of Amsterdam, Conservation \& Restoration carry out a condition survey of Célula Nave in the Museum Boijmans Van Beuningen, 31 March 2014. Photo by the author.

Figure 16 Conservators Emmy de Groot and Carien van Aubel make an assessment of damages of the membrane of Célula Nave, 31 March 2014. Photo by the author.

Figure 17 Preventive conservation measures are taken for future storage of Célula Nave, 31 March 2014. Photo by the author. 
Figure 18 Navedenga (1998/2010) by Ernesto Neto. Collection Museum of Modern Art, New York. Digital Image (C) 2020 Museum of Modern Art, New York/Scala, Florence. (C) Ernesto Neto.

Figure 19 Let Your Hair Down (2009) by Pipilotti Rist, installed in the museum's stairways. Collection Museum Boijmans Van Beuningen, Rotterdam (MBVB). Acquired with the support of Han Nefkens $\mathrm{H}+\mathrm{F}$ Mecenaat en BankGiro Loterij. Photo: Maarten Laupman. Courtesy photographer and MBVB.

Figure $20 \quad$ SLOTO. The secret life of the onion (2003) by Jason Rhoades. Collection Van Abbemuseum, Eindhoven. Installation view. Photo: Peter Cox. Courtesy Van Abbemuseum archives, Eindhoven. (C) Hauser \& Wirth, Jason Rhoades Archive.

Figure 21 Garden Sculpture (1968-1996) by Dieter Roth. Collection Nationalgalerie/Staatliche Museen zu Berlin. Installation view at Museum Hamburger Bahnhof, 22 January 2016. Photo by the author. (C) Dieter Roth Estate/Courtesy Hauser \& Wirth.

Figure 22 Garden Sculpture (1968-1996) by Dieter Roth.

Collection Nationalgalerie/Staatliche Museen zu Berlin. Detail with jars, installation view at Museum Hamburger Bahnhof, 22 January 2016. Photo by the author. (C) Dieter Roth Estate/Courtesy Hauser \& Wirth. ${ }_{161}$ Figure 23 SLOTO. The secret life of the onion (2003) by Jason Rhoades. Collection Van Abbemuseum, Eindhoven. Detail with jars. Photo: Peter Cox. Courtesy Van Abbemuseum archive, Eindhoven. (c) Hauser \& Wirth, Jason Rhoades Archive. 166

Figure 24 SLOTO. The secret life of the onion (2003) by Jason Rhoades. Collection Van Abbemuseum, Eindhoven. Detail of the installation with a Porky's Train. Photo: Peter Cox. Courtesy Van Abbemuseum archive, Eindhoven. (C) Hauser \& Wirth, Jason Rhoades Archive. 168 Figure 25 SLOTO. The secret life of the onion (2003) by Jason Rhoades. Collection Van Abbemuseum, Eindhoven. Detail with a $3 \mathrm{D}$ printed tree trunk. Photo: Peter Cox. Courtesy Van Abbemuseum archive, Eindhoven.

(C) Hauser \& Wirth, Jason Rhoades Archive. 
Figure 26 SLOTO. The secret life of the onion (2003/2012) by Jason Rhoades. Collection Van Abbemuseum, Eindhoven. Installation view in For Eindhoven - The City as Muse. Photo: Peter Cox. Courtesy Van Abbemuseum archive, Eindhoven. (C) Hauser \& Wirth, Jason Rhoades Archive.

Figure 27 Drifting Producers (2004) by Flying City. Collection Van Abbemuseum, Eindhoven. Installation view in PlugIn \# 7 in 2006. Photo: Peter Cox. Courtesy photographer and Van Abbemuseum archive, Eindhoven. (C) Flying City.

Figure 28 Jeon Yongseok, leading artist of Flying City, in front of the Gwangmyeong Lifetime Education Center in Seoul, 2011. Photo by the author.

Figure 29 Jeon Yongseok visits one of the metal craftsman in Cheonggyecheon district in Seoul, 2011. Photo by the author.

Figure $30 \quad$ Power of Cheonggyecheon (2003) by Flying City, part of the installation Drifting Producers. Collection Van Abbemuseum, Eindhoven. Photo: Peter Cox. Courtesy photographer and Van Abbemuseum archive, Eindhoven. (C) Flying City.

Figure $31 \quad$ Poster for a Flying City performance showing the artists and craftspeople in the Cheonggyecheon district, Seoul. Photo by the author. (C) Flying City.

Figure 32 Drifting Producers (2004) by Flying City. Collection Van Abbemuseum, Eindhoven. Installation view in PlugIn \# 7 in 2006. Photo: Peter Cox. Courtesy photographer and Van Abbemuseum archive, Eindhoven. (C) Flying City.

Figure 33 Drawing by Flying City, part of the installation Drifting Producers (2004). Collection Van Abbemuseum, Eindhoven. Photo: Peter Cox. Courtesy photographer and Archieven Van Abbemuseum, Eindhoven. (C) Flying City.

Figure 34 Tailormade crates and support layers created by the technical staff of Van Abbemuseum for the urban models of Drifting Producers. Photo: Peter Cox. Courtesy photographer and Van Abbemuseum archive, Eindhoven. 
Figure 35 City, Drifting Producers (second version) (2006) by Flying City. Detail of the installation at Central Tourist Hotel, Seoul. Photo by the author. (C) Flying City.

Figure $36 \quad$ New Babylon (1956-1974) by Constant Nieuwenhuys. Collection Kunstmuseum Den Haag. Installation view in 2012. Photo by the author. (C) Fondation Constant.

Figure 37 New Babylon (1956-1974) by Constant Nieuwenhuys. Collection Kunstmuseum Den Haag. Installation view in Constant - New Babylon in 2016. Photo by the author. (C) Fondation Constant.

Figure 38 Ruimte in kleur (1952) by Aldo van Eyck and

Constant. Reconstruction made for Constant - New Babylon, Centro de Arte Reina Sofia, Madrid in 2016. Photo by the author. (C) Fondation Constant.

\section{Diagrams}

Diagram 1 The installation artwork as network. (C) The author. Image editing: Arienne Boelens/Maxim Hoekmeijer.

Diagram 2 Three modalities of space: physical, social, and symbolic. (C) The author. Image editing: Arienne Boelens.

Diagram 3 Henri Lefebvre's triad of spatiality: conceived space, perceived space, lived space. (C) The author. Image editing: Arienne Boelens.

Diagram 4 Lefebvre's triad of spatiality transposed to sitespecific installation artworks. Time influences variations in the spatial network. (C) The author. Image editing: Arienne Boelens.

Diagram 5 Triadic model for the analysis of site-specific installation artworks with an additional toolbox of script and actors. (C) The author. Image editing: Arienne Boelens.

Diagram 6 Model for the analysis of site-specific installation artworks with a breakdown of the function of social space into: social space of production, social space of the visitors' experience, and social space of perpetuation and care. (C) The author. Image editing: Arienne Boelens. 
Diagram 7 Expanded version of the model for the analysis of site-specific installation artworks with a pentagonal structure. (C) The author. Image editing: Arienne Boelens.

Diagram 8 Pentagonal model for the analysis of site-specific installation artworks with the additional toolbox of script and actors. (C) The author. Image editing: Arienne Boelens.

Diagram 9 Célula Nave: Biographical stages 2004 and 2009.

(C) The author. Image editing: Arienne Boelens.

Diagram 10 Célula Nave: Three options for future scenarios. (C) The author. Image editing: Arienne Boelens.

Diagram 11 SLOTO. The secret life of the onion: Biographical stages 2003 and 2011. (C) The author. Image editing: Arienne Boelens.

Diagram 12 Drifting Producers: The first staging 2004 and second staging 2005. (C) The author. Image editing: Arienne Boelens.

Diagram 13 Drifting Producers: Staging in the Van Abbemuseum in 2006 and options for future staging. (C) The author. Image editing: Arienne Boelens.

Diagram 14 Two retrospective exhibitions of Constant's New Babylon project in 2016, in Kunstmuseum and Museo Nacional Centro de Arte Reina Sofia. (C) The author. Image editing: Arienne Boelens.

Diagram 15 Final model for the analysis of site-specific installation artworks. (C) The author. Image editing: Arienne Boelens/Maxim Hoekmeijer. 


\title{
1 The Problem of the Perpetuation of Site-Specific Installation Art
}

\author{
Introduction
}

Keywords: site-specific, installation art, cultural biography, relational network, Allan Kaprow, Olafur Eliasson

"If I feel that the space is tangible, if I feel there is time, a kind of dimension I could call time, I also feel that I can change the space." Olafur Eliasson ${ }^{1}$

\section{Introduction}

In the summer of 1961, Allan Kaprow (1927-2006) installed dozens of used car tyres in the courtyard of the Martha Jackson Townhouse Gallery in New York City. The artist had collected these tyres from a nearby garage and invited his friends and fellow artists to participate in the Happening called Yard. ${ }^{2}$ There was no audience except for the participants who jumped over the heaps of tyres and moved them around. Photographs of Yard show Kaprow arranging the tyres within the small space of the courtyard, which was officially the sculpture garden of the gallery. Apart from the photographs, accounts of the event are scarce, and the press hardly paid any attention to it. And yet, Yard became one of Kaprow's seminal Happenings. The work has been acquired for many museum collections and was re-executed on

1 This quote comes from the TED Talk "Olafur Eliasson: Playing with space and light," presented by Eliasson at an official TED conference, 7 August 2009, https://www.ted.com/talks/ olafur_eliasson_playing_with_space_and_light?language=en.

2 Yard was part of the exhibition Environments, Situations, Spaces, which took place at the Martha Jackson Gallery from 25 May to 23 June 1961. After his experiments with collages and environments, Kaprow coined the term Happening in 1959.

Scholte, T., The Perpetuation of Site-Specific Installation Artworks in Museums. Staging Contemporary Art. Amsterdam: Amsterdam University Press 2022 DOI: 10.5117/9789463723763_CHO1 
Figure 1 Yard (1961) by Allan Kaprow. Installation view Environments, Situations, Spaces, Sculpture Garden at Martha Jackson, Gallery, New York. Photo: Ken Heyman-Woodfin Camp. Courtesy photographer and Getty Research Institute, Los Angeles. @ Gallery Hauser \& Wirth.

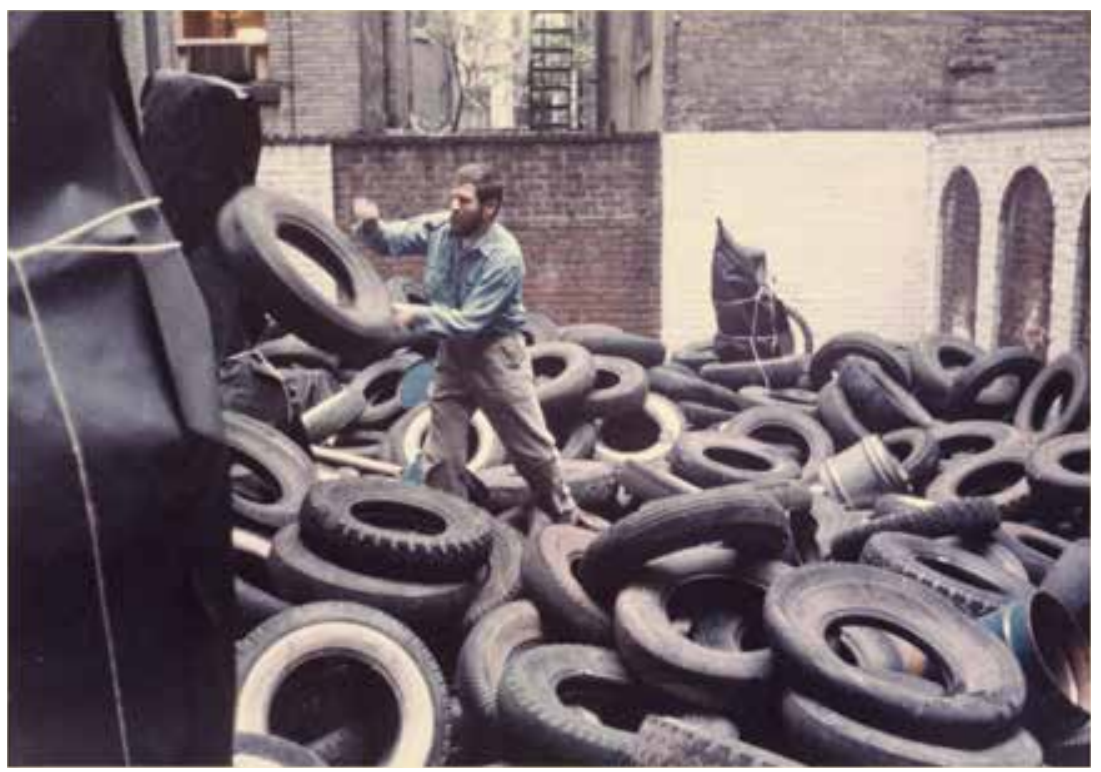

numerous occasions, both by Kaprow and others, at different places and with other participants.

A few years earlier, Kaprow coined the term Happening to describe the events he organized as an integration of "all the elements - people, space, the particular materials and character of the environment, time." In accordance with the 196os dictum to merge art and life, he preferred the use of everyday materials and orchestrated his Happenings in the here and now, employing the specifics of the space. ${ }^{4}$ Or, as curator Paul Schimmel states, with the invention of the Happening, a new art form

3 In Michael Huxley and Noel Witts, The Twentieth-Century Performance Reader ( $2^{\text {nd }}$ edition) (New York: Routledge, 2002), 264.

4 In fact, Kaprow orchestrated Happenings in detail and provided the participants with a set of instructions beforehand. For an elaborate description of Kaprow's working method, see: Paul Schimmel, "Leap into the Void: Performance and the Object," in Out of Actions: between performance and the object, 1949-1979, exhibition catalogue (New York: Thames and Hudson, 1998), $61 \mathrm{ff}$. 
emerged that resembled many things at once: object art, installation art, and performance art. ${ }^{5}$

In the case of Yard, Kaprow responded to the situation in yet another way, as art historian Martha Buskirk observes. The Martha Jackson Gallery usually presented artworks by modernist artists and, at the time of the Happening, sculptures by Barbara Hepworth and Alberto Giacometti were on display in the courtyard. As Buskirk points out, photographs of the Happening reveal that Kaprow had wrapped those sculptures in tarpaper and tied them up like packages. [Figure 1] The artist had "blocked" them from the audience's perception as a statement, and he "temporarily swallowed up the more traditional modernist sculptures already on the site," literally concealing the art of his predecessors. ${ }^{6}$ This contextual element was unique for the first iteration and tied the installation to the site of the performance.

In theory, Happenings have brief lives, because they are bound to specific sites and times. However, the many reiterations of Yard, varying from reinterpretations of the Happening to more sculptural site-specific installations, reveal something else. [Figure 2] Martha Buskirk concludes: "Indeed, Yard is not simply a 1961 work, but an environment with a surprisingly extended history." In the course of time, Yard was not only reiterated by the artist or by curators who used documentation of earlier versions but also by contemporary artists who were invited by his gallerist Hauser \& Wirth in 2009, three years after the artist had passed away. Several "reinventions" were created at different places, for instance by William Pope.L. ${ }^{8}$ The artist,

5 Paul Schimmel mentions the influence of John Cage and a New York-based group of artists (Jim Dine, Red Grooms, Claes Oldenburg, and Robert Whitman) as "pioneers" of the Happening. The influence of Jackson Pollock's Action paintings and John Cage's affinity with random sound can also be traced in Kaprow's preference with his use of everyday materials and nonprofessional participants. The citation comes from Paul Schimmel, "Only memory can carry it into the future," in Allan Kaprow, Art as Life, ed. E. Meyer-Hermann, A. Perchuk, and S. Rosenthal (Los Angeles: The Getty Research Institute, 2008), 8-19.

6 Martha Buskirk, Creative Enterprise. Contemporary Art Between Museum and Marketplace (International Texts in Critical Media Aesthetics. Volume 3) (New York: The Continuum International Publishing Group, 2012), 123.

7 Buskirk, Creative Enterprise, 129.

8 In 1991, at the occasion of the overview exhibition 7 Environment at the Fondazione Mudima in Milan, Kaprow expressed his preference for the term "reinvention" over "reconstruction," because each new manifestation should differ from the original. Allan Kaprow, 7 Environments (Naples: Studio Morra, 1992), 23. For an overview of Yard's reinventions, see http://allankaprow. com/about_reinvetion.html (last accessed 20 April 2021). The artists invited by Hauser \& Wirth in the 2009 show were William Pope.L, Josiah McElheny, and Sharon Hayes. Exhibitions — Allan Kaprow YARD - Allan Kaprow | Hauser \& Wirth (hauserwirth.com) (visited 20 April 2021). 
Figure 2 Yard (1961/2007) by Allan Kaprow. Collection Van Abbemuseum, Eindhoven (VAM). Installation view in Allan Kaprow. Art as Life in 2007. Photo: Peter Cox. Courtesy photographer and VAM.

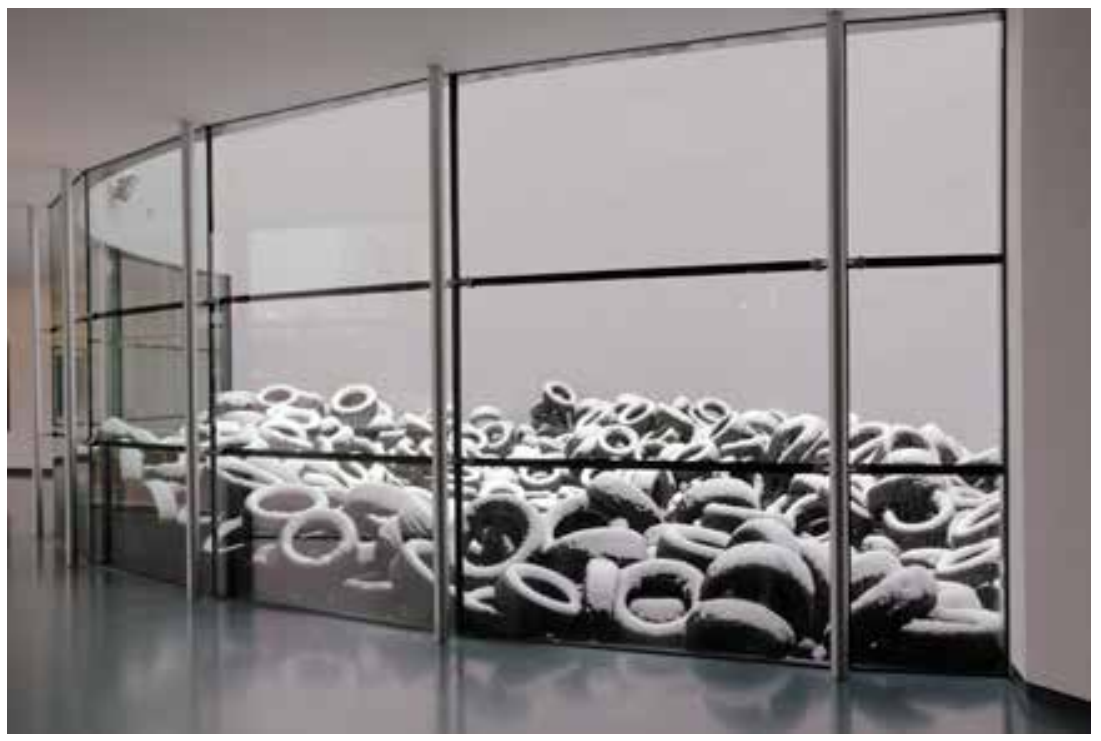

who is best known for his performance artworks, created a new version at the original location in the Martha Jackson Gallery, bearing the title Yard (to Harrow). Because the courtyard had been roofed over in the meantime, the artist decided to relocate the installation to the first floor of the gallery. In fact, Yard (to Harrow) covered more or less the same geographical co-ordinates as the original Happening, although this location had now turned into an indoor gallery.

Like in 1961, but with a wider audience, participants were invited to crawl and jump around. In William Pope.L's reinvention, sound and bright gallery spots were added as cinematographic elements. "Body bags" - like the ones wrapping the sculptures from Hepworth and Giacometti in the 1961 event - were also added to the installation, honouring Kaprow's statement of the original Happening. ${ }^{9}$ In the words of William Pope.L, "Kaprow wanted to hide something - I wanted to show something." With this gesture, the artist not only returned Yard to its place of origin in Martha Jackson's Townhouse but also reactivated a meaningful constituent of Kaprow's Happening in a different sociocultural environment.

9 William Pope.L calls them "body bags" in an interview with Mary Barone, Art in America, 6 October 2009 . 
Over the years, Yard turned into an iconic example of site specificity, performativity, and audience interaction; although the original Happening was rooted in the art practice of the 196os, its afterlife demonstrates a richness in approaches for reinvigorating site-specific installation artworks in different contexts and times.

\subsection{Research Question}

At first glance, relocating site-specific installations and extending their lives within a museum context seems to be contradictory to the principles of site specificity. As the term "site-specific" indicates, this kind of artwork is designed for a specific place and/or the surrounding context. Furthermore, the artworks are often intentionally temporary and performative, connecting the manifestation of the work not only to space but also to time. Hence, these artworks are spatiotemporally defined and would, theoretically, only exist as a singular manifestation for the duration of an exhibition. On the other hand, as the example of Yard has shown, artists, gallerists, and curators have frequently engaged with reiterations of site-specific installation artworks after the initial moment of creation.

Yard raises a number of questions that are central to my research project. First of all, Happenings are often seen as forerunners of "performance art," a term coined in the 1970 s as an umbrella term for avant-gardist artworks with a focus on process and action in the present moment. ${ }^{10}$ Likewise, site-specific installations engage the visitor in the here and now and could be compared to a temporary event or a "performance." In view of the spatiotemporal determinacy of performances and site-specific installations, a sincere problem arises with the acquisition of the work by a gallery or a museum. In the attempt to give these artworks an afterlife, an ontological gap is created between the initial "performance" of the artwork and its manifestations at later instances. Indeed, as outlined above with the history of Yard, site-specific artworks have been collected by museums ever since their emergence in the 196os. To this day, they have been presented in different contexts, just like they will be in the future. How can we understand this inherent paradox of the perpetuation of these artworks? What happens to the identity of site-specific installations once

10 For this comparison between Happenings and performance art, see: Richard Schechner, Performance Studies. An Introduction (London: Routledge, 2013), 39-40. 
they have been acquired for a museum collection and are reinstalled time and again?

Another key question is how site-specific installations survive in a museum context. Whereas Allan Kaprow preferred Yard to be "reinvented" by himself or others, this is not a standard approach in the production and conservation of contemporary art. The conservation discipline engaged with contemporary art is deeply concerned with matters of change and variability, due to the use of evanescent materials and transitory nature of, for example, installation artworks. The connectivity of site-specific installations to their surroundings poses an extra problem, because change, in this case, reaches beyond the configuration of the work itself. Relocation of the installation to a different place, renovation of the exhibition space for which the work was intended, or changes in museum policies and the sociocultural context may all have a major effect on the form and meaning of the work of art. Seen from the perspective of their perpetuation, could we assume that site-specific installations have a transformative identity, including the ability to accommodate their site specificity to new circumstances? And from a strategic and decision-making point of view, what are factors of influence that determine the reinvigoration of the artwork's site specificity and which approaches would apply in actual museum practices?

The above leads to two main questions that will be discussed in this book. The first question addresses the connectivity between the artwork and the "site" of its presentation: how can we describe this connection, and what set of parameters can support a comparison between one iteration and another? How does this systematic comparison contribute to answering the ontological question whether a manifestation of a site-specific installation is still recognizable as the same artwork, despite modifications of the spatial design of the work and/or of the surrounding exhibition space? What happens to the identity of a site-specific installation when the sociocultural context in which it is presented changes, especially when this context is intertwined with the artwork's meaning?

The second question focuses on the strategies artists and custodians have at their disposal in regard to the activation of a network of site-specific functions, which foregrounds the issue of the artwork's presentation in diverse contexts. In this part of my study, I will engage with the position of the museum's caretakers, conservators, and curators, and I will explore their motives during decision-making processes. What strategies are employed to give a site-specific installation a meaningful afterlife? What are the parameters steering these decisions? What is gained and what can be considered as lost in the artwork's site-specific functions? 
To answer these questions, my research offers a conceptual model for the analysis of site-specific installation artworks and their presentation in various contexts and times, enabling a systematic comparison of successive iterations and the factors that influence their presentation as a site-specific installation. The building blocks of the study are derived from various academic disciplines - art history, conservation, and sociogeography which will shape the conceptual model step by step. For each step, I will discuss a number of case studies; the exploration of concrete examples elucidates the considerations from the professional field. The aim of this study is to contribute to decision-making processes in museums by offering a framework that aligns with a current development in conservation to make a shift from an object-centred approach to a more relational approach. In the case of site-specific installations, this includes the relationships between places, objects, and people.

\section{Defining Site-Specific Installation Artworks and Their Perpetuation}

The generation of artists to which Allan Kaprow belonged opposed the mechanisms of the art market and criticized the emerging consumer society of the 1960 s. Life events, performances, and site-specific installations were strategies to oppose the idea of "art as commodity" and the circulation of art objects - not least because these artworks were supposed to be untradeable and could not be easily moved. Simultaneously, with their refusal to participate in the official art circuit, artists looked for alternative exhibition places where they could experiment with new forms and production methods for their art in situ. As a consequence, site-specific art was preferably created in factories, empty office buildings, or public space - places that offered the artists ample opportunity for experiment. From the 1960 s onwards, artists engaging with land art projects showed an interest in exploring the connectivity between art and the physical properties of a given site. Apart from that, a wide array of materials, media, techniques, and strategies were used to explore the site's conditions and incorporate them into the production of site-specific works of art.

Ideologies have changed over the past fifty years, and an ever-increasing number of site-specific installations is being produced by contemporary artists, often in co-operation with gallerists and museum curators. Today, artists are often invited to create spectacular installations for specific locations in a commercial gallery or museum building. Indeed, it is now part of the art practice to work with the conditions of a particular site or "a style 
of working," as the curator Christian L. Frock observes. ${ }^{11}$ In concordance with these developments in artistic practice, a broader notion of site specificity has come into vogue. As stated by Mary Tinti in the Oxford Dictionary of Art, site specificity "has evolved to encompass a broad range of philosophical and conceptual nuances. It continues to be the subject of much scholarly scrutiny, discussion and debate in the new millennium."12 In agreement with this wider view on site-specific art, my study contributes to the discussion by examining the problem of the extended lives of artworks that were created for a specific place and were subsequently acquired for a collection.

Arguably, the subject has a large scope, and it is important to provide a structure to get a grip on the kind of artworks under discussion and the problem of their perpetuation. Art historians and theorists have developed typologies for site-specific installations, mostly following the chronology of their creation process. Although I will gratefully make use of existing categorizations, for the current purpose, it seemed more productive to develop a model that applies to the phenomenon of site specificity independently from the historical context in which the artwork is created. Furthermore, given the focus on decision-making processes, the model offers a means to analyse different manifestations of one and the same site-specific artwork. To this end, a toolbox is proposed that enables the analysis of the network of factors that influence its successive iterations, by which means the impact of the artwork's musealization and perpetuation can be scrutinized over time.

In view of the above, a few words are needed regarding the terminology used. I have designated the term "perpetuation" to the processes and practices of safeguarding site-specific installation artworks, because its meaning, "to preserve something valued from oblivion or extinction," suggests an active approach that applies to the reinvigoration of site-specific artworks. ${ }^{13}$ The alternative term, "continuation" (which, in fact, is a more common term in conservation studies) would suggest that the artwork continues to exist in more or less the same format, which would be in contrast to the radical changes these artworks may undergo when exhibited in new contexts and/or times.

11 Christian L. Frock, "Site-Specific Installation: Some Historic Context," in Unexpected Art. Serendipitous Installations, Site-Specific Works and Surprising Interventions, ed. Jenny Moussa Spring (San Francisco: Chronicle Books, 2015), 8.

12 Mary M. Tinti, "Site-specific," Oxford Dictionary of Art, https://www.oxfordartonline.com/ search?q=site-specific\&searchBtn=Search\&isQuickSearch=true (last accessed 20 April 2021)

13 See English Grammar https://www.englishgrammar.org/perpetrate-vs-perpetuate/ (last accessed 20 April 2021). 
Furthermore, I will use the umbrella term "conservation" for several activities in the conservation field that are usually subdivided into "preventive conservation" (handling, transport, storage and display measurements), "conservation" (action carried out with the aim of stabilizing condition and retarding further deterioration), and "restoration" (action carried out on damaged or deteriorated objects). ${ }^{14}$

In addition, the terms "installation art" and "site-specific installation art" need clarification, because they partially overlap. Art historians and scholars usually call spatial constructions that are composed of heterogeneous elements "installation art." This term emerged in the 196os and has been ambiguous from the start. According to Claire Bishop, the term "installation" was used in art magazines to describe artworks "that used the whole space" of the gallery; in photo captions, it indicated the overall arrangement of an exhibition: the "installation shot." 5 Soon after, installation art became a general indicator of a wide array of artworks, varying "in appearance, content and scope." ${ }^{\prime 6}$ In the same vein, art critic and curator Mark Rosenthal refers to installations as an "integrated, cohesive, carefully contrived whole." ${ }^{\text {"7 }} \mathrm{He}$ stresses the presence of the viewer, who often needs to enter the installation space physically to experience the artwork, as a precondition for rendering the meaning of the installation. Rosenthal calls this the "lifelike qualities" of installation art, grouping the works together around the parameters of space and time:

The time and space of the viewer coincide with the art, with no separation or dichotomy between the perceiver and the object. In other words, life pervades this form of art. ${ }^{18}$

"Spatial configuration" and "temporality" are concepts that apply to installation art at large. However, in site-specific installations, an extra layer of meaning is added to the configuration; namely, the artwork's interrelatedness with the site. This interconnectivity between the configuration of the installation itself and the surrounding context is by definition both spatially

14 After E.C.C.O. Professional Guidelines, Promoted by the European Confederation of Conservator-Restorers' Organization, 2002, http://www.ecco-eu.org/fileadmin/user_upload/ ECCO_professional_guidelines_II.pdf.

15 Claire Bishop, Installation Art. A Critical History (London: Tate Publishing, 2005), 6.

16 Bishop, Installation Art, 6.

17 Mark Rosenthal, Understanding Installation Art. From Duchamp to Holzer (Munich: Prestel Verlag, 2003), 26.

18 Rosenthal, Installation Art, 27. 
and temporally defined. Hence, strictly speaking, a site-specific installation would only exist as a singular manifestation, because the work cannot exist in the same form in another space and/or time. In reality, however, many artworks continue their existence in a museum context, which means that, inevitably, change or loss of site specificity occurs, a crucial aspect that sets these artworks apart from the larger group of installations.

The aspect of singularity is at the heart of the current research, especially in regard to the question whether, and if so how, site specificity can be repeated, reactivated, or re-established. Many artists, gallerists, and museum practitioners have been involved in the relocation of site-specific installations to a museum, and on a regular basis, decisions are made regarding the site specificity of the artwork: some elements may survive, while others have been adjusted or omitted from the installation, depending on the situation. In the current research, I will closely examine such decisions and the underlying motives in concrete case examples in tandem with actual museum practices and the attempts to communicate site-specific art from the past to contemporary audiences.

In view of the above, I would like to make the additional remark that historical works have the advantage of a sequence of reiterations that can be studied as a trajectory of consistencies and transformations, as demonstrated in the introductory example of Allan Kaprow's Yard. With more recent site-specific installations, the approaches and strategies for their perpetuation are often not yet crystallized, which enables researchers to experience the decision-making process from up-close and to analyse the problems and solutions applied in current practice. In my research, I followed both directions by interlacing historic and contemporary examples to get a better grip on the full range of site-specific installations in museums. In fact, a contemporary example, which I will briefly introduce below, triggered my interest in this research topic. The kind of questions arising from its acquisition are illustrative of the issues encountered with many other site-specific installation artworks as well.

\subsection{Olafur Eliasson's Notion Motion}

In 2005, the Museum Boijmans Van Beuningen in Rotterdam asked the Berlin-based Danish Icelandic artist Olafur Eliasson to create a site-specific installation for the first floor of the Bodon Gallery: Notion Motion. [Figure 3] A few years earlier, Eliasson had stunned museum visitors with The Weather Project, in which he created the illusion of a sunset inside Tate Modern's 
Figure 3 Notion Motion (2005) by Olafur Eliasson. Collection Museum Boijmans Van Beuningen, Rotterdam (MBVB). Donation: Han Nefkens H+F Mecenaat. Photo: Hans Wilschut. Courtesy photographer and MBVB. (c) Studio Olafur Eliasson.

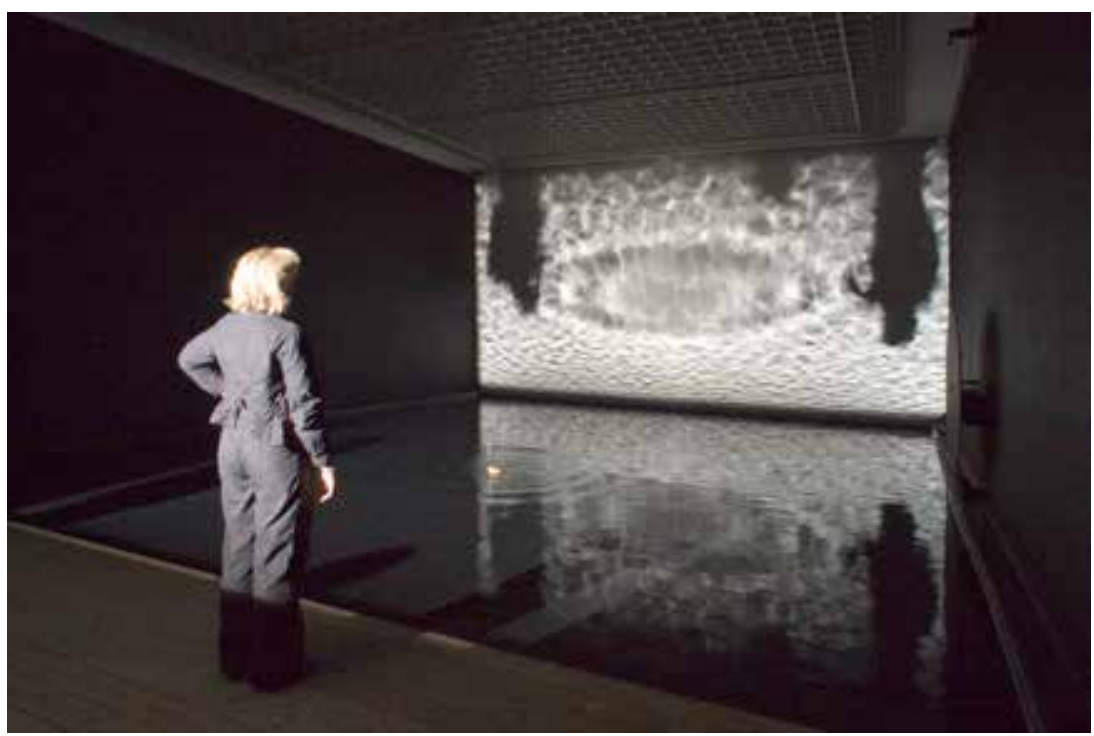

Turbine Hall. Natural phenomena and site specificity are key concepts in all of his works, reaching new heights in 2021, with the installation Life in Fondation Beyeler in Riehen, Switzerland. Together with landscape architect Günther Vogt, Eliasson literally blurred the line between the museum's interior space and the adjacent water lily pond by removing sections of the glass façade and flooding the interior with green-dyed water and water plants. Visitors could navigate the space through a network of walkways. Some of these elements are already present in Notion Motion, in which large water basins and wooden duckboards cover three adjacent compartments of the Bodon Gallery (measuring 1200 square metres in total).

Taking advantage of the large dimensions of the exhibition space, Eliasson created three adjacent compartments, covering 1200 square metres in total. The installation largely consists of water containers covered with raised, wooden duckboards on which visitors can walk. The rooms are darkened, with the exception of a few spotlights illuminating particular sections, like on a film set. Visitors literally breathe life into the artwork by walking over the duckboards and causing ripples when the boards touch the water. With each movement, ripples are amplified by wave activators, and as a result, light waves are projected on the walls. Notion Motion is 
Figure 4 Notion Motion (2005) by Olafur Eliasson. Collection Museum Boijmans Van Beuningen, Rotterdam (MBVB). Donation: Han Nefkens H+F Mecenaat. Installation view 2016. Photo: Hans Wilschut. Courtesy photographer and MBVB. $\odot$ Studio Olafur Eliasson.

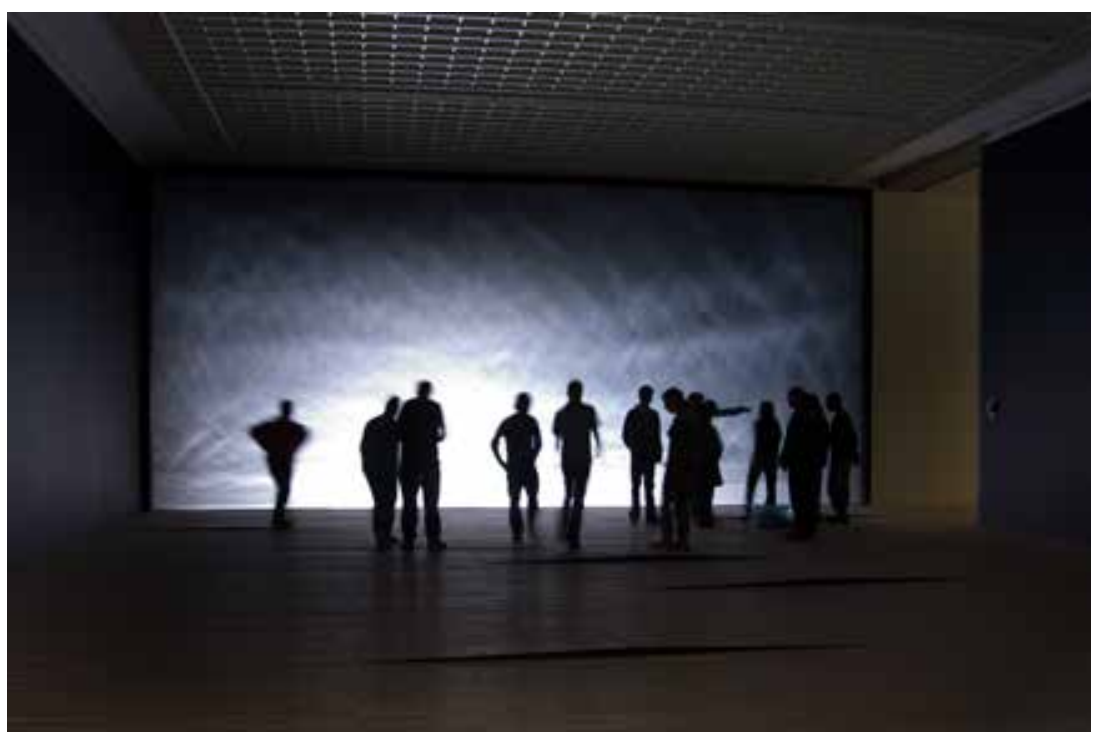

both spectacular and intimate, as it makes visitors aware of their own interactions and intensifies their perception when ripples in the water transform into patterns of light. ${ }^{19}$

According to Eliasson, museums offer a unique platform for presenting artworks that raise people's awareness of natural phenomena and of time and space:

So here I am with a museum exhibition and I want the time to take the museum out of its stigma, of being timeless, and add the time to it as a dimension which is productive to the quality of the work. So it is not, again, about the museum but about the spectator [...] and the principle question about taking your time. ${ }^{20}$

19 Claire Bishop describes the visitor's encounter in the museum space with Eliasson's Notion Motion as an experience of "returning to the subjective moment of perception." Claire Bishop, Installation Art. A Critical History (London: Tate Publishing, 2005), 76-80.

20 Olafur Eliasson made this statement in the documentary video "Take your Time," published on the website of MoMA, https://www.moma.org/interactives/exhibitions/2008/olafureliasson/\#/ video4/ (last accessed 20 April 2021). 
Notion Motion was created and acquired in 2005 and was rebuilt in the Bodon Gallery in 2010 and 2016. I visited Notion Motion twice and was touched by the cheerful way people behaved when touching the duckboards, sometimes even dancing in front of the projection. [Figure 4] The installation was appreciated by the public and art critics. The commission is exemplary for the curatorial agenda of Museum Boijmans Van Beuningen: offering its publics immersive experiences with contemporary art. On the reverse side are the high demands posed to the museum and its staff members in terms of reinstallation. Each time the installation is presented, interior walls have to be rebuilt to subdivide the Bodon Gallery into the necessary separate compartments; huge water basins need to be covered with foil to carry no less than 20,562 litres of water; and each time the installation is exhibited, 800 duckboards have to be assembled and reinstalled. ${ }^{21}$ Apart from the spotlights and a few technical devices, no material substances are kept, and for each new period of display the entire construction has to be reassembled.

Notion Motion is one of the most prestigious acquisitions of the Museum Boijmans Van Beuningen, which raises profound issues for the perpetuation of the artwork. The work could only be purchased with external financial support of a patron, and the agreement indicates that the artwork should be on show every five years. ${ }^{22}$ Apart from the huge efforts to rebuild the construction, there is the issue of safety relating to the management of the water basins and the visitors walking over the duckboards in darkened spaces. Site-specific installations often entice the public to interact with them because of their exciting, spatial, and sometimes interactive constructions, but they may also bring risks, as we shall see in a number of case studies in this book-risks for the building, the collection, and the public.

At the heart of the current research is Notion Motion's site specificity. Could the artwork lent to a different location? This problem was discussed during a European project, Inside Installations, in which I was directly involved as the main co-ordinator. ${ }^{23}$ The international conservation com-

21 A description of the work is provided at https://www.boijmans.nl/en/exhibitions/olafureliasson-notion-motion-2016 (last accessed 20 April 2021).

22 Notion Motion was acquired with the financial support of $\mathrm{H}+$ F Patronage (Han Nefkens).

23 The European project Inside Installations ran from 2004 to 2007 . On behalf of the Cultural Heritage Agency of The Netherlands, I was main co-ordinator of the project in which twenty-five European museums and institutions researched the problems of preservation and reinstallation, and carried out an equal number of case studies on installation art. See for the results of the project Tatja Scholte and Glenn Wharton, eds., Inside Installations: Theory and Practice in the Care of Complex Artworks (Amsterdam: Amsterdam University Press, 2011). Part of the project consisted of a recording of the reinstallation process of Notion Motion in 2010, included in the film "Installation Art: Who 
munity has a history of collaborative projects, in which conservators, curators, and scholars participate in individual case studies and in which the artist is involved wherever possible and desired. ${ }^{24}$ Against this background, Inside Installations focused on a an interdisciplinary approach during the investigation, conservation, and presentation of a large number of case studies on installation artworks in museums. Notion Motion was one of the more complex cases because of the few physical remains and the scarce documentation. When Eliasson was asked for his opinion on the matter of lending Notion Motion to other institutions, his answer was positive - on the condition that the spatial dimensions would differ no more than 10 per cent from the original. The interview conducted during the project clarified that "[it] should be attempted to show the work with all parts if possible. A partial showing should mention that the work is only partially represented." Only Olafur Eliasson or a representative of his estate could decide to do otherwise. ${ }^{25}$ This very precise specification would give the museum relative freedom to relocate the artwork to a different venue, which in fact has not happened to the date of this writing.

Most of the issues discussed above were not foreseen at the moment of Notion Motion's first display. Only with the passage of time, the problems of the artwork's perpetuation become manifest; each new iteration is challenging, especially with regard to a current development. In May 2019, Museum Boijmans Van Beuningen closed its doors for a major renovation of the entire museum. A new episode started in 2021, with the building of a public art depot next to the still to be renovated museum building, which will serve as an additional exhibition space. It is not unthinkable that Notion Motion will be reinstalled at this new site, and even when executed at (almost) the same geographical co-ordinates, these contextual changes will have a considerable effect on a new iteration of the work.

Cares?," published by the Foundation for the Conservation of Contemporary Art, the Netherlands, https://www.sbmk.nl/en/publications/filmInstallationArtWhoCares (last accessed 20 April 2021). 24 Examples of international collaboration projects in the conservation of contemporary are the symposium Modern Art: Who Cares? (1996) and the eponymous publication (1999) and the International Network for the Conservation of Contemporary Art (INCCA) (1999-present). See IJsbrand Hummelen and Dionne Sillé, eds., Modern Art: Who Cares? (London: Archetype Publications, 2006 [1999]); IJsbrand Hummelen and Tatja Scholte, "Sharing Knowledge for the Conservation of Contemporary Art: Changing Roles in a Museum without Walls?" in Modern Art, New Museums, ed. Roy Ashok and Perry Smith (Bilbao: The International Institute for Conservation of Historic and Artistic Works, 2004), 208-210.

25 This citation is taken from an interview with Olafur Eliasson by Elbrig de Groot and Jaap Guldemond, archive Museum Boijmans van Beuningen. 
The examples of Yard and Notion Motion indicate that site-specific installation artworks continue to give rise to new questions regarding the reinvigoration of their site-specific functions. As we shall see with quite a number of examples presented in the following chapters, it is no exception that site-specific installations end up in a deadlock at some point in their career. This is not to say that site-specific installations cannot survive changing circumstances. Especially if they are considered of significant value for the collection, custodians continue to search for solutions to the challenging questions those artworks pose, in order to keep the artworks alive.

\section{Methodology}

The aim of the study that follows is to contribute to the decision-making processes from an academic point of view, without losing sight of the issues at stake in museum practices. The cross-fertilization between practice and theory is a trademark of current research in the field of musealization, conservation, and presentation of contemporary art. ${ }^{26}$ In accord with this trend, the core of my method consists of two main parts. First, to develop a conceptual framework, I carried out profound literature research of relevant academic writings in art history, sociogeography, and conservation studies, which, each in their own way, contribute to the successive chapters and the various steps in which I develop my argument. Second, and of equal importance, are case study analyses carried out by means of archival research, literature reviews, interviews with a range of stakeholders, and personal observation. During my professional life, I have been fortunate to participate in many projects, such as Modern Art: Who Cares, International Network for the Conservation of Contemporary Art (INCCA), and Inside Installations; in these projects, I could closely follow the research carried out by conservators and curators. They taught me how to understand the complex problems of conserving transient works of art and the ethics involved in dealing with continuation and change. My background as co-ordinator of conservation projects also paved the way to gain access to the archives and staff of renowned contemporary art museums when carrying out my main case studies, in particular the Van Abbemuseum in Eindhoven, the Museum Boijmans Van Beuningen in Rotterdam, the Tate in London, and the Museum of Modern Art (MoMA) in New York.

26 See, for example, the innovative European training network New Approaches in the Conservation of Contemporary Art, co-ordinated by Maastricht University, 2017-2019, http://nacca.eu/ about/. 
Diagram 1 The installation artwork as network. $\odot$ The author. Image editing: Arienne Boelens/Maxim Hoekmeijer.

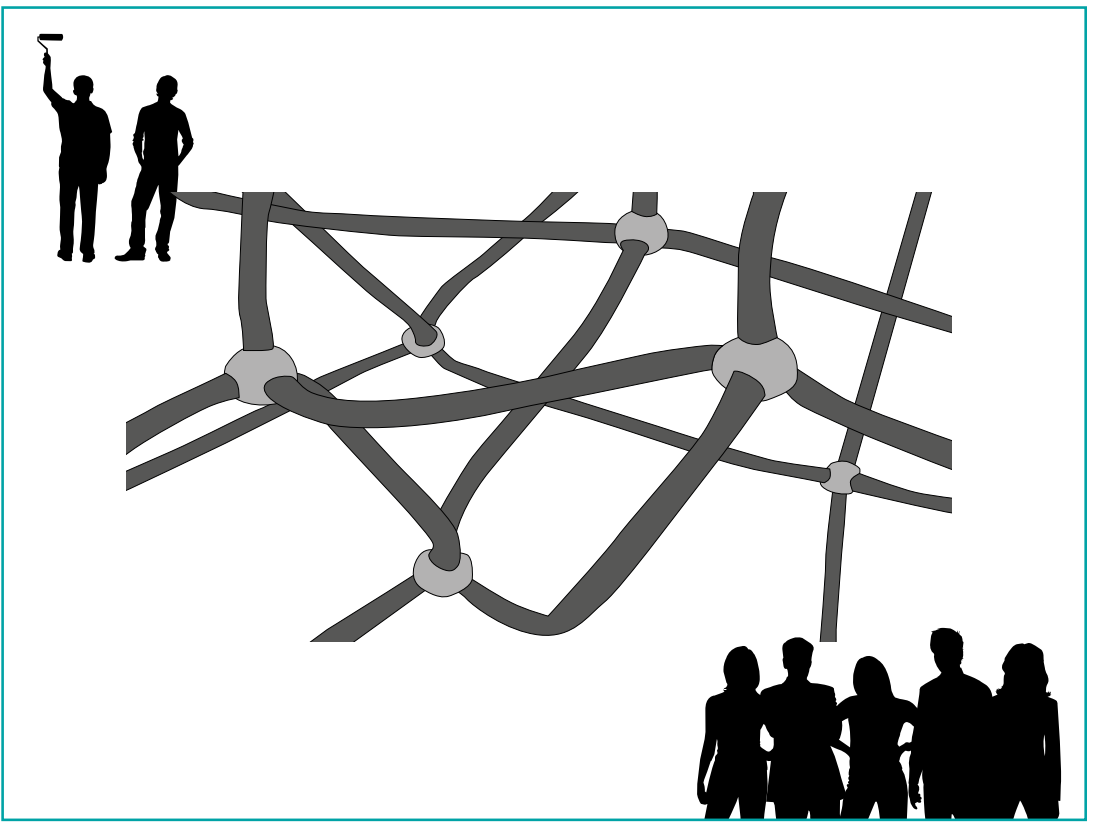

Two general concepts are at the heart of my methodological approach, briefly introduced below. The first is the proposition to study site-specific installation artworks from a biographical perspective. The second rests on the assumption that site-specific installations can be conceived as dynamic relational networks, which will be a guiding principle for structuring the conceptual model. [See Diagram 1]

\subsection{Biographical Approach}

The notion of the cultural biography of objects was introduced by anthropologists Igor Kopytoff and Arjun Appadurai, and has gained currency in heritage studies, archaeology, and more recently, in reflective writing on contemporary art conservation. ${ }^{27}$ Key to this notion is the idea that cultural objects have "social lives" and that the relevance of the object - its material, symbolic, social,

27 The concept of the biography of cultural objects was introduced in Arjun Appadurai, "Introduction: Commodities and the Politics of Value," in The Social Life of Things, ed. Arjun Appadurai (Cambridge: Cambridge University Press, 2005), 3-63. Also: Igor Kopytoff, “The 
utilitarian, and/or economic value - can be assessed at moments of transition, when the object moves from one cultural sphere to another. ${ }^{28}$ The authors state that the life of a cultural object can be studied by looking into the history of its making and by studying the shifts in meaning and changing "status" of the object during its journey through different value systems. Igor Kopytoff explains:

Biographies of things can make salient what might otherwise remain obscure. For example, in situations of culture contact, they can show what anthropologists have so often stressed: that what is significant about the adoption of alien objects - as of alien ideas - is not the fact that they are adopted, but the way they are culturally redefined. ${ }^{29}$

Within conservation of contemporary art research, the biographical approach has been embraced in order to study and compare various manifestations in the lives of works of art, considered as successive stages in which meaning is redefined. ${ }^{30}$ In the often complex trajectories of contemporary artworks, variation, change, and transformation frequently occur - and not always in concordance with the artwork's linear chronology. The assumption is that, by means of distinguishing, describing, and analysing "biographical stages," we might understand what elements of the artwork have changed or remained the same, and why this happened at moments of transition. Moreover, the approach brings into focus the processual character of contemporary art and the possibility that artworks can move into or out of a biographical stage: at some stages, significant differences may occur, whereas other stages are more consistent with each other; even similarities in biographical stages of different artworks may come to light. In this sense, conservation scholar Renée van de Vall suggests that the cultural biography enables us to follow individual trajectories that nevertheless may show similar phases and patterns of change..$^{31}$

Cultural Biography of Things: Commoditization as Process," in The Social Life of Things, ed. Arjun Appadurai (Cambridge: Cambridge University Press, 2005), 64-91.

28 Kopytoff, "Cultural Biography," 66-67.

29 Kopytoff, "Cultural Biography," 67.

30 For in-depth discussion of the biographical approach applied to the conservation of contemporary art, see: Renée van de Vall, Hanna Hölling, Tatja Scholte, and Sanneke Stigter, "Reflections on a biographical approach," Preprints ICOM Conservation Community 16 th Triennial Conference (Lisbon, 19-23 September 2011): 1-8. See also Deborah Cherry, "Altered States: the social biographies of works of art. She Loved to Breathe - Pure Silence $(1987-2012)$ by Zarina Bhimji," in Tra memoria e oblio: percorsi nella conservazione dell'arte contemporanea, ed. Paolo Martore (Rome: Castelvecchi, 2014), 210-228.

$31 \quad$ Van de Vall et al., "Biographical approach," 6. 
I will look for patterns of similarity and change in the lives of site-specific installation artworks by describing and analysing their biographical stages, especially with regard to elements that constitute the works' site specificity. That said, it should also be stressed that researchers who follow a biographical approach take part in the construction of the artwork's biography and, inevitably, bring a certain degree of subjectivity with them. Like a biographer portraying a person, my accounts will be constructions of the artworks' biographies made in hindsight and from a certain perspective; in the case of this research, the biographies will have a focus on the meaning production of the site-specific artwork in diverse circumstances and on the museum's strategies of perpetuation, display, and care.

\subsection{Typologies and Site-Specific Installations as Dynamic Networks}

The range of site-specific installations seems endless. To get a hold on this diversity, the first step is to scrutinize art historical writings and to make use of the typologies developed in this field. The best-known typology was offered by the art historian Miwon Kwon at the turn of this century, in two seminal publications on site-specific art. ${ }^{32}$ Kwon takes artworks from the late 1960 s and early 1970 s a main point of reference and explains how the inextricable bond between the artwork and the site was interconnected with a critical stance taken by the artists towards the institutions and the wider sociopolitical context in which the gallery system operates. ${ }^{33}$ When art galleries and museums started to collect site-specific artworks from the avant-garde two decades later, the meaning of this crucial relationship was lost, according to Kwon, and site-specific art was rendered harmless. Noteworthy for the discussion is that, simultaneously with the rise of the museums' interest in collecting site-specific artworks, artists started a second site-specific "trend" at the end of the 1980s, coinciding with the rise of globalization and communication technology. Kwon explains that, whereas in the previous decades site specificity was understood as an integrated whole - physically tied to a particular location for both the artist

32 Miwon Kwon, One Place After Another. Site-Specific Art and Locational identity (Cambridge, MA: The MIT Press, 2002, 1-31 and 33-55. And Miwon Kwon, "One Place after Another: Notes on Site-Specificity," in Space, Site, Intervention. Situating Installation Art, ed. Erika Suderburg (Minneapolis: University of Minnesota Press, 2000), 38-63.

33 Kwon, "Notes on Site-Specificity," 38-43. 
and the viewer - the new tendency was to use the conditions of a given place in site-specific art projects of which the "products" were subsequently distributed around the globe - creating a distance in time and space between the production and reception of the work. ${ }^{34}$

This brief summary does not do justice to Kwon's conceptual framework regarding the genealogy of site-specific art, and I will return to her view in more detail in chapter 2. Her argument draws attention to an important shift - roughly speaking, between the 1960s-1970s and the 1980s-1990s - that represents two different viewpoints regarding the notion of site specificity. This distinction between two art historical periods will be a recurring theme. It elucidates shifts in the artists' approaches towards site specificity and marks the turning point of the 199os when museums started to collect, conserve, and re-exhibit site-specific installation artworks.

Under the influence of globalization, the 199os introduced broader notions of site specificity in artistic practice and discourse. In this respect, art historian James Meyer signals a trend of "nomadic working" artists, who seek inspiration in the historical or sociopolitical meaning of a given site and start working with local communities in site-specific projects..$^{35}$ Both Kwon and Meyer specify this new form of connectivity as the capacity to establish a dynamic movement between sites. In this new paradigm, site specificity is conceived of as a function of the site that could be translated to various contexts. ${ }^{36}$ In the same vein, art historian Anne Ring Petersen introduces the notion of networked site specificity, understood as a metaphor "to describe the complex processes, relationships, materialities and intersection points." ${ }^{37}$ Petersen brings a processual approach into the discussion by focusing on the chain of actions that produce site specificity at specific moments in time and crystallize into a (temporary) meaning. Her view echoes what Doreen Massey stated in the early 1990s in "A Global Sense of Place" - namely, that "specificity" of a place is

constructed out of a particular constellation of social relations, meeting and weaving together at a particular locus. [...] Instead then, of thinking

34 Kwon, One Place After Another, $1-4$.

35 James Meyer, "The Functional Site or The Transformation of Site Specificity," in Space, Site, Intervention. Situating Installation Art, ed. Erika Suderburg (Minneapolis: University of Minnesota Press, 2000), 32.

36 Meyer was the first art historian who described this new form of site specificity as the "functional site" in: Meyer, "Functional Site," 23-27; followed by Kwon in her explanation of the "de-materialization" of site in: Kwon, "Notes on Site-Specificity," 45-46.

37 Anne Ring Petersen, Installation Art. Between Image and Stage (Copenhagen: Museum Tusculanum Press, 2015), 359. 
of places as areas with boundaries around, they can be imagined as articulated moments in networks of social relations and understandings..$^{3}$

In the slipstream of new art practices and global trends, contemporary art museums reconsidered their institutional role: on the one hand, this new interest in the "site" made the institutions receptive to site-specific installation artworks from previous periods, and on the other hand, collaboration with artists became more and more part of institutional policies. Increasingly, artists were invited to create site-specific installations for museum galleries, which still happens today.

The starting point for the conceptual framework I propose is that sitespecific installation artworks can best be understood as dynamic relational networks. Therewith, I follow the notion of "networked site specificity" from the art historical discourse. First of all, this notion is beneficial to a conceptual framework that applies to a wide range of site-specific installation artworks, as I will argue. Furthermore, the "network" is a familiar concept within various cultural discourses to describe art as a dynamic system, consisting of functions that operate in mutual relationship with one another. The idea that site specificity is produced as a network of functions - which are activated at specific sites and moments in time - enables an analysis of the constitutive elements of the network and their changes over time. Moreover, the institution itself can be regarded as a dynamic part of this system, because the cultural meaning production of the artwork takes place in the interaction between the work and the museum site.

Following insights gained from Fernando Domínguez Rubio, a cultural sociologist and science-and-technologies scholar, I suggest to consider sitespecific installations as the kind of transformative artworks that withdraw from the boundaries and "control mechanisms" usually applied to more traditional art. ${ }^{39}$ Domínguez Rubio makes a distinction between museum objects that behave as "docile" or "unruly" objects; installation artworks can be related to the latter category. Unruly objects are typified by their capacity to incite new practices for museum institutions and to establish new forms, meanings, and experiences while "producing different degrees of continuity and change." Domínguez Rubio advocates a relational approach when studying the ways in which unruly objects operate as "vectors of transformation

38 Doreen Massey, "A Global Sense of Place," in Situation (Documents of Contemporary Art), ed. Claire Doherty (London: Whitechapel Gallery, 2009), 167.

39 Fernando Domínguez Rubio, "Preserving the Unpreservable: Docile and Unruly Objects at MoMA," Springer Science+Business Media/UC San Diego (2014), unpaginated. 
and change" within the museum and the way in which competences and expertise, mainly of conservators and curators, are redistributed by them. ${ }^{40}$ Likewise, I aim to contribute to a deeper understanding of the impact of site-specific installations artworks on the museum's organizational structure and how they are influenced by the networks of care in which they circulate. ${ }^{41}$

\subsection{Outline}

After this introductory chapter, I will continue in chapter 2 with an art historical overview of the main concepts art historians and critics have attributed to site-specific art. Various typologies and terminologies developed in the discourse will be presented to gain a deeper insight into the phenomenon of site specificity in the art practice and into the relationship between artists and museums. Complemented with case studies and statements made by the artists themselves, I will make a first step towards developing a vocabulary for site-specific installations and the proposed model regarding their perpetuation.

In chapter 3 , this model is developed further by introducing the notion of site specificity as a triadic network of spatial functions. This view forms the backbone of my argument and is derived from a theory on space developed by social geographer Henri Lefebvre. His publication The Production of Space (first published in 1974) was embedded in a more general interest in space and spatiality of the generation city planners and sociologists active in 1968, and has been highly influential on the thinking about space in architecture, design, and contemporary art to this day. Following Lefebvre's theory, the network of site specificity is proposed in the current study as a conglomerate of three basic functions: the physical relationship between the artwork and its surrounding (in concept and realization), the social spaces in which the

\footnotetext{
40 Domínguez Rubio, unpaginated.

41 I gratefully borrow the term "networks of care" from Pip Laurenson and Vivian van Saaze, who elaborate this notion in Pip Laurenson, Vivian van Saaze, and Renée van de Vall (2022), "Bridging the Gaps between Theory and Practice through Cross-Institutional Collaboration in the Conservation of Contemporary Art" In Engaged Humanities: Rethinking Art, Culture, and Public Life, ed. Aagje Swinnen, Amanda Kluveld, and Renée van de Vall (Amsterdam: Amsterdam University Press, 2022), 298-329. See also Pip Laurenson and Vivian van Saaze, "Collecting Performance-Based Art: New Challenges and Shifting Perspectives" in Performativity in the Gallery. Staging Interactive Encounters, ed. Outi Remes, Laura MacCulloch, and Marika Leino (Oxford: Peter Lang, 2014), 28-41.
} 
artwork is produced and experienced, and the symbolic (representational) context in which the artwork is presented.

In the second part of chapter 3 , the focus shifts towards a current strand in the conservation discourse in which installation artworks are compared with a "performance" or "live event." The rationale for understanding sitespecific installations in terms of their performative quality is that the artwork's meaning is only produced when it is installed - or "staged" - at a particular place and moment in time. It also brings into focus that the staging of a site-specific installation is the result of a decision-making process, which can be analysed with a similar set of terms as applied in the performance arts: "script" and "actor." I incorporate this view into my conceptual model by developing a "toolbox" - based on the notions of "script" and "actor" - which enables the analysis of decision-making and of the factors of influence on successive iterations. Lefebvre's theory of the triadic network of spatial functions and the performance analogy are complementary. Together, they constitute my proposition of a conceptual framework for the perpetuation of site-specific installation artworks within a museum context.

In chapters 1, 2, and 3, several historical examples are included to develop the argument and the conceptual framework. In the case study chapters (4-6), most examples are more recent. The main artworks under discussion were created in the first decade of this century, and due to their relative youth, they pose dilemmas and challenges to museums that have not all been solved. The examples were selected on the basis of specific questions the artworks raise for custodians in view of their care and presentation.

Throughout the study that follows, I switch between theories, conceptual ideas, and case studies that allow me to undertake a detailed examination of the artworks and related documentation. Methods of collecting source material for the case studies consisted of archival research (consultation of floor plans, condition reports, artists' statements, conservation and curatorial reports, guidelines for reinstallation, etc.) and the examination of relevant literature (published statements, exhibition reviews, published interviews, etc.). Furthermore, I engaged with the network of caretakers by conducting interviews with conservators, curators of collections, exhibition designers, and other stakeholders. Sometimes, I was able to consult the artist directly, or I was a participant in the research carried out by the museum, such as in the case studies of Notion Motion and Ernesto Neto's Célula Nave (chapter 4). The approach of working with, as well as in, museums, was decisive for the selection of the main case examples, which are all hosted by museums in the Netherlands. 
Museum practices take a central role in this research. Testing the model against real-life examples in museums proved crucial and brought about some refinements of the proposed model (see, for example, chapter 4). Furthermore, each of the main case studies is accompanied by a comparative example that has a longer history of musealization, conservation, and reinstallation. This way, a fresh light could be shed on the dilemmas and options of repeatedly preserving and staging the artwork in various contexts.

\section{The Three Main Case Studies}

The case study in chapter 4-Ernesto Neto's Célula Nave. It happens in the body where truth dances (2004) - is a room-filling installation designed for and realized in the Bodon Gallery of Museum Boijmans van Beuningen. Célula Nave is a huge structure, resembling a tent, for which the artist used different kinds of knitted polyamide in various shades of turquoise. The stretchable material gives in when visitors entering the "nave" press the fabric to the floor and touch the membrane with their hands. It is an example of Neto's hallmark to reconsider architectural spaces through the tactility of sensual materials, a haptic sensation that is crucial in experiencing his art. However, in the case under consideration, the interaction proved to be harmful to the physical condition of the work.

After two periods of display, Célula Nave can no longer be installed and is considered a total loss. Although the installation was not initially intended to survive after its first display period, Célula Nave was acquired nonetheless. Hence, the main issue in this case is the dilemma of extending the lifespan of a temporary, site-specific installation, and, in addition, how the work's physical integrity relates to the interactive use and intended site specificity. Furthermore, the places of production play an important role in this case study, because they are significant parameters for the meaning of the work. With an eye to the current state of total loss, the model is employed for an exploration of possible scenarios for future iterations, taking into account the intended site-specific experience and the production sites, which are meaningful aspects of the work (these scenarios imply restoration, remake under supervision of the artist, remake by another fabricator).

Chapter 5 examines Jason Rhoades's SLOTO. The Secret Life of the Onion (2002), a room-filling installation in the collection of Van Abbemuseum in Eindhoven. The installation was created for the opening exhibition of the new museum building (2003), and its site specificity was connected to the museum's "project space" in the basement. The chapter focuses on 
the perpetuation of a site-specific installation, which is the outcome of a coproduction by the artist and the museum. Rhoades involved museum staff members in the preparations, for example, by collecting numerous objects of which the installation is composed (most of which refer to cultivation processes in agriculture) and engaging them in "uncommon" activities for a museum context - such as slicing onions into rings and cooking them in the museum canteen before adding them to the installation. The case study looks into various modes of site specificity: the physical location, the production process in the museum, and the symbolic references to the museum as institution, for example, by means of thumbnails of the entire collection of artworks which are interlaced with other visual material. When SLOTO was reinstalled in 2011, two major challenges had to be faced: in 2006, the artist had suddenly passed away, and the original location was no longer available as a gallery space. With this second iteration, the curators decided to relocate SLOTO to another gallery space and accommodated its site-specific functions to this new location. The model is employed for the analysis of the shifts in the artwork's site specificity and for understanding the underlying motives of the curatorial decision-making process during the second iteration. To what extent does the artwork behave as an unruly object and intervene with the standard procedures and museum protocols?

Chapter 6 is dedicated to the installation artwork Drifting Producers (2003) by the South Korean artists' group Flying City, in the collection of the Van Abbemuseum. This installation is one of the outcomes of a sociogeographical art project carried out by Flying City over a period of several years (2001-2009). Apart from being artists, the collective took on the role of urban researchers in Seoul and integrated this research into their installation. The case study examines the transition from a site-specific project into an installation artwork and analyses its perpetuation in a museum context with the following questions in mind: to what extent and how does the ongoing project conducted at a different sociogeographical location still resonate in the materialized installation artwork? What happened to the site-specific functions of the installation after the work entered the museum collection? What is the impact of conservation and curatorial adjustments? What is gained and lost in the relocation and transition of Drifting Producers to a musealized art object?

Chapter 7 presents the main outcomes of the research and reflects on the applicability of the proposed conceptual framework to museum practices. The analyses of the case studies show that the functions of the site-specific network are continuously redefined, often with the help 
of the artist, but certainly not always. Sometimes, custodians need to reinvigorate the functions of site specificity in a way that could not be foreseen at the moment of creation. Hence, one of the main conclusions is that a curatorial strategy for staging site-specific installations is often based on an interpretation of the functions of the spatial network, informed by the artist's intentions and, just as well, based on current museum policies and curatorial strategies. The inherent paradox of extending the lives of spatiotemporally defined installations in different circumstances may lead to radical interventions and transformation of the artwork. Still, if such a reinvigoration does not take place there is a chance that site-specific installations will completely lose their site-specific meaning and turn into site-generic works of art. 



\section{Site-Specific Installation Art in Historical Perspective}

Keywords: minimal art, avant-garde, public space, globalization, Miwon Kwon, Richard Serra

"Here, in fact, site-specificity arises precisely in uncertainties over the borders and limits of works and site."

Nick Kaye ${ }^{1}$

The argument in this chapter starts with a discussion of the art historical discourse on site-specific installation art. Artists as well as critics have explored various notions of site specificity, usually in concordance with successive art historical periods: the first "wave" of site-specific installations created during the late 1960 s and early 1970s, and a second period, from the 1980 s and early 1990 until today. The chapter elucidates several art historical perspectives on both periods and the shifts occurring in the relationship between artists and museum institutions, between the artwork and the site. Furthermore, it is important to realize that site-specific installation artworks are highly diverse in form, content, and meaning. For the current purpose of developing a model with an eye to the artworks' perpetuation, a chronological approach is only partly effective. A further abstraction in categorization is needed, focusing on the network of site-specific functions and their changes over time. To this end, a selection of relevant notions elucidate the extended lives of site-specific installations, which I derive from case studies and observations made by artists and art historians

1 Nick Kaye, Site Specific Art: Performance, Place, and Documentation (London: Routledge, 2000), 215 .

Scholte, T., The Perpetuation of Site-Specific Installation Artworks in Museums. Staging Contemporary Art. Amsterdam: Amsterdam University Press 2022 DOI: $10.5117 / 9789463723763 \_$CHO2 
in this respect. The discussion is a prelude to chapter 3 , in which I take the vocabulary for site-specific installation artworks one step further by employing a triadic set of spatial functions, which I derive from Henri Lefebvre's theory on space.

\subsection{The Rise of Site-Specific Installation Art: Criticism Towards the Established Art World}

There is no particular art movement or art form called "site-specific installation art." Nevertheless, site specificity has dominated the art discourse for decades. In particular, Miwon Kwon has built an extensive theoretical framework for site-specific installation art by analysing the development of site-specific installations from the 1960 s onwards in two seminal publications, both bearing the title One Place after Another. ${ }^{2}$ Historically, the interest in site specificity came to the fore in the 1960s, together with major art movements such as conceptual art, minimal art, Art in Public Space, Happenings, and performances. Kwon focuses on the influences of Minimalism for identifying the first category of her typology, indicated as "phenomenological" site specificity:

Emerging out of the lessons of minimalism, site-specific art was initially based in a phenomenological or experiential understanding of the site, defined primarily as an agglomeration of the actual "physical" attributes of a particular location (the size, scale, texture, and dimension of walls, ceilings, rooms; existing lighting conditions, topographical features, traffic patterns, seasonal characteristics of climate, etc.), with architecture serving as a foil for the art work in many instances. ${ }^{3}$

However, at the core of her critical theory is a second group of works, indicated as "social-institutional," in which artists worked with "the actuality of a location (as site) and the social conditions of the institutional frame (as site)." It was a vital element in the artistic practice of the 1960s and $1970 \mathrm{~s}$ to investigate institutional critique and reconfigure the site as

2 See footnote 32 in chapter 1.

3 Miwon Kwon, One Place After Another. Site-Specific Art and Locational identity (Cambridge, MA: The MIT Press, 2002), 3.

4 Kwon, One Place After Another, 44. 
[...] a relay or network of interrelated spaces and economies (studio, gallery, museum, art market, art criticism), which together frame and sustain art's ideological system. Works by artists such as Michael Asher, Daniel Buren, Hans Haacke, and Mierle Laderman Ukeles are seen as challenging the hermeticism of this system, complicating the site of art as not only a physical arena but one constituted through social, economic, and political processes. ${ }^{5}$

Kwon's incentive to develop a theoretical framework originated, largely, from institutional practices of a later date, the 1990s, when site-specific works from previous decades were collected and re-exhibited by commercial galleries and museums. Kwon points to the paradox that site-specific artworks resulting from critical strategies of the avant-garde were being incorporated into the very same system the artists once opposed. ${ }^{6}$ I will return to Kwon's viewpoint in this matter later on in this chapter.

In general, trends of the 1960s and 1970s gave primacy to notions of time and place, as well as to "process" and "presence." In The Fall of the Studio. Artists at Work, art historians Wouter Davidts and Kim Paice describe how artists abandoned the studio "as the unique and artisanal space of production." Space and place were among the most favoured means to reach beyond the established art system. Art in situ was created in all kinds of public spaces, including empty factories, office buildings, and alternative exhibition places, often run by the artists themselves.

A link with Art in Public Space and land art is frequently made when art historians explain the rise of site-specific installations during the late $1960 s$. Well-known examples of those art forms are, among others, Daniel Buren's painted stripes on buildings and street furniture, Christo and Jeanne-Claude's textile wrappings of buildings and bridges, and Earthworks created by Robert Smithson or Walter de Maria. Like Miwon Kwon, Davidts and Paice refer to artistic statements that establish a connection between the physical location and a critical take on the economic power of the art market. Because they were physically rooted in the site, these artworks were thought to resist commodification and distribution, an effective strategy to circumvent the market. ${ }^{8}$ Like no other artistic approach,

5 Kwon, One Place After Another, 3.

6 Kwon, One Place After Another, 2.

7 Wouter Davidts and Kim Paice, The Fall of the Studio. Artists at Work (Amsterdam: Valiz Publishers, 2009), 76 .

8 James Meyer, "The Functional Site or The Transformation of Site Specificity," in Space, Site, Intervention. Situating Installation Art, ed. Erika Suderburg (Minneapolis: University of 
works created on site provoked a critical stance towards the underlying mechanisms of the art system. Davidts and Paice illustrate this view in the following statement on Daniel Buren's coloured stripes on buildings in public space:

Through their specific application on a given site or support, the stripes aim to elucidate the material conditions of the work of art and its various modes of production, presentation, and reception. This undertaking, according to Buren, continues to oblige him to work "on site." ${ }^{\text {9 }}$

This thought is followed by one of Buren's own statements about the inseparability of his works and the sites for which they are produced:

"In situ" means, at least in my understanding of it, that there is a voluntary bond between the site of reception and the "work" that is produced, presented and exhibited there. ${ }^{10}$

By working directly with the conditions of the site, artists gave expression to their aversion to the ideology of the white cube, a term coined by artist and theorist Brian O'Doherty in $1976 .^{11}$ The white cube was the prevailing paradigm of modernist art - "a place deprived of location" - representing the claim of a universal form of art "with a direct line to the timeless, a set of conditions, an attitude. ${ }^{12}$ In contrast to the supposed neutrality of the exhibition space, artists employed the possibilities of the space itself as constituent for the artwork's meaning and emphasized their own presence and gestures in space. This view corresponds to the category of phenomenological site specificity identified by Kwon.

The interconnectivity with the actual location encouraged visitors of site-specific installations to explore the space of the installed artwork and its immediate surroundings; their own bodily movements were an

Minnesota Press, 2000), 25; Miwon Kwon, "One Place after Another: Notes on Site-Specificity," in Space, Site, Intervention. Situating Installation Art, ed. Erika Suderburg (Minneapolis: University of Minnesota Press, 2000), 40, 42-43; Mark Rosenthal, Understanding Installation Art. From Duchamp to Holzer (Munich: Prestel Verlag, 2003), 73; Claire Bishop, Installation Art. A Critical History (London: Tate Publishing, 2005), 17-20, 32.

9 Davidts and Paice, Fall of the Studio, 66.

10 Daniel Buren recited in Davidts and Paice, Fall of the Studio, 66.

11 Brian O'Doherty published a series of three articles in the journal Artforum in 1976. These articles have been republished in Brian O'Doherty, Inside the White Cube: The Ideology of the Gallery Space (Expanded Edition) (Berkeley: University of California Press, 1986).

12 O'Doherty, Inside the White Cube, 80. 
intrinsic part of the experience. Instead of looking at the art object, art critics observe, viewers of site-specific installations are surrounded by its composition in space, redirecting the focus from the creator and the autonomous art object to the position of the visitor. ${ }^{13}$ The visitor, in turn, undergoes a heightened perception of the here and now and of the "hidden" ideologies of the place in which the work is presented. As James Meyer states:

The body of site specificity was a physicalised body, aware of its surroundings, a body of heightened critical acuity. Thus, the premise of site specificity to locate the work in a single place, and only there, bespoke the 1960 s' $^{\prime}$ call for Presence, the demand for the experience of "being there."14

Site-specific installation artworks of the 1960 s and 1970s were imbued with a critical stance towards the institutions, which art historians explain in two different ways: the artworks represented a breach with the established art system of trade and modernist "neutrality" of the exhibition space; and secondly, they brought into focus the experience of art in "real life," represented by the inseparable bond between the artwork and the physical site. That said, the terms of phenomenological and institutional site specificity do not necessarily apply to all site-specific installation artworks created in the 196os and 1970s, and the terms may overlap when applied to practice. Moreover, Kwon acknowledges that, although her typology is presented in chronological order (as we shall also see below), these are "not stages in a linear trajectory of historical development." ${ }^{\prime 5}$ In fact, in today's cultural practices, similar approaches of phenomenological site specificity and institutional criticism still exist.

\section{Institutional Perspective}

Despite the critical attitude, it was common practice for vanguard artists to collaborate with progressive curators and sometimes they created site-specific installations in commercial galleries and museum spaces. Land art projects, in addition, could find their ways into the distribution system of museums and commercial galleries in the form of documentary

13 See Bishop, Installation Art, 11; Kwon, "Notes on Site-Specificity," 38; Nicolas De Oliveira, Michael Petry, and Nicola Oxley, Installation Art (London: Thames and Hudson, 1994), 13-14.

14 Meyer, "Functional site," 26.

15 Kwon, "Notes on site-specificity," 46. 
material relating to the project, such as sketches, photographs, and films. These derivatives were, in the words of Lucy Lippard, "consumed" by gallery visitors, who were unable to experience the art itself at the location. ${ }^{16}$ An overtly more critical stance was taken by Brian O'Doherty in his comment that the avant-garde of the 1960 os and 1970s "never attacked the idea of a gallery, except briefly to promote the move to the land which was then photographed and brought back to the gallery to be sold." ${ }^{17}$

That said, the site of the gallery had indisputably turned into a place of questioning the art system, as curator Christian Rattemeyer highlights in his reflection on site-specific art of the avant-garde. He observes that artists working in situ

[...] transformed the nature of art and its materials, questioning how and by whom art can be made, where a work of art can exist and even whether it needs to exist as a physical object at all. ${ }^{18}$

One of the most famous, progressive gallerists at the time was Leo Castelli (1907-1999), who invited young artists to respond in their own ways to the conceptual and literal space of art. In 1968, Castelli asked Robert Morris to curate an exhibition of conceptual and processual art for the Castelli Warehouse. Nine artists participated in the exhibition - called 9 at Castelli most of whom became famous artists later on. Quite a number of site-specific artworks were presented at this show, but most of them did not survive, because they were destroyed immediately afterwards. ${ }^{19}$

Other curators followed soon after, and within one year - 1969-several major exhibitions featured site-specific installations in prominent museums worldwide: Op losse schroeven in Stedelijk Museum Amsterdam, When Attitudes Become Form in Kunsthalle Bern, and Spaces in MoMA New York. ${ }^{20}$

16 Lucy Lippard, "Land Art in the Rearview Window," in Surface Tension: Problematics of Site, ed. Ken Ehrlich and Brandon Labelle (Downey: Errant Bodies Press, 2003), 59.

17 O'Doherty, Inside the White Cube, 93.

18 Christian Rattemeyer, Teresa Gleadowe, Charles Harrison, Harald Szeemann, and Wim Beeren eds., Exhibiting the New Art. "Op Losse Schroeven" and "When Attitudes Become Form" 1969 (New York: Distributed Art Publishers, 2011), 14.

19 In the exhibition 9 at Castelli (1968) the following artists participated: Giovannni Anselmo, Joseph Beuys, William Bollinger, Rafael Ferrer, Eva Hesse, Stephen Kaltenbach, Bruce Nauman, Alan Saret, Richard Serra, Keith Sonnier, Gilberto Zorio.

20 Op Losse Schroeven. Situaties en Cryptostructuren, Stedelijk Museum Amsterdam, took place from 15 March to 27 April 27, 1969 and was curated by Wim Beeren. Live in Your Head. When Attitudes Become Form, Kunsthalle Bern, took place from 22 March to 27 April 1969 and was 
Most site-specific installations were made with ephemeral and temporary materials, signalling the influences of conceptual art and process art. Their site specificity and ephemerality challenged common curatorial practices, as the art historian Julie Reiss notes in From Margin to Center: The Spaces of Installation Art:

Conceptual, Process, and installation works usually could not be seen by curators before they were installed, but were created by the artist, in situ, shortly before the exhibitions opened to the public. ${ }^{21}$

The exhibition Spaces was a typical example of this changed practice. Reiss explains that the usual processes of selection and valuation did not take place beforehand, meaning the curator could not be ensured of the quality of the works. Besides, immense pressure was put on the technical staff and the conservators, who had to accommodate gallery spaces to the requirements of spacious works of art, while the artists brought materials into the building that might pose a risk to the collection - such as mist or live spruce trees. ${ }^{22}$ These are usually severe enemies of the museum environment, and staff members had to take the necessary measures to protect the collection, the building, and the public. ${ }^{23}$

Site-specific installation artworks dating from the 1960 s and $1970 \mathrm{~s}$ intentionally challenged institutional policies and practices. Gallery spaces could be transformed into laboratories for artistic experiment or

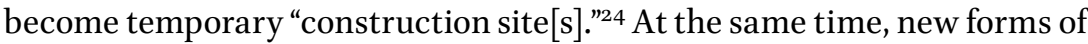
co-operation and negotiation between artists and curators arose, establishing networks of collaboration that could last a lifetime. ${ }^{25}$ In that respect, Brandon

curated by Harald Szeeman. Spaces, MoMA, took place from 30 December 1969 to 1 March 1970 and was curated by Jennifer Licht. For a detailed description of the first two exhibitions, see: Rattemeyer et al., Exhibiting the New Art. For an elaborate discussion of Spaces, see: Julie H. Reiss, From Margin to Center: The Spaces of Installation Art (Cambridge, MA: The MIT Press, 1999), 87-106.

21 Reiss, The Spaces of Installation Art, 81.

22 Reiss, The Spaces of Installation Art, 87, 88, 93.

23 For example, a room created by Larry Bell was completely darkened. Reiss, The Spaces of Installation Art, 93 .

24 Kim Paice uses the term "construction site" in relation to Robert Morris's Continuous Project at the warehouse of Leo Castelli's gallery in New York, to which the artist transported huge amounts of raw materials and reworked them during live performances. The project lasted from 28 February to 22 March 1969.

25 An example of a long-lasting relationship between artists and curators is Harald Szeemann's directorship of Kunsthalle Bern. In 1969, Szeeman curated When Attitudes Become Form and in successive years, opened numerous exhibitions with artist friends whose studios he frequently 
Labelle and Ken Ehrlich made a relevant comment in Surface Tension: Problematics of Site. The authors state that, alongside the production of site-specific art, the institutional context and artistic practices became increasingly intertwined:

In this sense, "site" might function as an operational term through which to gauge practice - it is both the physical location of presentation and the intrinsic negotiations site specificity entails. ${ }^{26}$

Hereafter and in continuation of the discussion of the notions of socialinstitutional and phenomenological site specificity, different perspectives on the extended lives of site-specific installation artworks will be elaborated. Two examples created by Richard Serra will illustrate the artist's view regarding the spatial design and sociocultural context of his site-specific art. The first is Serra's seminal installation in public space Tilted Arc (1981); the other is Serra's performance-based installation Splashing (1968).

\subsection{Unmoveable or Moveable? The Case of Richard Serra's Tilted Arc}

One of the most controversial examples of site-specific art is Richard Serra's Tilted Arc (1981), commissioned by the U.S. federal government for the Federal Plaza in New York. ${ }^{27}$ [Figure 5]

The work consists of a large wall made of Corten steel, measuring no less than $37 \times 3.70 \mathrm{~m}^{2}$. Therewith, Tilted Arc divides a large section of the square into two parts. A few years after the work was completed, neighbours and

visited. Due to this personal network and the archive he created, a remake of the original exhibition was possible with the co-operation of many participating artists: When Attitudes Become Form: Bern 1969/Venice 2013, curated by Germano Celant, Fondazione Prada, Ca' Corner della Regina, 1 June-3 November 2013. See, e.g., Marina Biryukova, "Reconsidering the exhibition When Attitudes Become Form curated by Harald Szeemann: form versus 'anti-form' in contemporary art," Journal of Aesthetics \& Culture 9, no. 1 (2017), https://www.tandfonline.com/doi/full/10.10 8o/20004214.2017.1362309.

26 Ehrlich and Labelle, Surface Tension, 10-11.

27 For a thorough analysis of the work by Richard Serra and its intellectual and perceptual basis, I refer to Rosalind E. Krauss, Richard Serra: Sculpture, ed. Rosalind Kraus, exhibition catalogue (New York: Museum of Modern Art, 1986). Tilted Arc is discussed by Douglas Crimp in “Serra's Public Sculpture: Redefining Site Specificity," in Richard Serra: Sculpture, ed. Rosalind Krauss, exhibition catalogue (New York: Museum of Modern Art, 1986), 41-56. 
Figure 5 Tilted Arc (1981, removed in 1989) by Richard Serra, Federal Plaza, New York City. Photo: Anne Chauvet. @ c/o Pictoright Amsterdam.

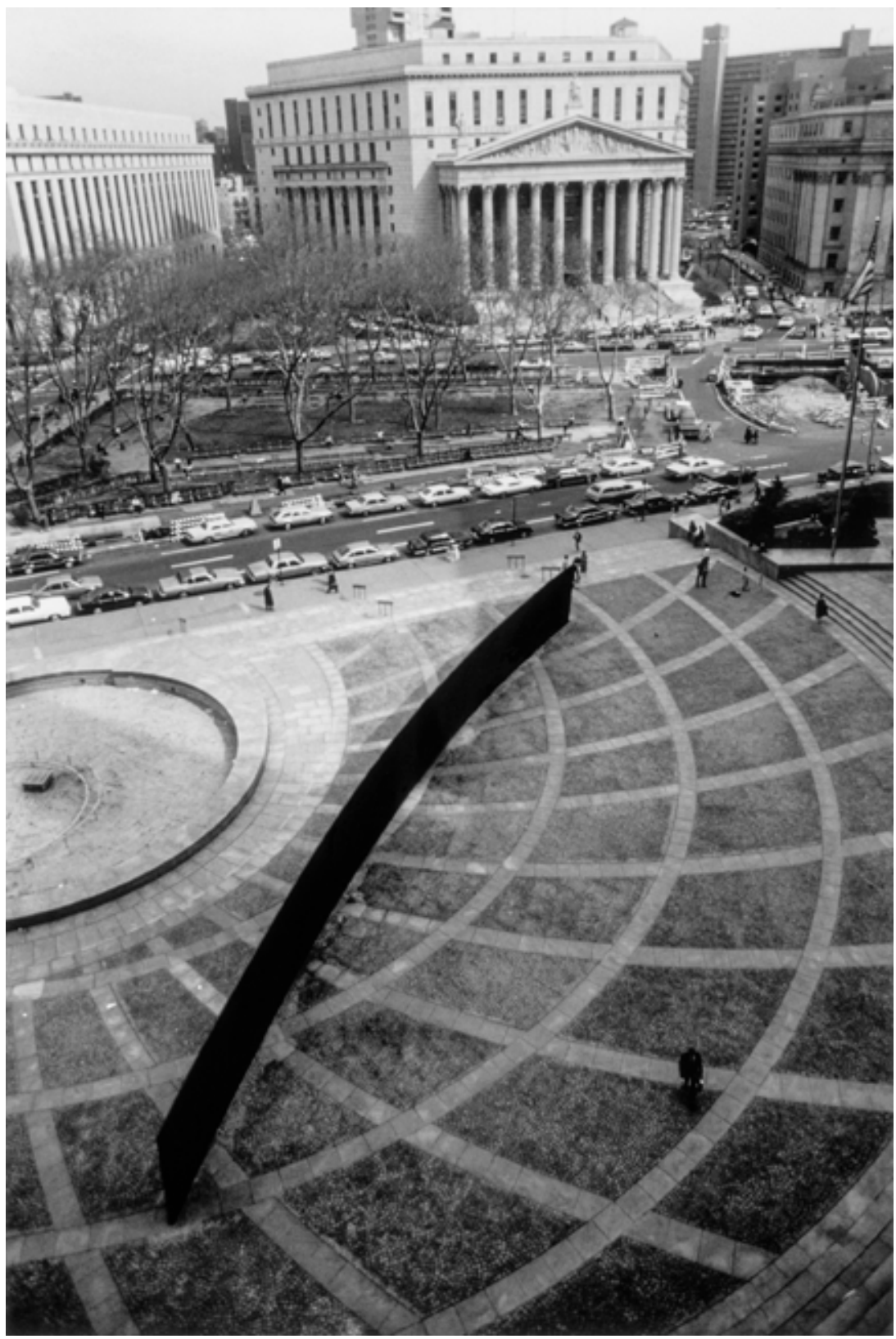


people working in the surrounding offices complained that, because the "wall" was placed in the centre of the square, the former social function of the plaza had been lost. ${ }^{28}$ The General Services Administration proposed to relocate Tilted Arc from the plaza to a scenic environment in the countryside where it would be "appropriately sited" and better appreciated by the public. ${ }^{29}$ Together with fellow artists, curators, and friends, Richard Serra started a lawsuit resulting in a famous public hearing in 1985. At this occasion, Serra declared:

Tilted Arc was conceived from the start as a site-specific sculpture and was not meant to be "site-adjusted" or "relocated." Site-specific works deal with the environmental components of given places. The scale, size, and location of site-specific works are determined by the topography of the site, whether it be urban or landscape or architectural enclosure. The works become part of the site and restructure both conceptually and perceptually the organization of the site. ${ }^{30}$

In the public hearing on March 1985, the issues of site specificity were addressed in an unprecedented way. On the one hand, Serra pointed out to his opponents the inseparability between the artwork and the site, in terms of their physical and optical dimensions. On the other hand, he objected to the fact that the government did not "respect the implications of the concept of site specificity," as it had been implied in the spatial design of the artwork that local pedestrians would need to adjust their routes when traversing the square. Hence, it could have been foreseen that the work would somehow interfere with the former social function of the square and the natural flow of the people. ${ }^{31}$

After a fierce debate between supporters and opponents, in 1989 it was decided that Tilted Arc would be removed and destroyed, in accordance with Serra's refusal to relocate the work. His statement that site-specific

28 For example, Joseph Liebman states: "I remember walking freely in the plaza, contemplating the examination of a witness, undisturbed by the presence of other people engaged in conversation or young lovers holding hands. I also remember my dreams of additional seating areas, more cultural events, temporary outdoor exhibits of painting and sculpture, and ethnic dance festivals." Clara Weyergraf-Serra and Martha Buskirk, The Destruction of Tilted Arc: Documents (Cambridge, MA: The MITT Press, 1991), 113 .

29 Memo from the Public Buildings Service to the responsible administrator of the General Services Administration William J. Diamond. See Weyergraf-Serra and Buskirk, Destruction of Tilted Arc, 31.

30 Richard Serra in Weyergraf-Serra and Buskirk, Destruction of Tilted Arc, 11-12.

$3^{1}$ Serra, Destruction of Tilted Arc, 13. 
art "cannot be moved without being destroyed" was effectuated by the Corten steel plates being carted off to a scrap metal yard, which the artist regarded an "accomplishment" of the process. ${ }^{32}$ Because of its destruction on 15 March 1989, Tilted Arc no longer exists as a physical work of art, but its life has been prolonged through many debates in art historical writings ever since, on site-specific art and the problem of relocation.

Art historian Douglas Crimp, who argued in support of Titled Arc at the lawsuit, notes that the case of Tilted Arc reveals "the radical aesthetics of site-specific sculpture," which is always politically charged. ${ }^{33}$ In his opinion, the crisis shows that neither the general public nor the government comprehended the implications of this radical and historical moment in artistic practice:

The work was conceived for the site, built on the site, had become an integral part of the site, altered the very nature of the site. Remove it and the work would simply cease to exist. ${ }^{34}$

Kwon takes a similar stance in One Place After Another - reminding us of an earlier statement, made by the installation artist Robert Barry, that site-specific art cannot be moved without being destroyed. ${ }^{35}$ (Barry made this statement in 1969, referring to his fragile room-filling installations made of nylon and iron wire.) Kwon points to the critical function of site-specific art

[...] of working against the physical and socio-political conditions of the site [and] simultaneously address the site as another medium, or another "language". Put a little differently, working against the site coincides with working against the modernist illusion of artistic autonomy. ${ }^{36}$

Relying on Barry's dictum and the controversy over Serra's Tilted Arc, Kwon develops a key for the discourse on site-specific installation art - namely, that this critical function is lost when the artwork is relocated. She extrapolates this view to an entire group of site-specific installations dating from the 
1960 s and 1970s, which had the function to "undercut the fallacy of the 'autonomy' of art and its institutions." ${ }^{37}$ Site specificity of this period is indeed seen as a new language or medium to question the conditions and hidden structures of the site.

Kwon's argument is also important for the topic of the perpetuation of site-specific installation artworks. The author takes her stance in reaction to an emerging trend of the late 1980s, when museums in Paris, New York, Los Angeles, and elsewhere started to re-exhibit, collect, and refabricate site-specific installations from previous decades. ${ }^{38}$ It is not by coincidence that fertile soil was found for opposing this practice, because, as Kwon indicates, it is precisely the mobilization of site-specific works that deprives them of their critical potential and sets a new norm in which the connection between artwork and site is rendered irrelevant. On the one hand, Kwon agrees that the re-execution of "unrepeatable" works offers an opportunity to reconsider their historical significance. On the other hand, she points to what is lost:

But the very process of institutionalization and the attendant commercialization of site-specific art also overturn the principle of placeboundedness through which such works developed their critique of the ahistorical autonomy of the art object. ${ }^{39}$

Seen from this perspective, there might be a problem with the continued existence of site-specific installation artworks in a museum context, because of the disruption of the historical ties to the location. Accountability for the afterlife of site-specific installations is attributed by Kwon (and others) to the art market and art institutions who have a commercial interest, and to the artists who, most of the times, co-operated with museums and galleries for a remake and/or acquisition..$^{40}$ According to Kwon,

37 Kwon, One Place After Another, 40.

38 Exhibitions featuring site-specific art from the 1960 s and 1970 in this period include L'art conceptuel, une perspective (1989) in Musée d'art moderne Paris; New Sculpture, 1965-75: Between Geometry and Gesture (1990) and Immaterial Objects (1991), both in the Whitney Museum, New York; and Out of Actions: Between Performance and the Object (1998) in Museum of Contemporary Art, Los Angeles.

39 Kwon, One Place After Another, 38.

40 An exception to this "rule" is a collection of artworks created during the 1960 os and 70 s (including site-specific installations) that was acquired by the Italian collector Giuseppe Panza di Biumo. The artists did not always authorize reinstallation and sometimes no longer acknowledged the reinstalled piece as their art. To ensure research, preservation and presentation of the Panza Collection, which is now with the Guggenheim Museum, New York, a grand-scale project was 
the heyday of this practice was in the 1990s, but it also continued in later years, up to today. Does this imply that all recreations and relocations of site-specific installations should be considered historical falsifications? Looking at site specificity as a dynamic network, I see a counterargument in the fact that collaboration between artists and visionary curators, which started in the 196os and 1970s, often continued during later years. Besides, the recreation of site-specific installations can also be envisioned as a process of transformation, in which the performative qualities of site specificity come to the fore. To illustrate this point, I will briefly discuss Richard Serra's Splashing, which was literally the outcome of a performance and in which Serra took the conditions of the site as a leading principle.

\subsection{The Extended Life of Richard Serra's Splashing}

Richard Serra created his first performance, Splashing (1968), by throwing molten lead in one of the corners of the Castelli Warehouse in New York. ${ }^{41}$ The lead hardened at the juncture between the wall and the floor, demarcating the dimensions of the gallery space. Douglas Crimp describes the initial iteration of Splashing as follows:

There it was, attached to the structure of that old warehouse on the Upper West Side, condemned to be abandoned there or scraped off and be destroyed. ${ }^{42}$

The result of Serra's performance was an installation that was defined by the specifics of the site and lasted no longer than the exhibition 9 at Castelli, which was curated for the gallery's warehouse by the artist Robert Morris. ${ }^{43}$ Most of the artworks on show were process-related and site-specific, and most of them have never been recreated. Splashing, however, was reperformed by Richard Serra many times, resulting in his Splash pieces that were

carried out by the Guggenheim Museum between 2010 and 2019: The Panza Collection Initiative. https://www.guggenheim.org/conservation/the-panza-collection-initiative (last accessed 22 April 2021).

41 Rosalind Krauss places Richard Serra's Splash pieces extensively in an art historical perspective in her essay "Portrait of the Artist. Throwing Lead," in Richard Serra: Sculpture, 15-39.

42 Crimp, Museum's Ruins, 151.

439 at Castelli, organized by Robert Morris for the Castelli Warehouse, was open from 4 to 28 December 1968, between 1 and 5 PM. 
defined by the conditions of the new location. [Figure 6] Serra repeated the performance of throwing lead in later years, even with the help of assistants. In hindsight, he emphasizes the repeatability of the Splash pieces, making no distinction between temporary or permanent iterations:

I did one at the Castelli Warehouse, just a very straight line. And then subsequently, I think about four months later, I did one in the Whitney Museum. And over the last twenty or twenty-five years I have been doing them every three or four years as the occasion allows, or as a museum calls for one or as an exhibition comes up. The museum in Tilburg [De Pont, 1992] asked me to build a permanent one. The one in SFMOMA [1995] is the second permanent one, and I think probably within this next six months I am going to build one in Hamburg [Kunsthalle Hamburg, 1996].44

Serra's statements can be read as a notion that site specificity is a means to define the artwork for a specific occasion, just like the lead is a medium to shape its form through the artist's own bodily movements. Serra's Splash pieces crystallize into (semipermanent) installations that last as long as they are not removed and therewith still follow the dictum that to remove the work is to destroy it. But different from his stance concerning the relocation of Tilted Arc (being a site-specific work in public space), it is part of the concept of the Splash pieces that the performance can be situated in different locations, making the installation site-specific time and again. From his own statement, the artist regards the gallery primarily as a formal space of which the dimensions determine the shape of the artwork, and not so much as a place to express a critical socioinstitutional stance. In this respect, it is worth looking at the following statement by Serra during an interview with Craig Owens in 2016:

I think I am a transitional figure. If anything, I would call myself a poststructuralist, not a postmodernist. I'm involved with the evolution of form, the connection where space and matter meet. One of the things that form constantly has to do is reach a point where it pushes back against content. [...] Form is something that metamorphoses into other forms. It has its own internal logic that can be dispelled and migrate into other forms. ${ }^{45}$

44 The interview with Richard Serra was recorded and published by the San Francisco Museum of Modern Art in 1995, https://www.youtube.com/watch?v=LjvVEN2v8rY.

45 Interview with Richard Serra by Craig Owens in The Guardian, 1 October 2016. 
Figure 6 Gutter Splash Two Corner Cast (1992/1998) by Richard Serra. Collection Museum De Pont, Tilburg. Photo: courtesy De Pont. $\odot$ c/o Pictoright Amsterdam.

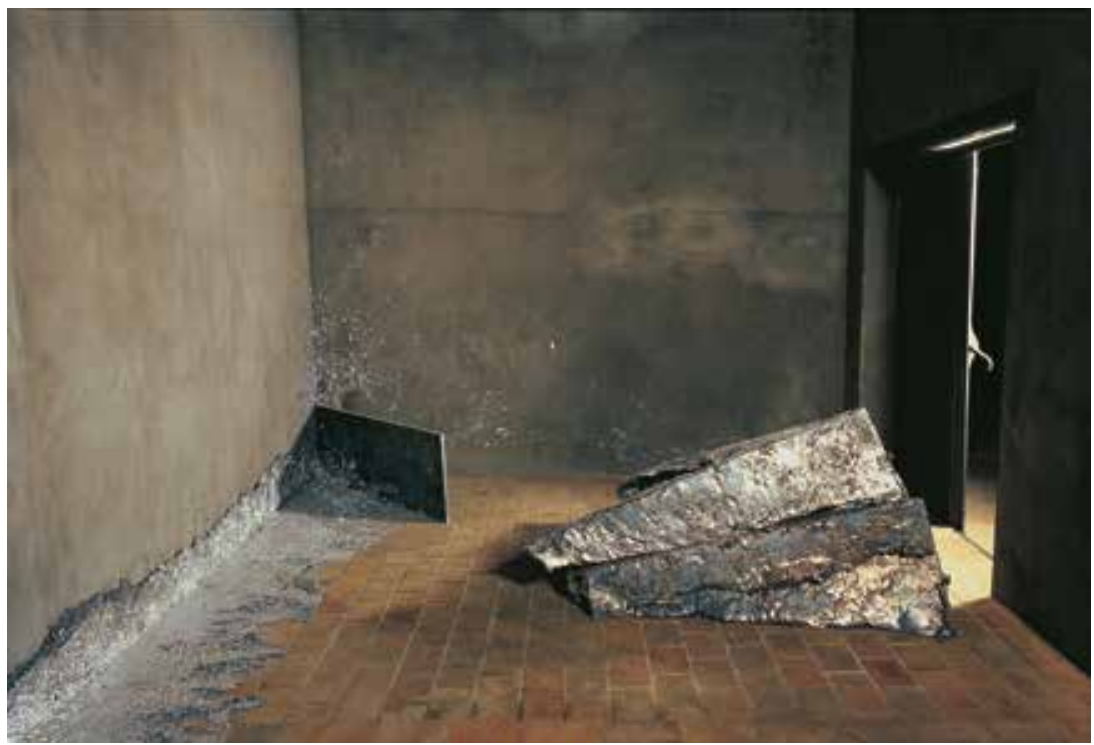

Serra's account might be a reason to place the Splash pieces in Kwon's category of phenomenological site specificity, the kind of work that is rooted in the physical conditions of the site. In her chapter "Unhinging of site specificity," Kwon criticizes the recreation of "unrepeatable" artworks, for which she takes Serra's Splashing as an example. ${ }^{46}$ She stresses the mechanisms of commodification when site-specific works are repeated, hence losing their historical and critical potential:

With the co-operation of the artists in many cases, art audiences are now offered the "real" aesthetic experiences of site-specific copies [...] As Susan Hapgood has observed, the once-popular term 'site-specific,' has come to mean "movable under the right circumstances, shattering the dictum that "to remove the work is to destroy the work."

It can be argued that the memory of the historical piece should have prevailed by not repeating the performance. However, taking the perpetuation 
of site-specific installations as a starting point and with an eye to Serra's own statements, I would argue that, even though each performance was adjusted to the respective context, the concept of the work remained the same, offering museum audiences a materialized site-specific installation. Indeed, a prerequisite for this view is that the artist executed the performances himself by throwing the lead into the corners of the space and by authorizing the installation resulting from it. Things might become more complex when others take over the role of the performer, therewith diminishing or replacing the artist's physical, bodily involvement. ${ }^{48}$ This happened in later years of Serra's career, for example with the execution of a Splash piece for SFMOMA in 1995, Gutter Corner Splash: Night Shift (1969/1995). In this case, the artist was supported by his assistants, but he was still present as a coworker and supervisor, and authorized the installation. ${ }^{49}$ That said, I still agree with Kwon that there are limits to the historical integrity of recreating site-specific installations, for example, when performance elements are part and parcel of the production process. In chapter 3 and the case study chapters, the question returns to what extent change and continuity can be paired with one another, or when the borders of integrity are crossed.

\section{Historical Evidence of Site Specificity}

Memories of site-specific installations are usually based on photographic documentation, and sometimes on narratives and discourses, as in the case of Tilted Arc. This point leads back to the role of photographs in the extended lives of site-specific installation artworks, which Martha Buskirk observed in the case of Allan Kaprow's Yard (see chapter 1). Buskirk indicates the importance of photography for reiterations of ephemeral works of art as follows:

Thus the photograph is part of a process that is both fixed and fluid, allowing comparison of the far-flung examples of a work that cannot be understood as singular, even as the work has, after each disturbance, largely settled back into its identity with photographs [from the past]. $5^{\circ}$

48 It goes beyond the scope of this discussion, but performance artworks are often re-executed by others, with the seminal example of reperformances of works by Marina Abramović.

49 Richard Serra's Gutter Corner Splash: Night Shift (1969/1995) has been created for SFMOMA with the help of his assistants, who splashed the lead in the corner under his supervision. For the creation process, see: https://www.sfmoma.org/watch/richard-serra-throws-molten-leadinside-sfmoma/ (last accessed 22 April 2021).

50 Buskirk, Creative Enterprise, 137. 
The role of photography and moving image cannot be underestimated in the daily practice of contemporary art museums that aim to keep spatiotemporally defined artworks alive and, in one way or another, develop "control mechanisms" for managing these complex works of art. Martha Buskirk points to the role of the artists in this process, who foresee a trajectory of relocation from the start. Recontextualization, she states, is often a "technique that artists [...] choose to employ as a key element of the artistic process" - they often collaborate with the institutions "in the process of organizing, staging, and documenting their site-dependent or event-based projects. ${ }^{11}$ She concludes that, during musealization, conservation, and presentation, an ongoing dialogue takes place between the artist and art institutions, which has the ability "to absorb, even foster, what once appeared to be critical discourse. ${ }^{52}$ Apart from this active engagement with preserving the past, in recent times, museums actively help to produce the art of the present. ${ }^{53}$ Hence, in view of the past, present, and future of site-specific installation artworks, it is vital to look into the entire network of actors involved, sharing the responsibility of their perpetuation, and to examine to what extent artworks are conceived as strictly spatiotemporal defined or as an artistic strategy that incorporates repeatability.

\section{Site Specificity as Artistic Strategy}

Various strategies may come into play during the processes of musealization, conservation, and reinstallation of site-specific installation artworks. The artist's intention is without doubt of primary importance, but personal networks, collaboration with museums, the know-how of assistants and professional staff, theoretical discourses, and technical means, such as photographs and other documentation can all play a part in their perpetuation.

The conservation scholar Tina Fiske offers an insightful example with her analysis of Andy Goldsworthy's site-specific installation White Walls (2007), in which she takes a processual point of view. ${ }^{54}$ The installation consists of slabs of wet porcelain clay, which were applied to the four walls of the Lelong gallery space in New York. The idea was that, when the clay dried, it would harden and crack, and eventually fall to the floor, as had happened with Goldsworthy's other clay installations. However, with the

Buskirk, Creative Enterprise, 10, 17.

Buskirk, Creative Enterprise, 7.

Buskirk, Creative Enterprise, 3.

Andy Goldsworthy created White Walls for Galerie Lelong, New York. 
2007 iteration, it appeared that the process was unpredictable and could be highly intrusive. Fiske explains that, because there is a bonding of the clay and the substrate, layers of wall paint were also taken off when the slabs fell to the floor, "revealing the physical substance of the walls and the traces of previous interventions by other artists." In the end, the artwork turned out to be a "material embodiment" of a "destructive" process that involved many participants, including the work of artists previously on show in the gallery. 55

Fiske takes the example as her starting point for a reflection on the "iterability" of site-specific installation artworks that have the potential of being repeated. Following Derrida's notion of différance, she holds the view that this kind of works resemble both identity and difference. ${ }^{6}$ Most of the time, she argues, a site-specific installation loses the "physical bond to its originating event or context of inscription" after the exhibition period. ${ }^{57}$ A period of "absence" starts when the artwork is disassembled; some parts may be put in storage, and materials that were intentionally temporary will be thrown away. Key to Fiske's argument is that, after such intermission and dormant state of the artwork, a radical understanding is required to reinstall the work (the author compares this process to a strategy of "translation"). ${ }^{8}$ Professionals need to understand the artwork's identity and genesis, and should have the know-how to reactivate the work's site specificity in terms of différance. Site specificity is thus seen as a process of reinterpretation (which, in the case of White Walls, took an unintentional and dramatic turn, because it revealed other site-specific works as well). Fiske concludes that the "iterability" of a site-specific work in a new context considers "a particular mode of repetition that mobilizes notions of breach, absence and difference. 59

Fiske's notion of iterability is also at the heart of the current investigation. From her discussion of White Walls, the insight can be drawn that site specificity is often a strategy to set a process in motion that can be

55 Tina Fiske, "White Walls: installations, iteration and difference," in Conservation: Principles, Dilemmas and Uncomfortable Truths, ed. Alison Richmond and Alison Bracker (Amsterdam: Elsevier, 2009), 229.

56 Tina Fiske offers an in-depth reflection on the conservation and presentation of site-specific installations in a museum context, which she understands as an exemplification of Derrida's notion of "iterability": a particular mode of repetition that "rather than 'aspiring to the fulfilment of the original,' searches or reaches beyond the original itself." Fiske, “White Walls," 234-235.

57 Fiske, "White Walls," 233.

$5^{8}$ Fiske, "White Walls," 236.

59 Fiske, "White Walls," 232. 
repeated with respect to the identity of the work, accepting the differences that may occur - sometimes even unintended. Another alluring argument is that sometimes radical solutions are taken by the artist and/or custodians in order to "translate" the artwork from one context to another.

An explicit call to conceive site specificity as a process or modus operandi has also been made by artist and philosopher Kevin Melchionne. Rejecting Crimp's belief in "the singularity of place" in site-specific art (as demonstrated with the case of Tilted Arc), Melchionne states that site specificity "denotes an increasingly complex set of practices." ${ }^{60}$ The relocation and/ or reiteration of a site-specific installation does not necessarily mean the work has lost its intended meaning:

the possibility of relocating site-specific works depends on an alternative conception of the relation between the ontology of space and the meaning of the work. Typically, in discussions of site-specificity, it is assumed that the meaning of the work relies on qualities that define a particular place as unique. [But] singularity is not their only quality. Those aspects of the place which constitute its singularity may not be the most relevant for a work of art made for the place. ${ }^{61}$

Instead of adhering too much to the artwork's physical rootedness, Melchionne suggests an approach of differentiating between different modes of site specificity. Scholars and curators, he states, should determine what the artist aims to achieve with a strategy of working in a site-specific way. To this end, he offers a list of possibilities: engagement with the formal structures of the site, interaction with the art system (institutional criticism) and/or with the viewer (in experiencing the installed work), incentives provided by a contest or a commission for a site-specific work (in galleries or public space), engagement with the historical and/or sociopolitical meaning of a place, and so forth. ${ }^{62}$ Following Melchionne's multilayered perspective on site specificity, I believe that the research into the perpetuation of sitespecific installations can be guided by the analysis of a set of site-specific strategies, applied by the artists, and the ways in which these are reactivated or disregarded in future iterations.

6o Kevin Melchionne, "Rethinking Site-Specificity: Some Critical and Philosophical Problems," Art Criticism 12, no. 2 (1998), 47.

61 Melchionne, "Rethinking Site-Specificity," 45, 47.

62 Melchionne, "Rethinking Site-Specificity," 38-39. 
Firstly, however, I will continue my search for notions that can help identify the strategies and site-specific functions applied by the artist. Whereas, in the discussion so far the primary focus has been on the relationship between the artist and the museum institution, it is time to include the visitor, in a triangular relationship between the work, the surrounding space, and the spectator. As previously stated, various art historical movements have influenced the rise of site-specific installation art and references are frequenty made to minimal art - in particular when addressing the perception of the work and the position of the visitor in the exhibition space. ${ }^{63}$ This, in fact, is a further elaboration on the type Kwon identified as phenomenological site specificity.

\subsection{Site Specificity and the Viewer's Position in the Gallery Space}

During the 196os, minimal art dominated the art world with abstract images that are defined by their spatial dimensions, colour, surface, and the surrounding space. The visitor's own position in the exhibition space contributes to the perception of the work - accentuating the awareness of the visitor's presence in the here and now. With Minimalism, the spatial arrangement became part of the meaning of the artwork, redirecting the attention from the artwork (and its creator) to the visitor, as Douglas Crimp observes:

During the 196os, minimal sculpture launched an attack on the prestige of both artist and artwork, granting that prestige instead to the situated spectator, whose self-conscious perception of the minimal object in relation to the site of its installation produced the work's meaning. ${ }^{64}$

Crimp continues by stating that the viewer becomes "the subject of the work" in minimal paintings and sculptures. These artworks are only completed when the viewer is present. Moreover, these artworks incite a sense of introspection and self-awareness through the reciprocal relationship between the artwork, the viewer, and "the place inhabited by both. ${ }^{\prime 6}$ There

63 For the influence of minimal art on site-specific installations, see: Crimp, Museum's Ruins, 16-17; De Oliveira et al., Installation Art, 23; Kaye, Site-Specific Art, 25; Kwon, One Place After Another, 12-13; Meyer, "Functional Site," 25-26; Rosenthal, Installation Art, 64; Bishop, Installation Art, 77.

64 Crimp, Museum's Ruins, 16-17.

65 Crimp, Museum's Ruins, 154. 
are differences in opinion apropos of the comparison between minimal art and site-specific installations. Art historian Mark Rosenthal observes that minimal art is indeed influenced by the spatial co-ordinates, light conditions, and the visitors' trajectories through space. Installations of minimal art are "in tandem with and even embrace literal space, if only in a generic sense - wall, floor, ceiling, corner." The author continues by stating that the artworks on display are seldom site-specific in a strict sense because they are, in fact, quite moveable. ${ }^{66} \mathrm{On}$ the other hand, in reaction to the "regularity and [the] structures and grids" of Minimalism, site-specific working artists such as Richard Serra went a step further, because they truly intervened with the physical conditions of the space, engaging visitors in such a way that it might feel "uncomfortable." ${ }^{67}$

Site-specific interventions have their "own internal logic and formal integrity," which, as Rosenthal states, could be reinvigorated when the artwork is relocated to a different location provided that a new connection with the site is established: "Again, the viewer has a real time and space experience of that location in particular." ${ }^{68}$ Rosenthal shows that, with such radical gestures and interventions - worded by Serra as "attacking and restructuring" a given space - the integrity of the artwork would not necessarily be lost when the work is relocated and distributed to different places. ${ }^{69}$ These observations bring into focus the conception of the spatial design of the artwork as a site-specific function that can be repeated or reperformed at different locations. In that sense, the perpetuation of Serra's Splashing could be explained as a succession of reiterations and reactivations of the function of the spatial design, characterizing Serra's approach for this particular work of art.

\section{The Performativity of Site Specificity}

Like the authors mentioned above, performance scholar Nick Kaye draws a comparison with minimal art in his book Site Specific Art: Performance, Place, and Documentation. Looking at site-specific installations as radical interventions "into the gallery, the city, and other 'found' sites," he suggests to focus on what those artworks $d o$ :

66 Rosenthal, Installation Art, 64.

67 Rosenthal, Installation Art, 64.

68 Rosenthal, Installation Art, 66-67.

69 Richard Serra's citation comes from Rosenthal, Installation Art, 64. 
Although operating through a variety of disciplines and means, each [of these works] take their effect in performance..$^{70}$

Site specificity is brought to life in interaction with the surrounding context and, as Kaye states, provokes uncertainties about the distinctions "under which a work's integrity and place are fixed." ${ }^{11}$

What makes Kaye's argument relevant to the current research? First of all, he points us to the performativity of site-specific installations in the sense that these artworks activate the connection between the work and conditions of the (museum) site. Secondly, his view that site-specific works "trouble the oppositions between the site and the work," can be interpreted as a deliberate effect of site-specific installations: to address the gallery space as an "activated site" where the usual procedures and practices of the museum regime are challenged..$^{2}$ In a sense, his argument does not seem to diverge from the notion of institutional criticism made by Kwon and others, but Kaye underscores the iterability of this function, as a continuous potential for questioning the gallery space and the museum's organizational structure. By "conceiving the museum as a conceptual framework rather than a built form," the work is not only defined by the site, but, conversely, site-specific installations define the site just as well. ${ }^{73}$

The above paragraphs discussed two main concepts regarding artistic strategies towards creating site-specific installations: minimal art of the 1960 and 1970s offered the notion that site specificity heightens the visitor's perception in the here and now. Secondly, Nick Kaye called attention to the "performativity" of site-specific installations, because they establish a reciprocal relationship between the artwork and the site. In respect of the latter, I would also call to mind Domínguez Rubio's statement that installation artworks behave as "unruly objects" through their capacity to shift the boundaries and traditional control mechanisms of the institution. Later on, in chapter 3 , I will return to this notion as well as to the idea that site-specific installations have agency to "perform" when discussing current theories and practices in the conservation of contemporary art. First, however, I will briefly introduce one particular site-specific installation that interfered with the usual practices of museum

70 Kaye, Site-Specific Art, 25.

71 Kaye, Site-Specific Art, 215. See also Kirsi Peltomaki, "Affect and Spectatorial Agency: Viewing Institutional Critique in the 1970s," Art Journal 66, no. $4(2007): 36 \mathrm{ff}$.

72 Kaye, Site-Specific Art, 11.

73 Kaye, Site-Specific Art, 191. Kaye refers to a statement made by Daniel Buren. 
professionals at several occasions, not least because the installation included a performance in which museum staff members were actively involved.

\subsection{Robert Morris's Amsterdam Project}

Robert Morris's Amsterdam Project: Specification for a Piece with Combustible Materials was first realized as a site-specific installation in 1969, at the Stedelijk Museum Amsterdam. [Figure 7] The installation was repeated at the same location in 2011.

Robert Morris used to work in the tradition of minimal art and conceptual art with a variety of art forms, including performance and installation art. ${ }^{74}$ In his writings, the artist familiarizes us with the idea that site-specific installations evoke a "present tense of space," because they are "temporary and situational, made for a time and place and later dismantled." 75 The first installation that made Robert Morris famous was Continuous Project Altered Daily (1969), executed at the Castelli Warehouse in New York. Over a period of several months, Morris took up residence in the warehouse and brought raw materials to the site, such as clay, water, cotton sheets, asbestos, felt, and wood. He used the place as a "construction site," continuously changing the spatial arrangement of the materials into new configurations, while people could watch him at work. ${ }^{6}$ Nothing remained of this project, except for photographic documentation and written reports.

In the same year, Morris participated in the aforementioned exhibition Op losse schroeven in the Stedelijk Museum, one of the first overviews of conceptual art and process art featuring a considerable number of site-specific installations. ${ }^{77}$ Morris's project consisted of a collection of inflammable materials, such as turf, branches, grass, and coal, that were arranged in a specific order on the gallery floor. Towards the end of the show, the artist handed over a set of instructions to the museum for the completion of the Amsterdam Project (see Appendix). He requested that

74 Initially a painter and sculptor, Morris co-operated with the Judson Dance Theater in the early 1960 , for which he choreographed a number of works.

75 In a series of essays, Robert Morris explains his views on site specificity: "Notes on Sculpture," published in Artforum (February and October 1966) and "The Present Tense of Space," Art in America (January-February 1978), reprinted in Continuous Project Altered Daily: The Writings of Robert Morris (Cambridge, MA: The MIT Press, 1994). This quote comes from the "The Present Tense of Space" in Continuous Project, 202.

76 Davidts and Paice, Fall of the Studio, 55.

77 See footnote 18 of this chapter. 


\section{Figure 7 The Amsterdam Project. Specifications for a Piece with Combustible Materials (1969) by Robert Morris. Collection Stedelijk Museum Amsterdam. Installation view in Op losse schroeven. Situaties en cryptostructuren. Photo: courtesy Stedelijk Museum Amsterdam. $\odot$ c/o Pictoright Amsterdam.}

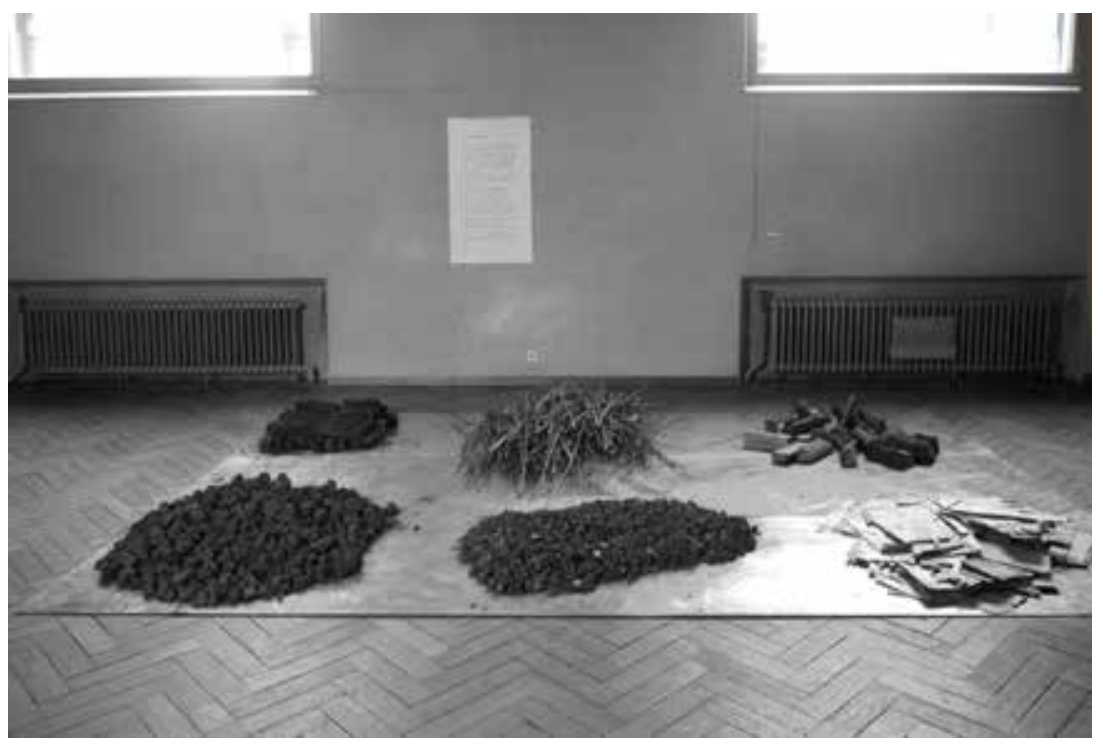

museum professionals carry out a performance by setting the combustibles on fire in front of the museum building. And so it happened in April 1969. The materials were brought to the front of the museum and were set on fire by the staff members, marking the end of this initial iteration of The Amsterdam Project. In accordance with the ideas of conceptual art, Morris allowed the Stedelijk Museum to restage the installation based on his instructions and to carry out the performance in a similar way. ${ }^{78}$

More than four decades later, in 2011, the Stedelijk Museum took up the challenge and re-executed The Amsterdam Project once more at the original location. At that time, the museum was right in the middle of a major

78 Conservator and scholar Sanneke Stigter explains that conceptual artworks in which the idea predominates the artwork's materialized form open up the vista that custodians can re-execute the artwork, although, in practice, questions of how "to cope with the dilemmas when having a responsibility towards the work's conservation and presentation" may still stand in the way of doing so without the presence of the artist. Sanneke Stigter, "Between Concept and Material. Working with Conceptual Art: A Conservator's Testimony” (PhD diss., University of Amsterdam, 2016), 36 . 
reconstruction, including renovation of the old building and the addition of a new wing. Before the Stedelijk would entirely be closed for a long time, it featured the series Recollections, restaging a number of artworks from $O p$ losse schroeven. ${ }^{79}$ Morris's Amsterdam Project was included and a similar set of materials was collected by the museum staff. ${ }^{80}$ The instructions were used to install the heaps of raw materials in the same room and with the exact same spatial arrangement as in 1969. In addition, as before, the show ended with a performance executed by the custodians, who set fire to the combustibles in front of the museum building. And, to convey the historical significance of the exhibition, visitors with a smartphone could take a virtual guided tour and experience $O p$ Losse Schroeven in the gallery spaces where the artworks had originally been displayed in 1969. In those cases where the original artworks could not be recreated, visual documentation and spoken word gave an impression of what the installation had been like at the time.

According to the museum's press release, Recollections restaged "one of the most innovative surveys" of the 1960 s, and Morris's project emphasized the role of the museum as a memory institution:

"Combustible" can be read as a criticism of the art world that places too much weight on technical virtuosity and the primacy of the object. Morris's critique is equally pertinent today and highlights a paradox of the current exhibition: in attempting to offer insights on a historical exhibition intended to subvert both the traditional art object and the traditional role of the museum, it must rely on objects from its own collection. ${ }^{81}$

The reinstallation of the Amsterdam Project puts dilemmas to the fore of re-executing a site-specific installation in the absence of the artist, even if it is intended this way in the concept of the work. With the original iteration, the artist made a powerful statement by bringing in combustible materials and letting them be burned by museum professionals, literally "troubling" the oppositions between the work and the site. Morris turned the museum regime upside down and yet intended his was work to being collected and re-executed. In the self-reflective statement cited above, the museum

79 Recollections - Op losse schroeven was curated by Margriet Schavemaker and Ann Goldstein, Stedelijk Museum Amsterdam, summer 2011.

80 Some of the artworks could not be refabricated and were presented in the form of documentation. A multimedia tour (including QR codes and GPS technology) explained the original location and meaning of the works.

81 See the press release, http://www.stedelijk.nl/en/press-releases/stedelijk-museum-presentsrecollections--op-losse-schroeven_(last accessed 22 April 2021). 
acknowledges that the reiteration of the installation and the performance in 2011 were not "subversive" acts in themselves, but ways to keep the memory of the original project alive. One could argue that this reactivation was in agreement with the artist's intention regarding the artwork's site specificity and his intent to interfere with museum practices. The exhibition space was still the same and the entire process was repeated, carefully following the artist's instructions in regard of the work's spatial arrangement and orchestration of the performance in front of the museum building.

That said, the impact of the restaged Amsterdam Project was completely different from its original iteration, not least because the sociocultural context had radically changed over forty years. Although the display setting was still anchored in the original location, the experience needed an explanation. To this end, much effort was put into communicating the historical context of Op losse schroeven to the public by means of a virtual tour, elucidating the initial site specificity of the works. After this final iteration, the building was renovated and with the disappearance of the original site it can be reasoned that a reconstruction like this can never be realized again.

\subsection{The Site of Production and the Site of Perception}

In the above literature review and introduction of case studies, the focus has been on artworks dating from the 196os and 1970s. In the following paragraphs, I will shift the discussion to the 1990s, when a renewed interest in site specificity emerged, both in the artists' production practices and the museums' collecting policies and exhibition programmes.

Influenced by the possibilities of travelling, globalization, and technological developments, artists of the 199os started to work across the globe, with well-known examples as Thomas Hirschhorn, Francis Alÿs, Mark Dion, and Renée Green. According to James Meyer, a large group of artists started to explore "a mobile notion of site and a nomadic subjectivity." ${ }^{82}$ Meyer describes this new form of site specificity in terms of the "functional site," moving it away from physically rootedness and institutional critique to a broader cultural sphere of investigation and communication. ${ }^{83}$

The functional work explores an "expanded" site: the "art world," in this activity has become a site within a network of sites, an institution among

82 Meyer, "Functional site," 32.

83 Meyer, "Functional site," 23-25. 
institutions. To be sure, previous institutional critique demonstrated the financial and ideological ties of the gallery to greater economic and political structures. [...] Today, much practice explores an expanded site, enlarging its scope of inquiry into contingent spheres of interest, contingent locations [and this practice] may engage several sites, institutions, and collaborations at once. ${ }^{84}$

The expanded notion of site specificity primarily applies to geographical site-specific projects. Quite often, site-specifıc working artists engaged with the history or geography of a particular place, and they often involved local communities in the production of their art. As Miwon Kwon also observes, in theory, any place, community, or social issue could prompt a site-specific work. The communication with "an audience," as was common in the 1990s, had largely replaced the fascination for site specificity of previous periods. ${ }^{85}$

Many geographical site-specific projects have resulted in a film, a series of photographs, or an archive, and these art objects (as they were considered) might easily find their way into a commercial gallery or museum. To some extent, the circulation of derivatives of land art projects of the 1960 s and 1970s are comparable, taking into account that Earthworks can still exist in the actual, physical environment, whereas these newer art productions were conceived as the main result of the project and circulated as "independent" artworks. The gap between the production site and the site of perception is denoted by Meyer as a "discursive" relationship and a juxtaposition of different "realities of site." ${ }^{86}$ Kwon therefore adds to her typology a third category - namely, that of discursive site-specific works:

This is not to say that the parameters of a particular place or institution no longer matter, because site-oriented art today still cannot be thought or executed without the contingencies of locational and institutional circumstances. But the primary site addressed by current manifestations of site-specificity is not necessarily bound to, or determined by, these contingencies in the long run. Consequently, although the site of action or intervention (physical) and the site of effects/reception (discursive) are conceived to be continuous, they are nonetheless pulled apart. ${ }^{87}$

84 Meyer, "Functional site," 27.

85 Kwon, One Place After Another, 109.

86 Meyer, "Functional site," 25-27; Kwon, One Place After Another, 26-30.

87 Kwon, "Notes on Site-Specificity," 45. Original emphasis. 
Also according to Meyer, the expanded notion of site does not necessarily imply that the spatiotemporal characteristics of the artwork are disregarded; they are just raised to another level, allowing for a potential coexistence of multiple site specificities, both real and virtual. Moving away from "the premise of site-specificity to locate the work in a single place, and only there," those strategies are primarily related to social and artistic practices. ${ }^{88}$ Hence, if we conceive site specificity this way, we could further explore its function as "an operation occurring between sites, a mapping of institutional and discursive filiations and the bodies that move between them (the artist's above all)." 89

It follows that, in conservation and presentation strategies applied during successive biographical stages of the artwork, all kind of mediation processes come into play. When fluid notions of a "discursive" and "mobile" site enter the art production as well as the discourse, the role of a "mediator" who presents these artworks to the public comes to the fore. Roles are shifting, and the person who takes on the function of mediator could either be the artist, the gallerist, or the museum curator - or a combination. In this respect, some critics emphasize that site specificity (and contemporary art in a broad sense) has primarily become a strategy of mediation; of connecting places and sites, art producers and art receivers. Martha Buskirk, for example, argues in The Contingent Object that contemporary art opens up "temporal gaps [...] at the level of production" and requires an act of mediation and interpretation:

This rift may appear in the very places where spatial and temporal experiences are the most important, as objects that depend on an unmarked uniformity are marked with the signs of age, as performances are known through partial documents or accounts, and as works initially installed or arranged with the artist's direct participation are increasingly interpreted by others. $9^{0}$

Following the idea that site specificity is not "fixed," but gradually unfolds as a network of relationships between the artwork and multiple sites, it sometimes happens that museums play an active role in the mediation of the work as "site-specific installation" (as we have seen with The Amsterdam

88 Meyer, "Functional Site," 26.

89 Meyer, "Functional Site," 25.

90 Martha Buskirk, The Contingent Object of Contemporary Art (Cambridge, MA: The MIT Press, 2003), 14 . 
Project), bridging the gap between the site of production and the site of perception. This "mobility" of site specificity is illustrated with the following case example of Phil Collins's geographical site-specific project and video installation they shoot horses (2004).

\subsection{Phil Collins's they shoot horses}

Phil Collins's installation they shoot horses, in the collection of Tate, consists of a two-channel video installation with sound, which is projected in a darkened space. [Figure 8] When Collins started the preceding geographical site-specific project in 2004, he lived and worked in Israel. Nine young volunteers from Ramallah were asked to perform a dance marathon of two days and record the dancing themselves..$^{91}$ They were provided with a nonprofessional camera and filmed each other mainly in close-up. Collins involved this local group of volunteers in creating the raw material for the installation in the same way that he used footage of reality TV for other art productions.

The meaning of they shoot horses is intertwined with the geography and sociopolitical situation in Ramallah, signifying not only the work's content but also the spatiotemporal conditions during the recording: the length of the performance and the location of the marathon were similar to dance events usually held in Ramallah; the screening of the artwork thus seems to represent the local situation. Claire Bishop describes this as follows:

It goes without saying that they shoot horses is a perverse representation of the "site" that the artist was invited to respond to: The occupied territories are never shown explicitly but are ever-present as a frame. [...] By using pop music as familiar to Palestinian as to Western teens, Collins also provides a commentary on globalization that is considerably more nuanced than most activist-oriented political art. ${ }^{92}$

91 The title refers to the novel They Shoot Horses, Don't They (1935) by Horace McCoy, in which dance marathons during the Great Depression of the 1930 are the central theme. For more information, see: http://www.tate.org.uk/art/artworks/collins-they-shoot-horses-t1203o (last accessed 22 April 2021).

92 Claire Bishop, "The Social Turn: Collaboration and its Discontents," Artforum International 44 (February 2006): 182. 
Figure 8 They shoot horses (2004) by Phil Collins. Collection Tate Galleries, London.
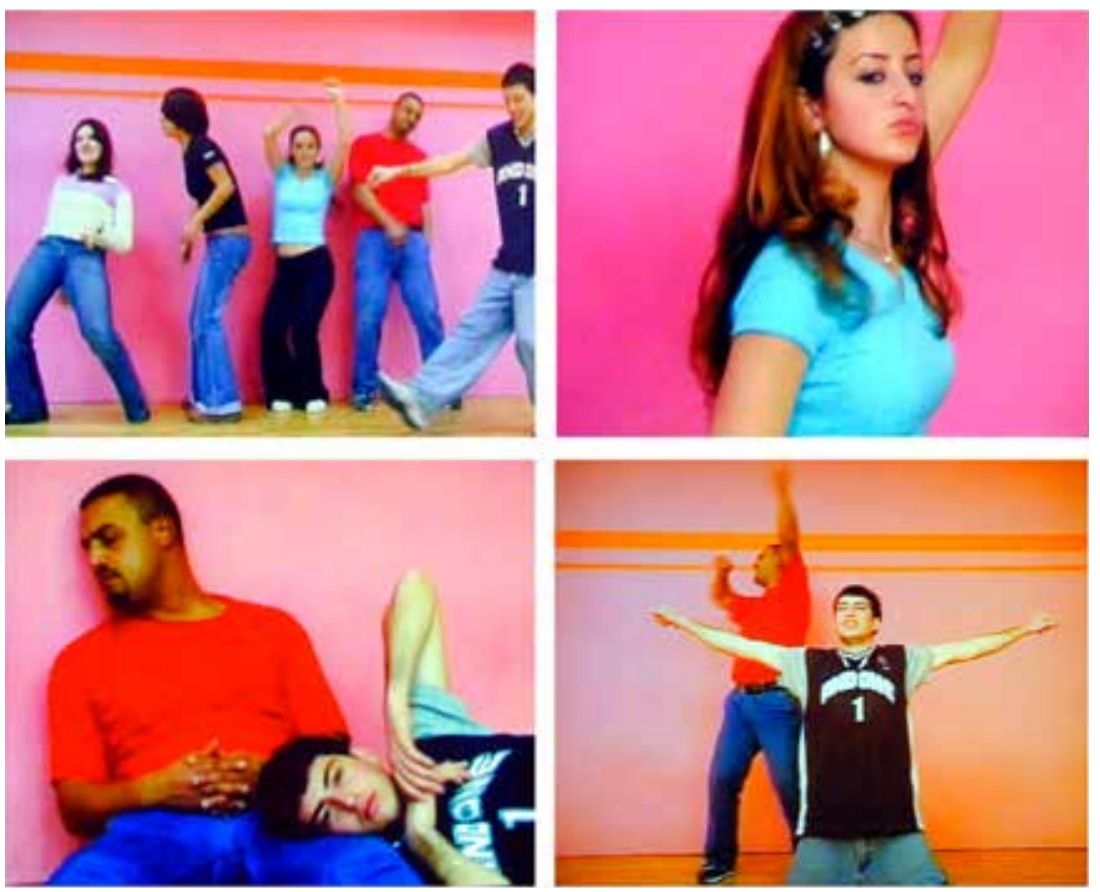

What the public may not have realized is that the artwork had to be accommodated to the museum conditions to be experienced at all. A second layer of site specificity was added to they shoot horses when the artwork was acquired and entered a stage of postproduction at the Tate: the raw footage was brought into the museum's technical department and, with the help of the artist and a team of conservators and curators, accommodated to a suitable work of art.

A case study carried out by Pip Laurenson during the Inside Installations project, demonstrates that Collins's preference for using a nonprofessional camera posed a challenge to the artwork's musealization, because the original footage was of insufficient quality for a museum screening. Moreover, the technicians expected a rapid degradation of the material. ${ }^{93}$ Hence, the

93 The case study was carried out by Pip Laurenson at the Tate during the European Inside Installations project (2004-2007) and has been published in Tatja Scholte and Paulien 't Hoen, ed., Project Preservation and Presentation of Installation Art (Amsterdam: Instituut Collectie Nederland, 2007), 9 . 
conservator and technicians of the Tate decided to transfer the footage to a more sustainable carrier and figure out an appropriate display. During this process, profound questions were posed in relation to the editing of the footage: what approach should be followed with regard to gaps in the footage resulting from technical failures during the dance marathon in Ramallah? How to treat the intervals when the calls for prayer from a nearby mosque interfered with the music? Should those calls be included or left out? And last but not least: one hour of footage had been lost when the material was confiscated at one of the Israeli checkpoints. How should this gap in the material be treated?

After discussions with the artist, it was decided to use a film-editing package and to cut the footage to a duration matching the opening hours of the Tate Modern, meaning six hours and forty minutes of dancing. The time slot was applied to both channels that were presented in the gallery in order to complete the installation. In other words, the real-time recording of they shoot horses was reconstructed to fit a site-specific installation, adjusting the work to the time-space co-ordinates of the gallery and presentation standards of the museum environment. Mediation, in this example, took place during the postproduction of the artwork with the support of advanced technology and was highly influenced by custodianship.

they shoot horses can be considered an illustration of what James Meyer and Miwon Kwon indicate as a discursive or mobile site, emerging in the movements and relationships between one site and the other. During the production and postproduction of they shoot horses, several stages of site specificity can be identified: firstly, the original sociogeographical location where the volunteers performed and filmed their own dancing in Ramallah; secondly, the travelling and the problems of smuggling the footage out of the country (and one part of it being confiscated); and thirdly, the postproduction in the technical department of the Tate, and the presentation of the artwork in the gallery. One question is not addressed in this context: what would happen if they shoot horses would be sent on loan. Would new adjustments regarding the duration of the screening have to be made to accommodate the work to another gallery space with different opening hours?

\subsection{Conclusion}

A number of notions support the analysis of the perpetuation of site-specific installations. The typology developed by Miwon Kwon set the terms for understanding site specificity as a multilayered phenomenon, which she 
takes apart in a genealogy of phenomenological, social-institutional, and discursive types of site specificity. The dividing line between the 1960s-1970s and the 1980s-1990s distinguishes the first two types from the third one, although Kwon acknowledges that these are overlapping categories in artistic practices. Based on James Meyer's discursive or mobile site, I elaborated on the functional mode of site specificity, situating the gallery or a museum as a "site" between other sites, for example, the site of the art project, the site of production, various sites of reception, the site of musealization, and so forth. The function of presenting a site-specific installation could thus be to bridge the gap between one and the other function of the "site." In respect to museum presentations, Nick Kaye pointed to the "performativity" of site-specific installations as an artistic strategy to activate the connection between the artwork and conditions of the site, posing challenges to the institutions when preserving and presenting the work of art. I put sitespecific installations in relation to Fernando Domínguez Rubio's suggestion of "unruly objects" that withdraw from the control mechanisms of the institutions and produce new forms, practices, and meanings, to varying degrees of continuity and change.

In chapter 1, I made the assumption that site-specific installation artworks are relational networks. Following Kevin Melchionne and Nick Kaye, I added the notion that site-specific installations can be understood as an artistic strategy and proposed to apply a set or network of site-specific functions to the analysis of their transformation over time. Still indebted to the Kwon's categorization, but bearing this notion in mind, I came up with the following set of site-specific functions, which can be activated when the installation is preserved and presented: first, the artwork's spatial design and its connection to the physical surrounding; second, the way in which a site-specific work activates the visitor's experience in the here and now and raises awareness of the sociocultural context; and third, the discursive dimension of site specificity, bridging the gap between the site of production and the site(s) of reception. The latter may reach beyond the installed artwork and take a variety of mediation forms, including photography, film, and other forms of documentation.

Various examples presented in this chapter show how diverse strategies are employed to reinvigorate site specificity in different contexts and times - by artists, conservators, curators, and art historians alike. Whereas the term site-specific suggests that these works are singular manifestations spatiotemporally defined like Serra's Tilted Arc - various authors took the position that these works can be reiterated, as the practices of museums and commercial galleries from the 1990 s onwards demonstrate. Mark Rosenthal, 
for example, takes the stance that reactivation of the work's site specificity can give the viewer a "real time and space" experience, despite the fact that the work is executed at different locations in different times (as, for example, Richard Serra's Splashing). And looking through the lens of the custodian, Tina Fiske proposes a strategy of "translation," ensuring that reinstallations of site-specific installation artworks are repetitions of a process of interaction between the work and the site, which may lead to radical solutions in the exhibition strategies.

Now that an overview has been provided of the history of site-specific installation art, and an inventory has been made of possible typologies and notions of site specificity, it is time to elaborate the conceptual model I propose for the analysis of site-specific installations artworks over time. In chapter 3, I will introduce Henri Lefebvre's The Production of Space to provide a descriptive set of site-specific functions. Furthermore, I will take a close look at contemporary art conservation to develop an analytical toolbox for tracing the factors of influence on successive iterations of site-specific installation artworks. 



\section{A Conceptual Model for the Analysis of Site-Specific Installations}

Keywords: spatial design, conservation, performance, actor-network theory, unruly objects, Henri Lefebvre

"The past leaves its traces; time has its own script. Yet this space is always, now and formerly, a present space." Henry Lefebvre ${ }^{1}$

In the previous chapter, I argued for a broader notion of site specificity than the connectivity between the artwork and the physical location of display. The institutional and sociocultural contexts of production and reception were also identified as parameters for a site-specific installation, leading to my suggestion to conceive site specificity as a network of site-specific functions.

In the current chapter, I develop a conceptual model for the analysis of site-specific installation artworks to understand how this network is formed and transforms over time. The model consists of two parts, one focusing on a categorization of the various functions of site specificity; the other proposing a methodology to compare successive iterations of the artwork and to analyse which "factors of influence" cause changes at a particular biographical stage.

The theoretical backbone for the first part is a theory on space offered by social geographer Henri Lefebvre (1901-1991), who published his famous book The Production of Space in 1974. Lefebvre takes the stance that spaces

1 Henri Lefebvre, The Production of Space, trans. Donald Nicholson-Smith (Oxford: Blackwell Publishing, 1991), 31.

Scholte, T., The Perpetuation of Site-Specific Installation Artworks in Museums. Staging Contemporary Art. Amsterdam: Amsterdam University Press 2022 DOI: 10.5117/9789463723763_CHO3 
are no "empty voids" that exist independently from the actions taking place. In real-life situations, people inhabit spaces and employ activities in relation to the space. In any production practice, he argues, there is a reciprocity between the physical space, the activities of people, and the symbolic or representational function of the space (for example, a museum has a different symbolic function than a factory or a living room). Lefebvre envisions the production of space as the activation of a triadic network of spatial functions, which he specifies in his triad of spatiality as the physical, social, and symbolic. After an in-depth examination of Lefebvre's theory, I propose to incorporate his views into a conceptual model for the analysis of site-specific installations by making a similar triadic distinction: the physical relationship between the artwork and its surrounding (in concept and realization), the social spaces in which the artwork is produced and experienced, and the symbolic (representational) context in which the artwork is presented.

However, to understand the influences of time and the actions applied to the artworks in museum practices, an additional approach is necessary. Hence, in the second part of the chapter, I propose to include this temporal aspect by examining the factors of influence on the artworks' transformation over time. Insights are derived from the current conservation discourse in which installation artworks are compared to a performance or live event. The analogy offers notions that are beneficial to understand the time-based ontology of contemporary artworks and to examine the causes of change in successive iterations. For the model I develop, the notion of "script" is adopted as an instrument to compare different manifestations and to understand underlying motives (by the artist and custodians). Furthermore, I translate the approach suggested by the conservation discourse, which is to "follow the actors" in daily practice, with the proposition to examine site-specific installation artworks "in action."

Both parts of my conceptual model will be applied in the examination of case examples, one directed towards a description of the network of spatial functions at distinct biographical stages (derived from Lefebvre); the other offering the analytical tools of "script" and "actor" to examine the causes of change (derived from the conservation discourse). I will argue that those two parts, which fit together and complement each other, are necessary to understand the perpetuation of site-specific installations in a museum context. The model not only offers insight into the paradoxes and dilemmas but also helps to reconsider the challenges and possibilities when re-exhibiting site-specific installations in different contexts and times. 


\section{The Conceptual Model Part 1: Triadic Model for Analysing Site Specificity}

\subsection{Introducing Henri Lefebvre's Theory on Space}

Henri Lefebvre ${ }^{2}$ (1901-1991) was a French philosopher, sociologist, and political activist, who theorized on a diversity of subjects and is best known for his engagement with social praxis and everyday life. Born and raised in Hagetmau (a rural village near the French Pyrenees), Lefebvre moved to Paris in 1919, where he studied philosophy. ${ }^{3}$ He became famous for his critical publications about societal problems, grouped together under the title The Critique of Every Day Life. ${ }^{4}$ From 1928 to 1957 , Lefebvre joined the French Communist Party. He is still considered one of the most prominent Marxist intellectuals of France, although he distanced himself from the party in later years. ${ }^{5}$ In his extensive oeuvre, Lefebvre synthesizes different disciplines and approaches of prominent thinkers of the twentieth century, looking for subjects that were disregarded in the discourse at the time. ${ }^{6}$ As his biographer Stuart Eldin states, Lefebvre was primarily interested in "the everyday, the urban, difference, social space."

Space became Lefebvre's favourite subject during the 1960s and 1970s, a period in which he experienced and criticized the influence of modern city planning; particularly in Paris, where he was involved in the 1968 protests. As he writes in the introduction to The Production of Space:

We are forever hearing about the space of this and/or the space of that: about literary space, ideological spaces, the space of the dream,

2 For an extensive reading of Lefebvre's theory of space, I refer to Edward Soja, Thirdspace: Journeys to Los Angeles and Other Real and Imaginary Spaces (Cambridge, MA: Blackwell, 1996) and Stuart Elden, Understanding Henri Lefebvre: Theory and the Possible (London: Continuum, 2004).

3 For the influence on Lefebvre's spatial theory of his youth spent in a rural area, see: Elden, Understanding Henri Lefebvre, 9.

4 Between 1947 and 1981, Henri Lefebvre published a series of articles under the title "Critique de la vie quotidienne." Republished in English translation as: Henri Lefebvre, Critique of Everyday Life, trans. John Moore and Gregory Elliott (New York: Verso Books, 2008).

5 Elden, Understanding Henri Lefebvre, 6-7.

6 For the influence of Marx's notion of "dialectic materialism" and Hegel's dialectical idealism, see: Elden, Understanding Henri Lefebvre, 15-64 and the first part of chapter 2 in the same volume, "Engaging with Philosophy," 65-69.

7 Elden, Understanding Henri Lefebvre, $1,65$. 
psychoanalytic topologies, and so on and so forth, but this thinking is never put in connection with the "actually lived space." 8

Lefebvre's goal was to bridge this gap between theory and praxis, between the spatial and social fields of interaction. His publication was highly influential for the discourse on urban planning and social geography at the end of the twentieth century, and it is still acknowledged for the way it raises awareness of "the interwoven complexity of the social, the historical, and the spatial." In developing his theory, Lefebvre drew on various disciplines, including philosophy, sociology, and human geography, and interlarded his theorems with an abundant amount of case studies. As his follower Edward Soja states, notwithstanding a "meandering and idiosyncratic style of writing," Lefebvre's ideas are still appealing to scholars, urban developers, architects, and art designers. ${ }^{10}$

As a social geographer himself, Edward Soja explains Lefebvre's theory as a critique on the traditional perspectives on space, which are based on a dual mode of thinking: one mode addressing "the concrete materiality of spatial forms, on things that can be empirically mapped"; the other concerning "re-presentations of human spatiality in mental or cognitive forms." Instead of adhering to such a binary opposition, Lefebvre envisioned a model that "draws upon the material and mental spaces of the traditional dualism but extends well beyond them in scope, substance, and meaning." ${ }^{12}$

\section{The Production of Space in Everyday Practice}

A source of inspiration for Lefebvre is Foucault's hermeneutic notion of "other spaces," or heterotopias, as he called them. ${ }^{13}$ Heterotopias are encountered

8 Henri Lefebvre first published La production de l'espace in 1974. This quote comes from the English translation: Lefebvre, Production of Space, $3^{-4}$.

9 Soja, Thirdspace, 3 .

10 Quote from Soja, Thirdspace, 8. Lefebvre's work is still part of universities' curricula in social geography and architecture. See, for example, Michael E. Leary-Owhin, ed. "Urban Planning and the Spatial Ideas of Henri Lefebvre." Urban Planning, no. 3 (June 2018). View Issue | Peer-Reviewed Open Access Journal | Cogitatio Press. In 2008, his notion of "spatial practice" was the central topic of the Dutch Artistic Research Event, organized by the Utrecht Graduate School of Visual Art and Design. See http://www.mahku.nl/mahku/philosophy.html (last accessed 23 April 2021).

11 Soja, Thirdspace, 10.

12 Soja, Thirdspace, 9, 11.

13 Foucault explains the notion of heterotopia in his famous essay "Of Other Spaces: Utopias and Heterotopias (1967)," trans. Jay Miskowiec, Architecture/Mouvement/Continuité 5 (October 1984): 46-49. 
in the cultural domain, such as a cinema or a museum, a church or a Turkish bath. According to Foucault, the spaces of heterotopia can only be fully understood if we recognize the connectivity of the actual space (the lived world) with the virtual space of the dream and the imagination (utopia). The function of heterotopias is that they overcome this dichotomy and establish a relationship between actual lived spaces and imaginary worlds, surpassing even the distance of different moments in time. According to Foucault, typical examples of heterotopias "proper to western culture of the nineteenth century" are museums and libraries, because those spaces have the capacity to enclose "in one place all times, all epochs, all forms, all tastes." ${ }^{\prime 14}$

Although Lefebvre borrows Foucault's concept of heterotopia when developing his theory, he complains that Foucault never really explains what space is. ${ }^{15}$ Quintessential to his own stance is that, whereas a comparable connectivity between real and imaginary spaces is envisioned, the focus is on the use of space or the production of space in everyday practice. To understand the production of space, Lefebvre proposes to employ a model for the analysis that envisions space as a network of productive forces - physical, social, and symbolic. It is up to the social geographer, or other social scientists for that matter, to unravel this network in concrete practices. ${ }^{16}$

I will illustrate the above by citing one of Lefebvre's own examples: a common door and its spatial functions in everyday practice. Doors can be described in a formal language - the geometrical dimensions of height, width, and depth - or in the optical terms of perception. Furthermore, doors connect spaces and allow passage when human beings step over the threshold; in fact, they become meaningful entities primarily in relation to human action. Moreover, every door has once been made, and traces of this production process may still be present when the door is in use. Finally, the door's threshold may serve a symbolic meaning, such as "crossing a threshold as analogous to passing through a lock," as Lefebvre states:

Its surrounding makes a door into an object. In conjunction with their frames, doors attain the status of works, works of a kind not far removed from pictures and mirrors. Transitional, symbolic and 
functional, the object "door" serves to bring a space, the space of a "room," say, or that of the street, to an end; and it heralds the reception to be expected in the neighbouring room, or in the house or interior that awaits. ${ }^{17}$

The tripartite dialectic suggested by Lefebvre for the analysis of space is thus geared to actual circumstances: to the physical dimensions of space, the sensory perception and practices in social life, and the symbolic meanings attributed to a particular space. If a space has a symbolic or ideological meaning, this is not because an ideology is projected onto a neutral space, but because ideologies are shaped by the space in which it is practised:

Ideologies dictate the locations of particular activities, determining that such and such a place should be sacred, for example, while some other should not, or that a temple, a palace or a church must be here, and not there. But ideologies do not produce space: rather, they are in space, and of it. ${ }^{18}$

Transposed to the current study on site-specific installation art in a museum context, the symbolic significance of a museum would thus not be projected onto the architecture of the building, but it would be shaped by $i t$, in a reciprocal interaction between the architecture, the institutional policies, the visitors' use of the space, and the wider sociocultural context in which the museum is located. This relational spatial network is subjected to continuous change; any given space can be considered the product of a transformation process within the context of the social and material world. The production of spaces should thus be studied in relation to their respective times and contexts. ${ }^{19}$

Lefebvre's theory lays the foundation for my conceptual model for sitespecific installation artworks and enables me to envision the staging or recreation of a site-specific installation as an activation of three modalities of space, attributed by Lefebvre to the physical, social, and symbolic. [See Diagram 2] 
Diagram 2 Three modalities of space: physical, social, and symbolic. $\odot$ The author. Image editing: Arienne Boelens.

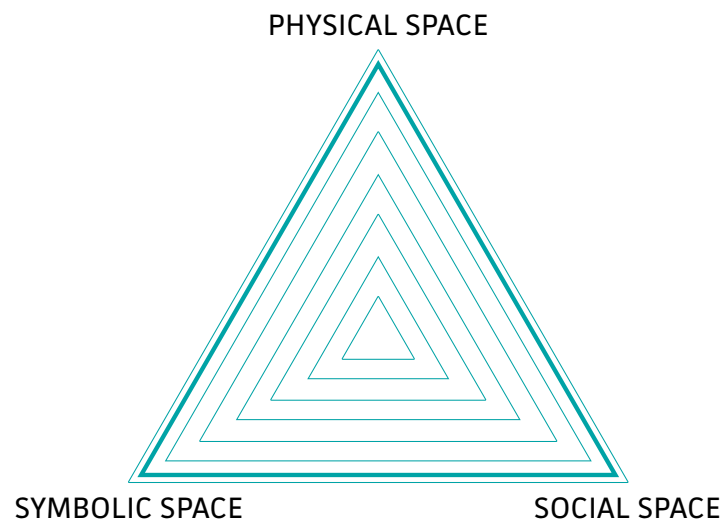

\subsection{Lefebvre's Triad of Spatiality Applied to Site-Specific Installations}

Lefebvre elaborated his thoughts on the network of spatial functions according to the following three modes: physical or "conceived" space, social or "perceived" space, and symbolic or "lived" space. ${ }^{20}$ [See Diagram 3] The first mode (conceived space) is considered the dominant and most familiar spatial function in urban planning, architecture, and other forms of design, as well as in engineering and social geography. In practice, we encounter this function in the spatial design or in abstract representations of space, as Lefebvre states - in architectural drawings, schemata of urban planning, maps, and other codes or signs. In the arts, for instance, spatial designs are expressed in sketches, technical drawings, floor plans, calculations, visualizations, or other representations of space on the basis of which works of (applied) art can be realized. The materialization of the concept into a physical space belongs to this first category as well. 
Diagram 3 Henri Lefebvre's triad of spatiality: conceived space, perceived space, lived space. $\odot$ The author. Image editing: Arienne Boelens.

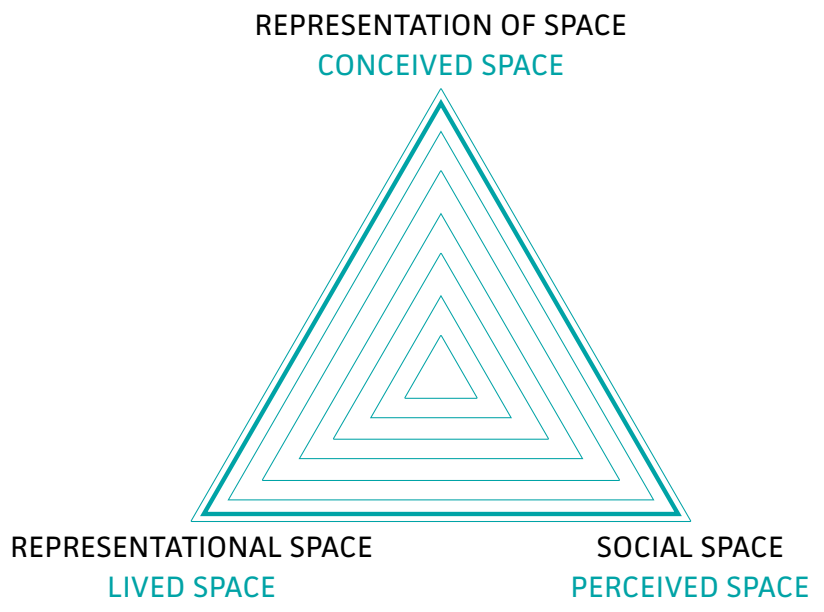

Transposed to site-specific installation art, the function of spatial design is referential for the artist's intentions regarding the spatial arrangement of the installed work in a specific context. For example, in the design process of land art projects, the spatial configuration is conceptualized by means of sketches, technical drawings and models, engineering calculations, and so forth, which serve as a "set of codes" for the realization of the work. The transformation from abstract representations to real spaces establishes, according to Lefebvre, a dialectical relationship between the formal codes and signs on the one hand, and the subjects who interpret and put them into practice on the other. ${ }^{21}$ During this process, some degree of subjectivity and contingency is unavoidable:

Representations of space are certainly abstract but they also play a part in social and political practice: established relations between objects and people in represented space are subordinate to a logic which will sooner or later break them up because of their lack of consistency. ${ }^{22}$ 
According to Lefebvre, representations of space are "relative and in the process of change," meaning that representations of a spatial design cannot be separated from the other modes of space: the social (or "perceived") and the symbolic (or "lived") space. ${ }^{23}$

In regard to the conceptual model for site-specific installations, this underscores the fact that the intended spatial design, in principle, can deviate from the materialized iteration of the work. Following Lefebvre, spatial configurations will always diverge from the plan to a certain extent, due to influences of the social and symbolic functions of space. Over the course of time, tensions between the three spatial modes might easily occur - in the case of site-specific installation artworks, sometimes with far-reaching effects on the form, function, and experience of the work of art.

Artists working with site specificity do not always follow a practice of coded representations that precede the realization of the work. In the discussion of site-specific installation art in chapter 2, I mentioned Robert Morris and Richard Serra as two artists who preferred to improvise during their performances and their realizations of site-specific installations. They discovered a working space "spontaneously" through bodily movements and handling of the material; they defined the spatial configuration of their installations "on the spot." Serra, for example, performed the Splash pieces from memory and embodied his know-how of the materials' behaviour into his actions of splashing the lead into the space. Hence, each performance established a site-specific relationship between the materials and their physical form, the spatial qualities of the room, and the artist's own body. This way, different manifestations could crystallize out of one concept, as Serra states: "Even if you try to do it [in the same way], you invariably make something else." ${ }^{24}$

The second function distinguished by Lefebvre is the "perceived space" or social space. This mode coincides with the practices employed in a given space, either by individuals or by a social group, while the indicator "perceived" refers to the conscious and unconscious ways in which spaces are being used or inhabited, and thereby influence the production process. The social or perceived space relates directly to everyday spaces where human labour, individual perception, and collective practices take place. For example, the spaces of factories, offices, schools, public transport, or

24 See, for example, an Interview with Richard Serra explaining the realization of his Splash Pieces, SFMOMA, published 23 March 2011, https://www.youtube.com/watch?v=LjvVEN2v8rY (last accessed 23 April 2021). 
museums are perceived in different ways, because people feel and behave differently in the respective places and employ different practices in them. Lefebvre emphasizes the sensorial perception of space and the use of the body in spatial practices:

Spatial practices presuppose the use of the body, [...] the use of the hands, members and sensory organs, and the gestures of work [and] activity unrelated to work. This is the realm of the perceived (the practical basis of the perception of the outside world, to put it in psychology's terms). ${ }^{25}$

Another feature of the social or perceived space is that a group of individuals may take part in the same practice, which ensures "continuity and some degree of cohesion," because the members of the group are familiar with the social patterns of that particular space and know what to do:

In terms of social space, and of each member of a given society's relationship to that space, this cohesion implies a guaranteed level of competence and a specific level of performance [original emphasis]. ${ }^{26}$

For example, the surgeons and assisting staff members in an operating room know exactly how to act and perceive the room in concord with the actions usually performed. Likewise, the conservation studio or technical department of a museum may have its own "social space," and each space will be perceived in concord with the actions usually employed in that space. Lefebvre notes that the employees or users of a space preferably have a shared know-how of the expected behaviour and competences, although this cannot always be structured in words or prescribed instructions.

Social space thus remains the space of society, of social life. Man does not live by words alone; all "subjects" are situated in a space in which they must either recognize themselves or lose themselves, a space which they may both enjoy and modify. ${ }^{27}$

In this respect, it is important to note that Lefebvre developed his theory from a post-Marxist point of view. The patterns of perception and behaviour he distinguishes in the "perceived space" are understood as collective 
production practices (of material objects) or other activities of social groups in urban society. Transposed to contemporary art, it may seem inappropriate to speak of a "shared practice" or "cohesion," because each artwork needs a particular approach and standard procedures seldom apply. Yet, I would argue that the notion of the "perceived" or "social space" does apply to the museum practice, because it is an indication of the various functions and disciplines, of skills and routines, that are performed in the various departments of the organization - behind the scenes as well as front and centre. For instance, conservation ethics is an intrinsic part of daily practices, and a set of shared codes are applicable to the diverse practices of staff members in storage rooms, technical departments, administration, galleries, visitor spaces, and so forth.

An illustration of the above is the earlier discussed site-specific project and video installation they shoot horses by Phil Collins. [See chapter 2] Various moments of spatial practices can be identified in the biography of this work. For example, during the original film shooting in the dance hall of Ramallah, there was a shared spatial practice among the volunteers; as a collective, they created a social space of dancing and stopped their movements during the calls for prayer. Later on, when the artwork entered the museum collection, the original footage was adjusted to the spatial and temporal conditions of the Tate Modern. The know-how and daily routines of staff members in the museum's technical department guaranteed the necessary adjustments of the raw footage to museum standards, not least to accommodate the installation to a gallery space and the opening hours of the museum. Finally, a spatial trajectory for they shoot horses was designed by the exhibition designers, who created a social space for the visitor's perception of the artwork. Underneath those various spatial practices, there was - at least to some degree - a consensus about what usually happens in the respective spaces of production, postproduction, and reception of the work of art.

As we have seen above, Lefebvre assumes that individuals and social groups have the potential to modify social space. Hence, individual perception is not completely disregarded, despite Lefebvre's emphasis on social space. But when I use the terms "spatial practice" or "social space" in the context of the conceptual model, I mean to say that, throughout successive biographical stages of the artwork, certain spaces may provoke certain activities while, conversely, certain actions can only take place in particular spaces; in this case, referring to the modification of the footage in the technical studio, the dancing in the dance hall, or people visiting the installed artwork in the museum's gallery space. 
The third mode introduced by Lefebvre is the "lived space" or representational space (not to be confused with "representation of space"). Every space, he states, carries a symbolic or cultural meaning for its "inhabitants" and "users," and represents a specific set of sociocultural values.

Representational space is alive: it speaks. It has an affective kernel or centre: Ego, bed, bedroom, dwelling, house; or: square, church, graveyard. It embraces the loci of passion, of action and of lived situations, and thus immediately implies time. Consequently it may be qualified in various ways: it may be directional, situational or relational, because it is essentially qualitative, fluid and dynamic. ${ }^{28}$

The lived space is variable, because ideologies and value system change over time. As mentioned in my introduction to Lefebvre's theory, ideologies and value systems may leave their imprint on any kind of spatial configuration, but they are also shaped by them. The symbolic meaning of a burial ritual, for example, is shaped by a pattern of gravestones, pathways, and trees in a graveyard; likewise, the symbolic value of a museum visit is shaped by the architectural structure of the exhibition rooms, education spaces, museum entrance, cafeteria, and so forth, as much as by the collection of artworks on display. All such spaces carry their own symbolic meaning of pleasure, reflection, education, socializing, and so on. Lived spaces are thus a combination of actual and symbolic (representational) space, both abstract and concrete and, as Lefebvre states, "need obey no rules of consistency or cohesiveness." ${ }^{29}$ In his discussion of representational space, Lefebvre refers to "the clandestine or underground side of social life, as also to art." ${ }^{\circ}$ Although the juxtaposition of the "underground side of social life" and "art" may give rise to different interpretations, in this context, Lefebvre indicates that in art, the imagination is still "free to play" with the spatial codes, making symbolic use of them and at the same time changing them..$^{31}$

Lefebvre's specification of representational space can be attributed to museum spaces in terms of a set of values, represented by the museum building as well as by the institutional philosophy and organizational principles. Even though Lefebvre developed his spatial theory several 
decades ago, his stance is still valid today and even gains significance in relation to recent research into the perpetuation of transformative and evanescent art in the contemporary art museum. With his term "unruly object," Fernando Domínguez Rubio (briefly introduced in chapter 1) provides insight into how these kind of works challenge institutional practices, boundaries, and control mechanisms that usually apply to more traditional - "docile" - artworks. His investigation focuses on how these objects play a generative role in which new practices, relations, and boundaries are formed:

In practical terms, unruly objects can be identified as those artworks that behave as variable rather than stable, elusive rather than classifiable, and unwieldy rather than portable [original emphasis]. [...] They are typically describes as "problems," "disruptions," "glitches," "challenges" that need to be fixed or solved. They are seen as those artworks that need to be transformed into docile objects. However, and this is perhaps their most distinctive feature, this transformation cannot be accomplished without altering the relations and practices wherein they inserted. Unruly objects, therefore, are characterized by the creation of organizational and institutional discontinuities that disrupt the production and sustenance of the processes whereby social practices, classifications, boundaries, and meanings are standardized and acquire their taken-for-granted nature. For this reason, unruly objects can be described as vectors of institutional and cultural change: as elements that require creative adaptations and negotiations, and the shifting of positions and boundaries around them..$^{2}$

In contrast to the stance taken by Miwon Kwon that acquisitions of sitespecific installation artworks, especially during the 199os, result from a desire to "control" the avant-garde, Domínguez Rubio highlights the inherent force these artworks possess to change institutional policies and strategies. This kind of dynamic interaction between art and the institution would, in Lefebvrian terminology, take place in the "lived space" or representational space.

It is worth reconsidering the triangular relationship between the artist, artwork, and institution with an eye to the function of lived space. Recent years have shown remarkable shifts in the representational spaces of 
museums: numerous renovations have been executed and spectacular museum buildings and annexes have been designed. This intense building activity was juxtaposed by a new take on exhibition narratives and demonstrated a renewed ambition of museums to play an active societal role. The architectural structure gives expression to new ideals by giving more room to social spaces, such as public entrances, café's, education rooms, and museum shops..$^{33}$ The curatorial interest of inviting artists to create site-specific installation artworks for museum spaces can be understood in the same light: a current emphasis on representational space.

During the late 1960 os and early 1970s, there was a similar focus on representational space when artists of the avant-garde effectuated a change in the administration of contemporary art museums. Vanguard artists (such as Allan Kaprow) rejected the representational function of the white cube gallery at first, because it was considered a representation of the commodification and "depersonalization" of art. Gradually, however, the same artists often created site-specific installations for museum galleries and agreed to the acquisition and re-exhibition of their work. This shift in practice can be explained as a transition of the museum's former representational space to a place for experiment (partly incited by the artists themselves, but even more so by energetic, visionary museum curators), changing the practice and codes of the gallery space. From a "neutral space," the galleries transformed into a "lived environment," where the artists became the "new inhabitants" of spaces that had formerly been solely the domain of museum directors, curators, and managerial staff.

\section{The Influence of Time and the Triad of Spatiality}

Lefebvre's three modes of space can be reformulated for the description of site-specific installation artworks as follows: the designed space of the artwork in connection to the spatial surrounding (coded and concrete), the social spaces of production (processes and action), and the representational space of the exhibition context (symbolic and "lived"). Based on these building blocks, the model takes shape with a first set of parameters that enable

33 See, for example, Dorus Hoebink, "The Museum as a Social Performance," in Metamorphosis. The Transformation of Dutch Museums, ed. Job Roos, Dorus Hoebink, and Arjan Kok (Delft: TU Delft - Heritage \& Architecture, 2019), 19-23. 
the conceptualization of site specificity and the description of the artwork's spatial functions across biographical stages.

At the heart of Lefebvre's model is the idea that space and time are inseparable. He argues that the production of space is anchored in a specific moment and, at the same time, is interlaced with historical traces that are left behind - or, to put it in his words, traces "inscribed" into the space:

The past leaves its traces; time has its own script. Yet this space is always, now and formerly, a present space, given as an immediate whole, complete with its associations and connections in their actuality. ${ }^{34}$

Elaborating on Lefebvre's statement, the idea takes root that a work's site specificity is produced in the actualization of the network of spatial functions (physical, social, and symbolic). In accord with the "associations and connections" of the actual site, certain spatial functions may be reinvigorated, while others may be disregarded or may have been lost altogether over time.

Furthermore, Lefebvre's collocation of past and present, supports the notion that whereas each iteration of a site-specific installation is rooted in the actuality, the work's display can bear material or immaterial traces of previous manifestations. In other words, since space and time are inseparable entities in this model, we can envision that site specificity evolves over time and takes into account that each iteration is a unique, site-specific manifestation of the work. [See Diagram 4]

The above insights about space and time, derived from Henri Lefebvre, are beneficial to the understanding of the ontology and transformative nature of site-specific installation artworks. However, they do not explain how the series of actions applied to the artwork throughout its biography influence the shifts of functions within the spatial network. In the actual practices of conservation and curation, the artwork's site specificity in a museum context is redefined again and again. Hence, to truly understand the challenges and possibilities these artworks pose to the institutions, an additional element of the model is needed - an analytical toolbox to identify the actors involved in the museum's strategies and practices, as well as the underlying "scripts" steering their decisions.

As a first step, an analogy will be drawn between the staging of a (sitespecific) installation artwork and the execution of a musical performance

Hoebink, “The Museum as a Social Performance," 36. Original emphasis. 
Diagram 4 Lefebvre's triad of spatiality transposed to site-specific installation artworks. Time influences variations in the spatial network. $\odot$ The author. Image editing: Arienne Boelens.

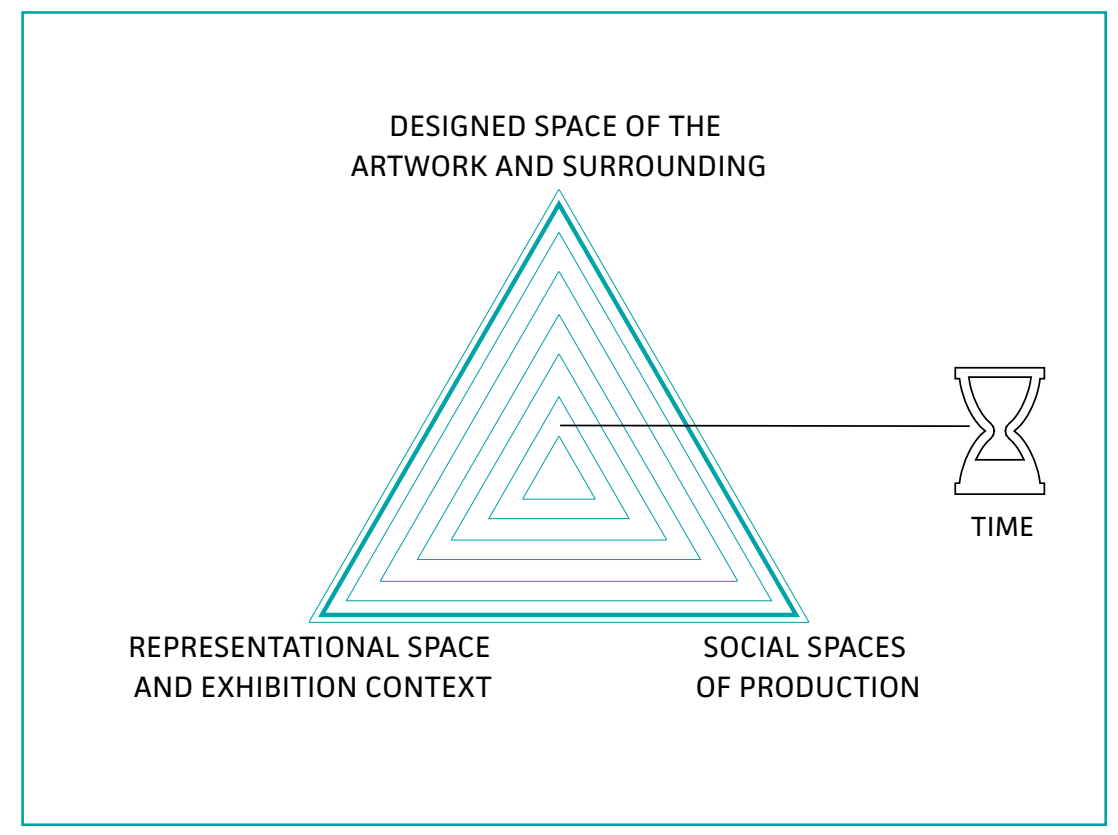

or a theatrical play. Such a comparison between two different art forms is not uncommon in the field of the humanities in general and contemporary art conservation in particular. I will start my argument with a general introduction on "performance" as an analytical tool and then zoom in on the notion of "performativity" in conservation studies.

\subsection{Analysing Cultural Phenomena "as Performance"}

The idea that cultural phenomena can be analysed as if they are performances originates from the so-called performative turn in the mid twentieth century. In 1955, the British philosopher of language J. L. Austin (1911-1960) coined the term "performativity" (1955) for speech acts. ${ }^{35}$ Austin took a stance against the prevailed, positivist claim in linguistics that utterances declare 
something as either true or false. He contended that certain utterances are not referential or descriptive but an act in themselves, like with a wedding ceremony. When a person says, "I take this woman as my lawful wedded wife," there is no reference made to a past or future action; it is an act in the here and now, changing reality at the moment of speaking. ${ }^{36}$ Austin attributed the notion of speech act only to language in real-life situations, but his ideas have been widely adopted in the social sciences and from the 1990s onwards; his views have become influential in the study of human culture in general.

Based on Austin's notion of performativity, performance scholar Richard Schechner states that any cultural manifestation can be studied in analogy with the performance arts. ${ }^{37}$ In classic theatre, the stage "frames" the action and draws a dividing line between the performance and the audience, between the "make-believe world" of the performance and everyday reality. ${ }^{3}$ However, with the 1960 s credo to fuse art with life, such traditional boundaries faded, and the "performative" has permeated contemporary cultural practice ever since. Schechner suggests that even works that are not performances in the classical sense can be analysed "as if" they were performances, provided that the manifestation is framed by the co-ordinates of space and time. ${ }^{39}$ Schechner deems visual arts and architecture suitable phenomena for this approach, because he does not consider them as "things" or "objects" in themselves, "but as players in ongoing relationships, that is 'as' performances." ${ }^{20}$ In this analysis, the focus is on a mutual comparison of manifestations that belong to the same category of work, which means he studies them "in process, and as they change over time."41

Schechner's viewpoints are relevant to the current research, because they emphasize the possibility of comparing and analysing site-specific installation artworks as a succession of iterations. By examining their "performance" in concrete circumstances, it may become feasible to discern patterns in their biographies and the causes of continuation and change, which relate to the questions posed in the first chapter of this book. First and foremost, however,

Stanford Encyclopedia of Philosophy, https://plato.stanford.edu/entries/austin-jl/ (last accessed 23 April 2021).

36 For Austin's influence on performance studies, see: Richard Schechner, Performance Studies: An Introduction (third edition) (London: Routledge, 2013), 123.

37 Schechner, Performance Studies, 28-51.

38 Schechner, Performance Studies, 42-43.

39 Schechner, Performance Studies, 38.

40 Schechner, Performance Studies, 2.

41 Schechner, Performance Studies, 48. 
a consistent set of analytical tools is needed for a systematic comparison. To this end, it is beneficial that the conservation discipline has developed a thorough theoretical framework over the past several years, based on the analogy between contemporary art and performance arts. In the following paragraphs, the focus shifts to the achievements in this field, offering a number of key notions that will prove to be highly beneficial for my own research.

\section{The Conceptual Model Part 2: Analysing Successive Iterations of Site-Specific Installation Artworks}

\subsection{Looking through the Lens of Conservation: Performativity of Site-Specific Installation Artworks}

In reaction to the many challenges posed by new art forms such as media art and installation art, conservators and curators have developed an entirely new set of theories and practices over the past two decades. One pivotal insight is that theory develops alongside practice, foregrounding the importance of communication with the artists or their representatives. Another one is the awareness that, in theory and practice, a (self-)reflective attitude is essential, given the transient nature of contemporary art. "Managing change" is an epithet that binds many contemporary artworks, as they are often intentionally made of temporary or ephemeral materials, and hence pose rigorous questions in respect to their reinstallation. ${ }^{42}$ In

42 For the discourse on managing change the following readings (among others), see: Hanna Hölling, "The Technique of Conservation: On Realms of Theory and Culture Practice," Journal of the Institute of Conservation 40, no. 2 (2017): 87-96; Vivian van Saaze, Installation Art and the Museum: Presentation and Conservation of Changing Artworks (Amsterdam: Amsterdam University Press, 2013), 22-23; Salvador Muňoz Vinas, "The Artwork that Became a Symbol of Itself: Reflections on the Conservation of Modern Art," in Theory and Practice in the Conservation of Modern and Contemporary Art: Reflections on the Roots and Perspectives, eds. Urusla Schaedler-Saub and Angela Weyer (London: Archetype Publishers, 2010), 12-17; Simon Cane, "Why Do We Conserve? Developing Understanding of Conservation as a Cultural Construct," in Conservation Principles, Dilemmas and Uncomfortable Truths, ed. Alison Richmond and Alison Bracker (Oxford: Elsevier, 2009), 164; Pip Laurenson, "Authenticity, Change and Loss in the Conservation of Time based Media," Tate Papers (Autumn 20o6), 6; Pip Laurenson, “The Management of Display Equipment in Time-Based Media Installations," in Modern Art, New Museums, ed. Roy Ashok and Perry Smith (Bilbao: The International Institute for Conservation of Historic and Artistic Works, 2004), 49-52; Glenn Wharton, "The Challenges of Conserving Contemporary Art," in Collecting the New: Museums and Contemporary Art, ed. Bruce Altshuler (Princeton: Princeton University Press, 2005), 174-176; Renée van de Vall, Hanna Hölling, Tatja Scholte, and Sanneke Stigter, "Reflections 
the early 200os, the focus shifted from safeguarding the artwork's physical constituents to the question what a transient artwork should do - or how the artwork is supposed to behave - given the ephemerality of its material composition. The primary source of information in this respect is the artist, although artist's assistants, gallerists, and custodians who are concerned with the perpetuation of the work may represent the artist in their attempt to decipher the artwork's "behaviour."

This notion was first developed by the Variable Media Initiative (founded by a group of museum professionals and media scholars) with their statement that artworks can be defined independently from the material composition or media of which they are composed. ${ }^{43}$ The Variable Media Initiative put the primary focus on the installation or "performance" of the artwork, in which it reveals its behaviour in actual circumstances. A qualification for an appropriate reinstallation is whether the conservator can identify the intended behaviour of the artwork, which is often indicated as the "ideal state." Crucial information can be obtained by consulting the artist or others who are knowledgeable about the composition and meaning of the work. ${ }^{44}$

Time-based media art conservator and scholar Pip Laurenson elaborates on this view in her seminal article "Authenticity, Change and Loss in the Conservation of Time-Based Media Installations." ${ }^{25}$ Focusing on time-based (media) artworks, Laurenson suggests comparing an installation with the performance of a piece of music or theatre. Time-based (media) artworks, she argues, can be positioned "on the ontological continuum somewhere between performance and sculpture," and can therefore be considered as "installed events" rather than as art objects that derive their meaning from material authenticity. ${ }^{46}$ Arguably, the object-centred paradigm, as usually

on a Biographical Approach," Preprints ICOM Conservation Community 16 th Triennial Conference (Lisbon, 19-23 September 2011): 1-81.

43 The Variable Media Initiative was initiated and developed by the Daniel Llanglois Foundation and the Guggenheim Museum in 2003. The approach consists of a classification based on eight medium-independent behaviours of the artwork, which are summarized as: contained, installed, performed, interactive, reproduced, duplicated, encoded, and networked. The corresponding conservation strategy includes storage, reinstallation, migration, emulation, and reinterpretation. See Jon Ippolito, "Accommodating the Unpredictable: The Variable Media Questionnaire," in Permanence Through Change: The Variable Media Approach, ed. Alain Depocas (New York: Solomon Guggenheim Museum, 2003), 47-53.

44 Ippolito, "Accommodating the Unpredictable," $50-51$.

45 At the time of publication, Pip Laurenson was Head of Conservation of Tate's Time-Based Media Art Collection.

46 Laurenson, "Authenticity," 4. Due to the rapid obsolescence of media art technology, physical components of media art installations change rapidly, and artists themselves may conceive their work to exist in multiple forms. 
applied to the conservation of "traditional" art, has its pitfalls in regard to performative artworks that rely on installation strategies and the execution of the artwork in concrete circumstances of an exhibition.

Scrutinizing the ontology of these kind of works, Laurenson compares their creation and realization with the two-staged process of a music performance; the first stage is the work of the composer, who records the musical composition in a score; the second stage begins when musicians perform the notation of the score and start to play. ${ }^{47}$ Transposed to timebased (media) installations, the concept of the work could be defined by a score, while its performance is in the actual realization of the work..$^{48}$ Like in music, a gap between the score and the execution defines the ontology of time-based artworks, which implies that, in principle, different iterations can be considered genuine performances. As Laurenson explains:

\section{Performances can occur in different times and different places with different performers and still be authentic instances of that performance. In the performance of a musical work it is recognised that there is a gap between a work as represented as a score and its performance. This allows}

47 Pip Laurenson borrows this partition into two stages from Nelson Goodman, a philosopher of art who distinguishes autographic art from allographic art forms. In general, the notion of autographic arts applies to paintings or sculptures; artworks that can be identified as genuine on the basis of the artist's signature, the evidence that the work is made by its creator and not a forgery. The performance arts, on the other hand, are based on a notational system - like a music score - created during the first stage of the work and serving as a reference for its performance during the second stage. For an elaborate discussion of Laurenson's proposition and Nelson Goodman's philosophy, see: Renée van de Vall, "The Devil and the Details: On the Relevance of Conservation Practice for the Theory of Contemporary Art and Vice Versa," British Journal of Aesthetics 55, no. 3 (2015): 288-29o.

48 In the conservation literature, the preferred term for a written definition of the artwork is "score." See Laurenson, "Authenticity," 5 ff; Joanna Phillips, "New Practices of Collecting and Conserving Live Performance Art at the Guggenheim Museum," VDR Beitrage 1 (2018): 124-132; Glenn Wharton, "Reconfiguring Contemporary Art in the Museum," in Authenticity in Transition: Changing Practices in Art Making and Conservation, ed. Erma Hermens and Frances Robertson (London: Archetype Publications, 2016), 28. Sometimes, "score" and "script" are used interchangeably. For example:Julia Noordegraaf, "Documenting the Analogue Past in Marijke van Warmerdam's Film Installations," Revista de História da Arte 4 (2015): 119; Van de Vall, "The Devil and the Details," 290; Pip Laurenson and Vivian van Saaze, "Collecting Performance-Based Art: New Challenges and Shifting Perspectives," in Performativity in the Gallery: Staging Interactive Encounters, ed. Outi Remes, Laura MacCulloch, and Marika Leino (Oxford: Peter Lang, 2014), 31; Ariane Noel de Tilly, "Scripting Artworks: Studying the Socialization of Editioned Video and Film Installations” (PhD diss., University of Amsterdam, 2011), 55. 
us to speak of good and bad performances while still being able to say that a work is the same work even if badly performed. ${ }^{49}$

It is part of the profession of a conservator to be knowledgeable about the determinative properties of the artwork and to perform its reinstallation accordingly. However, unlike the paradigm of Western music on which the analogy is based, there is no conventional notational system for this purpose. Laurenson suggests that an equivalent can be found in a set of "instructions" guiding the installation process, taking into account that these instructions may be very different for individual works in form and content, and are variable in the degree of prescription. Because "two-staged" artworks depend on interpretation, it is important to know what degree of interpretation is allowed by using the indicator of "thickly" or "thinly" defined works of art..$^{0}$ If the specifications are thinly described by the artist, Laurenson observes, "the work's determinative properties are comparatively few in number and most of the qualities of a performance are aspects of the performer's interpretation." Thickly specified works, on the other hand, are "works where the artist has specified the qualities of the work and its presentation as precisely as possible." $5^{1}$ Those specifications have a more prescriptive character for the execution, allowing for a lesser degree of interpretation. Looking at the daily practice in museums, conservators and curators often determine, in consultation with the artist, what are "fixed" elements for the work's meaning and to what extent variation and interpretation are permitted or even desired.

The above viewpoints, first stipulated by Laurenson and followed by others in the conservation field, are incentives to regard site-specific installations as a two-staged process as well. Although it might be confusing regarding another use of the term "stage," employed in this study in reference to the artwork's biographical stages, this distinction seems appropriate. The first stage could be attributed to the spatial design and the artist's specification of the spatial arrangement in relation to the surrounding site. Specifying the installation to a more or lesser degree, floor plans, sketches, photographs, films of the installed work, records of the sensorial requirements, as well as guidelines for reinstallation and material-technical information, could all qualify as a set of instructions defined during the first stage. Or, to put

49 Laurenson, "Authenticity," 5.

$5^{0}$ Laurenson, "Authenticity," 5. Laurenson borrows the distinction between thinly and thickly specified works from the philosopher Stephen Davies, who developed this theory in relation to Western music.

$5^{1}$ Laurenson, "Authenticity," 5 . 
it in Lefebvrian terminology, this first stage could be the conceptual mode of the artwork's site specificity. The second stage begins when the artwork is installed in the gallery space and is perceived by the audience, which can be considered the performance of the work.

More than with installation art at large, with site-specific installations (changes in) the physical surrounding and the representational space of the museum determine the form and content of the artwork's meaning and social space of the visitor's experience. These functions - identified by Lefebvre as social space and representational space - are susceptible to the contingency of the site, which may or may not be fully incorporated into the artwork's spatial design from the beginning. Usually, there is a time gap between iterations - when the artwork is dormant in a storage room or physical constituents no longer exist; museum buildings may be renovated, museum policies may evolve, and audiences may change. The passage of time and change of site are influential factors on site-specific installations. Arguably, the differences occurring between various biographical stages - between the "conceptual" stage and the "performance" stage - may be substantial. Most of the contingencies and changes cannot be foreseen when the artist conceptualizes the work nor at the moment of its acquisition by a museum curator. In this respect, a set of instructions may steer future performances, but to reactivate the work in different circumstances, an interpretative voice regarding the entire network of spatial functions may also be necessary.

As for the conceptual model under development here, the above discussion illuminates the mutual relationship between the functions of site specificity and the factor of time. Whereas the triangular set of functions (derived from Lefebvre's theory) helps to identify the constituents of site specificity, the discourse on the conservation of contemporary art offers a model that is based on the analogy of the performance arts and enables us to understand how the artwork evolves over time.

There are a few additional comments I would like to make. The first concerns the term "performance" used in the conservation discourse, in relation to the interpretative authority of the custodians. Assuming that site-specific installations come into being through an intended "interaction" with the gallery space and other contextual elements (such as the connection with the building, the collection, the public, and the sociocultural context at large), it is likely that custodians have at least some interpretative authority in future iterations. Social and representational functions of the museum largely belong to the domain of curators and other museum professionals. Although this is not the place to examine the degree to which the interpretation of a site-specific installation artwork can and should be interpreted, I 
would like to emphasize that, somewhere during the processes and practices of reinstallation, a "reflective space" is needed in which custodians consider how the artwork should be staged from the perspective of its spatial adaptation to the actual situation and the contingencies of the site.

The second comment is a refinement in terminology, as suggested by curator and conservation scholar Tiziana Caianiello, paving the way to the next step of the model. Caianiello makes a distinction between "performance" and "staging," the latter term referring to "the process of planning $[\ldots]$, testing, and determining strategies" - that is: to decision-making and the processes and practices of the artwork's perpetuation. "Performance," on the other hand, is the term assigned to the outcome of this process "that occurs only when an installation has already been staged and is taking effect on (at least) one viewer." ${ }^{2}$ Caianiello argues for leaving aside the terms $r e$-staging and $r e$-performance, because with each instantiation, a new staging and a new performance takes place. I consider this distinction appropriate, primarily because it incorporates the experience of the work as an important parameter, and the terms staging and performance will likewise be employed in this study. ${ }^{53}$

The third comment concerns the different ways requirements for a reinstallation can be captured in a notational system, including the visualizations of an installation with photographs and videos. Images are strong markers for the performance of an installation artwork, as Martha Buskirk observes (see the introductory case of Allan Kaprow's Yard and the discussion on historical evidence in chapter 2). She acknowledges the benefits of visualization, but is also cautious about it, because iconic photographs of the first iteration frequently serve as a reference for the identity of the work and may easily turn into a guidance for future iterations. Visual material or otherwise recorded evidence may give an impression of how visitors interact with the installation, but, as Buskirk contends, documentation not only registers but also isolates a historical moment that can never be retrieved. ${ }^{54}$

52 Tiziana Caianiello, Media Art Installations: Preservation and Presentation. Materializing the Ephemeral (Berlin: Dietrich Reimer Verlag, 2013), 209.

53 For the initial occurrence, Caianiello uses the term "first staging."

54 Buskirk demonstrates this view with the example of Kaprow's Yard. Audiences that were never there can experience the artwork from photographs, showing a diversity of reinterpretations of the original manifestation over time. The downside is that "the photograph falsely locks into place a conception of the work as a single, now inaccessible moment" and that iconic photographs of the initial Happening are referential for the ideal moment of display. Martha Buskirk, Creative Enterprise: Contemporary Art Between Museum And Marketplace (International Texts in Critical Media Aesthetics. Volume 3) (New York: The Continuum International Publishing Group, 2012), 129-144. 
Following Buskirk at this point, I would say that the use of photographs poses a risk that a site-specific installation is "fixed" in its (initial) historical state, while "live elements" such as contextual relationships with the gallery space and the wider sociocultural context, including the interaction with the audience, are disregarded. This way, the installation might lose its capacity to establish a connection with the new site, while only a relic of the spatial arrangement is maintained.

Taking note of the above, it is now time for a closer examination of the instruments developed in the conservation discipline for studying the staging and performance of installation artworks, and to see how these can be integrated into the model for the analysis of successive iterations of site-specific artworks.

\subsection{Site-Specific Installations as Networks "In Action"}

The idea that contemporary artworks can be understood as heterogeneously composed networks was first introduced by conservation scholar Vivian van Saaze. In Installation Art and the Museum: Presentation and Conservation of Changing Artworks, Van Saaze proposes to study contemporary art conservation by "following the actors" of the network during practices applied to the conservation and presentation of the artwork. ${ }^{55}$ Against the background of science-and-technology studies - in particular the actor-network theory (ANT) developed by Bruno Latour and others in the 1980s - Van Saaze puts into focus the social environment of museum practices and the "productive activity" of conservation and presentation. ${ }^{56}$ Contemporary art conservation is "done" in practice, as her credo reads. By scrutinizing the network of human and nonhuman actors, insight is gained into the meaning production of the artwork and the processes of decision-making. ${ }^{57}$

It helps to analyze "art in action," and draws attention to changes, transformations, and places of friction. Such an approach allows a consideration

55 Van Saaze, Installation Art, $147 \mathrm{ff}$.

56 ANT was first developed at the Centre de Sociologie de l'Innovation of the École nationale supérieure des mines de Paris in the early 1980 s by Bruno Latour, John Law, and Michel Callon. For an introduction to ANT, see: Bruno Latour, "On Actor-Network Theory: A Few Clarifications Plus More than a Few Complications," Soziale Welt, 47 (1996): 1-16. Van Saaze explains the relevance of Latour's theory for the study of museum practices in Van Saaze, Installation Art, 146-148.

57 Van Saaze, Installation Art, 27. 
of the constituting role of the museum and a recognition of the distinction among actors which is usually overlooked..$^{8}$

One of the cornerstones of the actor-network approach is that both human beings and nonhumans can have agency. According to Latour's own observation, "An actant can literally be anything provided it is granted to be the source of an action."59 Although ANT does not say that things have the capacity to act in the same way as human beings, it suggests that things and human beings are equally important participants of a productive network - of science, art, or the social world. By examining these networks as "a continuously altering association of humans and nonhumans," the causes of action and processes of production can be analysed. ${ }^{60}$ Latour and Van Saaze both raise the point that an actor-network analysis is not something one does from an objective distance:

The key point is that every entity, including the self, society, nature, every relation, every action, can be understood as "choices" or "selection" of finer and finer embranchments going from abstract structure - actants - to concrete ones - actors. ${ }^{61}$

Being aware that the researcher becomes an actor when studying the artwork in action, I see benefits in this approach for the analysis of the processes of staging and actual manifestation of site-specific installation artworks. ${ }^{62}$ It helps to understand the complex relationships between people and things, ideas and intentions, spatial conditions and visitors' behaviour, instructions, agreements, decision-making processes, and so forth, at specific places and moments in time.

58 Van Saaze, Installation Art, 28.

59 Latour, Sociale Welt, 7. According to ANT, both human and nonhuman "actants" have agency, because they act within dynamic networks. In the study of knowledge-production processes or cultural practices, the emphasis is on a "symmetrical approach" in which human and nonhuman actants are assigned as equally productive forces. The idea is illustrated with the well-known example of the gunshot. Is the person who shoots the gun or the gun that releases the bullet responsible for the shooting? The point made by Latour here is that the origin of the action is localized both with the gun and the shooter. For actants and the example, see: Bruno Latour, Resembling the Social. An Introduction to Actor-Network Theory (Oxford: Oxford University Press, 2005), 63-70, 76 .

6 o Van Saaze, Installation Art, 148.

61 Latour, Sociale Welt, 8.

62 For the current study, this applies, for example, to the research activities carried out within museums or in collaboration with interviewees and other researchers. 
In conclusion, in addition to Lefebvre's triad of spatiality and the performance analogy, the actor-network approach paves the way to develop an analytical toolbox for a systematic analysis of successive iterations. The assumption is that site-specific installations move from one stage to another as the result of a series of decisions and activities. Looking through the lens of ANT, the premise is that both human and nonhuman actors can fulfil an active role in the reactivation of the artwork's site specificity. Moreover, Van Saaze's proposition to follow the artwork in action is beneficial for identifying what factors influence the shifts in spatial functions of the artwork over time - not least because "mapping the network of actors" can bring to light discrepancies and contradictions regarding the initial site specificity, which might be easily overlooked otherwise.

Part of this approach is to regard the "script" as an analytical tool, as I will suggest in the following paragraphs. Similar to theatre or film actors, who mostly perform a play on the basis of a script composed by the playwright, we could imagine that custodians of a site-specific installation look for an underlying script, envisioned by the artist in the creation of the work and to which they aim to respond when staging the work in a new site-specific context. It seems to be a useful notion that deserves closer examination, first by looking into ANT again, followed by a discussion of the "script" as an agent in conservation and exhibition design.

\subsection{Using the Script as an Analytical Tool}

Against the background of the actor-network theory, Madeleine Akrich and Bruno Latour elaborate on the notion of script for technological objects. ${ }^{63}$ They aim to develop a vocabulary for describing the "association" of human and nonhuman actants, which, in the case of technology, starts from the idea that these "objects" contain a "program of action" and that "things-in-use" can prescribe a specific form of action. ${ }^{64}$ For example, the heavy weight attached to a hotel key has the prescription that the guest will return the key

63 Madeleine Akrich and Bruno Latour, "A Summary of a Convenient Vocabulary for the Semiotics of Human-Nonhuman Assembles," in Shaping Technology / Building Society, ed. Wiebe E. Bijker and John Law (Cambridge, MA: The MIT Press, 1992), 259-264.

64 Akrich and Latour, "A Summary of a Convenient Vocabulary," 259-26o. 
to the front desk before leaving the hotel. Or, as philosopher of technology Peter-Paul Verbeek observes,

[a] plastic coffee cup, for instance, has the script "throw me away after use"; the cameras along many roads in the Netherlands have the script "don't drive faster than $5^{\circ} \mathrm{km} / \mathrm{h}$." Artefacts are not passive and inert entities. They actively co-shape what actors do. ${ }^{65}$

Madeleine Akrich uses the script as an analytical tool to explain why designers' intentions regarding the use and form of an object may turn out differently when the object is put into use. Designers, she states, anticipate how future users will employ the object according to a "script" or "scenario," which may include guidelines as well as the functionality and competences "inscribed" into the object by the designers. ${ }^{66}$ The projected user, however, may be quite different from the real user who acts in another context and time. To understand this diversity, Akrich points to the effectuation of the script in terms of a performance, defined by the co-ordinates of space and time:

Thus, like a film script, technical objects define a frame of action together with the actors and the space in which they are supposed to act. ${ }^{67}$

As Akrich clarifies, there is uncertainty about the user's behaviour and sometimes "devices go wrong," not in the least due to differences in cultural contexts. ${ }^{68}$ Hence, the script can be best applied to a comparison between the intended design and the actual performance of the object in more or less comparable contexts.

[the script leads us] back and forth continually between the designer's projected user and the real user [...] and provides a "key" that can be used to interpret all subsequent events. [...] Nevertheless, although users add their own interpretations, so long as the circumstances in which the device is used do not diverge too radically from those predicted by the designer,

65 Peter-Paul Verbeek, What Things Do: Philosophical Reflections on Technology, Agency, and Design (University Park, PA: Penn State University Press, 2005), 125.

66 Madeleine Akrich, “The De-scripting of Technological Objects," in Shaping Technology / Building Society, ed. Wiebe E. Bijker and John Law (Cambridge, MA: The MIT Press, 1992), 208. 67 Akrich, "De-scripting," 208.

68 Akrich, "De-scripting," 211. 
it is likely that the script will become a major element for interpreting interaction between the object and its users. ${ }^{69}$

Following the principles of ANT, such an analysis is done in writing, because language provides applicable means to describe the actual form and use of the object, as well as to reveal the designer's intentions or possible deviations from the script. Hence, as Akrich proposes, the process of de-scripting may start from observations in the here and now and then, by moving backwards and putting into words the interaction between the object, human beings, and past contexts, we return to "the world in-scribed in the object."70

Although the notion of the script, defined by Latour and Akrich for technological objects, cannot be directly applied to most contemporary artworks (given fundamental differences in the nature and function of both object categories), it seems to offer a productive approach for the analysis of different iterations of site-specific installation artworks in a museum context. That said, it is a key to the current study whether we can still speak of a similar cultural context when the artwork is relocated, a question to which I will return in my case study chapters.

\section{The Method of De-scripting}

Within the conservation field, the method of de-scripting has gained currency, as, for example, in a study on installation art by the art historian Ariane Noel de Tilly. ${ }^{71}$ She applies Akrich's method to installation artworks that appear in multiple forms while still being considered the same work of art:

[De-scripting is] going back and forth between the artist's concept and the persons interpreting the work (curators, conservators, technicians, registrars, visitors, etc.). De-scribing here would mean identifying and analyzing the interactions taking place between the artistic creation (or art object), its creator, and other mediators interacting with it. In the end, the purpose of description is to put on paper the text of what the various actors in the settings are doing to one another. ${ }^{72}$

69 Akrich, "De-scripting," 208-209, 216.

70 Akrich, "De-scripting," 208-209.

71 Ariane Noel de Tilly, "Scripting Artworks: Studying the Socialization of Editioned Video and Film Installations" (PhD diss., University of Amsterdam, 2011), 58-59.

72 Noel de Tilly, "Scripting Artworks," 59. 
Noel De Tilly suggests to make a clear distinction between the "script" (or "score") defined as a set of inscriptions and the method of de-scripting as proposed by ANT. Whereas the script can be regarded as a steering factor in the decision-making processes on which the performance of the work is executed, the method of de-scripting can be considered a tool for observation and analysis of the similarities and deviations between various iterations. ${ }^{73}$

The art of de-scripting is also a methodological instrument for a scholar in the field of art and architecture, Albena Yaneva. Similar to Noel de Tilly, the author borrows viewpoints from Latour and Akrich regarding a method for analysing the trajectories of contemporary installation artworks as well as of architectural buildings. ${ }^{74}$ In Mapping Controversies in Architecture, Yaneva examines the underlying scripts of a building, particularly at moments when controversies arise, for example, when a historic building is renewed with a modern extension or is renovated. By comparing successive architectural stages of the building, not only could the controversy be explained from the standpoints and desires of the various parties (human actors) involved, but also an analysis of "the turmoil it triggers" can demonstrate that the building itself has "particular abilities to act." 75 The causes of "turmoil" can be understood by de-scripting all human and non-human actors; in architecture, this would include the architect, the spatial design of the building, the materials applied to its structure at various historical stages, or other influential forces and events, such as "the discordant voices of its makers; of qualities and substances; of passers-by's noises; and of accidents." ${ }^{76}$

This proposed method of de-scripting the actors and agents involved in a turmoil, opens up an interesting vista for the analytical toolbox of my model, because Yaneva takes into account the entire set of relationships activated at the moment of a controversy. In the case of site-specific installation artworks, this can be interpreted as a "turmoil" arising when the connectivity between the artwork and the site is redefined - or, to reuse the words of Nick Kaye, when uncertainties arise about the "fixation" of a site-specific installation artwork in the initial or any other given context of a biographical stage. [See chapter 2] In terms of Lefebvre's triad of spatiality, uncertainties would especially arise in the functions of social and representational space, because

Noel de Tilly, "Scripting Artworks," 58-59.

74 For an elaborated case study by Yaneva concerning the process of exhibiting a complex installation artwork in a museum context and the actors involved, see: Albena Yaneva, "When a Bus Met a Museum: Following Artists, Curators and Workers in Art Installation," Museum and Society 1, no. 3 (2003): 116-131.

75 Albena Yaneva, Mapping Controversies in Architecture (London: Ashgate, 2012), 26.

76 Yaneva, Mapping Controversies, 20. 
these are particularly time-dependent. The spatial design, on the other hand, might be a relatively stable factor, provided that the artist drew up a script in the form of spatial codes (technical drawings, set of instructions for the spatial arrangement, and so on), and only as long as the surrounding space in which the artwork is staged has not changed. In general, we may conclude that, in the case of site-specific installations, many different factors and contingencies come into play, which cannot be foreseen at the moment of creation and which reveal themselves only during the act of presenting the work in a new context. Arguably, a descriptive approach for successive iterations includes a wide range of actors and factors of influence, which cannot be standardized. But the approach of de-scripting the successive stages of a site-specific installation can at least map out which actors and agents come into play and how various scripts become a productive force in the realization of the artwork at a specific site.

Looking at exhibition design and curatorship, others have argued that the script is a useful tool for analysing exhibitions as a network of relationships. For example, cultural studies scholar Julia Noordegraaf introduces in her methodological study of museum exhibitions the notion of the script "to analyse the complex relations between such diverse components as people's ideas and intentions, material objects, buildings and visitor behaviour."77 Similar to Akrich's suggestion, Noordegraaf moves back and forth between the intentions of the exhibition designers, the objects themselves, and the "imagined" users of the exhibition, the visitors:

In the case of museums, the "object" is the presentation itself, which [...] comprises the location, the architecture and layout of the building, the organisation and design of the displays and the means of visitor guidance. An analysis of the script of museum presentation can bring to the fore the set of instructions that defines the relationship between the museum and its audience..$^{8}$

In the analysis of site-specific installation artworks, the script could thus be a tool for moving back and forth between the intentions of the artist and the motives of the curator and other custodians to safeguard the artwork and reinvigorate its site-specific functions, including the conditions of the space, the routes the visitors take, and safety measures. If we focused only 
Diagram 5 Triadic model for the analysis of site-specific installation artworks with an additional toolbox of script and actors. $\odot$ The author. Image editing: Arienne Boelens.

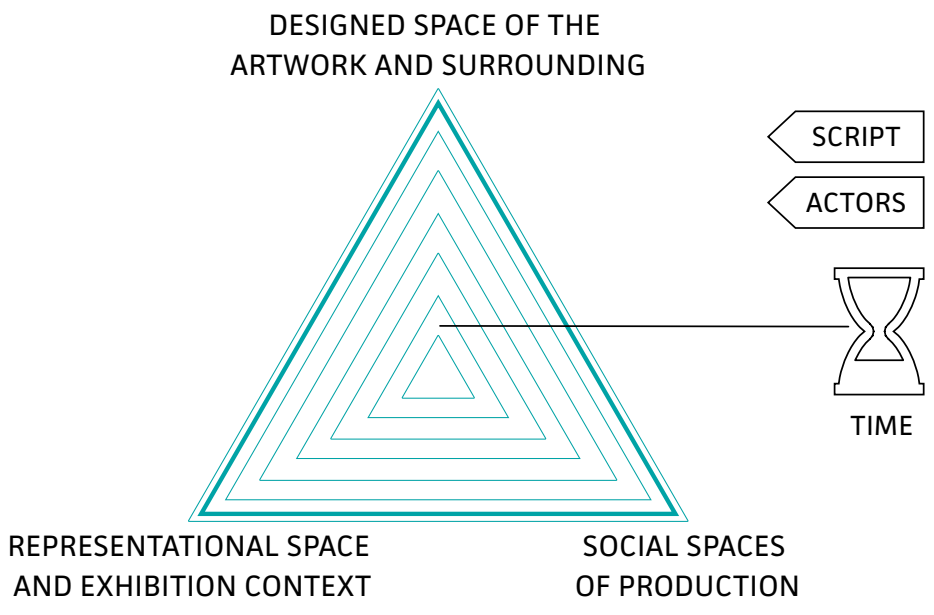

on the installation artwork itself, we might run the risk of overlooking how influential some of those seemingly insignificant actors are.

In conclusion, I propose to include an additional toolbox in the model (next to the triangular model of site specificity), consisting of an analysis of the network of actors involved and scripts employed during successive staging processes and the actual performance of the work. [See Diagram 5]

Earlier in this chapter, I adopted from the conservation discourse the idea that a script or score defines the ontology of the artwork, often in the form of a set of instructions provided by the artist for the preservation and reinstallation of the work. Thereafter, I argued that the script could also be seen as an analytical tool, opening the possibility for distinguishing the various actors and factors of influence during successive biographical stages of site-specific installations. Given the dynamics of changing contexts, it follows that the intended script cannot always be followed, and we might have to accept deviations that occur under the influence of decisions taken by others than the artist. In a museum context, the "others" are mostly the museum professionals, but gallerists or museum visitors might also turn into agents that provoke a decision, let alone the material 
and immaterial conditions that are "inscribed" into the artwork itself and the surrounding context. The toolbox of script and actors can support a description of these deviations, in particular by identifying which actors and underlying scripts are decisive in the process of staging the work in a particular context. However, as Latour and others observe, such an analysis is never a neutral exercise, and I am aware that the selection of what is described and analysed, as well as the act of de-scripting, incorporates a subjective element. However, the examination has at least some degree of objectivity in the systematic comparison of different iterations and the employment of well-described parameters, such as the proposed triangular set of site-specific functions.

Let me illustrate some of the above with a taste of what will follow in the case study chapters. A brief description of two of Richard Serra's site-specific installations will illuminate my approach of using the triad of spatiality and the analytical toolbox of script and actor. Tilted Arc (1981), discussed in the previous chapter, will be revisited from this perspective. The other example, Waxing Arcs (1980), created by Serra as a site-specific installation artwork for Museum Boijmans Van Beuningen, will show how a work's site specificity can be reactivated for a contemporary audience.

\subsection{A Short Analysis of Two Site-Specific Installations by Richard Serra}

\section{Tilted Arc Revisited}

The discussion on Tilted Arc specified that Richard Serra conceived his work as physically and conceptually rooted in the Federal Plaza. The curved Corten steel plates cutting the square in half were destined to stay in that site-specific environment forever. [Figure 5]

The spatial design (the conceived mode of the triad of spatiality) defined the dimensions and exact curves of the arc, and the Corten steel material and its finish were incorporated in this scheme. The trajectories taken by commuters to traverse the square were part of its social function, the way in which citizens experienced and "used" the artwork in their daily routines (the perceived or social space in terms of the model). As Richard Serra states, it was the "explicit intention of site-specific works to alter their contexts."79 
The artist anticipated how citizens would cross the square and navigate along the Corten steel "wall." This function can be seen as the intended outcome of a script elaborated in the functional design - the spatial arrangement and materialization of the arc. Furthermore, the Federal Plaza is a location with a special representational function (the lived space in terms of the model), because it hosts the offices of the federal government. The government commissioned the project and because of human traffic to its building, the plaza is usually a crowded space.

The "turmoil" that arose when the government proposed to relocate Tilted $A r c$ to a scenic environment outside the city can be analysed as a conflict between various scripts and actors. Serra and his protagonists claimed that the contract between the artist and the government was breached and that a proposition for relocation was an "assault on freedom of artistic expression." According to the opponents, Serra had not taken into account the social function of the plaza, and citizens reclaimed the right to use the square like before, as a social space meant for local inhabitants and employees. In this respect, the role of the federal government is interesting, because the government had installed a jury (representing the public), which had initially applauded the proposal, but turned against it during the lawsuit. ${ }^{81}$ This radical turn was unforeseen at the moment the artist developed his design. At that stage, the focus was on the spatial design and Serra's artistic views on site specificity. During the actual "performance" of Tilted Arc, however, the citizens and government put the representational function and social space of the plaza to the fore. The artwork itself was sacrificed in this process of conflicting values, following Serra's wish to adhere to the conceived mode of his spatial design. Although the artist inscribed site-specific functions to Tilted Arc, he could not foresee that such a dramatic deviation of the script would happen in later years.

In brief, three stages of Tilted Arc can be recognized: the first stage of its conception as a site-specific installation, the agreement with the government, and its realization; the second stage during the performance of the artwork in public space; and the third stage when the lawsuit marked the end of the project by means of the destruction of Tilted Arc. Perhaps, especially in the case of Titled Arc, an additional fourth stage should be acknowledged in the ongoing interest in this case example, as the discussions never came to an end, although all that remained were descriptions and a few photographs.

8o Weyergraf-Serra and Buskirk, Destruction of Tilted Arc, 69.

81 Weyergraf-Serra and Buskirk, Destruction of Tilted Arc, 68-69. 
Figure 9 Waxing Arcs (1980, second version 1999) by Richard Serra. Collection Museum Boijmans Van Beuningen, Rotterdam (MBVB). Donation: Stichting Fonds Willem van Rede. Photo: Nieuwe Beeldenmakers, Ernie Buts. Courtesy photographer and MBVB. @ c/o Pictoright Amsterdam.

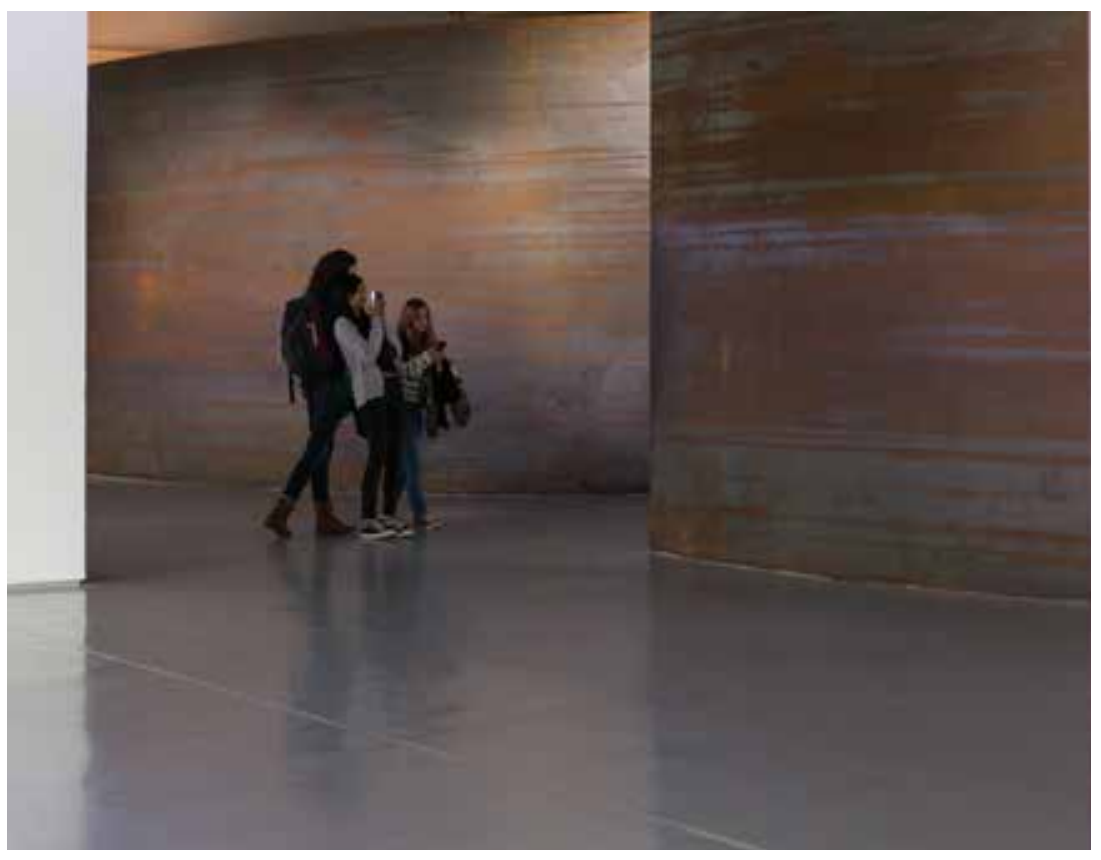

The Extended Life of Waxing Arcs

The second example is Richard Serra's site-specific installation Waxing Arcs (1980). [Figure 9] The artwork was created for Museum Boijmans Van Beuningen and followed a completely different trajectory than Tilted Arc. ${ }^{82}$ Waxing Arcs still exists, but the surroundings have changed several times and the current version is, in fact, a remake of the original. The work consists of two huge, curved plates made of Corten steel, and was specifically created for the entrance hall of the museum in commission of the then director Wim Beeren. In the course of time, the initial site specificity was challenged more than once, because the architectural surroundings and the function of the exhibition space repeatedly changed. At a certain moment, the arcs

82 The information for this case example was kindly provided by Saskia van Kampen, curator of contemporary art at the Museum Boijmans Van Beuningen, who initiated and executed the project Serra on the Move in 2014. 
marked the museum's cloakrooms; later, they gave access to the ticket office; and later still, the museum's café was placed opposite the arcs. Until May 2019, Waxing Arcs was exhibited in a separate space on the museum's ground-floor Bodon Gallery, the so-called Serra Room.

A crucial moment in the biography of Waxing Arcs was 1999, when Serra agreed to its refabrication to accommodate the artwork to the reconstruction of the museum building. The entrance of the building was relocated and equipped with a façade of concrete, steel, and glass - affecting the dimensions of the space surrounding Waxing Arcs. Two new Corten steel plates were manufactured, with a slightly different curve and measuring one metre higher; the plates were half a centimetre thicker than the originals. In addition, the suspended ceiling of the exhibition space was removed to create a more industrial look.

In terms of the triad of spatiality, the successive biographical stages show a strong mutual relationship between the spatial design of Waxing Arcs and the representational functions of its surrounding space. One can even observe a dominance of the representational space at the expense of the spatial design as originally intended by the artist. Furthermore, together with the series of new functions, the social use of the space surrounding Waxing Arcs varied, and the public's perception was influenced by those changes, not least because their trajectories along the arcs altered with each modification.

When examining the actors involved and the underlying scripts of the decision-making processes, we see a range of directors and architects who developed their own "script" for the building. Serra himself agreed to the adjustments, but in 2003, when the Serra Room was created, he stipulated that no other artworks could be exhibited next to Waxing Arcs. The only exception to this script were artworks made of light by the Minimalist artist Dan Flavin, whose artworks Serra was familiar with and which were often site-specific as well. As it turned out, the Museum Boijmans Van Beuningen could not comply with this request. The Serra Room has large dimensions, and the space is frequently needed for other exhibition purposes so that other artworks are shown in close vicinity to the arcs. ${ }^{83}$

In 2013, the museum's curator of contemporary art, Saskia Van Kampen, acknowledged that incongruences had taken place vis-à-vis the intended

83 Sometimes, Waxing Arcs has even served as a "background" for other artworks. When I visited a solo exhibition of the Dutch artist Peter Zegveld in 2013, for example, I was surprised to see one of Zegveld's lightworks projected on the orange-brownish surface of one of the Waxing Arcs. 
Figure 10 In Constant Motion: Richard Serra's 'Waxing Arcs' (2013), multimedia presentation by IJsfontein in Museum Boijmans Van Beuningen, Rotterdam (MBVB). Courtesy IJsfontein/MBVB.

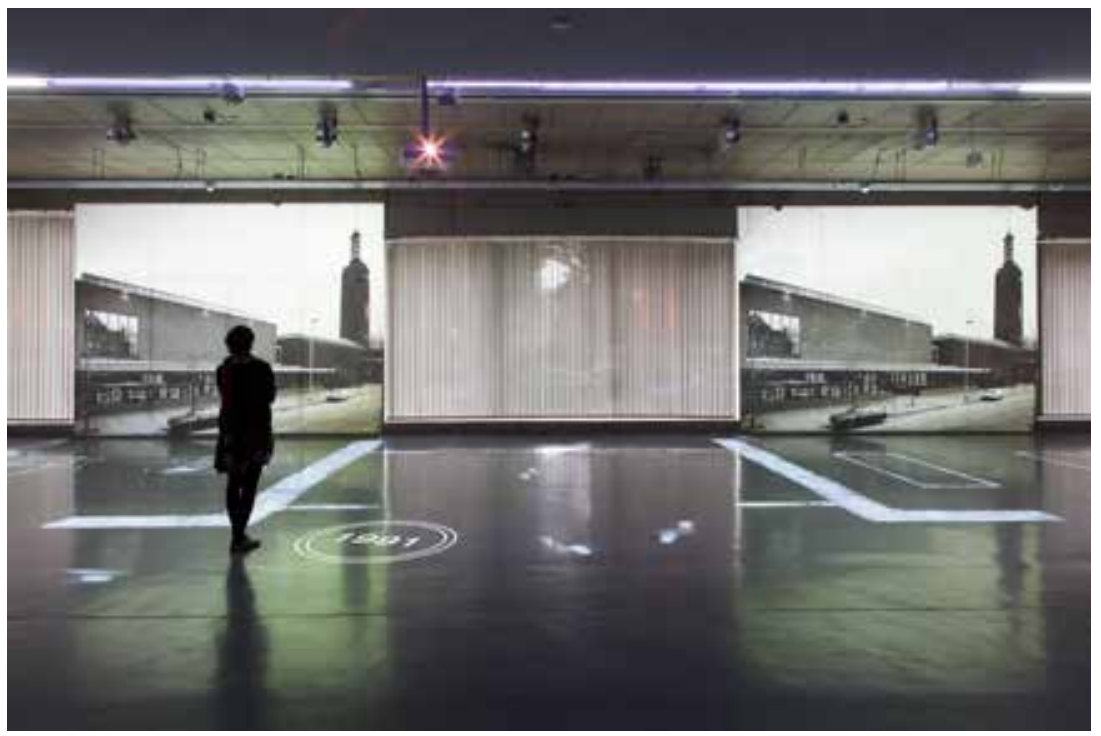

site specificity and the current "performance" of Waxing Arcs. Many shifts in the spatial network had occurred over time, as she states: "sometimes, the arcs only serve as some sort of 'obstacle' in the room." Van Kampen initiated a project to rehabilitate the work and to provide insight into the rich biography of the artwork, featuring the actors who had been involved and the underlying scripts of their decision-making. ${ }^{84}$

Focusing on the site specificity of Waxing Arcs, Van Kampen carried out in-depth research and commissioned the multimedia company IJsfontein to draw a script for a guided tour in the Serra Room, called In Constant Motion-Richard Serra's "Waxing Arcs." [Figure 10]

84 The project was part of the Stichting Behoud Moderne Kunst (Foundation for the Conservation of Contemporary Art, SBMK)'s Platform for Conservation Issues, 2013-2014. A group of museum professionals examined site-specific installation artworks made by Richard Serra in four museum collections in the Netherlands. In 2014, Saskia van Kampen realized a multimedia tour and an exhibition solely dedicated to Waxing Arcs. Additionally, the SBMK project resulted in the symposium Serra on the Move, held on 14 November 2014, https:/www.sbmk.nl/nl/ activiteiten/serraonthemove. The project was also presented at the international symposium Revisited: Site-Specificity in Recent Outdoor Sculpture, Stiftung Situation Kunst, Bochum, 26-27 February 2016. 
During the five-minute performance, the room was darkened and film fragments, photographs, and other documentary material illuminated the respective biographical stages. A voice-over explained the many twists and turns the artwork and the building had undergone. After each performance, the lights were turned off and the audience could experience the installation in daylight, just as the artist intended in $2003 .{ }^{85}$ The guided tour was on show in the museum for one year. ${ }^{86}$

What fascinates me about this performance is that the curator made the history of Waxing Arcs accessible in two ways: the virtual tour gave access to the complex network of spatial functions and its shifts over a long period of time, while at the end of the show the artist's script was followed - illuminating the "ideal" biographical stage in which the relationship between the arcs' spatial design and the gallery space was established in a room that was only separated from public space outside the building by means of the glass façade. I would like to conclude that this staging of Waxing Arcs shows a variation in possibilities to keep site-specific installation artworks alive, especially by employing virtual means of communication. Some of the options may have a documentary character, shedding light on the biographical stages of the artwork, while others may reinvigorate one spatial function of the artwork in particular and establish a renewed, spatiotemporally defined, connectivity with the exhibition site.

\subsection{Conclusion}

This chapter was dedicated to developing a conceptual model for the analysis of site-specific installation artworks. [Diagrams 1-5] The model combines two approaches, one derived from Henri Lefebvre's triad of spatiality; the other based on current notions and approaches in contemporary art conservation. The connection between the two elements of the model was first established by the argument that site-specific installation artworks move from one biographical stage to another as a result of a series of activities. Secondly, because of their performative ontology, these artworks can be analysed as performances.

85 For a full description of the project, see: https://www.boijmans.nl/en/exhibitions/richardserra-waxing-arcs_(last accessed 23 April 2021).

86 In Constant Motion: Richard Serra's "Waxing Arcs" was on show from 11 October 2014 to December 2015 . 
The benefit of the performance analogy is that it paves the way for a method to compare different iterations in a systematic way. Using the triadic model of spatial design, social space, and representational space for each manifestation of the work, the site-specific network can be described. When the artwork moves from one stage to another, it will be subjected to shifts in the spatial network due to a renewed connection of the artwork to the physical surrounding, institutional conventions, professional practices, variations in the wider sociocultural context, changed audiences, and so forth. Identifying these changes with the help of the three spatial functions sheds light on the extent and nature of the artwork's adaptability to new circumstances.

From the conservation discourse, I adopted the idea to study the artwork "in action," translated into the model as an analytical search of influential factors on the perpetuation of site-specific installations. Borrowing the notions of "script" and "actor" from conservation scholars and the actor-network theory, a "toolbox" for the model was proposed, enabling the analysis of the actors, actions, and decision-making processes leading to the reinvigoration of spatial functions, or disregarding them, in a given context and time.

The combination of the descriptive part of the model - making use of the triad of spatial functions - and the analytical part - making use of the toolbox of script and actor - should be sufficient to understand how and why site-specific installation artworks transform over time and how their perpetuation is shaped within a museum context.

In the following three main case study chapters of this book, the conceptual model will be applied to a range of site-specific installation artworks in museum collections, varying in content, form, and spatial function. Each of these case studies will emphasize a particular set of spatial functions and discuss the problem of their perpetuation.

In chapter 4 , the focus is on the functions of spatial design and social space in the site-specific installation artworks of Ernesto Neto. The example of Neto's Célula Nave. It happens in the body of time, where truth dances highlights the problem of the transition of a site-specific, temporary, and interactive installation into an artwork in a permanent collection.

In chapter 5 , the focus is on the functions of social space and representational space in Jason Rhoades's SLOTO. The Secret Life of the Onion, highlighting the problem of a commissioned site-specific installation artwork that can no longer be installed at its original location. One of the main questions in this chapter is which curatorial strategies were applied after the artist suddenly passed away. 
In chapter 6 , the focus is on the functions of spatial design and representational space of the installation Drifting Producers, created by the artists' group Flying City, as part of a sociogeographical project. The main question is if and how the museum, as the host of the only existing materialized product of this project, can reinvigorate the various dimensions of its site specificity in the past and present, within a museum context. 



\title{
4 Ernesto Neto's Célula Nave
}

\author{
Extending the Lifespan of a Temporary, Site-Specific \\ Installation in a Museum Context
}

Keywords: original object, production space, visitor interaction, knowledgeable network, Ernesto Neto, Pipilotti Rist

"I think architectonically in a biological way."

Ernesto Neto ${ }^{1}$

Célula Nave. It happens in the body of time, where truth dances (2004) by the Brazilian artist Ernesto Neto is an interactive installation artwork, commissioned by the Museum Boijmans Van Beuningen in Rotterdam. The artwork consists of a spacious construction of turquoise fabric - the "nave" - hanging on a series of aluminium poles. Visitors are allowed to enter the nave and touch the fabric with their hands and feet. The spatial design of Célula Nave is intertwined with the museum's Bodon Gallery, for which the artwork was created. The size of the installation has been adapted to its large-scale dimensions; the colour of the fabric matches the greenish floor of the gallery, and the daylight falling into the room enhances the fabric's translucency.

Célula Nave was intended as a singular manifestation, meant to resist interactive use during a display period of three months. However, the Museum Boijmans Van Beuningen purchased Célula Nave after the show and put the installation on display again in 2009. As Tina Fiske observes for a larger group of spatiotemporally defined artworks, such unforeseen prolongation

1 Ernesto Neto made his statement during an interview with Nathan Gulick at the occasion of the installation of Animal Architecture, January 2007, https://www.youtube.com/ watch?v=yoMSbpiXsıw-.

Scholte, T., The Perpetuation of Site-Specific Installation Artworks in Museums. Staging Contemporary Art. Amsterdam: Amsterdam University Press 2022 DOI: 10.5117/9789463723763_CHO4 
of an installation implies that the institution "might accession a work that may not be fully or 'finally' determined in terms of their re-installation." ${ }^{2}$ This appeared to be true for Célula Nave: its transition from a temporary, interactive installation into an artwork in a permanent collection is the main focus of this case study.

By applying Lefebvre's triad of spatiality, I discuss in this chapter various modes of Célula Nave's site specificity, focusing primarily on its function as an interactive, site-specific installation and its fabrication process at various geographical locations. The institutional policies of commissioning and collecting site-specific installations will bring to the fore the function of "representational space," in relation to the Bodon Gallery. Also, Lefebvre's notion of "social space" will be discussed in two ways: first, in regard to the visitors' interaction with the artwork - interpreted here as a definition of the relationship between the artwork and its surrounding context. As a result of the interactive use, the artwork is currently in poor condition and cannot be exhibited again. Hence, the case study not only examines biographical stages of the past but also explores scenarios for extending the lifespan of Célula Nave. The second function of "social space" concerns the spaces of fabrication and the social networks involved with the production of Célula Nave. Because the artist considers this social production practice a meaningful constituent of the artwork, the question arises where a refabrication would be executed, and by whom, and how this would affect the spatial functions of the work (if a remake was considered).

Many actors play a role in this case study, varying from the artist and coworkers or cofabricators to the interactive audiences and custodians involved with the acquisition and perpetuation of the work. In the analysis of the causes of damage and the performance of the work, various dimensions of the notion of script will be applied. Following the proposition made by Latour and Akrich, I will suggest that the interaction with the visitor was "inscribed" by the artist into the materiality and spatial design of Célula Nave, which is also the reason the artwork suffered during display. Furthermore, by "de-scripting" the artist's statements and the museum's acquisition and display policies, light is shed on the contradictions and

2 Fiske refers to We Fishing the Time (densidades e buracos de minhoca (2001) in the collection of the Tate. Tina Fiske, "Accessioning Ernesto Neto: Some Recent Installations and Acquisitions Considered," in Contemporary Art: Creation, Curation, Collection and Conservation (Dublin: Irish Museum of Modern Art, 2001), 24. 
dilemmas of extending the lifespan of site-specific installations intended for temporary display.

This chapter begins with a brief introduction of the artist Ernesto Neto and his site-specific installations, followed by a description of the first and second staging of Célula Nave, including the shifts of site-specific functions leading to the current deadlock of the artwork. Furthermore, by examining the spatial functions and tracing the underlying scripts, suggestions are made for future scenarios. To this end, I will draw on a number of additional sources. First is a study into Célula Nave's material composition, executed by conservator Carien van Aubel. Her research helps to understand the reasons of damage and provides options for a restoration or a remake of Célula Nave in the future. Second, this case study draws on observations made by conservators, members of the technical staff, and exhibition designers in relation to a number of comparable cases: two site-specific installations created by Ernesto Neto (in the collections of the Tate, London and Museum of Modern Art, New York) and one site-specific installation created by Pipilotti Rist (in the collection of the Museum Boijmans Van Beuningen).

\section{Ernesto Neto as a Site-Specific Working Artist}

Ernesto Neto (Rio de Janeiro, 1964) became world famous for his spatial constructions made of stretchable fabrics (Lycra) that provoke a multisensorial experience of vision, touch, smell, movement, and sometimes, sound. It is often said that two Brazilian artists of a previous generation have influenced Neto to focus his attention on the position of the body in the experience of his art. The first is Lygia Clark, whose series of "wearable objects" - consisting of hoods, suits, or gloves - invited visitors to physically interact with the art objects she created. The second is Hélio Oiticica, who is famous for his Tropicália environments; he included biological elements into his works, such as parrots and plants, and radically rethought the process of art making. ${ }^{3}$ Neto, however, does not share the political ideologies of his Brazilian predecessors of the 1960-1970s. On the contrary, he embraces today's communication and "spectacle" society. ${ }^{4}$ In form and content, the specifics of the site are always part and parcel of his installations: they make

3 See, for example, Lisette Lagnado, "Longing for the Body: Yesterday and Today," in Brazil: Body Nostalgia (Tokyo: National Museum of Modern Art, 2004), 164-169.

4 Interview with Ernesto Neto by Luiz Camillo Osario, in madness is part of life (Tokyo: Espace Louis Vuitton, 29 September 2012-6 January 2013), 9-11. 
Figure 11 Um Sagrado Lugar (A Sacred Place) (2017) by Ernesto Neto. Installation view at $57^{\text {th }}$ Venice Bienniale. Photo by the author.

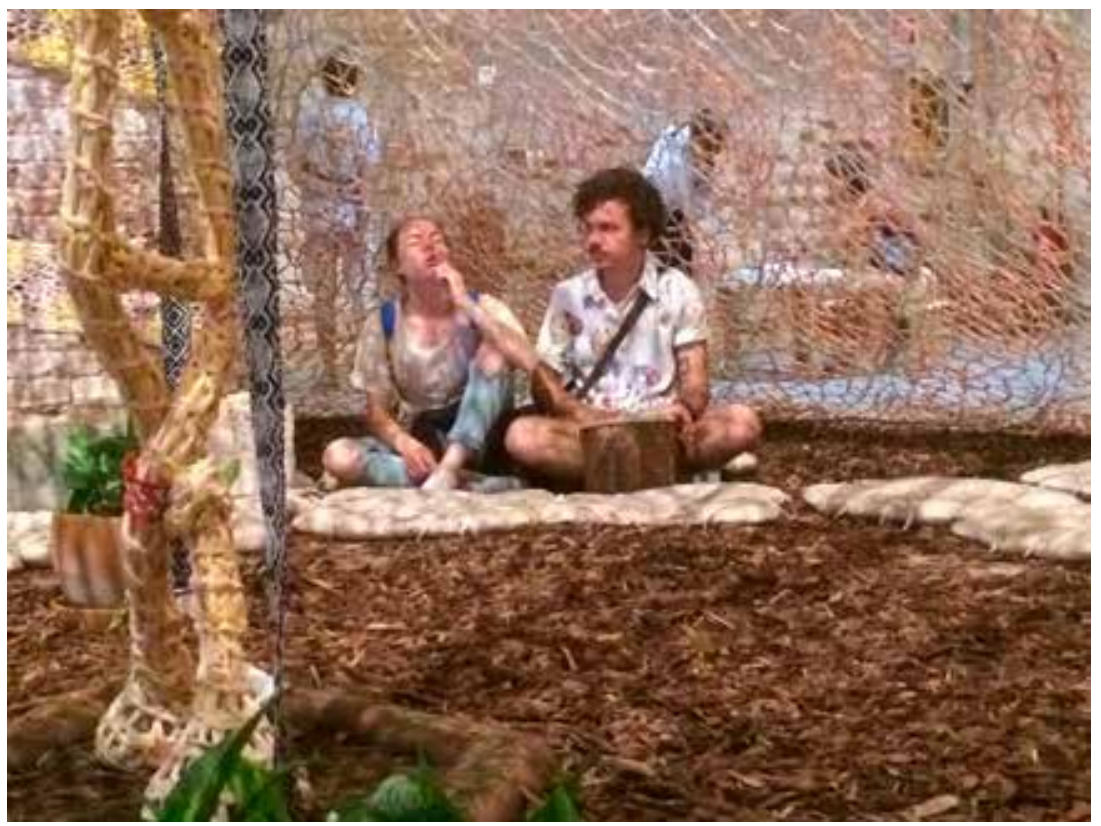

the viewer aware of the actual space of the artwork and its surroundings, while simultaneously raising consciousness of the recipient's "inner space." The excitement - and also the conservation challenge - of Neto's spatial constructions lies in the fact that these artworks involve delicate textile materials and are often interactive.

At the 2017 Venice Bienniale, Neto created a Shamanic Pavilion - in reaction to curator Christine Macel's call to celebrate art as "the favourite realm for dreams and utopias." Neto's colourful, site-specific installation Um Sagrado Lugar (A Sacred Place) consisted of a huge structure suspended from the beams of the ceiling of the Arsenale. The pavilion was made of manually crocheted, polyamide fabric, and visitors could gather inside for a "ritual" and play the drums or relax on the cushions placed along the sides. [Figure 11]

5 Introduction by Christine Macel to "Viva Arte Viva" the $57^{\text {th }}$ edition of the Venice Biennial, https://universes.art/en/venice-biennale/2017/viva-arte-viva/christine-macel-statement/ (last accessed 23 April 2021) 
In a much older installation, Leviathan Thot (2006), Neto transformed the austere space of the Panthéon in Paris into a sensual, organic architecture of draped nets and pods suspended from the ceiling. Similarly, the immense exhibition space of the New York Armory Show (2009) was covered with a "membrane" of fabric, and pods were attached to its ceiling, while the spices put inside added extra flavour to the experience. ${ }^{6}$ The artwork literally became a stage for a site-specific performance when the Shen Wei Dance Company combined a performance of professional dancers with members of the public moving and running around the interior spaces of the installation.

Key to understanding Neto's work is (to paraphrase the artist) his search for a symbiosis between the "spirit" of a place and the "texture" of the work. He seldom works from a predefined script for the artwork's materialization, but as he states: "I am really developing the piece when I am doing it."7 Most of his installations are commissioned by galleries, museums, and other exhibition venues and are, most of the time, intended as temporary works. Such was also the case with Célula Nave, one of his earliest large-scale, site-specific installation artworks.

\section{The First Display of Célula Nave}

Participating in the group exhibition Perception of Space (2004) in the Museum Boijmans Van Beuningen, Neto created Célula Nave for the central room of the Bodon Gallery. ${ }^{8}$ [Figure 12] In technical terms, the shape of the installation resembles a tent, because the entire structure is suspended on twelve aluminium poles and can be mounted as a single entity in space. The large construction of the nave, composed of various shades of turquoise polyamide fabric, is counterweighted by a number of bigger and smaller bags placed on the ground and filled with river sand. Visitors can enter the nave - or "spaceship" as Neto occasionally calls it - after which they have to push the fabric to the ground with their feet to move around, meanwhile

6 In an interview with Jess Wilcox, Neto describes the installation as "a center of energy for the people who move around it." Jess Wilcox, "Anthropodino: A Conversation with Ernesto Neto," Art in America (26 May 2009, online version), https:/www.artinamericamagazine.com/ news-features/interviews/anthropodino-a-conversation-with-ernesto-neto/.

7 See footnote 1 of this chapter.

8 The exhibition Perception of Space ran from 20 May to 1 August 2004. It featured (next to Célula Nave) works from Mark Bain, Massimo Bartolini, and Ann Veronica Janssens. 
Figure 12 Célula Nave. It happens in the body of time, where truth dances (2004) by Ernesto Neto. Collection Museum Boijmans Van Beuningen, Rotterdam (MBVB). Donation: Stichting Fonds Willem van Rede. Installation view in Perception of Space. Photo: Bob Goedewaagen. Courtesy photographer and MBVB. $\odot$ Ernesto Neto.

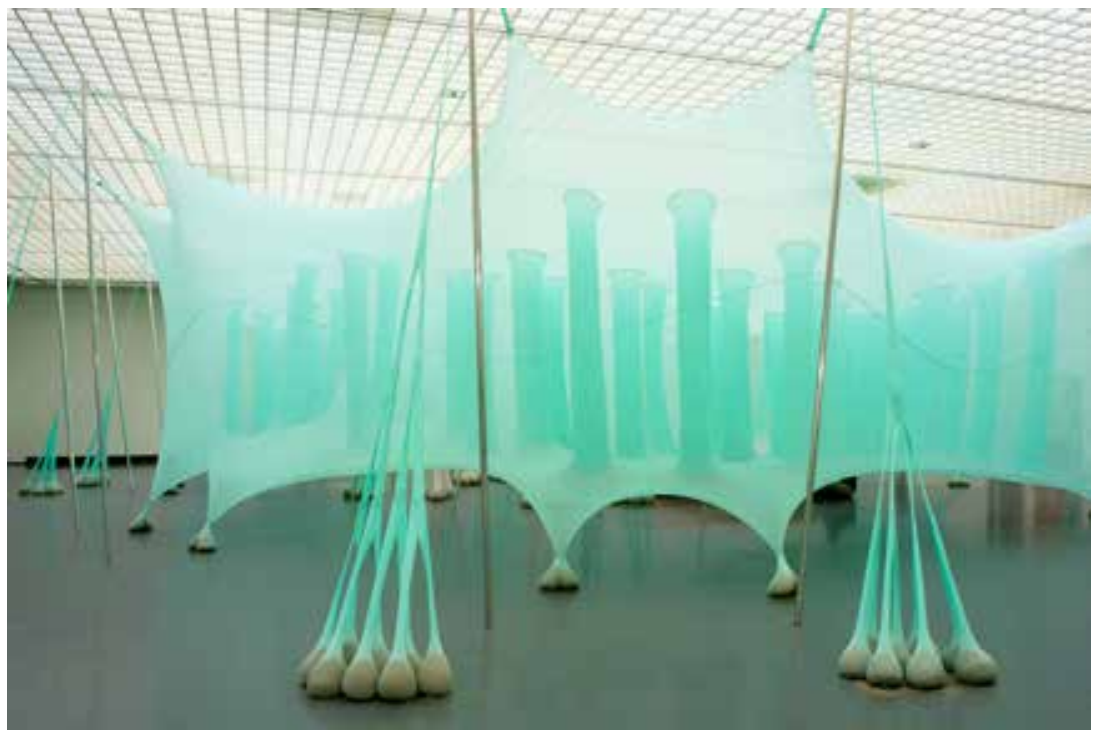

seeking balance by touching the membrane at the sides. ${ }^{9}$ [Figure 13 and Figure 13a]

The artwork has a sensual appearance, due to the softness and colour of the fabric. For visitors, it is a multisensorial experience to enter the nave and touch it. When strolling around the interior spaces of the nave, they can literally reshape its form. According to Neto, this physical contact with the artwork offers "a state of sensuality [that] will give you the idea of a risk, an idea of how delicate things can be." ${ }^{\prime 10}$ From this statement, it can be presumed that the artist considered bodily interaction and the visitors' movements essential to the meaning of Célula Nave, and secondly, that the material of which it was made contributed to this sensation.

9 Statement by Ernesto Neto during a Skype interview with the Museum Boijmans Van Beuningen, incorporated into the video by Alexander Goekjian, "Megastructures: Building 'Célula Nave,'” Arttube, 7 July2oog. https://vimeo.com/124817865.

10 Neto in "Megastructures: Building 'Célula Nave," Arttube. 
Figure 13/13a Célula Nave. It happens in the body of time, where truth dances (2004) by Ernesto Neto. Collection Museum Boijmans Van Beuningen, Rotterdam (MBVB). Donation: Stichting Fonds Willem van Rede. Installation view in Perception of Space. Photo: Bob Goedewaagen. Courtesy photographer and MBVB. $\odot$ Ernesto Neto.
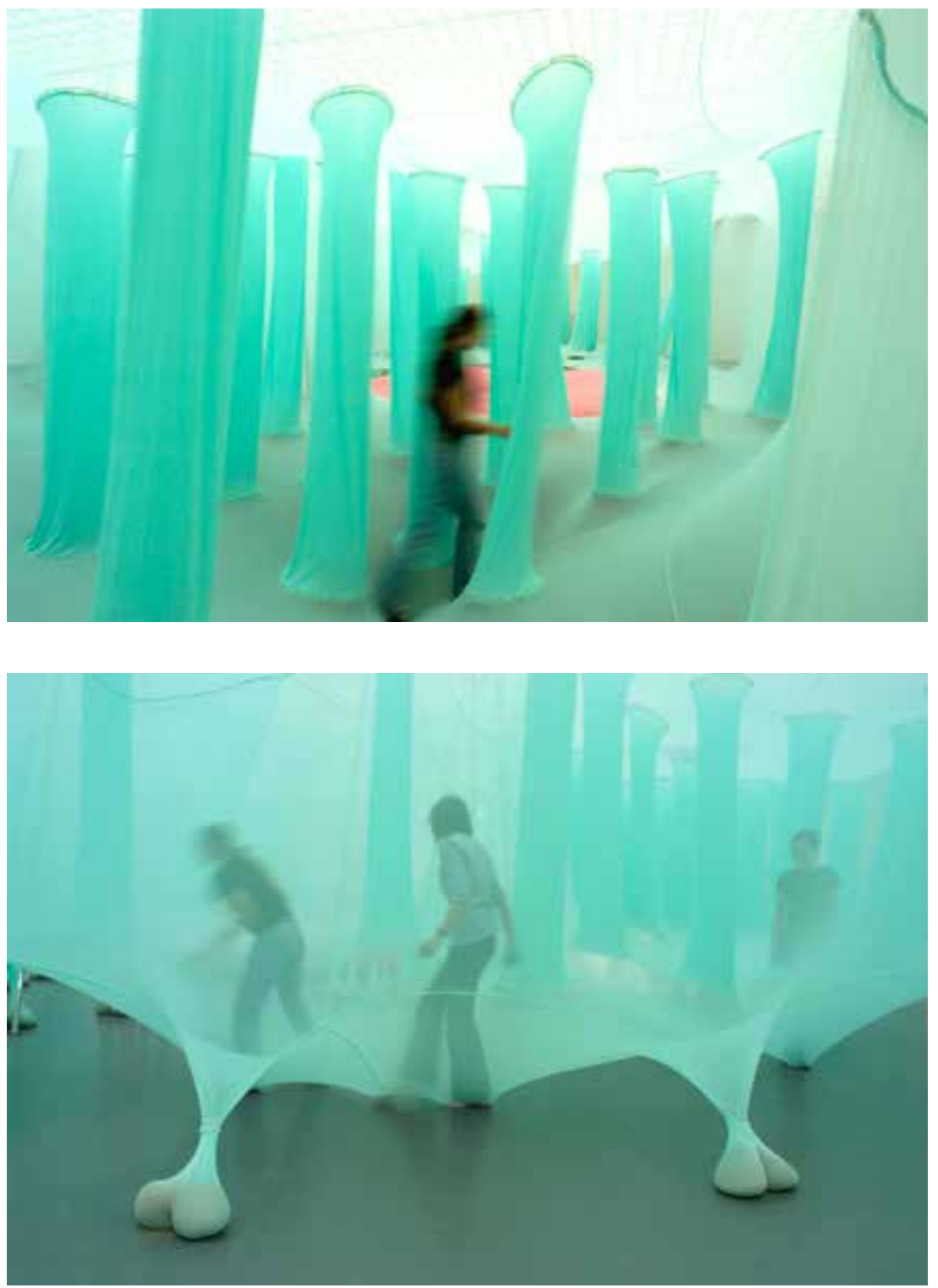
After the show, the installation was accessioned by the museum, followed by a second term of display in 2009. This time, the physical interaction appeared to be disastrous for the fragile material and spatial design of the artwork. ${ }^{11}$ Later on in this chapter, I will elaborate on this problem, but let us first take a closer look at the spatial design and materiality of Célula Nave in relation to the surrounding space and the values attributed by the custodians to the visitors' interaction.

\subsection{The Spatial Design and Materiality of Célula Nave}

Célula Nave is composed of hundreds of metres of turquoise polyamide fabric, an elastic material normally used for the fabrication of stockings. The measurements of the construction ( $20 \times 24 \times 4.75$ metres) surpass the usual size of an artwork, even compared to other large-scale installations. The spatial design is attuned to the surrounding architecture of the middle room of the Bodon Gallery - built by Alexander Bodon in 1972 as an annex to the original museum building. ${ }^{12}$ The first floor consists of three spacious and flexible galleries, which can be reconfigured depending on the needs of the exhibition. Neto geared the floor plan of Célula Nave to those dimensions and used the height of the room for the suspension construction of the nave.

The entire nave is supported by twelve aluminium poles. Their mutual distances determine the stretch on the fabric when the poles are placed upright. The tension increases when visitors are strolling around the nave's interior and press the fabric to the floor. Bags made of the same fabric and filled with river sand serve as counterweights placed around the poles: several clusters of small bags are connected to the nave's ceiling by means of strips folded over the top of the poles; in addition, an inner series of counterweights keep the nave's floor in balance. This delicate construction and the colour and translucency of the stretched polyamide give the

11 "Condition Report" by Saskia Rijsdijk and "Report" by Jaqueline Rapmund and Marjolijn de Bakker, March 2011, Museum Boijmans Van Beuningen archive.

12 The three upper rooms of the Bodon Gallery are located on the first floor and measure approximately 1,450 square metres in total. The central Bodon Room covers approximately 800 metres and has a height of 5 metres. The rooms were especially designed for large works of contemporary art. In principle, they have no walls that would obstruct the visitor's visual perception, but, if necessary, the rooms can be subdivided into smaller compartments and still keep the spatial qualities of the room. Windows and skylights allow for fluctuations of daylight to enter the room. For a detailed description of the history of the museum building, see: Julia Noordegraaf, Strategies of Display: Museum Presentation in Nineteenth-and Twentieth-Century Visual Culture (Rotterdam: NAi Publishers, 2004), 150-157. 
Figure 14 Floor plan of Célula Nave by Studio Ernesto Neto. Image editing: Arienne Boelens. $\odot$ Ernesto Neto.

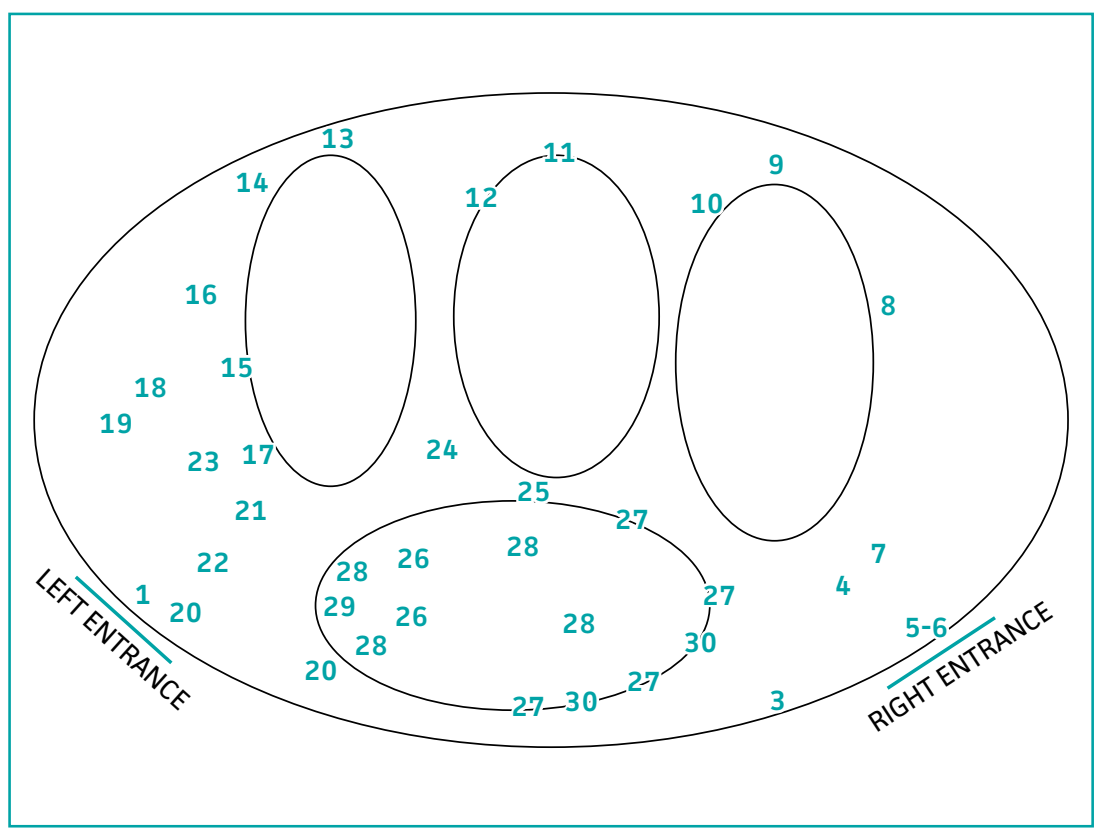

impression the nave is floating in the air. Daylight falling into the room through a series of skylights and windows of the façade of the Bodon Gallery grants the top layer and sides of the membrane a vibrant translucency, which is even further emphasized by the greenish colour of the gallery floor.

Neto often gives biomorphic titles to his work and he did so, too, with the above-mentioned constituents: the counterweights attached to the inner nave are called "feet," the clusters of counterweights around the poles are "fingers," and the strips of fabric connecting them with the ceiling are "arms."

The museum archive holds a floor plan indicating two openings in the membrane, through which visitors can enter and leave the nave. [Figure 14] Inside the nave, a rhythmic structure of vertical tubes (indicated with numbers in the drawing) alternates with a number of empty spaces. In terms of Lefbevre's triad of spatiality, the drawing can be considered a representation of the spatial design, but is it not a very detailed description. Photographs give an impression of the installed artwork, although these convey little about the forces put on the fabric when the artwork is installed and actually in use. Other files include a remark that three voids, called "bubbles," are not accessible to the public. One large open space has a round 
circle in the middle, representing a pink mattress placed directly on the floor. This is the largest void and a "playground" for visitors, who can relax on the mattress and watch a turquoise pod hanging from the ceiling, or they can bounce on the mattress, reinforcing their experience through physical interaction.

According to visitors' accounts, Célula Nave is "a sensory installation that allows visitors to immerse themselves into a fluid and cellular symbiosis after they have taken off their shoes."13 $\mathrm{Or}$, as someone else observes:

In this work, the visitor enters, lies down, lets himself go, goes through an experience of abandonment and displacement in an almost organic structure that rocks him and detaches him from the outward life to reconcile him with the inner one. ${ }^{14}$

The public loved the artwork, as some museum staff members confirmed during the interviews I conducted for this case study. ${ }^{15}$ It was considered a highly experiential and playful work, with a touch of entertainment. Looking upon site-specific installations as performances, I would deem the visitors, in this case, both spectators and actors: interacting with the artwork, they can watch each other "play," both from the inside and from the outside of the nave.

\subsection{The Functions of "Social Space" and "Representational Space" in Célula Nave}

According to Sjarel Ex, the director of the Museum Boijmans Van Beuningen, the aesthetics of Célula Nave and the interactive experience were reasons to acquire the installation. Ex describes his enthusiasm for the playful aspects as follows:

At the opening night people were excited, waiting in the line to get in. They had to take of their shoes and then they could enter the nave. I saw

13 designboom magazine, Instagram Post, 25 October 2016, at 11:07 UTC, https://nl.pinterest. com/pin/501799583480146199/.

$14 \mathrm{http}$ //digicult.it/design/the-contemporary-brazil-pass-through-its-modernity/ (last accessed 23 April 2021).

15 Interview conducted with the director of Museum Boijmans Van Beuningen, Sjarel Ex, on 5 December 2011. 
people diving into the pink mattress. [...] You really jump into it. Just like that, flat on your stomach. It's great. It's life. Célulife. ${ }^{16}$

In terms of the triadic model for site specificity, the director's statement can be read as a reference to Célula Nave's social space, which, according to Lefebvre, is intertwined with perception and spatial practice. As explained in the previous chapter, Lefebvre suggests that spatial practices presuppose the use of the body and the senses for spatial orientation. Social space is an active and real space - corresponding to the activities, routines, and practices of the inhabitants of a space, employed at a particular moment in time. Applied to Célula Nave, the production of social space starts when visitors stroll around or jump on the mattress. By using their own bodies and senses, they become coproducers of the social space and bring variation into the spatial design of the artwork.

Furthermore, the Bodon Room is an important parameter for Célula Nave's physical site specificity, offering the conditions in dimensions and aesthetics for the experience described above. Moreover, at a conceptual level - and in accord with the proposed model - a juxtaposition can be observed between this actual, physical site specificity and the "representational space" of the gallery. The museum has a long history of granting commissions to artists, who create their work specifically for the Bodon Gallery; commissions are often followed by an acquisition.

As Julia Noordegraaf elucidates in Strategies of Display: Museum Presentation in Nineteenth- and Twentieth-Century Visual Culture (2004), the spacious rooms of the Bodon Gallery offer ample possibilities to contemporary artists to create artworks in situ. Especially under the leadership of Wim Beeren (1978-1985), the galleries became a substitute for the artist's studio: “[...] a place where the artworks were born," in other words, where visitors could witness the moment of creation. ${ }^{17}$ Later directors continued Beeren's approach, and there is still a close relationship between the museum's acquisition policy and the architecture of the Bodon Gallery, as the current director states:

We conduct an active commission and acquisition policy towards artists who explore architectural space and seek to collect installations specifically made for the Bodon Gallery. This goes back to the 1980s, when we acquired the large Corten-steel Waxing Arcs by Richard Serra 
[discussed in chapter 3 ] and a floor piece by Walter de Maria. ${ }^{18}$ We still feel very much attached to these older works. The stainless-steel by De Maria are frequently re-installed and the Serra piece is on permanent display. We follow these artists, but we also follow the talents of the building. ${ }^{19}$

His statement underlines the symbolic meaning of the Bodon Room for Célula Nave, the representational space that Lefebvre denotes as "lived space." This space embraces "the loci of passion, of action and of lived situations, and thus immediately implies time." ${ }^{20}$ The Bodon Room offers this representational space to the artwork and, in return, the acquisition of Célula Nave confirms that the Museum Boijmans Van Beuningen "performs" as a prominent contemporary art museum and represents world-famous artists.

In view of Lefebvre's triad of spatiality, we can identify the first staging and acquisition of Célula Nave as an "ideal" performance of interrelated site-specific functions of the artwork. Neto created an inseparable bond between the spatial design of the artwork and the surrounding architecture (designed space); a social space was produced by the visitors' interaction with the spatial design of the artwork (perceived space); and Célula Nave represented a progressive commission and collection policy of the Museum Boijmans Van Beuningen (lived space).

\subsection{The Fabrication of Célula Nave and "Spaces of Production"}

Throughout his career, Ernesto Neto has used polyamide fabrics and employed their sensual appearance and properties of translucency and elasticity. For Célula Nave, the artist purchased the materials from the Rosset fabric company in Brazil: various shades of turquoise were used for the membrane (and additional elements of the tubes, arms, fingers, and feet) and a pink colour for the mattress. ${ }^{21}$ In Neto's studio in Rio de Janeiro,

18 Sjarel Ex refers to Walter de Maria, A Computer which will solve Every Problem in the World /3-12 Polygon (1984).

19 See footnote 15 of this chapter.

20 Henri Lefebvre, The Production of Space, trans. Donald Nicholson-Smith (Oxford: Blackwell Publishing, 1991), 42.

21 See Carien van Van Aubel, Suzan de Groot, Henk van Keulen, Tatja Scholte, and Bill Wei, "Stretch in Space: Research into the Mechanical Properties of Installations of Knitted Polyamide under Stress," Postprints Future Talks o15 (Munich Pinakothek der Moderne, 28-30 October 2015), 29-38. 
coworkers and assistants sewed the large pieces together and produced the elementary shape of the nave. Looped lace ribbons were added to the edges of the tubes to establish - at a later instance - a connection between the tubes and the ceiling of the nave.

After the preproduction in the factory and the artist's studio, the production process was relocated to a different geographical location: the Bodon Room of the Museum Boijmans Van Beuningen. Together with the artworkto-be, a group of Neto's coworkers travelled to Rotterdam and "occupied" the gallery space. The final production process consisted of stitching the large parts together and creating the joints between the columns and the rest of the membrane. Wout Braber, the head of the technical department at the museum, recalls:

For three weeks, no less than 10 to 12 Brazilian men and women worked on a daily basis in the gallery space. It is all handcraft, sewing together the large pieces that were prepared in Brazil. It was amazing. ${ }^{22}$

These production practices introduce a second dimension of Lefebvre's notion of "social space" to this case study; namely, the succession of production spaces and networks of human actors that are involved in the fabrication of the artwork at different locations. Neto himself emphasizes the significance of the production practice in Brazil when he states that the craftsmanship and physical labour needed for the fabrication of his works is part of its meaning: "[...] to use one's own body for an act of creativity reflects the Brazilian way of celebrating life and art." ${ }^{23}$

According to Lefebvre, each production space has "a guaranteed level of competence and a specific level of performance." ${ }^{24}$ In this respect, it is worth noting that Neto migrated his coworkers from one geographical region to another for reasons that relate to competence and performance: he deemed their craftsmanship necessary for the fabrication of the nave. Considering this production process inside the Bodon Gallery in hindsight, he stated: "We were building it here like primitive people." ${ }^{25}$ The artist came over to the museum for the "finishing touch," determining the exact position of the

22 Interview conducted with Wout Braber and Jaqueline Rapmund on 28 November 2011.

23 Statement by Ernesto Neto in a video-recorded presentation at the Tate conference Spaces of Transformation: Edges of the World (Part 3), 21 January 2012, https://www.tate.org.uk/whats-on/ tate-modern/symposium/topology/spaces-transformation-edges-world.

24 Lefebvre, Production of Space, 33. Original emphasis.

25 See footnote 9 of this chapter. 
poles and the stretch of the fabric. Neto describes this as his own "physical relationship with the piece":

It comes from the mind, than to the arm, than to the hand. Of course, that's not the way you do it. It takes a long time, from the head to the hand and to the earth. Art is something that goes away from my fingers, like that [he makes a spontaneous gesture with his hand] Wow. Like magic! ${ }^{26}$

The above observations highlight some of the problems that will be addressed later on when discussing possible scenarios for the perpetuation of Célula Nave: should the artist be present when the work is reinstalled, accommodating the nave's shape to the specifics of the site? In case of a restoration or remake, should the same trajectory of successive production spaces be followed involving the same network of skilled coworkers? These questions did not come forwards during the first period of display, and the problem would not occur if the installation had not been acquired for a museum collection. However, because the lifespan of the artwork has been prolonged through its acquisition by the Museum Boijmans Van Beuningen, these questions became relevant for further research.

\section{Conservation of Célula Nave}

Already during the first period of display, the museum's technical staff members had to take care of small holes and ladders (caused by nails, jewellery, or belts) on a regular basis; sometimes, larger tears had to be stitched at places where the fabric had been put under stress. ${ }^{27}$ At the time of the acquisition, the damages were communicated with Neto's assistants, who made a condition survey of the nave. The conclusion was that the work could be reinstalled and, apart from the above-mentioned floor plan and general instructions for repair, the studio provided a set of sample materials of the various fabrics to be used in case of a restoration. In the instructions, it was stated that the museum could take care of restoration if needed. Apart from this, the artist was, in theory, positive about a remake in case the condition of the artwork demanded it. Detailed instructions were provided for replacing individual parts of the nave, and in particular the floor, where damages

26 See footnote 1 of this chapter.

27 One of the technical staff members recalls that she worked on the repairs while sitting in the nave with her toolbox, which intensified her relationship with the artwork (interview conducted with Marjolijn de Bakker on 15 March 2012). 
would be most severe. ${ }^{28}$ The entire set of instructions for reinstallation and restoration provided by the artist's studio can be read as a script for sustaining the material construction of Célula Nave. Or, to follow Akrich's notion of the script, as a prescription for a specific form of action, which, in this case, implied that visitors could stroll around while conservators would restore the damage. However, as we shall see below, the intended script did not keep up with the material properties of the object during the second iteration.

\subsection{The Reinstallation of Célula Nave without the Presence of the Artist}

In 2009, on the occasion of the exhibition Brazil Contemporary, the installation Célula Nave was staged again in the Bodon Gallery. ${ }^{29}$ Neither the artist nor his coworkers were present, and the museum staff was entirely in charge of the reinstallation. The preparations consisted of collecting all parts and support material (such as a large volume of river sand to fill the "feet" and "fingers," and styrofoam balls for the mattress and the pod). The membrane was spread out and the poles were placed at their proper position on the gallery floor. As Wout Braber recalls, the crucial moment was when the aluminium poles were set up in a vertical position, pulling up the nave like a tent:

We started with measuring the exact distances between the poles in relation to the height of the entire structure, from the top of the poles

28 The instruction file includes the following paragraph: "These instructions teach how to remake the whole Nave. But we believe that just remaking the floor will be sufficient to restore Célula Nave. In the future, if necessary, the whole piece could be remade as an 'exhibition copy.' Nevertheless, the original Nave must be kept by the institution (by its owner), to always be used as a reference and 'since the proposed restorations of the piece concern it's daily use and not its existential state in time. The piece's trajectory in time is extremely important." Statement made by Ernesto Neto, part of the archive of the Museum Boijmans Van Beuningen.

29 Célula Nave was acquired through the Willem van Rede Fund, which is officially under the administration of the Dutch state. However, Museum Boijmans van Beuningen is in charge of the work's preservation and presentation. The museum follows the policy to show purchased installation artworks every five years. The exhibition Brazil Contemporary, was a shared event organized by the Museum Boijmans van Beuningen, the Netherlands Architecture Institute, and the Netherlands Photo Museum, Rotterdam, 30 May-23 August 2009. The Museum Boijmans Van Beuningen featured artworks by Hélio Oiticica, Rivane Neuenschwander, Cao Guimaraes, Ernesto Neto, and Ricardo Basbaum. 
to the arms, and fingers and feet resting on the floor. These distances determine the flexibility when people are navigating the tent. We needed twelve persons to keep an eye on their own poles, fingers and feet, because if the tension would get wrong, the whole structure would collapse. And then I gave the sign "fire under control." From the inside we controlled the flux of the poles, how they would bend inward and outward when the work was "in function." ${ }^{0}$

The poles are flexible, and their inwards and outwards bending is decisive for the pressure on the fabric when visitors move around the interior spaces of the nave. Their lengths and the shape of the membrane are indicators for the right position, but this is no hard science. Because the instructions for reinstallation was mainly based on the floor plan, staff members had to make their own decisions. It was a matter of getting the right feeling, as Braber said, just like Neto would perform the act.

A few days after opening night, the artist came over and authorized the installation. ${ }^{31}$ Whereas, for the original manifestation, he had used his own body to position the poles, therewith determining the stretch on the fabric, this time he agreed with the way the staff members had measured the installation. Among the museum staff members, however, there were differences in opinion with regard to the stretching of the fabric. According to the technical staff, the height of the poles was rather similar to the initial staging and an argument to put them slightly more upright was to prevent them from toppling, as sometimes happened during the first iteration..$^{32}$ The director, Sjarel Ex, took a different stance. He observed that the poles were actually put more upright the second time, so that the membrane seemed taut in contrast to the intended appearance:

Célula Nave is like a spider. Some sort of big animal walking through the exhibition space. It should look like a living creature, not so much like a rigid work of art. ${ }^{33}$

Those different voices show how sensitive the work is to the slightest variation in stretch, especially because mechanical pressure is exerted on the fabric when the artwork is in use. During the second iteration, the number 
of holes and small tears in the membrane multiplied, due to the visitor's physical engagement. A dramatic situation occurred when, alongside a repaired large tear in the nave's ceiling, a new tear - larger than the previous one - appeared. This occurred exactly in the area where visitors would play on and around the pink mattress in the middle. Because the ceiling could no longer hold the structure together, there was a serious risk the poles would topple. Hence, for safety reasons, Célula Nave was closed to the public and has since then been considered a total loss. The nave and poles are being kept in storage until a solution is found. ${ }^{34}$

\subsection{Shifts in the Spatial Network of Célula Nave and Refinement of the Conceptual Model}

In the above discussion, I stated that the first biographical stage of Célula Nave shows a well-balanced spatial network established by the spatial design of the artwork, the representational space of the Bodon Gallery, and the social spaces of production and perception. The surrounding architecture, important for the artwork's physical site specificity, did not change during the second iteration. The museum's policies of commissioning experiential installations and their subsequent acquisition can be regarded a function of the representational space - a "lived space" - which, in the case of Célua Nave, was activated by the acquisition in 2004 and reinstallation in 2009. Furthermore, social-production spaces can be allocated to a diversity of places and productive activities: the factory and the artist's studio in Brazil, as well as the Bodon Room during the fabrication of Célula Nave (emphasizing the skills and craftsmanship of the artist's coworkers). Besides, the visitors' interaction with the artwork was considered a meaningful constituent, setting into motion the social space of perception.

Yet another mode can be discerned in the practices applied to the perpetuation of Célula Nave, particularly in regard to the physical maintenance of the artwork. During the first iteration, relatively little action was required to keep the artwork in shape, while this demand intensified during the second staging. When the number of holes and ladders in the membrane increased due to physical contact with the visitors, considerably more actions were needed and the "production space" expanded even more as a result

34 Conservators explain the new tear as resulting from the fact that the first tear was sewn together with fishing line, creating a rigid seam that does not give under pressure. See footnote 11 of this chapter. 
Diagram 6 Model for the analysis of site-specific installation artworks with a breakdown of the function of social space into: social space of production, social space of the visitors' experience, and social space of perpetuation and care. $\odot$ The author. Image editing: Arienne Boelens.

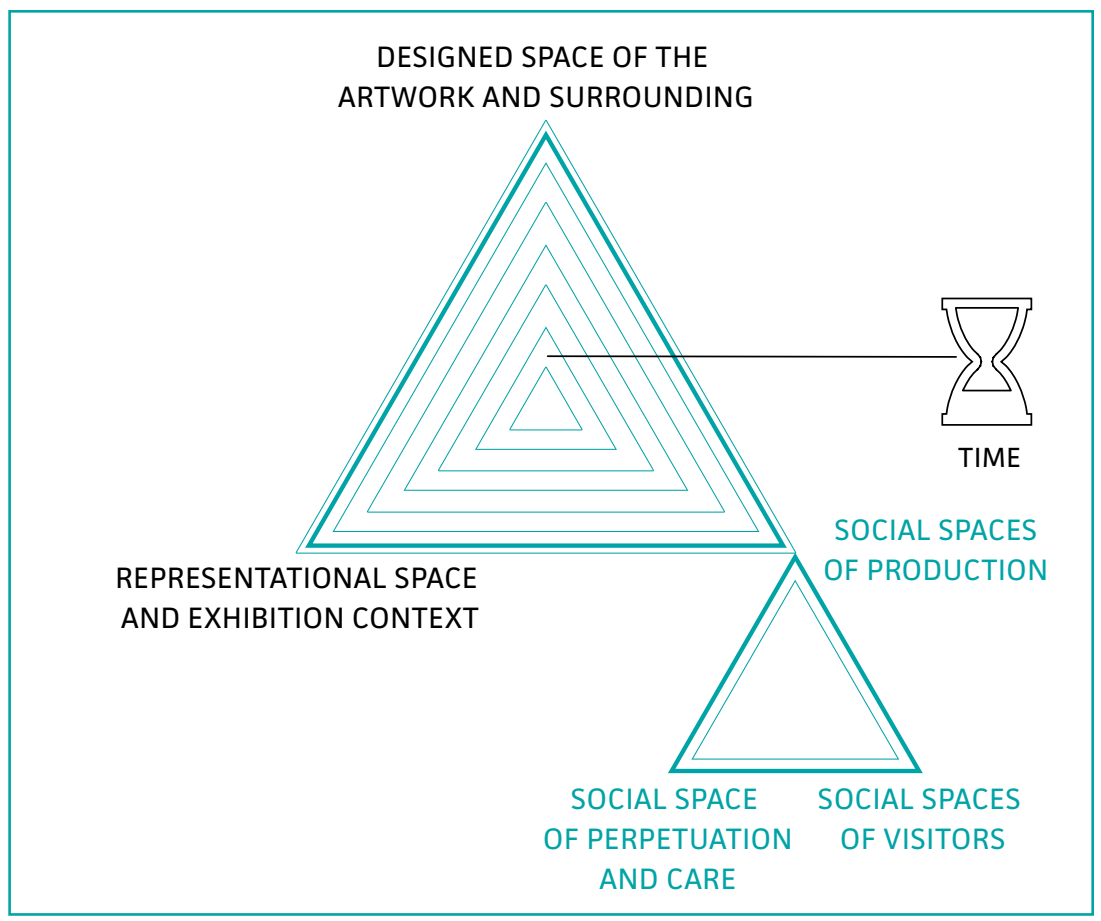

of this daily maintenance. Marjolijn de Bakker, one of the museum's staff members, recalls how she performed dozens of repairs, kneeling inside the nave, and how, sitting on a stool, she had to reattach numerous buttons to the mattress, which had sprung off during the public's interaction. ${ }^{35}$ And yet, all these actions could not prevent the artwork from suffering severe damage, resulting in the current state of a total loss.

\section{Refinement of the Conceptual Model}

Based on the insights listed above, it can be concluded that the sensibility of the material of Célula Nave plays an active and constitutive role in the production, perception, and restoration of the artwork. In accord with the 
Diagram 7 Expanded version of the model for the analysis of site-specific installation artworks with a pentagonal structure. $\odot$ The author. Image editing: Arienne Boelens.

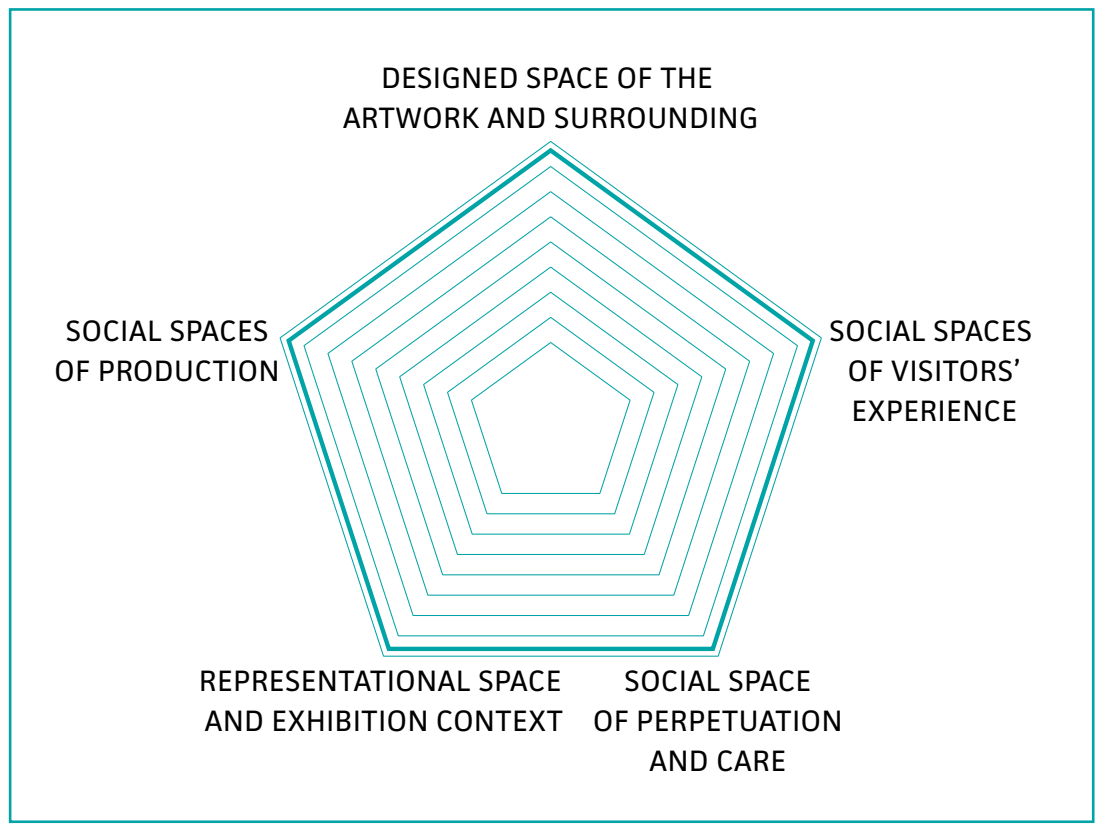

conceptual model for site-specific installation art, I take the stance that the various places in which the artwork and its meaning are produced are not neutral but intertwined with the social groups that inhabit these spaces as well as with the function of representational space (factory, artist's studio, museum, and so forth). The case study highlights the variation in social spaces of production and perception during the successive stages of Célula Nave - from the fabrication of the raw material and preparation of the nave's basic elements in Brazil to sewing the large pieces together and installing the artwork, as well as to its restoration, in the Bodon Gallery, and last but not least to the visitors' space of perception during the experience of the work. In view of all this and to analyse possible scenarios for Célula Nave's future existence, I propose a further breakdown of the function of social space into the following categories: the social spaces of the initial production of the artwork, the social spaces of the artwork's perpetuation and care, and the social space of the visitors' experience inside the exhibition room. [See Diagram 6] This means that, for the model's visualization, the original triangle of spatial functions turns into a pentagonal shape. [See Diagram 7] Furthermore, as suggested in the previous chapter and 
Diagram 8 Pentagonal model for the analysis of site-specific installation artworks with the additional toolbox of script and actors. $\odot$ The author. Image editing: Arienne Boelens.

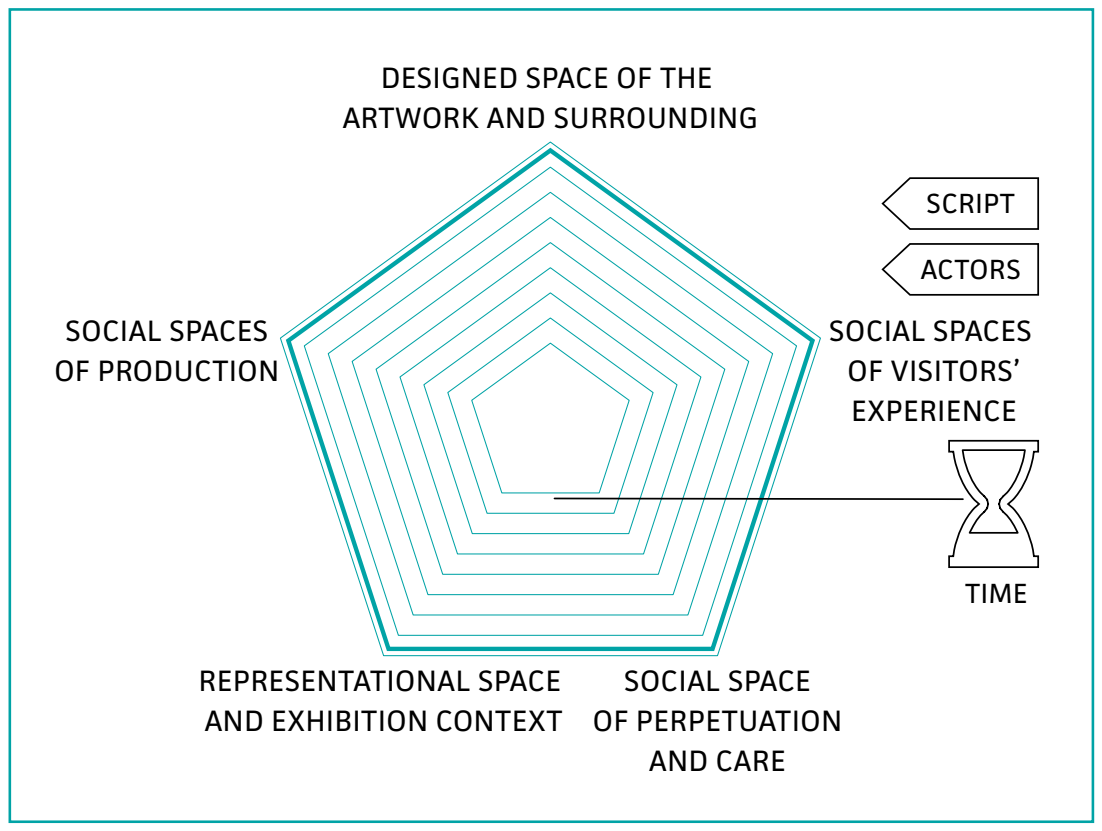

illustrated with the current case study, human actors may have a specific relationship with the network of spatial functions that can be analysed as such, also in relation to the underlying motives or scripts, in this case the artist himself, conservators and other staff members, the director, or the public (more a general indicator for a social group than a specific person). Finally, to make the conceptual model complete, the pentagonal structure is envisioned in a diagram that includes the influential factors of actor and script. [See Diagram 8]

\section{Interactive Visitors' Engagement}

The core issue for the perpetuation of Célula Nave was analysed earlier as the transition from a temporarily intended artwork to an installation artwork that is part of the permanent museum collection. In fact, the problem of Célula Nave's current state is directly related to the public's physical interaction during the second iteration (after the work had survived the first exhibition term). In terms of the proposed model, this 
could be explained as a friction between the artist's intention to create a social space for visitors and the aesthetic, spatial design of Célula Nave, which could not resist such forces in the longer term. An underlying motive for the acquisition - and an additional cause of the problem - can be allocated to the museum's desire to give the audience access to an experiential work of art. My conclusion would be that the performance of Célula Nave (as an interactive installation) gained priority over the protection of the physical artwork, especially because no strict regulation was imposed on the visitors during their interaction with the delicate construction.

This situation is not unique. Many more examples could be listed of interactive artworks that suffer from the public's engagement and have nonetheless been accessioned and re-exhibited. ${ }^{36}$ In this respect, Célula Nave could be seen as just another example of the problems and dilemmas contemporary art museums are confronted with when offering their publics a space for art experience - a zone of "purposeless free play," as the art historian Julian Stallabras would say. ${ }^{37}$

Moreover, in the case of Célula Nave, the problem was partly caused by the fact that Ernesto Neto had given no instructions for the visitors' behaviour (clearly, this was part of the script, but never explicitly addressed in the instructions). The instructions provided by the studio to the custodians regarded only reinstallation and repair, and Neto expressed his intentions only in fairly general terms, such as: "I think this piece is very much about a hug," or "Beyond the whole architecture, beyond the whole biological idea, I think there is this point of human psychology: the need to touch." ${ }^{38}$ The measures taken by the museum were limited to a

$3^{6}$ Time-based media installations offer notorious examples of failure due to visitors' interaction. It is not always the artwork that suffers. Sometimes, interactive installations have to be accommodated to meet safety requirements for the public.

37 I am referring here to the art historian Julian Stallabrass, who states that contemporary art museums and in particular installation artworks persuade "an audience to travel to a museum or other site," where there is "freedom in appreciating the purposeless play of ideas and forms, not in slavishly attempting to divine artists' intentions, but in allowing the work to elicit thoughts and sensations that connect with their own experiences," and to get "the feeling of a body moving through a particular space surrounded by huge video projections or work that has weight, fragrance, vibration, or temperature." Julian Stallabras, Contemporary Art: A Very Short Introduction (Oxford: Oxford University Press, 2006), 3 and 17 .

$3^{8}$ See footnote 9 of this chapter. 
few regulations, such as allowing only a certain number of visitors to enter the nave simultaneously, and the instruction that visitors should take off their shoes and leave their bags behind. Furthermore, two large openings in the nave's membrane were appointed as entrance and exit to direct the visitors' trajectories.

In the absence of instructions for the behaviour of the audience, Célula Nave fell prey to both foreseen and unforeseen bodily movements. As Marjolijn de Bakker observed:

At first they were really careful, touching the fabric with care. The turquoise fabric gave you the feeling of being under water and one had to take real big, careful steps to push the fabric to the floor. But when visitors approached the mattress, they jumped onto it and you could see that it was really fun to do that. Especially for children. Sometimes they entered the bubbles where they were actually not allowed. The openings were too small and too much pressure was put onto it. 39

Looking at the underlying scripts for a performance of Célula Nave, the public's playful behaviour could be traced back to the haptic material and spatial design (inviting people to touch the membrane) and the artist's intention to encourage interaction with this installation. As Akrich also observes, the designer of a piece may inscribe a specific form of action, but Neto could not foresee the damage caused by overexcitement when the artwork was in use. The fact is that neither the artist nor the custodians, who encourage the interactive experience with art, provided the visitors with guidelines how to act when inside the nave. All in all, it is not surprising that the current deadlock occurred, as a result of the friction arising between these various interests and the insufficient resilience of the material to the interactive use.

A schematic representation shows the two biographical stages of Célula Nave as discussed above: the "ideal" first stage in which a balance is reached between the various spatial functions and the shifts occurring in the spatial network during the second staging. [See Diagram 9]

In the following section, three different scenarios for the future will be outlined, using the outcomes of the above analysis. It should be noted that, in the course of the research, several attempts have been made to explain 
Diagram 9 Célula Nave: Biographical stages 2004 and 2009. ๑ The author. Image editing: Arienne Boelens.

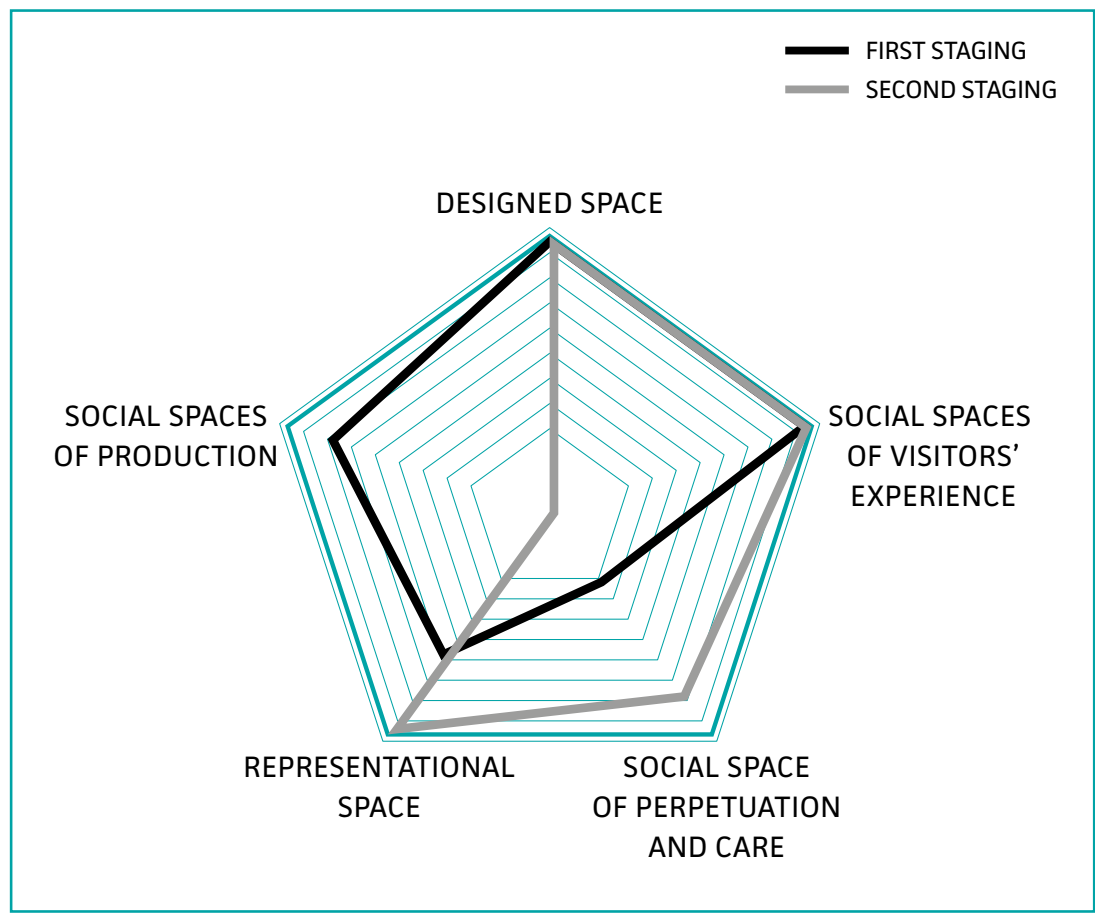

the problem to the artist and his studio, to engage Ernesto Neto in Célula Nave's perpetuation. ${ }^{40}$ Because this approach proved unsuccessful, the scenarios focus on what could happen in the future. The discussion will also include two comparative examples of site-specific installations by Ernesto Neto in the collections of the Tate and MoMA. A third comparative case is a site-specific installation by Pipilotti Rist, in the collection of the Museum Boijmans Van Beuningen.

40 For her master's research project, Carien van Aubel contacted Ernesto Neto's gallery Tanya Bonakdar. The request for consultation was sent to Neto's studio in July 2016 (confirmed by his gallerist). A similar attempt was made by the Head of Collections and Research of Museum Boijmans Van Beuningen, Sandra Kisters, in September 2016, followed by a request I sent to the studio in May 2018. 


\subsection{We Fishing the Time: The Relocation of a Temporary Installation to the Permanent Collection of the Tate Modern}

It proved to be beneficial to make a comparison with We Fishing the Time (densidades e buracos de minhoca) (1999, Tate) to gain insight into Neto's views on the relocation of his site-specific installations to a permanent collection. This artwork was fabricated in Brazil as well and was installed by the artist for the Tate Liverpool Biennial in 1999. After the exhibition, the Tate purchased the installation and moved it to the storage facilities in London, where it became part of Tate Modern's collection. In 2002, staff members of Tate Modern researched the possibility of reinstalling the work in a newly appointed gallery space and conducted an in-depth interview with the artist. ${ }^{41}$

We Fishing the Time consists of several large hanging pods made of the same type of polyamide fabric used in Célula Nave. The pods were suspended from a stretchable structure made of a similar material and attached to the ceiling of the Tate Liverpool's gallery. The pods included various spices and alternated in height; some touched the ground, and others reached halfway to the pillars of the room. In an interview, conducted by Tanya Barson of the Tate's conservation department, Neto describes the installation process and explains the meaning of two different sociocultural production contexts:

One part [of the title] is in English, the other part in Portuguese. It was calculated and sewn in Brazil but the whole putting it up was there [in Liverpool]. I didn't know if [the structure] would hold everything, I mean I was sure that it would, but it was extremely emotional. It was one of the most emotional pieces I have ever made, because when I work with this kind of materials, which are the spices, it is very colourful, a very strong smell. When you work with these things hanging, not touching the ground, it becomes even more emotional. [The] first installation in general is part of the creation, for example, why this [pod] is bigger than that one, why the yellow one is here and the brown one there. I decided on that in that moment [...], the sensible decisions [are made] in the place. ${ }^{42}$

41 For all information of this example, I am indebted to the staff members of the Tate's conservation department, who kindly provided access to the archives and an interview conducted with Ernesto Neto in 2002.

42 Interview conducted with Ernesto Neto by Tanya Barson, Conservation Department of Tate, on 18 February 2002 (Archive of Tate Conservation Department). 
Regarding a future reinstallation of We Fishing the Time in the Tate Modern, the artist stated that staff members who had assisted with the installation in Liverpool, or one of his own assistants, could perform the preparatory work. He preferred to be present when the work was reinstalled for the first time in a different gallery space. When asked about using documentation for future iterations, he answered that preferably a staff member would learn from his assistant "a kind of sensibility of understanding how to do it." 43 On future occasions, this staff member could then transfer the knowledge obtained from practical experience to others. Documentation was only considered an option for future staging when this concerned a recording of the installation process, but not a guideline with elaborated instructions.

From those statements, it can be reasoned that Neto was willing to delegate to future custodians the "emotional moment" of deciding on the exact spatial arrangement and height of the individual parts of the installation, provided that they have learned "how to do it." This would mean a transfer of knowledge from the artist or his assistant to the custodians, who would then be able to act in a sensible way and in accord with the conditions of a given space.

Neto's viewpoint calls to mind the concepts of "embodied knowledge" and personal transfer of "understanding how to do it," as developed in the conservation literature in recent years. With respect to time-based media and other performative art, Joanna Phillips, for example, points out that, if in such cases embodied knowledge is not transferred to custodians, there might even be the danger of misrepresenting the artwork's identity. She states that "the institution may not be able to implement essential aspects of the work and inadvertently create a distorted experience of it." 44 In the case of site-specific installation artworks, the connectivity with the surroundings is important, and given the variables of the "site," custodians need to know how to adjust the work to new circumstances. As shown above, the museum's technical staff took a different stance than the director envisioned for the reinstallation of Célula Nave. A solution to this dilemma could be to establish a knowledgeable network around site-specific works of art.

43 Interview with Ernesto Neto.

44 Joanna Phillips, "New Practices of Collecting and Conserving Live Performance Art at the Guggenheim Museum," VDR Beitrage 1 (2018): 127. See also Renée van de Vall, "The Devil and the Details: On the Relevance of Conservation Practice for the Theory of Contemporary Art and Vice Cersa," British Journal of Aesthetics 55: 3 (2015), 230. 


\section{Establishing Knowledgeable Networks around Performative Installation Artworks}

An ideal scenario for the perpetuation of Neto's site-specific installations would imply a continuous transference of knowledge about the artwork's manifestation, from one person to another. Conservation researchers have pointed out that documentation strategies are part of the wider conglomerate of actions taken for the perpetuation of contemporary artworks (as discussed in chapter 3 ). However, documentation is not always considered the most effective strategy in the case of performative - and for that matter, site-specific - installation artworks. The personal transfer of knowledge can be added as an aid to safeguard open-ended installations that were not created with the purpose of being accessioned for a collection. As, for example, Tina Fiske observes, documentation is usually considered a way to record "objective" facts of the work "on which future decisions can be based." However, when there is ambiguity in "what it is exactly that a collection commits to" a documented set of instructions might be less self-evident as a conservation strategy, given the uncertainties about what is intended by the artist. ${ }^{45}$ Moreover, at the moment of acquisition, it is not always clear how the installation should perform on future occasions or what kind of documentation or installation instructions would be needed. Therefore, Fiske suggests that personal accounts of earlier manifestations or experiences with other works from the same artist might offer a more suitable alternative. In the case of Célula Nave, Fiske's observation is beneficial for understanding what happened during the transition from one stage to another and the role of the personal account of the staff vis-à-vis the position of the poles. However, their accounts were insufficiently discussed with the artist or internally, and it was unclear what would happen during the second staging.

Laurenson and Van Saaze have made a comparable statement in their publication "Collecting Performance-Based Art: New Challenges and Shifting Perspectives." ${ }^{\text {6 }}$ The authors elaborate their argument around the work of performance artist Tino Sehgal, who prohibits any form of documentation. His live works in museums leave the visitor to an unexpected encounter with one or more performers (never the artist himself). The

46 Pip Laurenson and Vivian van Saaze, "Collecting Performance-Based Art: New Challenges and Shifting Perspectives," in Performativity in the Gallery: Staging Interactive Encounters, ed. Outi Remes, Laura MacCulloch, and Marika Leino (Oxford: Peter Lang, 2014), 28-41. 
performers present themselves to the public, for instance, while singing, shouting, or posing questions to the visitor. The performers are either instructed by the artist, or they pass on their knowledge from memory, from one performer to another. The authors explain that Sehgal's works can be "collectibles," because, despite the nonmaterial characteristic of the performance, there is a set of regulations (such as a limited edition of the performance or its duration) that integrates the artwork into a museum structure. To a wider group of performative artworks, building knowledgeable networks might apply as well as a productive strategy to keep the artworks alive, especially if characteristics are not easily captured in the documentation systems at hand. The final point the authors make is that "maintenance" in this context can be conceived in terms of an "active engagement" with the "networks of relationship" established around the work of art. 47

Although Laurenson and Van Saaze's argument has been developed for performance artworks, the concept of establishing knowledgeable networks seems to apply to site-specific installations, too, in particular to the functions of site specificity that are performative and depend on the context of display. For this type of art, it may be beneficial to establish networks of stakeholders who are well informed about the work and/or were involved with past iterations, and who can "replace" the artist during the process of staging the installation in a new context.

Because of the absence of detailed instructions in respect to reinstallations of Célula Nave and the visitors' behaviour, as well as the lack of interest on the part of the artist, the Museum Boijmans Van Beuningen had to develop its own display strategy in 2009 and is confronted with urgent questions for the future.$^{48} \mathrm{~A}$ knowledgeable network was started by conservator Carien van Aubel, who carried out a master's research project in 2014 and established a network of students, conservators, university teachers, and museum staff members around Célula Nave. ${ }^{49}$ Extensive scientific research into the material composition was carried out, and a condition survey

47 Laurenson and van Saaze, "Collecting Performance-Based Art," 39.

48 For example, the artist's studio provided general instructions, e.g., the floor plan, but no detailed information about the amount of stretch put on the fabric. As a guideline for future staging, the museum recorded the reinstallation process. See footnote 9 of this chapter.

49 Carien van Aubel, "De Ontrafeling van Gebreid Polyamide. Onderzoek naar het ontstaan van mechanische schade bij kunstwerken uit gebreid polyamide" (master's thesis, University of Amsterdam - Conservation and Restoration, 2014). 
Figure 15 Students and teachers of University of Amsterdam, Conservation \& Restoration carry out a condition survey of Célula Nave in the Museum Boijmans Van Beuningen, 31 March 2014. Photo by the author.

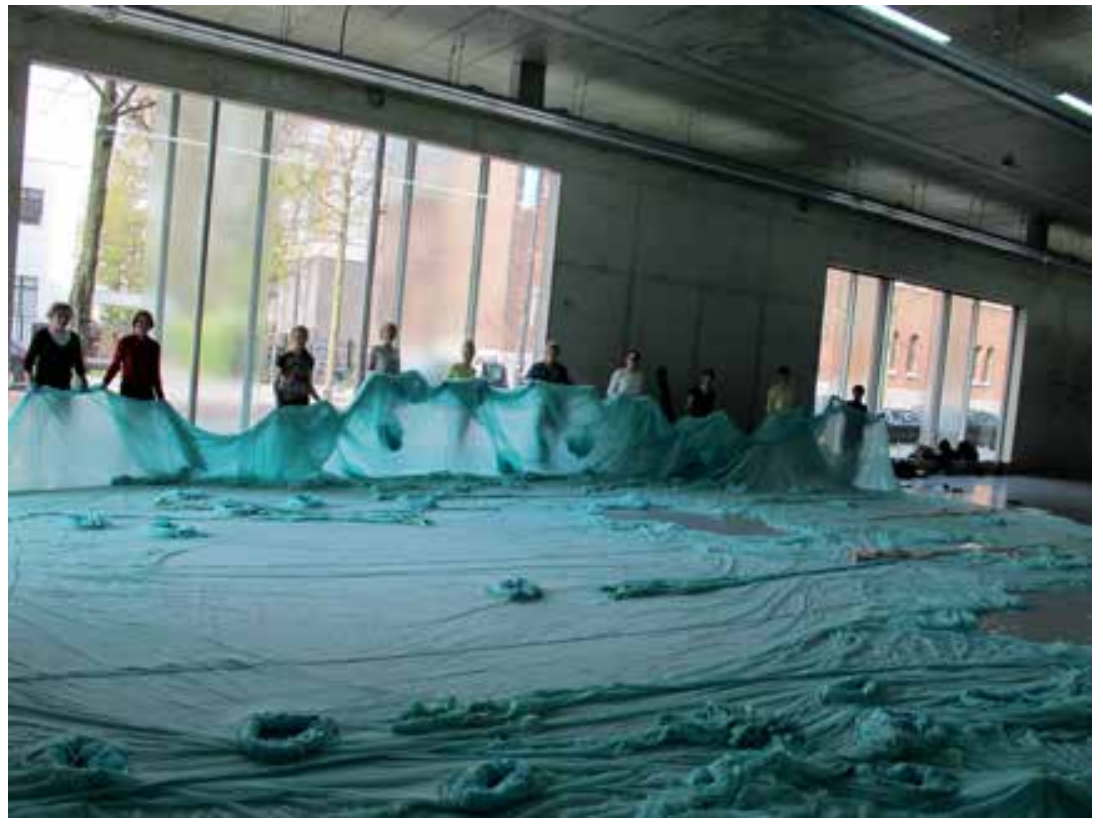

of the nave was made..$^{\circ}$ [Figure 15] In addition, preventive conservation measures were taken, such as proper storage conditions and documentation, and last but not least, the stretch properties of the polyamide fabric were investigated. [Figure 16, 17] It was concluded that - after restoration - the artwork might survive three to five more display periods before the fabrics would lose colour and elasticity. ${ }^{51}$ In my discussion of the three scenarios for Célula Nave's perpetuation, I will gratefully make use of Van Aubel's research project, while the main focus will be on the shifts occurring in the spatial network. Each option is connected to various places of production, the social space of the visitor's interaction, and the representational space of the Museum Boijmans Van Beuningen. The respective scenarios have been visualized in a diagram, explaining which elements of the network

$5^{0}$ The condition survey was carried out on 31 March 2014. The nave was spread out on the ground floor of the Bodon Gallery. The group consisted of around ten students and teachers, external conservators and museum staff, and myself.

51 Van Aubel, "De Ontrafeling van Gebreid Polyamide," 83-84. 
Figure 16 Conservators Emmy de Groot and Carien van Aubel make an assessment of damages of the membrane of Célula Nave, 31 March 2014. Photo by the author.

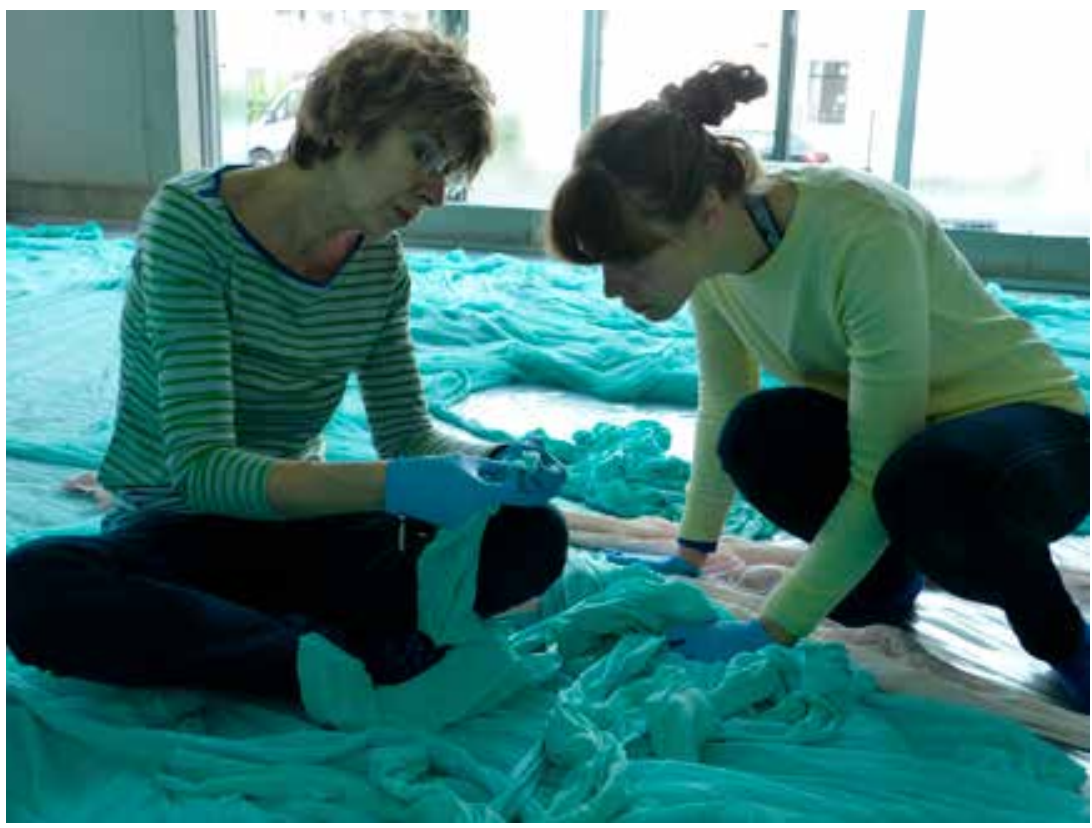

Figure 17 Preventive conservation measures are taken for future storage of Célula Nave, 31 March 2014. Photo by the author.

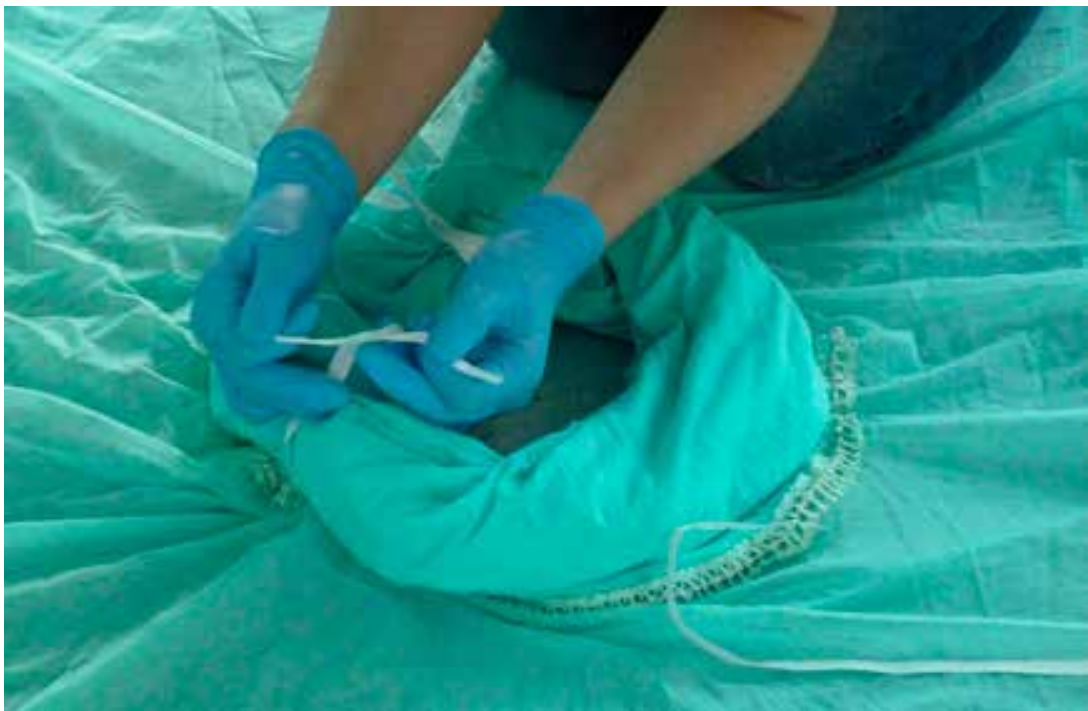


Diagram 10 Célula Nave: Three options for future scenarios. ๑ The author. Image editing: Arienne Boelens.

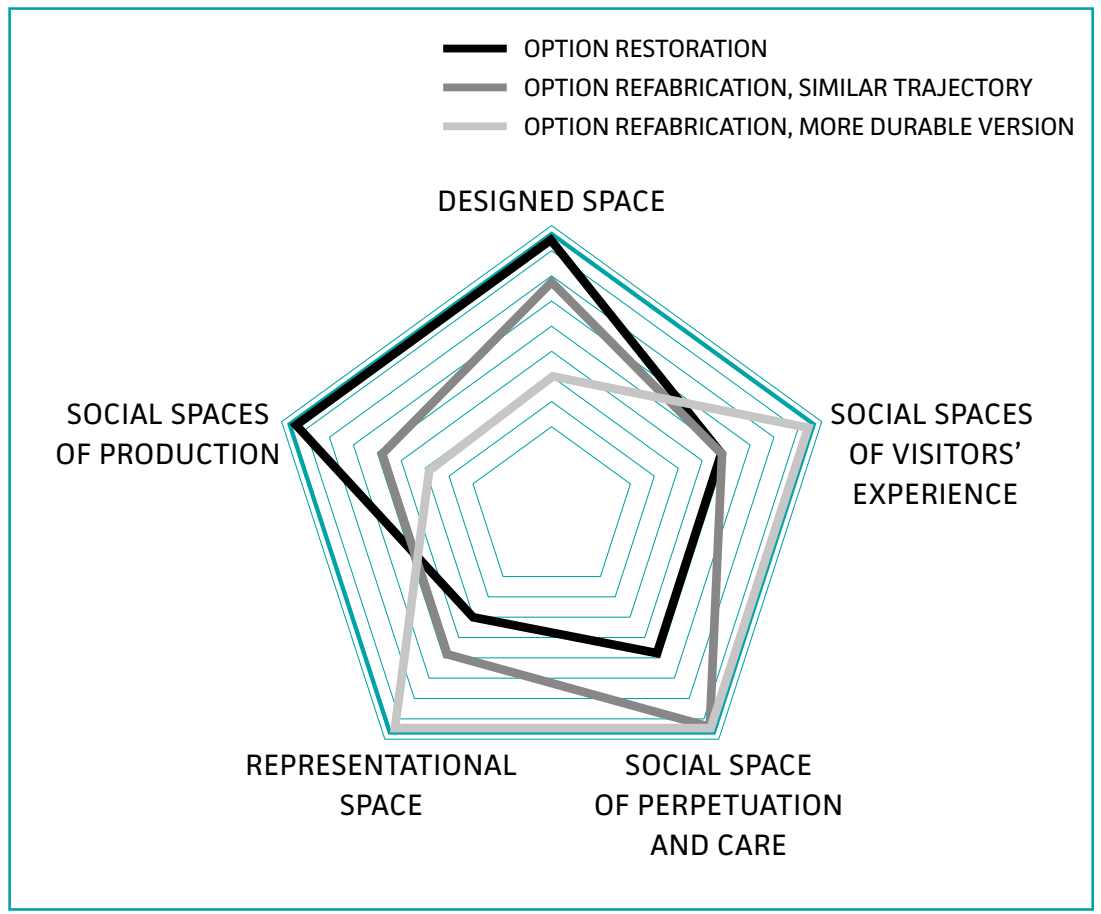

of spatial functions would be activated when the scenario was followed. [See Diagram 10]

\subsection{Option 1: Restoration of the Original Artwork}

Van Aubel's research shows that restoration of Célula Nave is a feasible option, because a spare piece of the original fabric could be inserted into the ceiling, covering the large tear running through it, which had caused the presumed state of total loss. Her recommendations include a removal of the old rigid stitches and the repair of the ladders and holes with a kind of thread that gives way when pressure is put on the membrane..$^{2}$ The option of restoration was also suggested by the artist, as confirmed by a document in the archives; for that same reason, spare pieces of fabric were provided

$5^{2}$ Replacement of the rigid seams with more flexible stitches would prevent new tears from running next to the old ones. 
by the studio. A restoration could be performed either in the museum or in a nearby conservation studio, keeping Célula Nave close to the production space of the Bodon Gallery during its first iteration.

The overall spatial design would not considerably be changed after restoration, although an extra layer of fabric would affect the artwork's aesthetics. Besides, as Van Aubel explains, the double layer would diminish the stretch properties of the membrane and increase residual stress at places where point loads are most intense (i.e., where visitors push the fabric to the floor). Especially the area around the pink mattress would be subject to this pressure. Hence, Van Aubel suggests strengthening the junction between the arms and the ceiling with a protective layer. This way, the restoration would not be limited to adding an extra layer of fabric to the ceiling but involve a reinforcement of the entire structure. The conclusion of her research is that a restoration would prolong the lifespan of Célula Nave with three to four exhibition terms. ${ }^{53}$

From the perspective of Célula Nave's site specificity, a restoration would not directly affect the spatial design of the artwork (except for the changes in translucency and stretch of the fabric). However, the experience (social space) would be reduced, because visitors would be instructed to behave cautiously and would, for example, no longer be allowed to bounce on and around the mattress. As Van Aubel furthermore proposes, fewer visitors should have access to the nave; jewellery and watches should be taken off, and visitors should wear protective gloves and shoes. To safeguard the artwork, more guards and conservators would be needed to instruct the public and monitor their behaviour. In short, not only would the aesthetics and perception be affected but also the physical interaction with the artwork. Visitors would become more conscious of the damage they might cause and suppress spontaneous movements, diminishing the experiential values of the social space and the representational space, attributed to Célula Nave by the museum and visitors at previous moments of display.

\subsection{Option 2: Remake by a Textile Factory in Brazil and the Artist's Studio}

According to the instructions provided by Neto's studio, the artist would agree to a remake, although restoration was the preferable scenario. ${ }^{54}$ Apart

53 Van Aubel, "De Ontrafeling van Gebreid Polyamide," 36-38.

54 Report by Jaqueline Rapmund, 10 September 2009. Archive of Museum Boijmans Van Beuningen. 
Figure 18 Navedenga (1998/2010) by Ernesto Neto. Collection Museum of Modern Art, New York. Digital Image $\odot 2020$ Museum of Modern Art, New York/ Scala, Florence. $\odot$ Ernesto Neto.

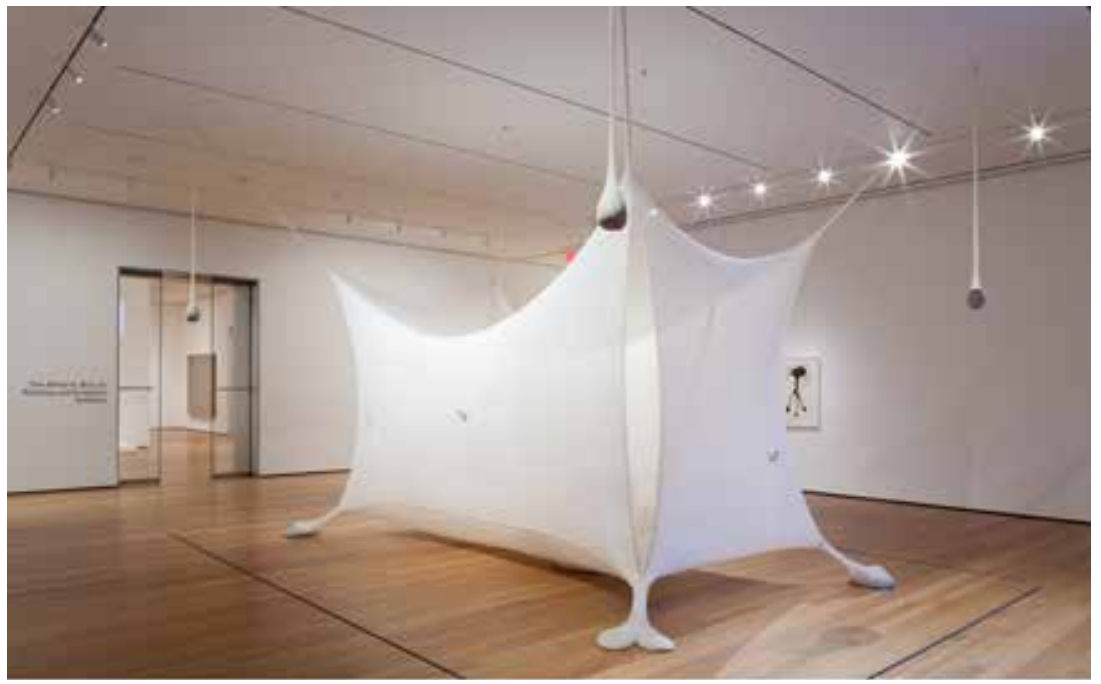

from practical issues, such as the considerable costs involved, this option raises a number of questions in view of the network of spatial functions. For example, no pattern for the spatial design of the nave exists. Should and could such a pattern be produced in hindsight? And most relevant for this study, where and by whom should a refabrication of the nave be executed? Should the same trajectory be followed as before? Earlier in this chapter, we have seen that the artist deems places of production important for the meaning production of his art. Could we thus speak of an "authentic" production place?

Van Aubel's research clarifies that the preproduction process of Célula Nave started in the Rosett factory in Brazil, where the polyamide fabric was woven and knitted. 55 The artist's studio continued the production by modelling and sewing the large pieces together, and the installation was finalized in the large Bodon Room. Hence, three different production places were involved: two in Brazil and one in the Netherlands. And, as we have seen before, the artist attributes meaning to the locations of production. In the following comparative case, the trajectory of a remake will be followed, 
taking a closer look at the option of a refabrication in Brazil under supervision of the artist.

The installation Navedenga (1998) consists of a similar, though less complex, spatial construction as Célula Nave, and belongs to the collection of the Museum of Modern Art, New York. [Figure 18] The membrane is white and made of a similar type of polyamide fabric. The tent, or nave, is accessible for visitors, who are allowed to move around in the interior of the nave. The installation was first shown in the Tanya Bonakdar Gallery in New York in 1998. In contrast to Célula Nave, the artwork was designed and created for a gallery space and could thus be considered a moveable installation artwork instead of a site-specific installation. And yet, as photographs show, the light conditions of the Tanya Bonakdar Gallery contribute to the translucency of the fabric, similar to Célula Nave installed in the Bodon Gallery. Daylight falling in through the skylights enhanced the experience of the materiality and spatial design of the installation during its initial performance.

In 2007, Navedenga was acquired by MoMA and was later shown in a different spatial context: the white cube gallery of MoMA, provided with artificial lighting, and with a ceiling that was lower than that of the gallery in which the artwork was first presented.

In 2010, MoMA planned to put Navedenga on show. From interviews conducted with MoMA's freelance conservator, Margo Delidow, and the exhibition designer and production manager of MoMA, Eric Meier, I learned that, in agreement with the artist, it was decided not to reinstall the original: the work had suffered from the initial display and would be damaged even further when people strolled around the nave. ${ }^{5}$ Ernesto Neto was in charge of the refabrication, and the accounts of this process are instructive for what might happen with a remake of Célula Nave.

In comparison to Célula Nave, Navedenga is much smaller (approximately $370 \times 450 \times 640$ centimetres), and its refabrication can be considered less complex. The membrane, made of a similar stretchable, white polyamide fabric as that used in Célula Nave, encloses only one interior space. The nave is suspended from the ceiling by means of four "arms" folded over hooks and with pods at their tail ends, filled with river sand. Together with four "feet" placed on the ground, the arms hold the construction in balance while people walk around. A big, soft bollard (filled with styrofoam balls) is placed in one of the side compartments, and in the middle of the nave a large pod is suspended, filled with cloves. 
Meier and Delidow note that Neto could not purchase the original type of fabric from the Rosett factory and had to accept the "next best thing, a kind of aerospace fabric." This material has a slightly different appearance, but its stretch properties were acceptable to the artist. A team of coworkers of Neto's studio fabricated two exhibition copies, and his assistant installed one of the remakes for the venue. MoMA keeps the original Navendenga in storage as a reference object that should not be exhibited again.

When Navedenga was on show at the MoMA, the museum's staff members had to take several measures to stabilize the structure on the slippery, wood-waxen floor of the gallery. One solution was to position tennis balls, cut into halves, on the inside of the feet to prevent them from sliding. Another adjustment regarded the position of the arms. Beacuse visitors liked to touch them when they were waiting in line before entering the installation, the artwork was put at risk. As the conservator states: "People loved it and touched it, any chance they got. We put the arms higher, so the people could not knock them anymore." These were relatively minor adjustments meant to accommodate the installation to the conditions of the gallery space, and they were not discussed with the artist. According to the conservator, Neto would agree as long as the work's visual appearance was not affected: “[Neto] is pretty easy-going, only when you would change something visible this would have bothered him." 57

\section{Navendenga's Network of Site-Specific Functions}

Regarding the functions of site specificity in a refabrication of Navedenga, I would like to make a few comments. First, the reproduction process took place in the same geographical region and (almost) the same production spaces as the original version. Apart from the symbolic meaning of the Brazilian factory and the artist's workshop, which resonates with Lefebvre's notion of representational space, the craftsmanship was similar, which would be in accord with Lefebvre's notion of shared "competences" of a given social production space. As Glenn Adamson and Julia Bryan-Wilson also observe in Art in the Making: Artists and their Materials from the Studio to Crowdsourcing, it may be important for the fabrication process of contemporary works of art that fabricators and artists are located in the same geographical region. This way, they can develop a strong bond, 
and in many cases, "artists do not simply outsource production to these firms, but remain actively involved throughout the process. ${ }^{m 8}$ Regarding Navedenga, the repetition of the production process in Brazil sets the remake alongside the original artwork, and in that sense, I belief that the original geographical region could be considered an authentic production place. A significant detail in relation to a possible remake of Célula Nave is that no pattern was used for the reconstruction of the nave, as the production manager stated during the interview. ${ }^{59}$ After the work moved to MoMA, Navedenga was installed by one of Neto's assistants, not by the artist himself. This marks a deviation from the original production, which, in addition to the changed materiality of the nave, preludes a shift in the site specificity of Navedenga.

My second comment addresses this shift in site specificity, after the artwork was obtained and staged in the white cube gallery of the MoMA. The ceiling of the space was lower than in the Tanya Bonakdar Gallery and it had no skylights, turning the transparent membrane into a more opaque cubicle form, although additional spotlights helped to overcome this problem. An even more fundamental challenge concerned the "social space" of the visitors' experience. Every day of the week, MoMA welcomes a large number of visitors, including school classes, which poses serious risks to the delicate fabric. To adjust the artwork to these circumstances, the spatial design of Navedenga was slightly modified. The tail ends of the arms were pulled up higher by repositioning the four hooks in the ceiling, so that the public would no longer be able to touch the pods. In addition, safety measures were taken by adding tape around the nave to keep the audience at a distance. Furthermore, a number of museum guards were positioned in the room, giving instructions to the visitors when they became too excited. As Margo Delidow recalls:

I remember that people would laugh. It wasn't serious to go in. It was something about the piece that made people happy. It was a fun house to jump around, the aesthetic appearance. That is the whole meaning of the work. ${ }^{60}$

58 Glenn Adamson and Julia Bryan-Wilson, Art in the Making:Artists and Their Materials from the Studio to Crowdsourcing (London: Thames \& Hudson, 2016), 167.

59 According to Eric Meier, "Neto does not use any computer. He does everything by hand." Interview with Eric Meier, conducted on 8 July 2012.

60 Interview with Margo Delidow, conducted on 8 July 2012. 
Ernesto Neto's view on the adjustments is unknown, but according to the conservator, he would agree with measures regulating the visitors' behaviour. In this respect, it is worth taking note of a statement he made on the occasion of the Tate's acquisition and presentation of We Fishing the Time. Although Neto is in favour of physical interaction, he was dissatisfied when visitors touched one of his other installation artworks in an unintended manner. Referring to the finger imprints on the fabric or names and hearts scribbled onto the surface, he expresses his reluctance:

I have to say I prefer it if you don't touch it. I think this is a piece much more to touch with your eyes, your nose, you know, with the senses. ${ }^{61}$

Neto's statement that "touching it with your eyes" would be preferable to physical interaction casts a different light on what I have earlier said about the artist's intent towards the spatial design and social space of Célula Nave - that is, to perceive the artwork through a cheerful physical experience. This point was also acknowledged by the custodians of the Museum Boijmans Van Beuningen as one of the main values of the installation, and in that respect, it also denotes a representational function of Célula Nave (as elaborated above). Does this mean that my earlier understanding of the meaning of the work should be reconsidered? In reference to Navedenga, Neto declares:

I don't know if the idea is play, exactly. Navedenga fully exists by itself as sculpture which can simply be looked at like any traditional sculpture, but it is in the interaction with people that it shows other levels of itself. Interaction provides a more intimate relationship between the artwork and the viewer. When people climb into new pieces for the first time, I watch new aspects of the works being born. Also, when someone decides to get inside of a piece, they have another level of experience through the atmosphere created by these unexpectedly organic bodies. ${ }^{62}$

Following the proposed model, I would argue that the artist's statements incite a breach, shifting the focus from the interactive experience (social space of perception) to the function of the spatial design and aesthetics

61 Statement made by Ernesto Neto during an interview conducted by Tanya Barson, Tate Conservation Department. See footnote 42 of this chapter.

62 Interview with Ernesto Neto conducted by Bill Arning on 1 January 200o. https://bombmagazine.org/articles/ernesto-neto/. 
of the installation. What matters most is the visual effect of the visitors' bodies, reshaping the form of the installation through cautious, "dancing" movements. In fact, Neto may have never intended the excitement of play and entertainment, or as he stated earlier, the "idea of a risk." ${ }^{63}$ In this respect, it is interesting to note that Neto positions himself often as a sculptor, whose works fit well into the ideology of modernism and artists such as Calder and Brancusi. ${ }^{64}$

In brief, the variation in statements suggests that the artist may intend different things under different circumstances. This again touches upon the absence of clear instructions, which the artist never stipulated in regard to the visitors' behaviour. When applied to the examples of Navedenga or Célula Nave, Neto may not have foreseen the consequences of physical interaction and may have preferred a minimum of physical contact from the moment it became evident the artwork would suffer, reducing the interaction to the extent that visitors' movements contribute only to a visual, aesthetic sensation.

Transposing the above findings to a remake of Célula Nave, it is feasible that Ernesto Neto would prefer a remake in Brazil under his supervision following the same trajectory as with Navedenga. This way, the production practice and sequence of production spaces would be continued and the production network would remain more or less the same. However, the new site specificity of Célula Nave - as a "permanent" work of a museum collection - would need adjustments to the social space of the visitors' experience, regulating their behaviour more strictly. Arguably, the museum staff members would be more involved than with the original version. Last but not least, the longevity of the remake would be a point of discussion in this scenario as well. The problem of damages, due to interactive movements of the visitors, would not be entirely solved. As Meier and Delidow observed with the display of Navedenga, an exhibition copy "will have its lifespan" nonetheless, because the material would lose its elasticity over time and it would suffer from the visitors' bodily interaction. ${ }^{65}$ Even if Célula Nave was refabricated as is suggested here, the copy would not last forever. This

63 Statement by Ernesto Neto on the occasion of the reinstallation of Célula Nave in 2009, https://vimeo.com/124817865.

64 See, for example, the following interviews with Ernesto Neto: by Bill Arning in 2000 (see footnote 62 of this chapter); by Tanya Barson, Tate Conservation Department, in 2002 (see footnote 61 of this chapter); by Nathan Gulick in 2007 (see footnote 1 of this chapter); and the presentation by Ernesto Neto himself at Spaces of Transformation: Edges of the World in 2012 (see footnote 23 of this chapter).

65 Interview with Margo Delidow, conducted on 8 July 2012. 
brings into focus the third option for the work's perpetuation: a relocation of the production process to another geographical region, to produce a more durable version of the nave.

\subsection{Option 3: Remake by Another Fabricator Aiming at a More Durable Version}

Although it would be a radical solution to overcome the current deadlock, the fabrication of Célula Nave could, in theory, be outsourced to a factory located in a different geographical region - to DSM in the Netherlands, for example, a company specialized in polyamide fabrics. Whereas the remake of Navedenga was fabricated from a similar type of material, it is not unthinkable that a stronger type of fabric is available on the market. If the polyamide fabric was less susceptible to wear and tear and retained its elasticity for longer, the lifespan of the physical object could be extended.

A condition for this option is the availability of substitute material, meeting the same criteria as the original, in other words, respecting the aesthetics in colour and translucency as well as the stretch properties when the nave is suspended from the aluminium poles and is in use. A specialized company could deliver the fabric, leading to two different scenarios: either the artist's studio could create the basic forms of the nave or this task could be assigned to another sewing workshop. As for the final stages of production, the same process as with the original could be repeated, when the nave was assembled in the Bodon Room by stitching the large parts together, either by the artist's coworkers or by other craftspeople. For the finalization and authorization of the installation, the presence of the artist would be needed, and Neto would again be able to decide on the final stretch and shape of the installation.

This option would have considerable impact on the social spaces of production and the production networks involved. Relocating the production to another geographical and sociocultural region would influence the meaning of the artwork, according to the artist's statements. On the other hand, Neto himself has been in favour of a liaison between different geographical contexts, as expressed, for example, in his explanation of the bilingual title We Fishing the Time (densidades e buracos de minhoca). Given the above observations, I would argue that a remake by another fabricator could be a point of negotiation between the custodians and the artist, weighing the advantages of a stronger substitute material against the 
shift in the production places when the nave would be produced partly or entirely in a different geographical region.

The scenario of a remake with stronger material opens up the vista of an expansion of the social space of the visitors' experience, in the sense that more physical interaction would be allowed than with a restoration or a remake with similar materials as the original. In fact, this option was suggested by the museum's head of the technical department, Wout Braber. ${ }^{66}$ The main argument for suggesting this option was the technical department's practical experience with a comparative installation on permanent display in one of the stairways of the Museum Boijmans Van Beuningen: Pipilotti Rist's Let your hair down (2009). [Figure 19] This interactive installation is composed of a giant network of polyamide ropes, with similar stretch properties as the polyamide fabric of Célula Nave; however, the ropes are much thicker and stronger than the stocking material used for the nave. Visitors can climb into the net and, when reaching the top level several metres above the ground, they enter a "safety net" suspended approximately one metre underneath the stairway's ceiling. Here, they can relax and watch video artworks created by Pipilotti Rist and other artists. As Braber explains, the "net" is checked and maintained regularly:

Once in a while we have to tighten it again when the construction becomes feeble. We have left spaces at the sides and the company who installed the artwork tightens the ropes until the right tension is recovered. Obviously, there is a limited number of times one can do this, it's the same story as with Célula Nave. The more times you do it, the more the structure will lose its stretch. And the more visitors are using it, the sooner material fatigue will occur. ${ }^{67}$

His statement suggests that, even with a more durable version, the lifespan of Célula Nave would not be infinite, and regular check-ups would be needed. On the other hand, it would allow visitors to stroll the nave more freely and without too strict regulations regarding their behaviour. At a conceptual level, this would return Neto's original "idea of risk" to the experience, without putting the material object too much at risk.

In terms of the site-specific functions of social space and representational space of Célula Nave, this option would restore these functions to a greater 
Figure 19 Let Your Hair Down (2009) by Pipilotti Rist, installed in the museum's stairways. Collection Museum Boijmans Van Beuningen, Rotterdam (MBVB). Acquired with the support of Han Nefkens H+F Mecenaat en BankGiro Loterij. Photo: Maarten Laupman. Courtesy photographer and MBVB.

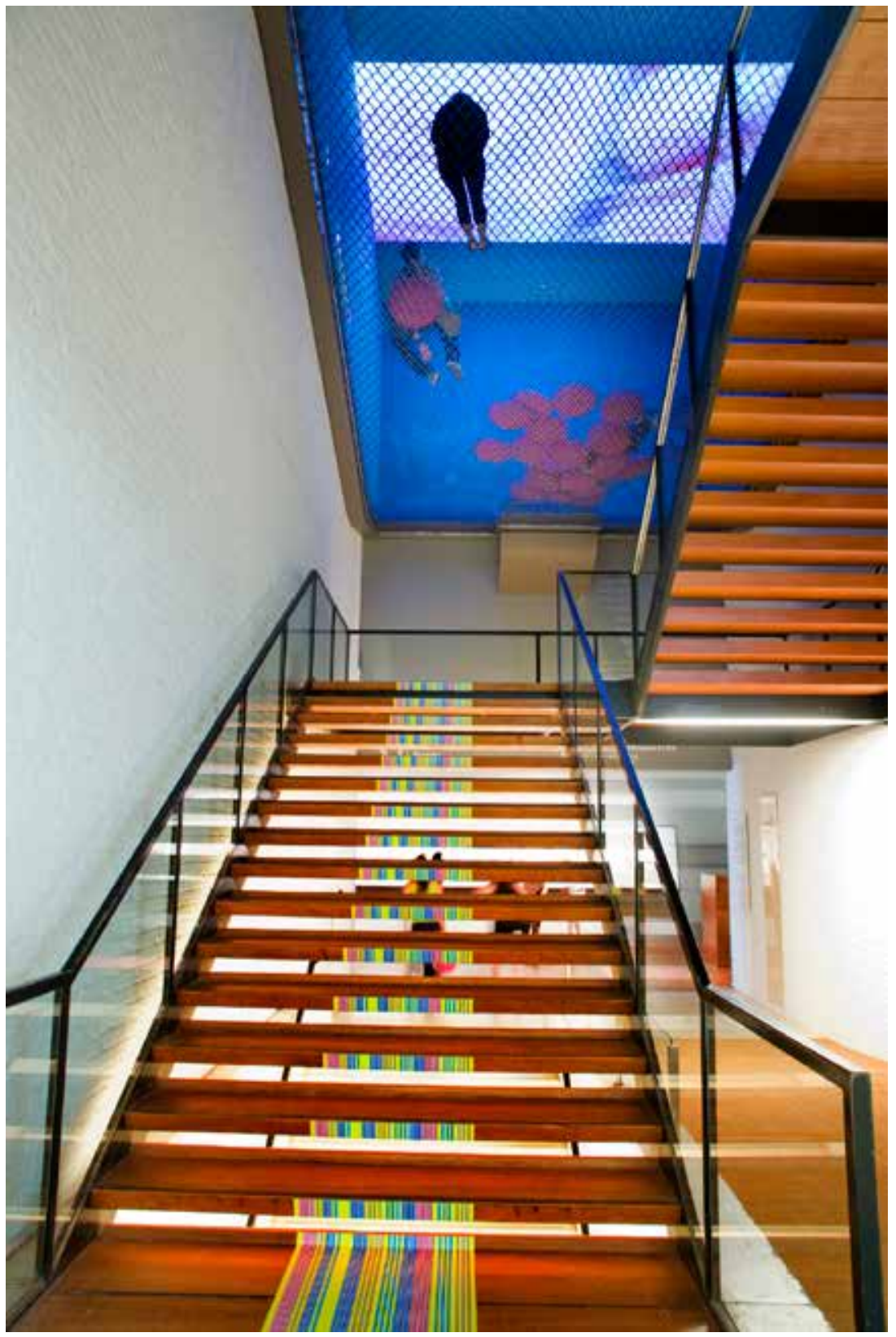


extent than in the case of the two other options discussed above: the installation would once again fulfil its function of experiential, interactive installation and would represent the values attributed to the commissioned and accessioned installations created for the Bodon Gallery.

Last but not least, the refabrication with a stronger material and carried out primarily under supervision of the museum staff would anchor the artwork in the social and professional space of the institution. It would activate the social space of perpetuation and care, to an even greater extent than with a restoration, because the staff members would engage with in-depth research into the material composition regarding the function of the spatial design of the artwork, and the actions of finding an appropriate fabricator. To effectuate this option, first and foremost the communication with the artist or his studio needs to be re-established. More than in the case of the other two scenarios, this option would extend the lifespan of Célula Nave, replacing its temporariness with relative "permanency," and reinvigorating its function of representational site specificity.

\subsection{Conclusion}

This case study highlighted the dilemma of acquiring a temporary, interactive installation for a permanent museum collection. The current state of total loss was first analysed as a friction (occurring during the second iteration) between the visitors' interaction with the spatial design of the artwork and the delicate, stretchable material of the nave. On the one hand, the aesthetics of the material and spatial design were identified as agents for the meaning production of Célula Nave; on the other hand various site-specific functions were considered agents as well, specifically those intertwined with the production processes at various locations and the experience of the work in the museum room. Using the conceptual model for site-specific installation art, I analysed the complexities of this network and was able to trace the main causes of friction. As for the future life of Célula Nave, I proposed three possible scenarios, taking into account that the production place is not a neutral space for Ernesto Neto, nor is the Bodon Gallery considered an impartial gallery space by the staff members of the Museum Boijmans Van Beuningen. A significant feature of the museum's representational space is attributed to this gallery in particular, where the public is provided access to interactive, experiential installation artworks of the collection. The conclusion was drawn that, although Célula Nave's lifespan could be prolonged with several exhibition terms (by means of 
a restoration or a remake with similar material), this would be limited. Only the use of a more sustainable fabric would allow for a genuine playful interaction with the artwork in the future.

That said, the museum may have to reconsider the functions of representational space and the social space of the visitors' experience for any kind of decision. In my analysis, I propose that Célula Nave's physical construction was the vehicle for an artistic script geared towards the use of the artwork, in other words, to touch the fabric of the nave with hands and feet. However, the consequences in the long term were not foreseen, and the artist did not provide instructions (or scripts) for visitors' behaviour. Nor did the museum interfere when things got worse during the second iteration. Assuming that the intended script was followed with a restoration or remake, the experience would still be limited if a similar fabric was employed. Interestingly, the artist nuanced his own view by stressing the visual experience, "touching the artwork with your eyes," at later instances. In brief, the case study exemplified the many uncertainties that may arise in the course of the biographies of "unruly objects" (Domínguez Rubio) - not least because

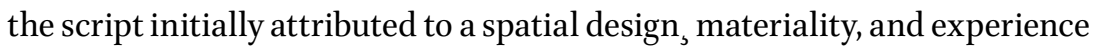
of the work of art cannot always be followed when the distance between the initial and later iterations grows.

Célula Nave would gain a new form of site specificity if custodians would directly be involved in the processes of perpetuation, particularly in the options of a restoration or a remake by another fabricator. Those options would anchor Célula Nave in the institutional practices and policies, identified as the social space of perpetuation and care. In particular, the latter option would bring about the ethical question of "authenticity" of the production place. The Brazilian production practice was identified as a key factor to the meaning of Célula Nave, which I observed also for other site-specific installations of Ernesto Neto (We fishing the time and Navedenga). To relocate the production process to a factory of more durable fabrics would have its advantages but might cause a geographical distance from the original production places. Transposing the entire production to the geographical region of the museum, would turn Célula Nave even more into an artwork that represents the site specificity of the Museum Boijmans Van Beuningen. Whether this would be a justified decision remains to be seen and deserves further research. 


\title{
5 Jason Rhoades's SLOTO
}

\author{
Reactivating Site Specificity and the Social Space of \\ Perpetuation and Care
}

Keywords: popular culture, artistic intention, cocreation, curatorial intervention, Jason Rhoades, Dieter Roth

"If you know my work, you know that it is unfinished."

Jason Rhoades ${ }^{1}$

This chapter is dedicated to Jason Rhoades's SLOTO. The Secret Life of the Onion (2003), a complex, multilayered, site-specific installation artwork in the collection of the Van Abbemuseum. [Figure 2o] It introduces the problem of perpetuating a site-specific installation that includes processes of growth and transformation, not only in content but also in form. Museum professionals are often confronted with profound questions in order to keep processual artworks alive and sometimes need to make radical decisions when reinstalling the work in different contexts than foreseen by the artist. Comparative examples are Dieter Roth's Garden Sculpture (1968-1996) and Jason Rhoades's P.I.G. (Piece in Ghent) (1994).

The case study takes two problems as a starting point. The first relates to the space for which SLOTO was created, a "project space" located in the museum's basement. Because this space is no longer available for exhibitions, the installation was relocated to a different gallery for a new exhibition term (2011), to which the spatial design was accommodated. Secondly, Jason Rhoades was usually closely involved when his artworks

1 Statement by Jason Rhoades, recorded in: Ingrid Schaffner, “Jason Rhoades, Four Roads: A Case Study of Contemporary Art and Conservation," VOCAJournal (9 November 2015): unpaginated. https://journal.voca.network/jason-rhoades-four-roads/.

Scholte, T., The Perpetuation of Site-Specific Installation Artworks in Museums. Staging Contemporary Art. Amsterdam: Amsterdam University Press 2022 DOI: 10.5117/9789463723763_CHO5 
were reinstalled. However, the artist unfortunately passed away in 2006 and could no longer be consulted. In this chapter, I discuss the preparatory process and the role of Rhoades's sketches and notes for the initial iteration, which can be considered a "script" for the artwork's materialization. During the second staging, a radical shift occurred in the network of site-specific functions. It will be argued that the exhibition curators followed a different script for this iteration, partly based on drawings and statements provided by the artist, and partly on their own interpretation of the installation's site specificity.

Looking at the radical changes in SLOTO's spatial design during the second staging, a key question is whether this iteration can still be recognized as a genuine performance of the work. Jason Rhoades could not authorize the reinstallation, and we will never know his answer, but the chapter aims to understand the reasoning of the custodians in their attempt to accommodate the installation to the specifics of the new gallery space. This brings about the following subquestions: how was the installation's site specificity reactivated in a different gallery space? What was the underlying script for the curatorial decisions?

Key to the analysis is to examine the elements of change while taking into account the ontology of the installation as a network of spatial functions. Following the triadic model of site specificity, changes of the spatial design are put in relation to the institutional policies and practices, and the various spaces of production. In the previous chapter, the question came to the fore whether it was acceptable to move the production of a remake of a site-specific installation artwork, signified by the production place (Ernesto Neto's studio and nearby industry producing the polyamide fabric, both in Brazil), to a different location (for example, a factory in the Netherlands). The production of The Secret Life of the Onion, on the other hand, was distributed to various production spaces and fabricators from the start: Jason Rhoades made use of consumer goods and involved many different fabricators, including the museum staff. In several ways, the staff acted as coproducers of the work and thus shared the social space of production with the artist. The installation also received a representational meaning for the Van Abbemuseum, because it was created in commission for the opening exhibition of its new building in 2003. The case study illuminates how SLOTO is inextricably bound to the museum site in terms of representational space and social space, whereby a conversion took place in the period between the initial production and the institutional practices and policies in the longer term. 
Figure 20 SLOTO. The secret life of the onion (2003) by Jason Rhoades. Collection Van Abbemuseum, Eindhoven. Installation view. Photo: Peter Cox. Courtesy Van Abbemuseum archives, Eindhoven. $\odot$ Hauser \& Wirth, Jason Rhoades Archive.

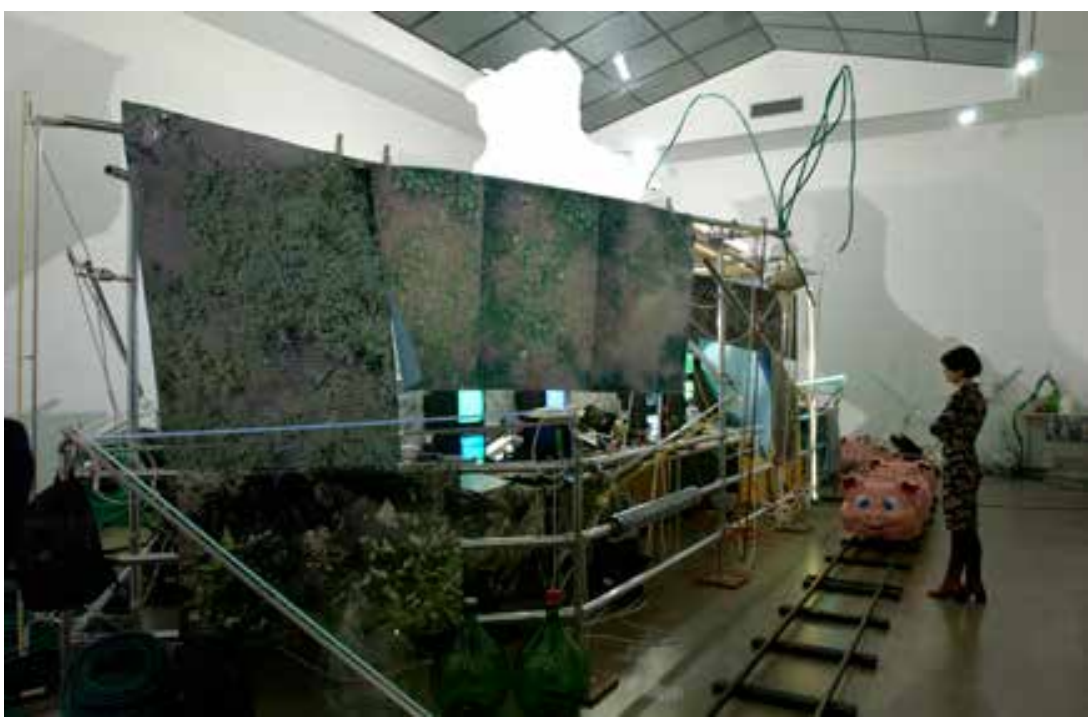

Before discussing the work of Jason Rhoades more deeply and reflecting on the genesis and site specificity of SLOTO, I will provide a broader outline of the perpetuation of processual installations in a museum context with an introduction on the site-specific installation Garden Sculpture by Dieter Roth.

\section{Comparative Example}

Apart from Jason Rhoades, other artists have followed similar artistic strategies of incorporating natural elements and processes into their work. For example, Dieter Roth developed his Garden Sculpture (Gartenskulptur, Nationalgalerie Berlin) over a long period (1968-1996). [Figure 21] The installation includes elements that result from natural processes, such as rainwater, plants, and a substance produced out of compost. Originally conceived as a site-specific, processual installation, located in the backyard of his assistant's studio, the installation evolved into an increasingly complex artwork that was moved around and frequently adjusted over thirty years. Dieter Roth included a heterogeneous collection of reused artefacts into his installation, such as a workbench, cart, ladders, window frames, chairs, 
Figure 21 Garden Sculpture (1968-1996) by Dieter Roth. Collection Nationalgalerie/Staatliche Museen zu Berlin. Installation view at Museum Hamburger Bahnhof, 22 January 2016. Photo by the author. ๑) Dieter Roth Estate/Courtesy Hauser \& Wirth.

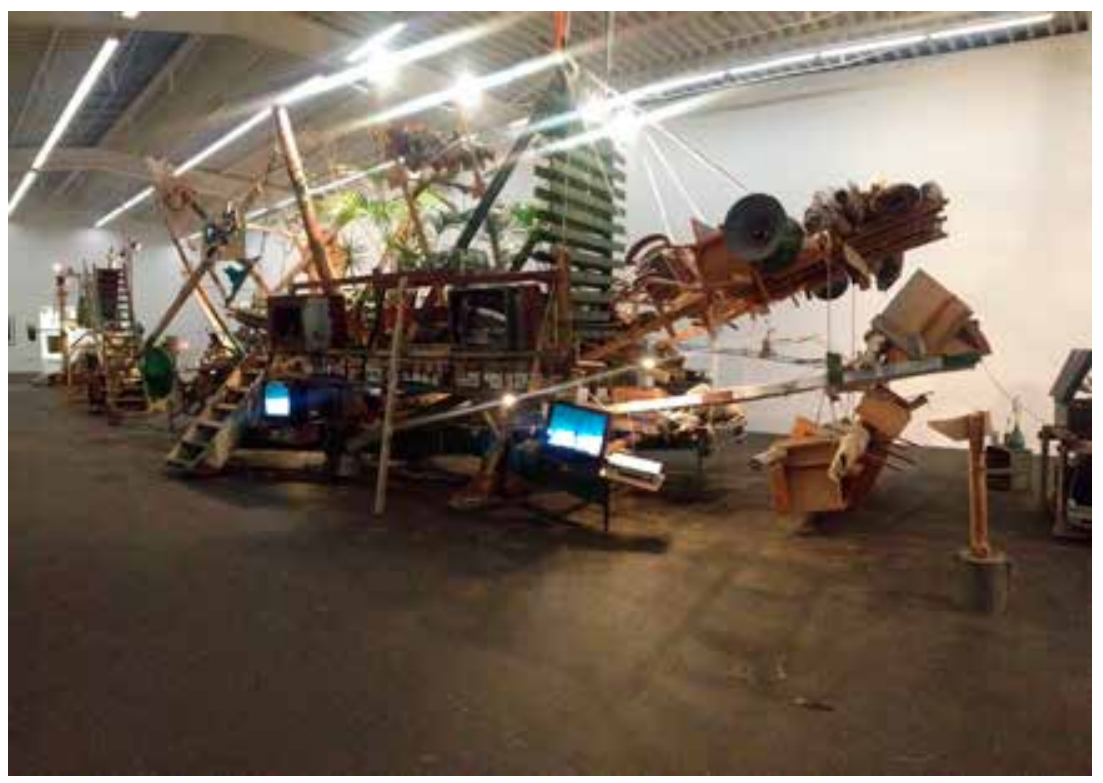

water hoses, pipes, televisions, tubes, rabbit hutches, books and art objects, and organic materials such as plants, bird seed, and the compost substance. He repeatedly reworked and reshaped Garden Sculpture. After the artist passed away, his work was continued by his son and collaborator Björn Roth, the legal and artistic inheritor of Dieter Roth's oeuvre. ${ }^{2}$ New elements were added to Dieter's ouevre, including artworks created by Björn Roth, and with each new iteration the presentation was adjusted to the conditions of the gallery space.

In 2008, Garden Sculpture was acquired by the Flick Collection and has since been hosted by the museum Hamburger Bahnhof in Berlin. ${ }^{3}$ In 2016, an expert meeting was organized by the museum, dedicated to the conservation

2 For example, the chocolate sculptures made by Dieter Roth are often recasted by his son Björn.

3 In 2003, Friedrich Christian Flick agreed with the Stiftung Preußischer Kulturbesitz and the Staatlichen Museen zu Berlin that part of his collection of contemporary art would be hosted by the Hamburger Bahnhof. 
Figure 22 Garden Sculpture (1968-1996) by Dieter Roth. Collection

Nationalgalerie/Staatliche Museen zu Berlin. Detail with jars, installation view at Museum Hamburger Bahnhof, 22 January 2016. Photo by the author. $\odot$ Dieter Roth Estate/Courtesy Hauser \& Wirth.

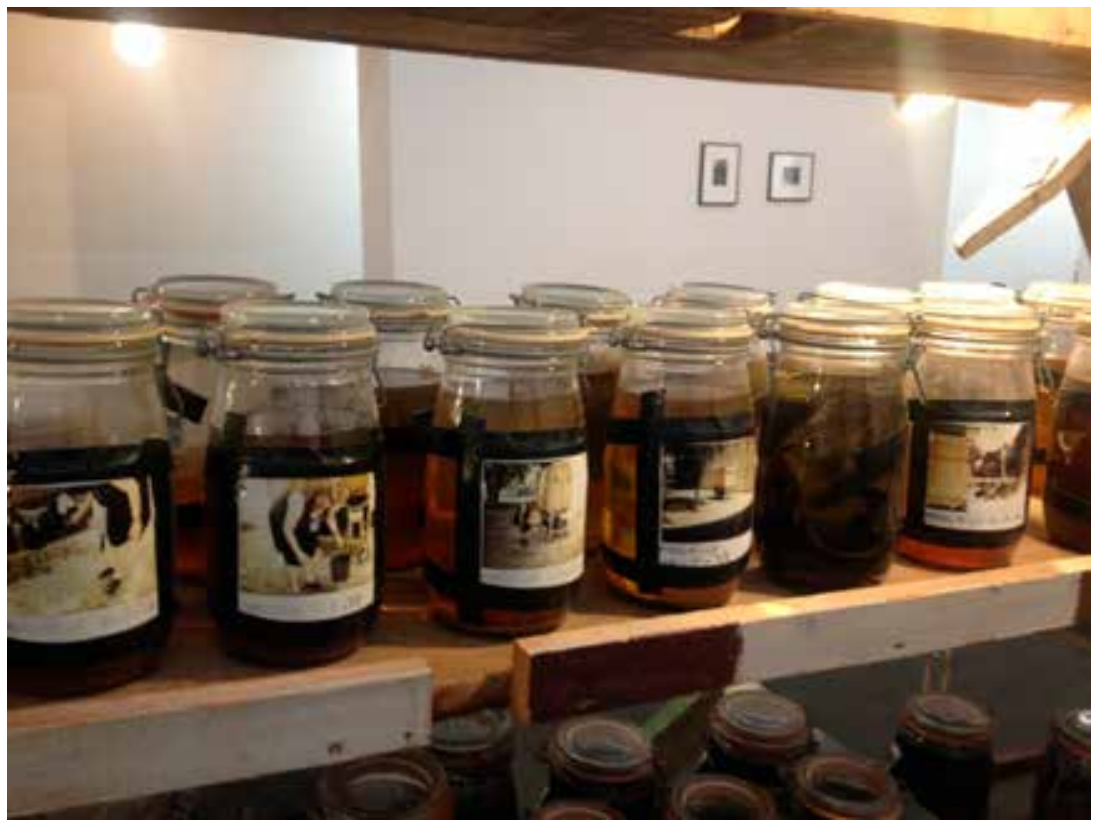

and future staging of the installation. ${ }^{4}$ Questions similar to those posed about The Secret Life of the Onion were raised by the museum's conservator in view of the acquisition of the installation for the collection. Regarding the site specificity of Garden Sculpture, one constituent is of particular relevance for the current case study - namely, a "juice machine," which produced the compost substance. Originally, the juice machine was employed by the artist and his assistant in the courtyard to produce the compost, which was put in jars and subsequently became part of the installation. [Figure 22]

4 An extensive research project into the history of Garden Sculpture was carried out by Carolin Bohlmann, conservator at Hamburger Bahnhof, and art historian Angela Matyssek. I attended the expert meeting on 20 February 2016 and was kindly allowed to use the information for this case study. In addition to the expert meeting, Bohlmann and Matyssek organized the symposium Prozesskunst und das Museum, Hamburger Bahnhof - Museum für Gegenwart Berlin, 19 February 2016, https://www.smb.museum/en/museums-institutions/hamburger-bahnhof/ collection-research/restoration-and-conservation/symposium-on-process-art-and-the-museum. html. 
With the acquisition and relocation to the museum collection, the question of whether this production process could be continued became crucial. For some time, it had been possible to place the juice machine in an outdoor space connected to the exhibition space of Garden Sculpture in Hamburger Bahnhof. The museum's conservator, Carolin Bohlmann, repeated the process of juice production on a regular basis. However, due to a revision of the museum building, it is unlikely that the juice machine will again be placed in an outdoor space. Should the machine still be incorporated into the installation, even if it then would turn into a relic? Should the installation enter a biographical stage of "freeze" after the artist passed away, or should it remain to exist as an open-ended artwork, "in flux"? And who has the authority to act and decide in this matter: the current representative Björn Roth or the museum staff, or both?

The case example of Garden Sculpture highlights a number of key issues regarding the perpetuation of processual, site-specific installations in general. Site-specific installations often include a processual element, which - ideally - should be repeated to keep the artwork alive as intended. However, within a museum context, a repetition of processes in which the artist plays a pivotal role is a complex matter, especially if the artist is no longer around. In turn, it often happens that, after acquisition the installation enters a stage of freeze, it loses the site-specific function of a production practice on the spot. In the case of Garden Sculpture, I was fortunate to be a participant in the discussions. Although definite answers regarding the future life of the installation and the position of the juice machine could not be reached, this meeting sharpened my thoughts regarding both the curatorial decisions made for SLOTO and the broader question of what is presented where and why in the case of a processual artwork in a museum collection.

\section{Jason Rhoades and His Processual Works of Art}

Jason Rhoades (1965-2006) grew up in the rural area of Newcastle, California. He spent his youth on a farm, a biographical detail to which he often refers as a source of inspiration. Mixing references to nature and farming with the history of popular culture is typical of his artistic approach, which is often interpreted as a comment on mass consumerism and societal conventions. ${ }^{5}$

5 For a full description of the life and work of Jason Rhoades, I refer to: Julien Bismuth, "The Real World of Hoists and Holes," in Jason Rhoades: PeaRoeFoam, ed. Julien Bismuth and David Zwirner (New York: David Zwirner Books, 2015), 46-59. 
Rhoades's teacher at the University of California, Los Angeles in the early 199os was Paul McCarthy. Alongside his contemporaries Matthew Barney and Mike Kelly, Rhoades's international fame was established soon after he graduated from the academy, with the production of complex installation artworks which are packed with objects and layers of meaning. Usually, wide spaces are covered with heterogeneous materials: consumer goods and ready-mades from popular culture, construction material and tools, images, texts, neon signs, and so forth. Art critics sometimes typify his work as "non-consensual" and "unafraid of awkwardness" or as referencing capitalist society and globalization. ${ }^{6}$ Often, his installations are provocative as, for example, in the case of The Black Pussy (2005-2006), in which 185 synonyms for female genitalia were depicted in neon light. An art critic described this installation as consisting of

[...] myriad objects, including hundreds of Egyptian Hookah pipes from a seized shipping container, over 350 unique Dream Catchers [...], 89 beaverfelt cowboy hats, 72 Chinese Scholar stones, Venetian glass vegetables [...], colorful cloth rugs, a homemade aluminium replica of Jeff Koons' famous stainless steel Rabbit (1986), and more. ${ }^{7}$

Rhoades created The Black Pussy in his studio in Los Angeles and organized soirées for groups of carefully selected guests, who participated in performances and contributed with their personal "pussy word." At other occasions, Rhoades had already involved friends and colleague artists in the creation process, too. According to gallerist David Zwirner, Rhoades was utterly intrigued by certain themes, which he investigated time and again: "The conditions under which art is possible, the role of the artist, the sources for creativity, the notion of abstraction." ${ }^{8}$ Finally, an equally important characteristic is Rhoades's great sense of control and ordering, concealed by an apparent arbitrariness, as Zwirner observes:

For Rhoades, the creative process demanded ultimate freedom. His work could be dangerous, overwhelming, politically incorrect, obnoxious, or

6 The first two references come from Dana Goodyear, The New Yorker, 8 March 2017, https:// www.newyorker.com/culture/culture-desk/an-l-a-artist-who-anticipated-our-trumpian-moment). The third reference comes from Eric David, Yatzer Art, 15 April 2017, https://www.yatzer. com/jason-rhoades-installations.

7 David Zwirner, “Black Pussy: Press Release," New York: David Zwirner Gallery, 13 November 2007-26 January 2008. https://www.davidzwirner.com/exhibitions/black-pussy/press-release.

8 Zwirner, "Black Pussy: Press Release". 
utterly sublime. [...] On a formal level, the work reveals great precision and beauty, and attests to the artist's singular aesthetic. [...] He not only tried to control the actual space of the work, but also the imaginary space in his installations. ${ }^{9}$

Installations by Jason Rhoades are processual not only because he sometimes used organic materials but also in the sense that parts of previous works were often reused. He continued working on them after the initial installation, like with the abovementioned The Black Pussy or with his installation P.I.G. (Piece for Ghent), discussed further on in this chapter. When galleries and museums invited Rhoades to create a site-specific installation, he usually worked on the site for a period of time, incorporating the conditions of the exhibition space and bringing cartloads of materials into the gallery space.

\section{Rhoades's Collaboration with the Van Abbemuseum}

Jason Rhoades first collaborated with Van Abbemuseum in 1999, when - due to a renovation of the building - exhibitions were temporally relocated to a venue called Entr'acte. With The Purple Penis and the Venus (1999), the artist covered almost the entire exhibition space with (primarily) consumer goods and construction material. ${ }^{10}$ "He juggles with colour, form and words," an art critic observes, "as in a swirling theatre featuring the paraphernalia of consumer culture."11 The success of this show encouraged Jan Debbaut, then director of Van Abbemuseum, to invite Jason Rhoades for the opening exhibition of the new building in 2003, Over wij / About we. ${ }^{12}$ According to a staff member, it could just as well have resulted in a modified version of the earlier installation, but negotiations between the director and the artist finally led to a commission for a new site-specific installation, located in the

9 Zwirner, "Black Pussy: Press Release".

10 The full title is The Purple Penis and the Venus (and Sutter's Mill) for Eindhoven: A Spiral with Flaps and Two Useless Appendages. After the Seven Stomachs of Nuremberg (as Part of 'The Creation Myth'), Van Abbemuseum Entr'acte, 24 October 1998 - 17 January 1999.

11 Rogier Schumacher, "Een paarse penis, venus, molen en spiraal. De jonge Amerikaan Jason Rhoades blaast zijn beelden op tot wervelende theaters, waarin de parafernalia van de consumptiecultuur een warm onthaal wordt geboden," Parool, 5 November 1998.

12 Over wij / About we ran from 19 January to 31 August 2003. The exhibition was curated by then director Jan Debbaut and head of collections Christiane Berndes, with the assistance of Monique Verhulst. Eva Meyer-Hermann and Phillip van den Bossche prepared a number of special projects for the opening exhibition, including SLOTO. The Secret Life of the Onion by Jason Rhoades. 
annex of the old museum building. ${ }^{13}$ It was the first monumental installation the Van Abbemuseum commissioned and subsequently acquired. ${ }^{14}$

\subsection{The Spatial Design of The Secret Life of the Onion}

With The Secret Life of the Onion, Jason Rhoades was the first artist who used the so-called project space in the basement of the Van Abbemuseum. [Figure 20] Artists were invited to employ this large gallery as a "laboratory" or studio, where they could experiment with an artwork before it reached its final form. The artists could decide when to open or close the studio's door to the public. ${ }^{15}$

General themes Rhoades investigated with The Secret Life of the Onion were processes of growth and cultivation, both in agriculture and culture. The location matched perfectly with this theme. Various modes of site specificity - in content, form, and creation - can be associated with the underground "laboratory" of the museum's basement. The artist provided the museum with a set of drawings and additional comments laying the foundation for the spatial arrangement of the actual installation. ${ }^{16}$ Following Lefebvre's triad of spatiality, these coded messages are representations of space giving direction to the spatial arrangement when the installation takes shape. The drawings indeed gave an indication of what the artist intended, but they were not precise and could not be used as an actual floor plan for the installation process.

The first iteration of The Secret Life of the Onion consisted of three different compartments. One part comprises shelves and tables displaying objects and substances that are associated with a laboratory for food processing, placed along the walls of the project space. Onion-shaped demijohn jars and other vessels are filled with onion rings and a "mysterious" mixture of substances, as described below. ${ }^{17}$ [Figure 23] Green tubes are attached

13 Interview conducted with Margo van de Wiel on 13 July 2016.

14 Another installation for the opening exhibition, which has been accessioned for the museum collection afterwards, was the project No Ghost Just a Shell (1999-2002), by Philippe Parreno and Pierre Huyghe. This acquisition raised profound questions about conservation and presentation strategies, discussed by Vivian Saaze in the chapter "From Object to Collective, from Artists to Actants: Ownership Reframed," in Installation Art and the Museum: Presentation and Conservation of Changing Artworks (Amsterdam: Amsterdam University Press, 2013), 144-18o.

15 See a fact sheet for the new building of Van Abbemuseum in the Press Folder for Over wij / About we (archive Van Abbemuseum).

16 The drawings and additional notes by Jason Rhoades are in the archive of the Van Abbemuseum.

17 A demijohn jar is an oversized glass bottle, originally used for making wine. 
Figure 23 SLOTO. The secret life of the onion (2003) by Jason Rhoades. Collection Van Abbemuseum, Eindhoven. Detail with jars. Photo: Peter Cox. Courtesy Van Abbemuseum archive, Eindhoven. $\odot$ Hauser \& Wirth, Jason Rhoades Archive.

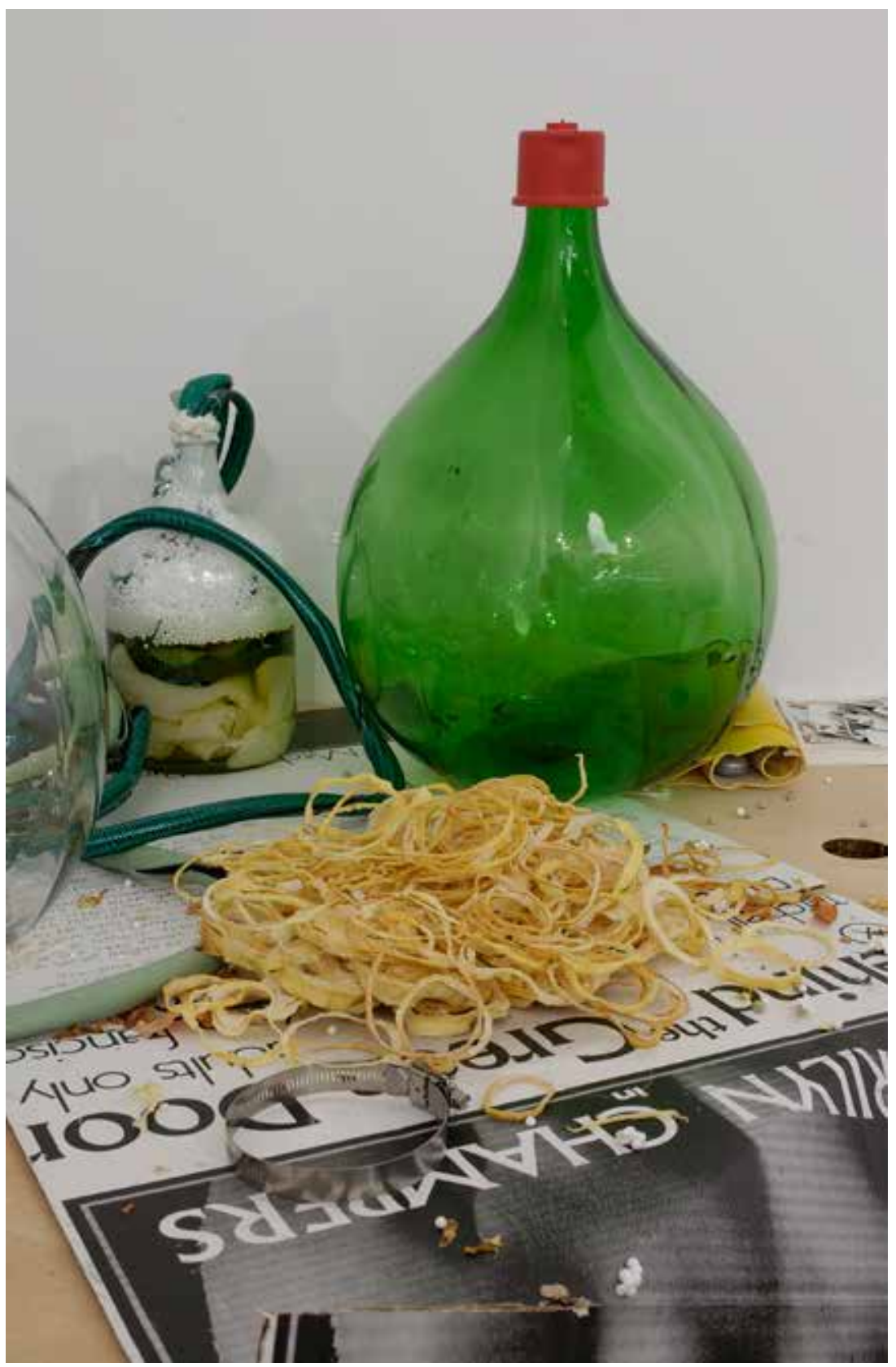


to some of the jars, as if they are dehydration bottles, but the tubes are cut off. In the corners of the room, heaps of onion rings are spread out on the tables, and two large oil barrels seem to supply the laboratory with fuel. The installation conveys an imaginary purpose of food production, but no real action is taken, as if time is arrested in the middle of a process.

In the second and the third part of the installation, there is plenty of movement and action. Halfway through the room, an oval-shaped track carries four swine-snouted train wagons. [Figure 24] This so-called Porky's Train, running around the inner part of the installation, is specified by the artist as an autobiographical reference to the "kiddie rides" he had enjoyed in similar trains when living in Texas. ${ }^{18}$ Rhoades suggests in his sketches and comments that visitors could be seated in the train and so perceive the installation in "one round look," but this was not allowed in the actual installation. ${ }^{19}$ Instead, one of the vessels is carried around in one of the wagons of the running train. This vessel is filled with a mix of ingredients just like the other jars: sliced onion rings, worn socks (which Rhoades considers "artistic material," meant to collect museum dust), water, oil, and a construction material he created himself, called PeaRoeFoam. ${ }^{20}$

Rhoades introduced this material in 2002 and used it for a number of installations. The mixture is composed of dried green peas, white styrofoam beads, and salmon eggs, mixed together with glue. The artist put the PeaRoeFoam inside the vessel and jars, and spread it over the wagons in large quantities, and randomly over the rest of the installation. In contrast to the objects placed along the walls as "silent witnesses," the train wagons and their content are actual agents for a "performance" that visitors can watch without participating. In a sense, they take a similar position as silent witness, just like the onion jars placed at the shelves.

The third, inner compartment of the installation is full of action. Twentyfive monitors are placed on a workbench in the middle of the room. The monitors show video games collected by the artist on eBay. ${ }^{21}$ They are

18 Rhoades includes this note in his drawings. The Porky's Train was bought in Sweden and transported to Eindhoven. Another reference for the train are so-called Porky's, a genre of comical sex movies Rhoades used to watch in the early 1980 s (notes from an interview conducted by Eva Meyer-Hermann in November 2002). A transcription of the interview is in the archive of the Van Abbemuseum.

19 This note is part of the series of drawings Jason Rhoades delivered to the museum. See footnote 16 of this chapter.

20 In his drawings, the artist states: "This is a material I have wanted to work with for some time." See footnote 16 of this chapter.

21 The video games include the oldest game Pong, and other games developed for Nintendo and Playstation. 
Figure 24 SLOTO. The secret life of the onion (2003) by Jason Rhoades. Collection Van Abbemuseum, Eindhoven. Detail of the installation with a Porky's Train. Photo: Peter Cox. Courtesy Van Abbemuseum archive, Eindhoven. @ Hauser \& Wirth, Jason Rhoades Archive.

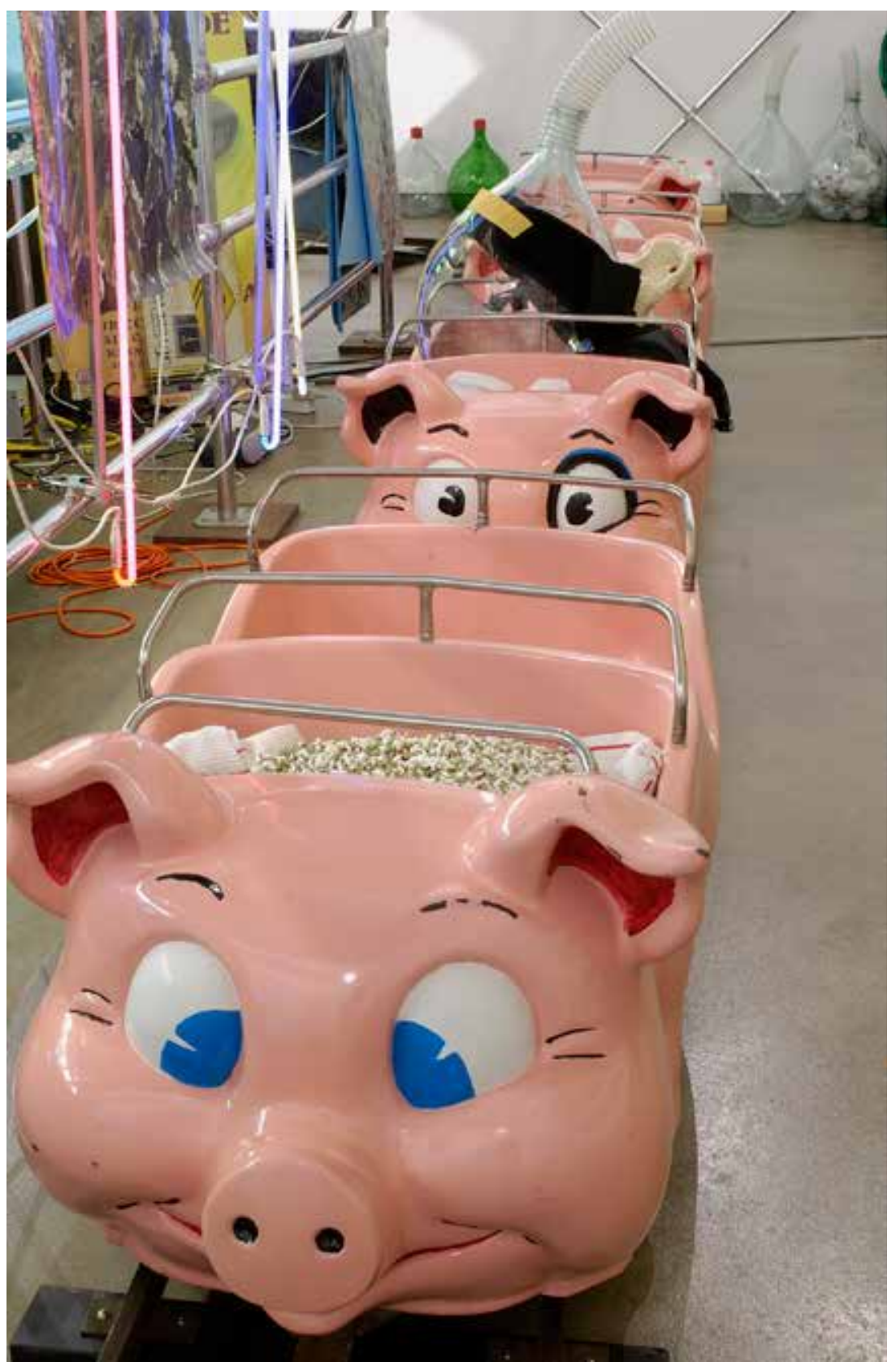


piled up amid a seemingly random mass of electric parts, construction material, tools, and rather undefinable objects. A steel fence is connected to the workbench, holding neon tubes, laminated inkjet prints showing plants, power cables, garden hoses, and rolls of plastic foil. In the centre of this part, a large $3 \mathrm{D}$-printed tree trunk rises up from a platform to the room's ceiling. Its spatial position matches with the ground level of the adjacent rivulet Dommel, where trees would normally grow. [Figure 25] These tokens of agriculture and farming juxtapose the video games and other references made to popular culture of the 1980s (such as the Porky's Train). The curator of the exhibition, Eva Meyer-Hermann, observes that the cultivation of onions symbolizes Rhoades's own process of becoming an artist:

Ever since his childhood the artist has always been close to life in the countryside. As a young boy he used to grow his own onions and sold them to people door-to-door; an activity which he later called his first artistic entrepeneurship. Here and there in his later work vegetables and other elements of natural life still turn up. ${ }^{22}$

According to Rhoades, the inner compartment formed an "ideal world" of the combination of natural processes and the history of popular culture. ${ }^{23}$ Visitors could not enter the inner part, but they could hear the sound and get a glimpse of the video games through open spaces in the fence. From my own visit in 2003, I remember the overwhelming impression of the installation and the associations provoked by the electric train and the action in the centre, in contrast to the stillness at the sides. Somewhere in the middle, I thought, "the secret life of the onion" is situated.

\subsection{Representational Site Specificity of The Secret Life of the Onion}

As said above, the location in the museum's basement is a significant parameter for the site specificity of the installation. The location is literally underground, symbolizing the meaningful concepts of growth and 
cultivation. There is yet another reference made by Jason Rhoades, as Eva Meyer-Hermann states in a text accompanying the exhibition:

Rhoades has deliberately placed his piece in a space below ground. In many museums the basement normally serves as storage space for artworks. Thus SLOTO is situated on a level which alludes to the archive of the museum. A museum archive can be interpreted as the semi-conscious part of the collection, and in Rhoades' piece, images of every single work in the Van Abbemuseum's collection are inserted subliminally into the various video games. These barely noticeable images refer to the idea of the completeness of the archive as well as to the never-ending challenge of the visitor's experience in any museum. ${ }^{24}$

As noted in chapter 3 , Lefebvre attributes a dual concept to the function of representational space, which I have earlier specified as a combination of the symbolic, imaginary space of the museum and the actual "lived" space, fluctuating with the museum's policies and employment of the space in exhibitions. The latter function can be recognized in the underground location of the museum's project space, whereas the images of the collection, included in the installation by Rhoades, can be read as a reference to the representational function of The Secret Life of the Onion. The images were added to some of the vessels or inserted into the video games by the artist himself. This way, the installation becomes an "imaginary space" for the hosting institution and its collection development.

The $3 \mathrm{D}$-printed tree trunk placed in the middle is another indication of the representational function of the installation. The trunk is brightly illuminated by the room's skylights and spots, accentuating its spatial position - matching with the ground level of the Dommel rivulet. [Figure 25] Rhoades mentions in his comments to the sketches that the tree refers to a legend of a tree in his home country. The story tells of a nineteenth-century shepherd who was looking for onions at the bottom of an oak tree and who, finding gold instead, started the gold rush in California. (There is still a landmark in California for the Oak of the Golden Dream.) The $3 \mathrm{D}$-printed trunk of this tree added a marker to the installation of what Rhoades calls the "ideal world [...] just a bit underground." ${ }^{25}$ Hence, the physical location 
Figure 25 SLOTO. The secret life of the onion (2003) by Jason Rhoades. Collection Van Abbemuseum, Eindhoven. Detail with a 3D printed tree trunk. Photo: Peter Cox. Courtesy Van Abbemuseum archive, Eindhoven. (c) Hauser \& Wirth, Jason Rhoades Archive.

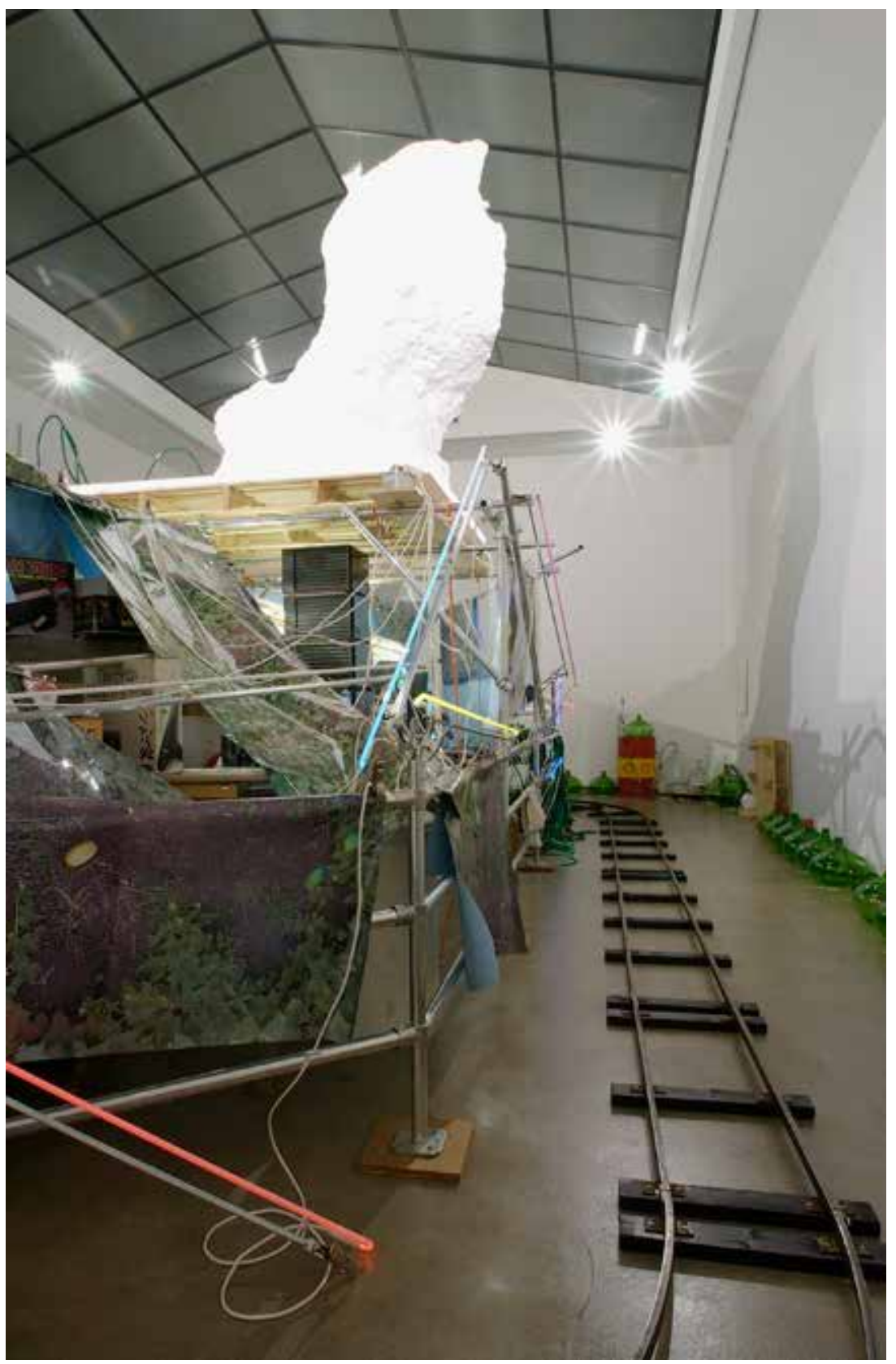


of the tree is a meaningful element of the spatial design of the installation and a signifier for the symbolic meaning of SLOTO.

\subsection{Social Production Spaces of The Secret Life of the Onion}

Jason Rhoades developed his installations organically by reusing parts of previous works. In conversation with Heimir Björgúlfsson, he states:

I'm uncomfortable with actually finishing something. This feeds into that and that feeds into this - I am trying to keep it in flux somehow. But that flux can be stopped in time by an institution or a collector, and then the relationship changes. ${ }^{26}$

A workbench placed in the inner part of SLOTO had previously featured in the Costner Complex (Perfect Process) (2001), another site-specific installation by Jason Rhoades created for the Kunsthalle Portikus in Frankfurt. ${ }^{27}$ Rhoades had used the workbench for cutting vegetables, after which the sliced parts were put into jars, just like the onions were added to the jars in SLOTO. In the Costner Complex, Rhoades "exposed" organic material to images of the film actor Kevin Costner; similarly, he would later add thumbnails of the Van Abbemuseum's collection to the vessel placed inside the train, "exposing" them to the inner part of the installation, the place where the video games were screened. In brief, the workbench had served as a starting point for SLOTO, which, as the artist states, had asked "to be filled" again like "an empty space. ${ }^{\prime 28}$ Once more, the vegetables (in this case, onions) fulfilled a role in the juxtaposition of natural and cultural processes.

26 Interview with Jason Rhoades. Heimir Björgúlfsson, "Charisma Catcher," Artnet Magazine, 29 July 2006. http://www.artnet.com/magazineus/features/bjorgulfsson/bjorgulfsson8-23-o6. asp.

27 It is worth quoting David Zwirner's description of the Costner Complex here, because it shows a striking parallel with SLOTO: "Rhoades had been experimenting with cooking during his [visiting professorship] at the Städelschule in Frankfurt, and for his installation, The Costner Complex (Perfect Process), he created a factory setting to produce a pickled potpourri of vegetables that he exposed to the oeuvre of Kevin Costner, whose movies he had been watching on his transcontinental flights from Los Angeles to Frankfurt. Rhoades and his students exposed them to the films, then placed the cans on a large rack." David Zwirner, "PeaRoeFoam: The Impetuous Process \& From the Costner Complex," in Jason Rhoades: PeaRoeFoam, ed. Julien Bismuth and David Zwirner (New York: David Zwirner Books, 2015), 65.

28 Conversation between Eva Meyer-Hermann and Jason Rhoades, 2002 (archive Van Abbemuseum). 


\section{The Production Process of SLOTO}

The Costner workbench, the fence, and the video games came straight from the artist's studio. Other parts, such as the $3 \mathrm{D}$-printed tree trunk, the Porky's Train, the vessels and jars, the tables, shelves, oil barrels, and substances for the PeaRoeFoam were obtained from a variety of suppliers. The archive of Van Abbemuseum contains a list of supplies and the set of drawings and comments provided by the artist indicate how certain elements could be obtained (such as the Porky's train). Apart from that, several documents in the archive refer to the production process, which will be used for my analysis of the fist staging. In addition, I will gratefully make use of an interview conducted with Margo van de Wiel, a former staff member at Van Abbemuseum who was closely involved with SLOTO's preparatory phase.

The process started with huge quantities of ingredients assembled by staff members in the project space. In the absence of an elevator to the underground location, heavy substances such as the Costner workbench and oil jars had to be transported by hand. Rhoades asked the staff to be closely involved in the preparatory process, in many ways. Not only did they purchase and transport the materials to the basement, they also prepared the mixtures that would fill the jars and vessels, and printed the thumbnails of the museum collection of artworks and the images Jason Rhoades had sent in advance on CD-ROM, both from his own art and taken out of magazines. Furthermore, the staff was asked to walk around with white socks, which would later be added to the mixture in the jars, and to collect ingredients for the PeaRoeFoam: peas, salmon eggs, and styrofoam balls.

The most unusual part, however, was the preparation of the onions. A staff canteen located behind the project space was used for this purpose. The onions were peeled and cooked by several staff members, and as Margo van de Wiel recalls, "it were a lot of onions that had to be cut into rings and their scent spread throughout the museum."29 To avoid mould and rot, the drying time for the onions took at least four days, a long period for the museum to endure the smell and to supervise the cooking process.

After these preparations and provisional mounting of the installation (by staff as well as Rhoades's assistants), the artist joined the team and moved into the project space as an "inhabitant," just as the Van Abbemuseum had intended when they made this space available for experiment. Rhoades fitted the spatial arrangement to a definite spatial design; mixed the ingredients of the PeaRoeFoam, filled the demijohn jars and the liver-shaped vessel with 
it; and spread it over the entire installation. Last but not least, the electricity and screening of the video games in the inner part of the installation were checked and necessary safety measures were taken.

In addition to the above description of the first staging, it should be noted that Rhoades expected an ongoing engagement of the staff members throughout the exhibition period. A poster in the exhibition room conveyed an instruction, made by Rhoades for the curators, that the jars should be filled frequently with new sliced onions. Furthermore, a curator should make regular rides in the Porky's Train to gather more "experience" for the jars by moving them around. After the ride, the jars should be put on the shelves as a memory of the experience.

In several ways, SLOTO can be considered a performative artwork, given the actions required for the experience, such as ensuring that the train runs and the video games for the public to watch function well. At a deeper level, however, the involvement of the staff members can also be interpreted as a performative dimension of the artwork, because these actions contributed to the production, manifestation, and meaning of the artwork, rooted in the physical location and the actual museum practice (social space).

\subsection{Summarizing the Spatial Network of the First Staging}

As my examination of the network of spatial functions of SLOTO shows, the location in the museum's basement was significant to the site specificity of the installation in various ways: the project space determined the spatial design of the installation (spatial dimensions, position of the tree trunk); the underground location had a representational function (references to cultivation and "semi-consciousness," laboratory, museum archive); and a social production space was activated (actions by the museum staff and the artist needed for the realization of the installation, riding the Porky's train, etc.). Diagram 11 shows how those respective functions are interrelated.

Apart from the project space, the museum's staff canteen and the registrar's office were incorporated into the production as well (the registrar selected the collection of artworks and prepared them for printing as thumbnails). Because the staff members where involved in the production to such a large extent, they can be seen as coproducers of the first staging of The Secret Life of the Onion. This is not unusual in the production of contemporary art installations, but what is remarkable in this case is the forceful drive behind it. Rhoades insisted on making 
Diagram 11 SLOTO. The secret life of the onion: Biographical stages 2003 and 2011. ( The author. Image editing: Arienne Boelens.

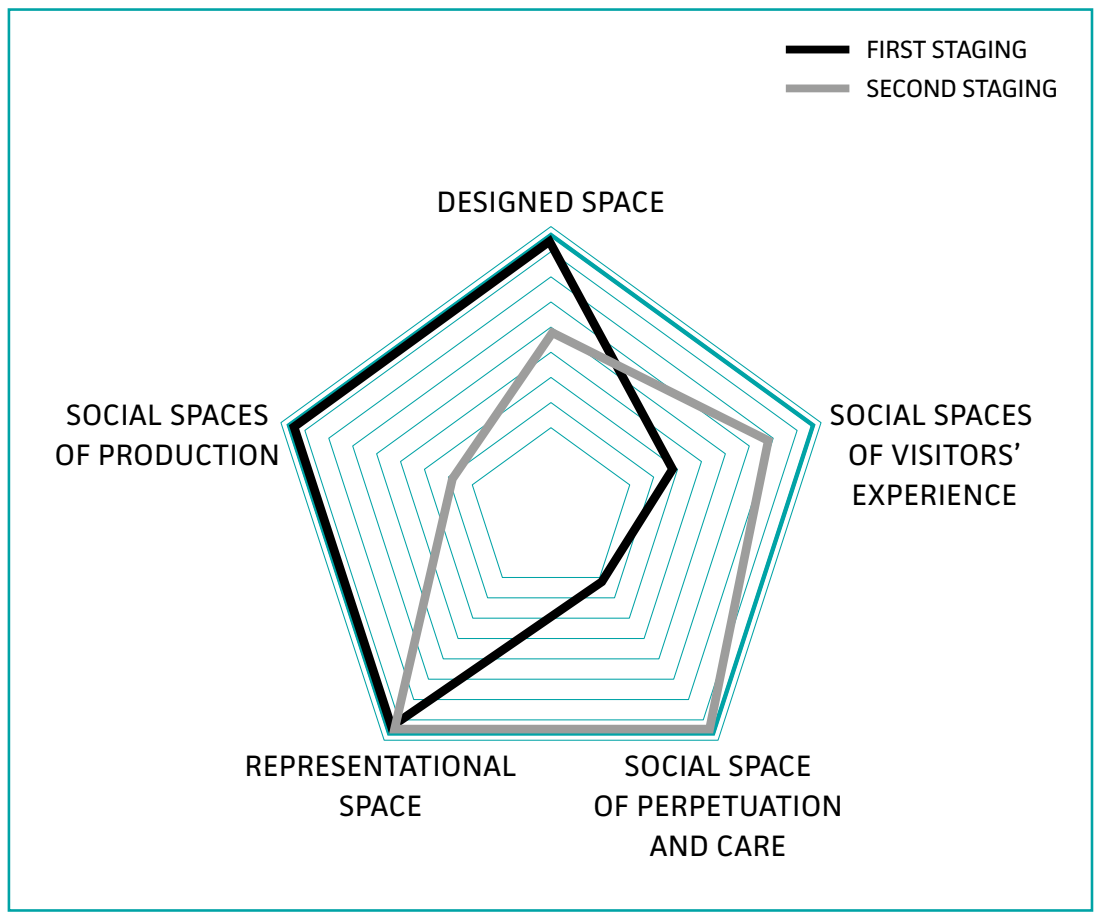

the staff members his accomplices, as also Van de Wiel suggests: "Jason tried to create chaos to some degree, but the museum really loved the work and engaged with it." ${ }^{\prime 0}$

Following Lefebvre's triad of spatiality, the function of social production space refers to patterns of daily practice and the competences of producers, which can be transposed to a museum as the daily routines of caretaking and presenting art objects. Lefebvre's triadic model furthermore implies a relationship between the social production space and other spatial functions, such as, in this case, the representational function of a contemporary art museum where unconventional practices are not uncommon. As Nick Kaye observes, site-specific installation artworks have the inherent capacity to challenge professional routines and following, Fernando Domínguez Rubio notion of unruly objects, they can change them. [See chapters 1 and 3 ] Rhoades succeeded in troubling the opposition of the artwork and the site by demanding unconventional actions of the 
museum staff and by inhabiting several museum spaces. However, the representational space of the museum also limits this spatial practice and the staff members complied with the artist's requirements only to a certain degree. They did not wear the white socks to collect dust before these were added to the installation, nor did they continue the practice of cooking onions, nor "perform" the curator's task of riding around with the onions in the Porky's train..$^{31}$

In terms of its representational function, SLOTO fulfilled the aspiration of both the director and the curators to commission and collect a groundbreaking installation artwork for the opening show. As said, it was the first grand-scale installation commissioned by the Van Abbemuseum at the turn of the century. To introduce the experimental function of the project space and to make the public aware of the deeper layers of meaning of SLOTO, a seminar was organized for which the artist was invited as a speaker. Apart from an introduction by curator Eva Meyer-Hermann, a public conversation was held with Jason Rhoades, and professor Chris Kik of Wageningen University presented a lecture about the species of alliums and the beneficial effects of onions on human health. ${ }^{32}$ It was another attempt by the curators to communicate the installation to a larger public and to convey the connection between the "secrets" of both natural and cultural processes, as expressed by Jason Rhoades in this monumental, overwhelming, and "activist," site-specific installation artwork.

In conclusion, I would argue that during the first staging of The Secret Life of the Onion a strong bond was established between the physical site specificity of the project space and the various social spaces of production, strengthened even more by a dual bond with the representational space: firstly, by the direct link established with the Van Abbemuseum collection by means of the inserted thumbnails, and secondly, through its representational value as a groundbreaking installation exhibited and acquired at the museum's opening.

In the analysis of the first staging, little has been said about the social space of the visitors' experience. Jason Rhoades suggested in his drawings that visitors could observe the installation "in one round look," but in the actual manifestation, the real visitor was replaced by the liver-shaped

31 Personal information obtained from the head of collections, Christiane Berndes, kindly shared when I visited the exhibition of SLOTO in 2003.

32 The event was organized by Eva Meyer-Hermann on 26 June 2003, in the auditorium of the Van Abbemuseum. 
vessel in the Porky's Train. There was no way visitors could grasp the entire installation in one look, and they got only a limited presentation of what happened in the inner part of the installation, because the video games could not properly be watched. Neither could they decipher the collection of thumbnails of the Van Abbemuseum, inserted into the video games and added to the substance of the vessels and jars. For those reasons, the visitors' experience got lesser attention than the social spaces of production in my analysis of the first staging, in contrast to Célula Nave, where the visitor's physical interaction played a pivotal role.

The challenges facing the perpetuation of The Secret Life if the Onion could be grouped together as a more general problem concerning the preservation and presentation of processual, open-ended artworks in museums. There are many complexities for the registration, storage, and reinstallation of these kind of works, let alone the meaning production over a longer period of time. But in addition, SLOTO's perpetuation asks for unconventional action to ensure the reactivation of the artwork's site specificity. In particular, the latter comes into focus with the second staging in 2011, when the original space in the basement was no longer available and major shifts in the network of site-specific functions marked a turning point in the artwork's biography. According to the head of collections, Christiane Berndes, Jason Rhoades and the Van Abbemuseum had, at the moment of the acquisition, agreed that separate parts of the installation could be shown independently and that variation in their display was allowed. ${ }^{33}$ The set of drawings and comments provided by the artist, as well as conversations between the artist and then curator Eva Meyer-Herman, were considered sufficient information to develop an alternative script (or scenario) for a new manifestation of SLOTO. In the following paragraphs, I will scrutinize the reasoning of the curators' intervention and analyse the changes of site-specific functions of this second iteration.

\subsection{A Curatorial Intervention with SLOTO's Second Staging}

The sketches and comments Jason Rhoades provided to Van Abbemuseum can be considered a script for the intended design of the spatial arrangement and for the meaning of individual constituents, such as the Porky's Train, the onions, the video games and the liver-shaped vessel. For example, the 
floor plan in which Rhoades included a sketch of the oval shaped train track, is accompanied by the comment that $S L O T O$ is

[...] a work to be seen as "one round look". [...] To look at an action, a history, art historical reference, a place, to see something and have an experience. Then to remember it by putting it on a shelf for the future. ${ }^{34}$

The train wagons are "probably filled with PeaRoeFoam for comfort" and the fence is a "perfect world fence." ${ }^{35}$ In almost every drawing, the physical location is accompanied with a metaphorical reference, often a pointer to the representational site specificity in the basement: the imaginary "ideal space" of the experience (the fence), the track for the visitors' experience in "one round look," the addition of "the oak of the Golden Dream on top" (a reference to the tree trunk and the story of the gold rush in California). This all underscores the physical location, considered by the artist to be an important marker for the content and form of the artwork.

Apart from the sketches and comments, no other indicators were available for a future reinstallation, except for the documents recording the first staging (consisting of a collection of photographs, notes on production processes, and budget calculations). Besides those, the interviews with the artist preceding the production and during the initial staging process formed the basis for the curatorial decisions, although at the time, it was not discussed what approach should be taken if the project space would no longer be available or if the artist would no longer be around. In the absence of the artist, the curators of Van Abbemuseum took the initiative to develop their own scenario for exhibiting the artwork in a different gallery space.

The second staging of SLOTO took place in 2011, on the occasion of the Van Abbemuseum's seventy-fifth-anniversary exhibition, titled For Eindhoven The City as Muse.$^{36}$ The curatorial team consisted of museum staff members Christiane Berndes and Annie Fletcher. In a press release, the curators state that the exhibition's focus was on the museum collection and "important moments or quotations in the history of art, the story of the city and the museum itself. Some of these works are built up in a new form or context."37

34 This is part of the museum's file on SLOTO. The secret life of the onion. See footnote 16 of this chapter.

35 See footnote 16 of this chapter.

36 The exhibition For Eindhoven - The City as Muse was curated by Christiane Berndes, Charles Esche, and Annie Fletcher, and ran from 3 September 2011 to 9 January 2012.

37 Press release of the exhibition For Eindhoven - The City as Muse. 
Because it was the first acquisition of a complex, grand-scale installation artwork, SLOTO had been significant for the history of the museum collection. In addition, its experimental character had raised interesting questions about the role of the contemporary art museum in society. Berndes explains the incentive for the acquisition as follows:

SLOTO inspired the question of how the museum could respond to such an open-ended work of art. What is art today? Exhibition and acquisition policies are always a reflection of the spirit of the time. At that time there was still a relative high level of prosperity and we figured that we would stay in contact with the artist, who would guide us through the process of reinstallation. There was an agreement between Jan Debbaut and Jason Rhoades that the museum could put the installation on display in separate parts, since we have only few large exhibition spaces in the museum. We could even just show the shelves together with the jars ${ }^{38}$

This agreement provided a fertile soil to investigate possible scenarios and posed considerable challenges. First of all, because the project space - as the main parameter of the initial site specificity of the installation - was no longer available. Aware of the site specificity of SLOTO in both content and form, the curators came up with an alternative solution. [Figure 26]

The basement room was out of the question, as it had been rejected as an exposition space since there is no lift or emergency exit. The sitespecificity of the installation was, among other things, connected to the position of the tree trunk, just below the level of the Dommel. This was a vital element of the inner part of the installation, because the tree was connected to the workbench and the video games. So we realized we could never repeat a similar set-up in another space of the building and therefore we decided to leave out this whole part from the installation. ${ }^{39}$

The newly appointed gallery was a space in the historical part of the building, a smaller room supplied with artificial light (instead of the combination of artificial light and daylight in the initial project space). The workbench had disappeared, just as the computers and video games, the fence and

$3^{8}$ Interview with Christiane Berndes. See footnote 33 of this chapter.

39 Interview with Christiane Berndes. There is also a written document in the museum's archive about this agreement. 
Figure 26 SLOTO. The secret life of the onion (2003/2012) by Jason Rhoades. Collection Van Abbemuseum, Eindhoven. Installation view in For Eindhoven - The City as Muse. Photo: Peter Cox. Courtesy Van Abbemuseum archive, Eindhoven. $\odot$ Hauser \& Wirth, Jason Rhoades Archive.

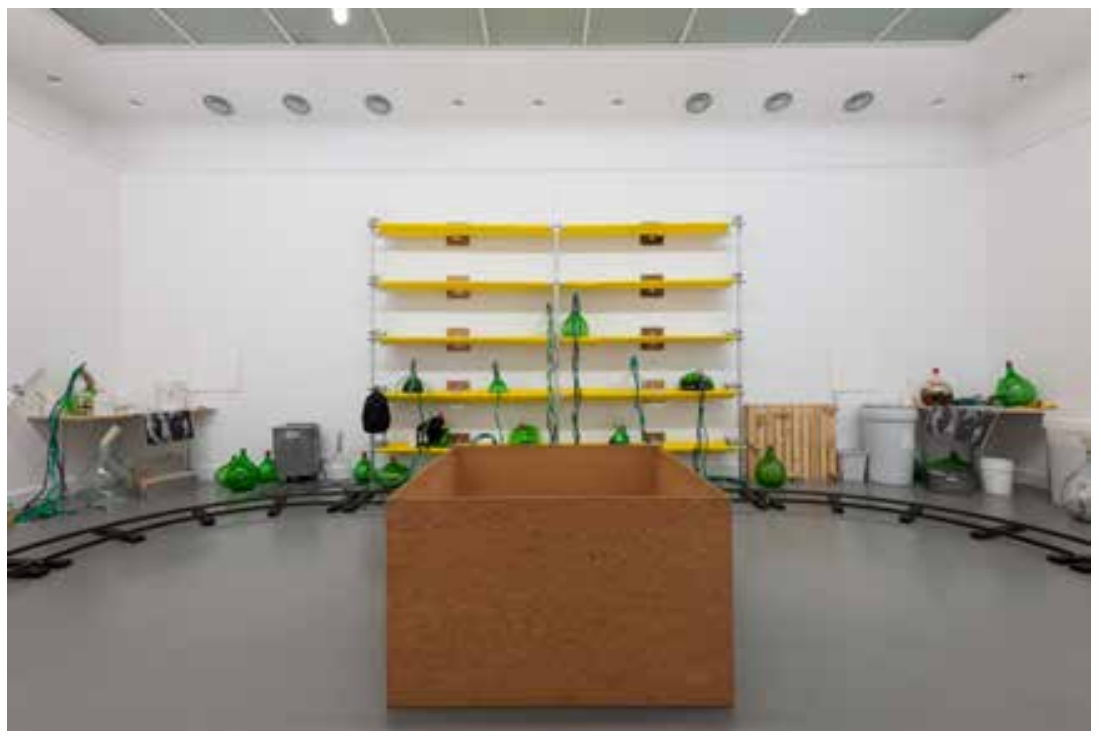

agricultural tools, the neon lamps, the electricity cables and the inkjet prints. Nor did the iconic tree trunk - rising up to the ceiling - reappear. And last but not least, another sweeping decision was to replace the inner part of the installation with an artwork from the Van Abbemuseum's collection: Donald Judd's Untitled (1974-1976). As one of the few examples of minimal art by a famous artist, Untitled is considered one of the collection's most precious works. It consists of a cubical shaped box (1.5 metres for each side) made of multiplex and open at the top. In combination with the glossy surfaces of both the Porky's Train and the shelves, the materiality of the "box" is an eye-catching element, adding an industrial look and feel to the installation. Moreover, its static appearance is quite different from the dynamic centre part of the originally installed artwork. [See Diagram 11] The curator explains:

It had to be a contrast. The visitor is now guided, as it where, around Judd's minimalist sculpture. If the work had been closer to SLOTO, there would have been no contrast, it would not work properly. ${ }^{40}$ 
At least, one core element of the installation was kept intact: the Porky's Train - although the tracks were slightly shortened in order to fit the dimensions of the room. In this new version, the train made its circular movements around Donald Judd's Untitled. Visitors were allowed more space to move around, as they could step over the rails and have a look inside the open "box" (in contrast to the distance visitors had to keep from the inner compartment of the initial manifestation, emphasizing their role as "silent witnesses").

The parts placed along the walls of the gallery space were still quite similar: onion-shaped glass jars were placed on the shelves again; buckets and one of the oil barrels reappeared along the edges of the installation and in a corner of the room. In that sense, the impression of a "laboratory" was kept intact, although the floor plan had been modified to fit the dimensions of the new space.

The above citation from the interview with Christiane Berndes shows that the curators were aware of the impact of the relocation and of the replacement of the inner compartment with Donald Judd's Minimalist artwork. ${ }^{41}$ Looking at this matter from a different angle - namely, Rhoades's fascination with frameworks, boxes, and construction materials - it may be not such a strange element after all. For the first iteration, the fence was put around the workbench by Rhoades himself and served as the marker of a "box." Moreover, several of Rhoades's installation artworks had objects stacked inside a three-dimensional frame, and in his first installation in the Van Abbemuseum, The Purple Penis and the Venus, for instance, industrially manufactured boxes had literally featured. ${ }^{42}$

In this respect, Rhoades's gallerist David Zwirner made an interesting statement when recalling a large number of boxes which arrived in his gallery, prior to the first show of Rhoades's PeaRoeFoam project in 2002. The boxes were filled with the substances from which the PeaRoeFoam would be composed. Zwirner writes:

The back room included a few of these pallets waiting for "activation," the performance that would turn them into the material, while the front room had more finished sculptures. Interestingly, the simplicity of the pallets and the uniformity of their material and shape made them look

41 In the press, the challenges and accompanying decisions were not taken into considerations. One critic observed that The Secret Life of the Onion was shown in a "peeled off form." Hans den Hartog Jager, "Van Abbemuseum viert zijn $75^{\text {ste }}$ verjaardag met drie tentoonstellingen die helaas niet feestelijk zijn. Niet in Eindhoven blijven, lijkt de boodschap," NRC, Beeldende Kunst, 9 September 2011.

42 See footnote 10 of this chapter. 
and seem like Minimalist works of art, and I felt as I was walking through them like I was looking at Sol LeWitt or a Donald Judd. ${ }^{43}$

Summarizing the above in terms of the network of site-specific functions, the change of location and therewith the loss of the original site specificity affected the spatial design of the installation, as well as the content of the work as a representation of natural growth, and the "underground" world of video games and Porky movies. Conversely, it can be argued that the function of representational space was reactivated by placing Donald Judd's Untitled in the centre of the installation. The initial performative presence of the screens showing the video games and flickering neon lights, both on and around the workbench, had been replaced by a reference to a different - industrial - production process: the fabrication of Donald Judd's open "box." This in turn could be interpreted as an echo of the industrial production process and the shiny surfaces of the Porky's Train and the "laboratory" shelves, as well as of the boxes used for PeaRoeFoam in other installations. Looking at the intervention as a script for reactivating the installation's site specificity, I would also argue that exchanging the collection's thumbnails for Donald Judd's Untitled emphasized the representational space of the installation, namely, by literally putting the collection in the centre of attention (just like Rhoades had intended with the insertion of the thumbnails in the video games and jars).

According to Berndes, the commission and subsequent acquisition of a processual, site-specific installation reflects the museum's policies of the early 2000s. The realization had been a challenge from the start and the acquisition had prolonged the "experiment" even more, unfortunately without the presence of the artist after 2006. Taking Rhoades's sketches and comments as a primary source of information, the curators reasoned that the Porky's Train was "the heart" of the installation, because the artist more than once mentioned the kiddie rides and porky movies as biographical and essential elements. ${ }^{44}$ Besides, more than with the reinstallation of the outer part of the installation and the train, the reinstallation of the inner part would have required the presence of the artist. Last but not least, as the experimental space of the laboratory in the basement had been exchanged for a white cube gallery, the Minimalist artwork of Donald Judd was a suitable choice in respect of the representational function of this space.

43 David Zwirner, "Introduction," in Jason Rhoades: PeaRoeFoam, ed. Julien Bismuth and David Zwirner (New York: David Zwirner Books, 2015), 8-9.

44 Interview with Christiane Berndes. See footnote 33 of this chapter. 
In conclusion, the second iteration of The Secret Life of the Onion demonstrates a curatorial approach in concord with the view that processual installation artworks need reactivation - or else they may easily be maintained in a frozen state. In this example, the installation's site-specific network was reactivated by means of a radical adaptation of the spatial design. Whereas this may count as a feasible approach for processual, site-specific installation artworks, other scenarios are conceivable as well. My examination will continue with a comparative example - Jason Rhoades's P.I.G. (Piece in Ghent) (1994) in the collection of Stedelijk Museum voor Actuele Kunst (S.M.A.K.), Ghent - where a different approach was followed.

\subsection{Comparison with Jason Rhoades's P.I.G. (Piece in Ghent)}

Site specificity is also at the heart of Jason Rhoades's installation P.I.G. (Piece in Ghent), created for the exhibition This is the show and the show is many things at S.M.A.K. in $1994 .{ }^{45}$ While the show was still running, many participating artists created their artworks on the spot and modified them several times, with the purpose of presenting a series of ongoing "conversations" between them. ${ }^{46}$ This was also the case with Jason Rhoades's installation.

P.I.G. (Piece in Ghent) was intended as a dialogue between the American life of the artist (living in Los Angeles) and the cultural context of Ghent, symbolized by the Ghent Altarpiece, a masterpiece painted by Hubert and Jan Van Eyck in the early fifteenth century. The iconology of the painting was juxtaposed with the consumer goods Rhoades incorporated into the installation and the performances he carried out during the production phase. The reference to Van Eyck's painting technique was a means to tie the installation to the city of Ghent in a symbolic way, while the production of French fries in one of his performances was another reference to the sociocultural context of the installation.

P.I.G. was created for one of the museum's largest exhibition spaces - large enough for the artist to ride a motorcycle and to relax in a Jacuzzi, which was placed in the middle of the gallery. The French fries performance is

45 The exhibition This is the show and the show is many things was curated by Bart de Baere and ran from 17 September to 27 November 1994.

46 For an explanation of This is the show and the show is many things, see: "Exhibitions History Talks: Bart de Baere," Afterall (16 March 2017), https://www.afterall.org/online/exhibitionhistories-talks-bart-de-baere-video-online\#.XG7TQuTsbbo. 
described in detail by conservator Julie Gilman in a publication on the preservation of the fries. ${ }^{47}$ Jason Rhoades started the performance by shooting French fries with a self-made "potato gun." He loaded the gun with potatoes and used a special type of hairspray as a combustible. ${ }^{48}$ After the "shooting" (reminiscent of Nikki de Saint Phalle's "shooting paintings"), the fries were collected by the artist and baked in an aluminium cooker, placed outside of the museum. ${ }^{49}$ According to Rhoades, the production of the fries was not only a national symbol but also referred to the "sophisticated oil painting technique used by fifteenth century painting techniques," as Gilman states..$^{\circ}$

After the respective performances were carried out (both inside and outside the gallery space), their remainders - such as the motorcycle, the Jacuzzi, and the fries - were stacked inside a frame (or open "box"), together with other consumer objects and utensils, construction material, and a printed reproduction of the Altarpiece. Some objects were displayed outside the frame, in the otherwise empty space of the gallery.

After the initial period of display, P.I.G. (Piece in Ghent) has been reinstalled at least twice, in 2001 and 2010. In the following paragraphs, the discussion will revolve around the question what strategies were followed regarding the site specificity and conservation of the installation.

\section{Conservation or Reperformance of Shooting and Baking the French Fries?}

Rhoades declared that, because the fries were comparable to religious relics, their fading colour and distortion should not be considered a problem, as long as they would be presented according to museum standards. If their degradation had advanced to an unacceptable degree, an alternative option was to reperform the shooting and to bake the fries again. For that purpose, Rhoades provided an extensive manual to the museum, including precise

47 Julie Gilman, Liesbeth Jacxens, and Bruno Demeulenaer, “Conservation Strategy for FoodBased Perishable Art: Preservation versus Reconstruction Illustrated by Piece in Ghent by Jason Rhoades," Studies in Conservation 61, no. 1 (2016): 3-12.

48 Rhoades composed so-called A.B.S guns from parts he collected from DIY stores, to which he added Aqua Net hairspray as a propellent to shoot the potatoes through the mesh. Besides the five guns provided for P.I.G., Rhoades also produced and signed a series of multiples of the so called A.B.S. Gun with Pom Fritz Choke and Aqua Net. These are now in several museums and private collections. Gilman et al., "Piece in Ghent," $5^{-8 .}$

49 For Nikki de Saint Phalle's “shooting painings," see: e.g., https://www.moma.org/collection/ works/150143\# (last accessed 26 April 2021).

$5^{0}$ Gilman et al., "Piece in Ghent," 4. 
instructions for the production process. In addition, S.M.A.K. received a toolkit with no less than five, differently sized "guns" for shooting the potatoes; the guns could be put together by the conservator or collection manager in case a reperformance of the fries was required.

Ethical considerations and safety reasons kept the staff members from undertaking this action, notwithstanding the gradual degradation of the fries..$^{11}$ Instead, the original fries were preserved by applying similar packing techniques as in the food industry. ${ }^{52}$ The underlying motive for this approach was to "freeze" the original installation artwork in the best possible way. As the conservator suggests, an alternative option would be to repeat the performance in a different way, by recreating a series of French fries like a "mock-up" of the originals. When the fries would be reconstructed, their form would resemble the fries of the original piece, whereas in the act of shooting the fries of the original performance would be repeated - two different ways of perpetuation. ${ }^{3}$

\section{Strategies of Flux or Freeze?}

During the first months when P.I.G. was on display, visitors were allowed to move parts of the installation around, and Rhoades himself adjusted the installation several times. Transformation of the artwork was intended by Rhoades, although at a certain point, he drafted guidelines for how the work should be reinstalled in the future. On the front page of the manual, he wrote:

Jason Rhoades reserves the right to change, alter or otherwise improve the product at any time without prior notice. ${ }^{54}$

In other words, the artist himself was allowed to make adjustments to the installation when he deemed this appropriate. In 2001, this situation changed when S.M.A.K. invited Rhoades to reinstall the work and renew the

51 Gilman et al., "Piece in Ghent," 8.

52 Gilman et al., "Piece in Ghent," 9-10. Gilman describes the options of several food preservation techniques applied, such as Modified Atmosphere Packaging, reducing the oxygen content, and storing the fries in packages constructed from a suitable barrier film. An additional treatment could consist of a technique of controlled freeze-drying.

53 Gilman et al., "Piece in Ghent," 9. Gilman's research has shown that the fries are in a "microbiologically stable condition" and that further decay would be prevented by using Modified Atmosphere Packaging, frequently applied in the food industry as well as in the preservation of artworks. For recreation of the French fries, also see Gilman et al., "Piece in Ghent," 10.

54 Gilman et al., "Piece in Ghent," 6. 
guidelines for reinstallation. At that moment, a more definitive spatial design was determined and a "a strict scenography" was designed, as conservator Gilman observes. ${ }^{55}$ The openness to alteration had given way to a freeze strategy, with respect to the arrangement of the objects inside the frame as well as to its site-specific relation to the surrounding gallery space.

When P.I.G. (Piece in Ghent) was reinstalled again in 2010, S.M.A.K. continued with a "freeze-framing strategy," following the meticulous registration of the 2001 version. ${ }^{6}$ On this occasion, the museum's website stated that in-depth research and elaborate documentation methods had been applied, so that the arrangement devised by Jason Rhoades in 2001 could be adhered to with every new display. ${ }^{57}$ It can therefore be concluded that although P.I.G. (Piece in Ghent) started as a processual, open-ended site-specific installation artwork, both Jason Rhoades and the museum eventually established a "frozen" state; individual elements of the installation are well preserved or, if needed, can be recreated. As long as the initial exhibition space remains available for staging P.I.G., its physical site specificity is guaranteed. I would add to this that the "social space of perpetuation and care" is considered in this case an appropriate substitute for the dynamics of the "production space" of the initial iteration.

\subsection{The Spatial Network "In Flux"}

Based on the above examination of Jason Rhoades's SLOTO. The Secret Life of the Onion and P.I.G. (Piece in Ghent), the analysis of shifts in the spatial network continues by looking into the curatorial decisions regarding the reinstallation and further elaboration of the social spaces of production.

With the relocation to a smaller gallery space in the museum's old wing, the original spatial design of $S L O T O$ was affected by exchanging the central part with Donald Judd's Untitled. On the other hand, the other two parts - the Porky's Train and the "laboratory" placed along the walls - reappeared in

55 Gilman et al., "Piece in Ghent," 5-6.

$5^{6}$ The display of P.I.G (Piece in Ghent) was part of the European project Inside Installations in S.M.A.K., which ran from 5 June to 3 December 2010, https://smak.be/en/exhibitions/ inside-installations-collectietentoonstelling.

57 S.M.A.K. followed the principle of documenting every single part of the installation and taking this as guidance for reinstallation. As Niek Hendrix observes: "Het grootste probleem is dat alles heel precies vastgelegd is hoe het moet." (The biggest problem is that everything recorded should be followed; translation by the author.) http://www.lost-painters.nl/s-m-a-kinside-installations/ (last accessed 26 April 2021). 
the installation in much the same way. In terms of the triad of spatiality, the relocation of SLOTO to a white cube gallery interfered with the spatial design as intended by the artist and deviated to a large extent from the representational space of underground processes of growth and cultivation (although the onions and references to cultivation were still present in the onions and jars included in the installation). Even so, the Porky's Train was appointed the "heart" of the spatial arrangement and Judd's Untitled replaced the representational function of Van Abbemuseum's collection (originally represented by the thumbnails inserted into the video games and jars). This is not to say that other functions of the spatial network were affected in an equal manner.

One of the questions of this chapter is if and how the initial spaces of production (engaging the museum spaces and its staff members) played a role in the second staging of SLOTO. The way in which Jason Rhoades encouraged the staff to take part in assembling the installation's constituents and engaged them in other preparatory acts is somewhat similar to what the artist expected from participatory audiences and custodians in the case of P.I.G. (Piece in Ghent) or The Black Pussy. Such involvement of various types of participants in the production of the installation was common practice for Jason Rhoades during the preparatory stage. However, as we have seen above with P.I.G., soon after the first phase of performance and experiment, his installations are often "fixed" in a definite form. Either on the initiative of the artist or on that of the custodians, especially after the artist had passed away. Based on Lefebvre's notion of the social space of production, I recognize this "freeze" strategy as an attempt to expand the initial spatial production practice, which is thus defined as the most "authentic" stage of the artwork. Such an extension of the original production practice is, for example, pursued by S.M.A.K. in the preservation of physical constituents, such as the French fries, and in a freeze strategy regarding the spatial design of the installation.

A different approach was followed by the Van Abbemuseum. Here, I observe a conversion of the initial social space of production into the social space of perpetuation and care as an active space of meaning production. Although the Van Abbemuseum took similar measures for the conservation of the content of the jars, vessels, and other physical constituents, the initial production was continued with a curatorial intervention to adapt the installation to a different gallery space..$^{8}$ In the absence of the artist,

58 For example, conservation research was carried out by conservator Lydia Beerkens in order to preserve the oil and contents of the demijohn jars. See the conservation report by Lydia Beerkens, 2002 (archive of Van Abbemuseum). 
this conversion took shape on the basis of available information and a professional assessment of the situation. I would argue that communication and negotiation with the artist - which in other circumstances might have been part of the reinstallation process - still contributed to this conversion, because a reconstruction was made following the artist's intentions (derived from the set of drawings and comments). For the other part, an extensive decision-making process was carried out by the curators themselves.

In the preceding chapters, I have frequently argued that site-specific installation artworks problematize the opposition of the artwork and the site, and in this respect the second staging of SLOTO may serve as an example of how the connection between the artwork and the site of its manifestation (the white cube gallery space) is redefined by means of a curatorial scenario, in this case interpreted as an activation of the space of perpetuation and care. ${ }^{59}$

\section{Continued Dialogue with the Work of Art}

In view of the above, there is an interesting statement by Jason Rhoades regarding the "real time" of his installations. Julien Bismuth describes how the artist envisioned the interference of time with his installations:

In the videotaped interview with Hans Ulrich Obrist cited above, Rhoades explains that he is primarily interested in having things function in real time and in the real world, open to all the concomitant contingencies, and made vulnerable by their exposure. "I believe in making things lie in a precarious state $[. .$.$] because they have to function in real time, they$ have to function in reality," he explains. ${ }^{60}$

This precarious state, entangled with the here and now of the exhibition site, is at odds with "freeze-framing" strategies of musealization and preservation, as Bismuth's statement continues:

Whereas the way we handle objects in exhibitions is predicated on the idea of an immutable work that is always exhibited in the same preserved

59 One additional comment could be made concerning the inner compartment of the original. The disappearance of this part during the second staging might cause a side effect that certain conservation actions are circumvented (like upgrading the functionalities to current display formats). This would potentially limit a reinstallation at the original site, if ever possible again in the future.

6 o Bismuth, PeaRoeFoam, 55. Bismuth refers to a videotaped interview with Jason Rhoades by Hans Ulrich Obrist, 1998 (no further reference available). 
or archival condition, Rhoades goes on to explain that he is interested in working with rather than against the inevitable alterations of material objects: "so many things don't have the capacity not to work [...] they should have the capacity not to work [...] and that should be okay, but most art is made in a way that can't accommodate that, because there's no life in it, no reality." ${ }^{n 1}$

Applying this statement to The Secret Life of the Onion, Rhoades might not have resented when technical devices (such as the video games or flickering neon lights) were not functioning in the exact same way as during the initial manifestation. In other respects, too, he might have applauded the installation becoming part of a new "reality." The curators took over by accommodating SLOTO to the actuality of the exhibition context of For Eindhoven - The City as Muse, dedicated to the museum's strategies of collecting and presenting contemporary art. The press release states that some of the artworks were shown in a new form and context, which clearly applies to this reinterpretation of SLOTO. In terms of the physical components of the installation, this iteration could be repeated relatively easily in the future, following a similar scenario. The alternative to this option would be that a strategy of freeze-framing would once again prevail, which in terms of the site-specific network implies that SLOTO would no longer represent an activated space of perpetuation and care, nor would it revive the function of the installation's representational site specificity.

At this point, once more a reference can be made to the site-specific installations created during the 1960 s and 1970s, in particular regarding the ongoing dialogue between artists and custodians. Jason Rhoades engaged the museum's staff members perhaps even to a greater extent than, for example, Robert Morris in the 1960s (with the Amsterdam Project; see chapter 2). Clearly, his intention was to root the installation in the specific context of the Van Abbemuseum by engaging the staff in the production, by employing the site specificity of the basement, and by incorporating thumbnails of the entire museum collection. What the example of P.I.G. has shown, and what might happen with SLOTO, too, is that most of those site-specific strategies do not survive in the longer term. It seems unavoidable that site-specific installations become site-generic at some point, due to their extended 
lives in the white cube gallery - described by Brian O'Doherty as "a place deprived of location." ${ }^{62}$

The question arises if SLOTO has transformed into a site-generic installation, given its replacement to a white cube gallery and the fact that a dialogue with the artist could not be continued. I believe that Lefebvre's notion of representational space can shed a different light, because it emphasizes the dynamics of meaning production as a function of the "lived space, the locus of ideas and aspirations." 33 Even with a shift in the spatial arrangement, and in the absence of the artist, the curators continued a dialogue with $S L O T O$, precisely by adapting the work to the conditions of the new site.

According to Christiane Berndes, the significance of SLOTO for the collection of the Van Abbemuseum is that the work resonates with an open-minded policy, a continuous interrogation of the museum's own curatorial practices:

For us the philosophy of the museum is central. That determines the room we leave to the actors, how you want the artwork to survive, how open you are to reinterpretation. In the past, institutional criticism took place in the gallery space. Today we are looking for an open dialogue with the artists, and vice versa. Curation develops into the direction of developing a scenography. How you position the museum and how you organize the scenography. ${ }^{64}$

By analogy with Berndes's statement, a distinction can be made between the strategy followed by Jason Rhoades and the stance taken by site-specific working artists from the previous generation. Instead of criticizing the institution from within, Rhoades made use of dialogue, and he engaged staff members in the production of his installations, rooting his work in museum institutions from the start. The Van Abbemuseum's response was a reversed strategy - reactivating the work's representational space - by employing the installation, both for their exhibition programme and for the underlying philosophy. ${ }^{6}$ In this respect, it is worth mentioning that

62 Brian O'Doherty, Inside the White Cube, The Ideology of the Gallery Space (Expanded Edition) (Berkeley: University of California Press, 1986), 8 o.

63 Henri Lefebvre, The Production of Space, trans. Donald Nicholson-Smith (Oxford: Blackwell Publishing, 1991), 42.

64 Interview with Christiane Berndes. See footnote 33 of this chapter.

65 The curatorial strategy of "open dialogue" and coproduction was followed with an exhibition programme in the Van Abbemuseum dedicated to the Politics of Collecting - The Collecting of Politics, starting in 2010 and lasting for several years. 
the representational function of the initial project space in the museum's basement was transformed in 2018; currently, it serves as a public space for dialogue. ${ }^{66}$

Before completing this case study, I would like to note that the Van Abbemuseum is passionate to give insight into their thoughts and curatorial considerations, and the above analyses could only be made, because I was allowed access to the archives, as well as to the curators' argumentation for the decision-making. The general public, however, is usually not informed about those strategies and underlying thoughts, and there was no clarifying text accompanying the second staging of SLOTO. It might have been an added value to the visitors' experience if the reasons for the intervention had been explained, in a similar fashion to the information text explaining the meaning of the "laboratory space" during the initial staging of the work.

\subsection{Conclusion}

A large part of this case study was dedicated to a reflection on the processbased content and production of SLOTO. The Secret Life of the Onion in relation to its site specificity. Because Jason Rhoades deliberately involved the staff members in the production process and incorporated the museum site and its collection in his installation, the functions of social space and representational space played an important role in the discussion on the shifts in spatial functions that occurred between the first and second staging. A radical deviation was caused by the loss of the initial site (the project space in the basement) and the absence of the artist during the second iteration. In addition, I identified other functions of the spatial network as important parameters for the perpetuation of the artwork: first, I identified a shift from the production space to the social space of perpetuation and care, based on the curators' interpretation of the set of drawings and comments provided by the artist and earlier communications. Furthermore, I analysed the radical change of the second staging as a confirmation of the value attributed to SLOTO from the start, in other words, its function for the museum's representational space. Envisioning the museum as place for dialogue, and striving for interaction between different works from the collection in their exhibition philosophy, the Van

66 The design of The Parliament is inspired by the Kurdish People's Parliament of Rojava in northern Syria and has a representational function for stimulating dialogue. This space is a cocreation between the museum, the artist Jonas Staal, and a production team. 
Abbemuseum took the freedom of interpretation, which reaches beyond the usual strategies applied to reinstallations of contemporary art. Indeed, the sudden death of Jason Rhoades and the absence of instructions for future iterations has given the custodians a prominent role, probably more than otherwise had been considered to be ethically justified. But I suggested that, from the perspective of site-specific working artists who strive for integration of their installations with the "lived" environment and current context of display, this approach might open up the vista for custodians to become more actively involved in the reinterpretation of a site-specific work, adjusting it to the co-ordinates of place and time. The comparison with P.I.G. made clear that different museums may follow different strategies. The strategy followed in P.I.G.s particular case - the artist drawing up an instruction guideline and the museum's effort to preserve all ingredients (including the fries) - was interpreted as the museum's desire for freezing the installation in an authentic spatial production stage. It remains to be seen how the Van Abbemuseum will approach a future staging of SLOTO; whether a different relationship between the artwork and the site will be obtained, or whether the scenario of the second staging will be repeated (which just as well will freeze the artwork in a particular biographical stage).

Having said that, there is still a follow-up question that concerns me: is it conceivable that the authority of the artist is conveyed to conservators and curators, and if so, should there be preconditions, and how would those be defined? The artist's legacy is often in the hands of legal and artistic inheritors, as we have seen in the introductory example of Dieter Roth's Garden Sculpture. In the case of SLOTO, the curators acted, in a sense, like the legacy keepers of the installation. A similar approach could be followed by establishing "knowledgeable networks," as suggested in the case study on Ernesto Neto's Célula Nave.

During my research for the current case, I touched upon an example showing active involvement of such a network in the effort to stage Jason Rhoades's works in a contemporary context. Admitting that I have no definite answer to the above question (it would deserve another research project), I would like to end this chapter by reciting it.

In 2015, a retrospective exhibition, Jason Rhoades, Four Roads, was organized by the Institute of Contemporary Art of the University of Pennsylvania. ${ }^{67}$

67 The exhibition Jason Rhoades, Four Roads was held at the Institute of Contemporary Art, University of Pennsylvania, Philadelphia, in 2014, curated by Ingrid Schaffner. The exhibition 
The curator of the exhibition, Ingrid Schaffner, recalls how the team proceeded during the preparation of the show:

We worked closely with the artist's estate and studio manager (whose involvement was essential), with the two galleries that represented Rhoades throughout his career, and with artists, scholars, curators, dealers, and collectors who were close to Rhoades and his art. It was a collective and discursive effort on every level, as well as a generative one. ${ }^{68}$

The artist's assistants, conservators and exhibition designers who had worked with Jason Rhoades in the past, were involved in the project "to have his work work" and contributed to the interpretation that was needed after so many years of relative curatorial silence. ${ }^{69}$ It was a collective effort, which replaced the presence of the artist; the group decided in what ways the artist's intentions would best be represented at the exhibition. I see this as an activation of the function of the social space, denoted by Lefebvre as a guaranteed level of competence in production practices, because the members of the group "know what to do" when they inhabit the same space (see chapter 3). Transposed to the reinstallation of site-specific installation artworks, I would argue that the collective can be large (as in the case of Jason Rhoades, Four Roads) or small (as with the second iteration of SLOTO), but in all cases the social space is defined by the occasion of a particular exhibition. In other words, the reactivation of the network of spatial functions is temporary and specific for a given occasion. Universal solutions can hardly be provided for artworks that are inherently depending on the co-ordinates of time and space, but the more knowledge is collected on previous iterations and the more expertise is available on the possibilities of reinvigorating the artwork's site-specific dimensions, the bigger the chances of being able to perpetuate the "life" of a site-specific installation.

travelled to Kunsthalle Bremen, Germany, and BALTIC Centre for Contemporary Art, England. https://icaphila.org/exhibitions/jason-rhoades-four-roads/ (last accessed 26 April 2021).

68 Schaffner, "Jason Rhoades," unpaginated. See footnote 1 of this chapter.

69 Schaffner, "Jason Rhoades," unpaginated. 



\section{$6 \quad$ Drifting Producers}

The Perpetuation of an Installation Artwork Emerging from a Site-Specific Project

Keywords: urban structures, cross-cultural dialogue, craftsmanship, Situationist International, Flying City, New Babylon

"Those who admire the western Alexandrian tradition - the magicians of Surrealism, the sorcerers of illegible language - have been constructing general images of the dream. But we need to redefine the notion of the dream in a completely different context, as a space where reality returns."

Jeon Yongseok $^{1}$

Drifting Producers (2004) is an installation artwork built around three large urban models representing a utopian city. [Figure 27] The installation is created by a group of South Korean artists, designers, and curators who call themselves Flying City. The installation is part of a larger project which the artists carried out in an old neighbourhood in Seoul. The project and the installation of Drifting Producers (they bear the same title) are interconnected, although the project lasted for many years (2003-2009) and took many different forms, such as art-and-community workshops, performances, publications, and yet another installation artwork (no longer existent).

With this project, the artists aimed to raise awareness for a network of metal craftspeople and traders who had brought relative prosperity to the neighbourhood and were threatened to be expelled from the district due to urban renovation. Flying City saw it as their mission to preserve the ideas behind this network and to pay tribute to the skills of the metal craftspeople: the models they created for the installation were spatial representations

1 Jeon Yongseok, "Drifting Producers," in Art and Social Change: A Critical Reader, ed. Will Bradley and Charles Esche (London: Tate Publishing, 2008), 373.

Scholte, T., The Perpetuation of Site-Specific Installation Artworks in Museums. Staging Contemporary Art. Amsterdam: Amsterdam University Press 2022 DOI: 10.5117/9789463723763_CHo6 
Figure 27 Drifting Producers (2004) by Flying City. Collection Van Abbemuseum, Eindhoven. Installation view in Plugln \#7 in 2006. Photo: Peter Cox. Courtesy photographer and Van Abbemuseum archive, Eindhoven. ๑) Flying City.

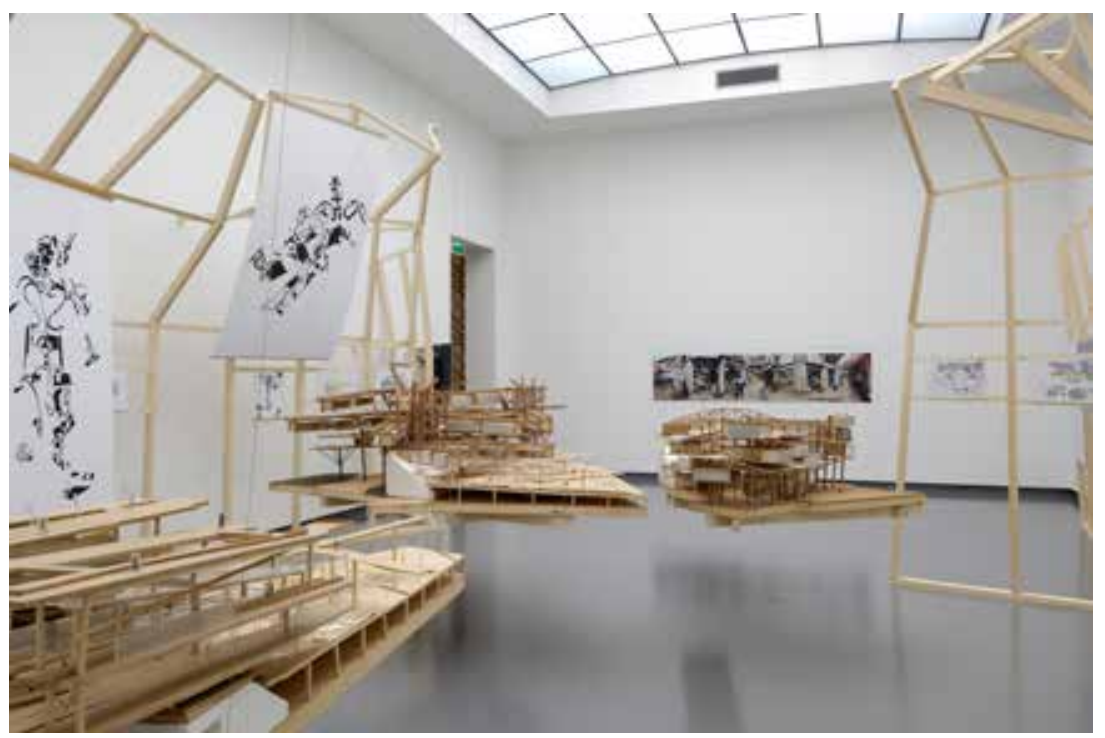

of the labyrinthian structure of workplaces of the metal craftspeople; in the drawings, photographs, and other images, references were made to the tools made by the metal craftspeople and to design objects created by the artists themselves. Furthermore, the models were accompanied by documentation about the history of the neighbourhood and the protests against the impending demolishment of the district in the early 2000 . This conglomerate of heterogeneous elements constitutes the installation artwork Drifting Producers, which has been in the collection of the Van Abbemuseum since 2006.

The site specificity of Drifting Producers is determined by both the sociogeographical context of the project and the urban structure and production practices of its inhabitants, which the artists tried to preserve. The artists were inspired by the history of the neighbourhood and engaged with the local community, which is an analogy with case examples mentioned in chapter 3 discussed in relation to sociogeographical site specificity. For example, in Phil Collins's they shoot horses, the young dancers in Ramallah participated in the project by filming themselves; later on, Phil Collins and members of the technical department Tate (the owner of the piece) turned the raw footage of the dance marathon into an installation artwork. Although 
there are major differences between both installations, a similarity can be observed in the process of transformation: from a sociogeographical project into a permanent installation artwork in a museum collection. As this chapter will show, when the artwork is subjected to the mechanisms of musealization and presentation, the spatiotemporal co-ordinates of the museum environment often determine the final stage of such a site-specific project.

The questions of this case study address this transition process and its consequences for the installation's network of spatial functions. Is there a breach at the moment of acquisition and what happens at subsequent stages of the work? What is the impact of the conservation measures and display strategies, followed by the hosting institution, on its content and form? What was left of the connection between the work and the site-specific project after the project ended in 2009?

The questions are investigated with the help of the conceptual model proposed in this book. Firstly, I will look into the relationship between the spatial design of the artwork and the various sites of its presentation, in terms of the triad of spatiality between the physical space and representational space. Secondly, the study focuses on the social spaces of production since the function of social networks is omnipresent in Drifting Producers. During the project of Drifting Producers, the artists activated the local network of craftspeople and other participants in the art-and-community workshops. Furthermore, the artists formed their own network - the collective Flying City - and lastly, the group was involved in an international network of art curators and artists, in which also the current director of the Van Abbemuseum, Charles Esche, participated. The chapter clarifies that the personal relationship between two main actors, the museum director and the principal artist of Flying City, as well as networks in which they were involved, played a crucial role in the realization and perpetuation of the installation Drifting Producers.

Drifting Producers is intertwined with an activist approach towards the sociogeographical circumstances of a specific place (the neighbourhood in Seoul), as it was the artists' intent to introduce the artwork in the international art world and to establish an ongoing relationship with the museum "site." Besides, the custodians had their own ambitions with the acquisition, and they had the intention to stay involved with the project. To understand this interrelatedness of various (and at times, contradictory) intentions and the perpetuation of the work, the notion of the script is beneficial, because this enables us to analyse the conglomerate of underlying 
motives (of the artists to produce the installation and of the custodians to keep it alive), and to recognize the steering factors that caused shifts in the spatial network when the installation was relocated from one context to another.

The chapter starts with a brief introduction of the artists and the early work of the collective Flying City in their role as urban researchers. This stage coincided with the international workshops held in Asia, where a professional relationship was established between Jeon Yongseok and Charles Esche. The chapter continues with a description of the project Drifting Producers and the art-and-community workshops, organized by the artists in the neighbourhood in Seoul.

Employing the conceptual model, I examine the first exhibition of the installation Drifting Producers in terms of the functions of the spatial network, including the production spaces and social networks involved. Of significance in this respect is, apart from the engagement with the local community, the purpose of the artists to establish a connection with the international network of art critics and museums. During cross-cultural workshops, organized by Charles Esche, among others, the artists became acquainted with the New Babylon project (1956-1974) by Dutch artist Constant Nieuwenhuys (best known as Constant). The urban models created by Constant and his utopian vision on city life inspired the Korean artists, who welcomed the idea of Drifting Producers being recognized as a comparable project given shape at the other end of the world.

The next sections are dedicated to a relocation of the installation from Seoul to international art venues and the acquisition by the Van Abbemuseum. The analysis continues by scrutinizing various scenarios - developed both by the artists and the custodians - for the perpetuation of Drifting Producers in the Van Abbemuseum (with an emphasis on the social space of perpetuation and care). This helps to understand the modification of the spatial design to a museum environment and gives insight into the custodians' stance towards the sociogeographical and representational function of the work.

The chapter ends with a discussion of the New Babylon project and its two retrospective exhibitions (both in 2016), one in Museo Nacional Centro de Arte Reina Sofia in Madrid and one in the Kunstmuseum Den Haag (The Hague). This comparison illustrates two different exhibition strategies regarding Constant's urban models and their role in communicating his sociogeographical project to a contemporary public. 
Figure 28 Jeon Yongseok, leading artist of Flying City, in front of the Gwangmyeong Lifetime Education Center in Seoul, 2011. Photo by the author.

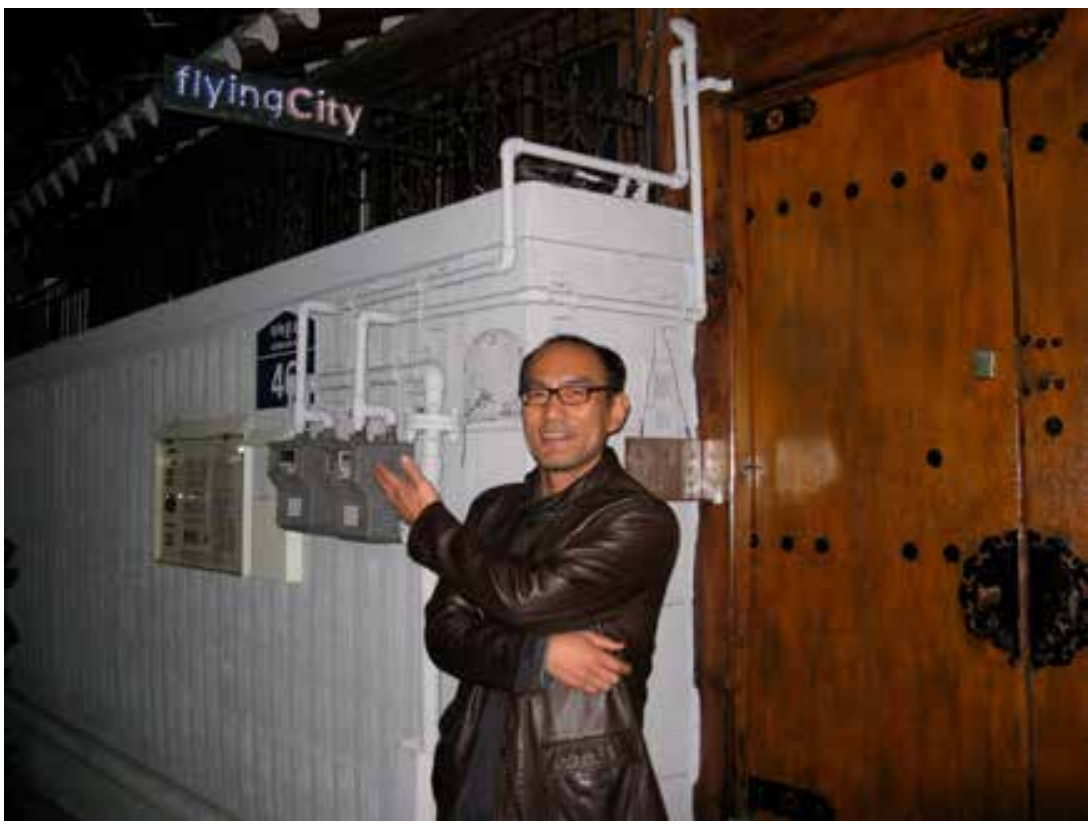

\section{Flying City}

Flying City is a collective formed by artists, designers, and curators who live and work in Seoul, South Korea. ${ }^{2}$ In 2001, Jeon Yongseok, Jang Jongkwan, and Kim Gisu established the collective. ${ }^{3}$ Until 2009, Flying City participated in national and international exhibitions, in various constellations. ${ }^{4}$ The founding members of the group belong to a first generation of artists who experienced the effects of globalization on the South Korean lifestyle in the 1990s. They responded to the societal changes and urban renewal of the metropolis Seoul with a wide variety of artistic expressions: performances in public space, films, photographs, as well as art-and-community projects,

2 The artists write the name of their collective as flyingCity, but in literature it is often referred to as Flying City. Unless spelled differently in a quote, I will use the spelling Flying City.

3 The English rendition of Korean names is not standardized. I will follow the Asian order of putting family names first, followed by a given name, and employ spelling of names as preferred in the literature.

4 One of the last group exhibitions in which Flying City participated is Weak Signals, Wild Cards, curatorial programme of De Appel, Tolhuistuin Amsterdam, 27 June-27 July 2009. 
carried out with a sense of humour and imagination. As art critic Mark Kremer observes in 2003:

These artists are driven by the desire to depict the consequences of these changes: what Seoul looks like now but also what has been forgotten and suppressed in the process. These artists show Seoul as it is, but also as it could be imagined. 5

Jeon Yongseok (Gwanju, 1968), whose works have been exhibited at venues worldwide, is the leading artist of the group. ${ }^{6} \mathrm{He}$ is also product designer and teaches at the Gwangmyeong Lifetime Education Center. ${ }^{7}$ In one of the remaining traditional wooden houses of the city, Jeon educates children about the history and cultural heritage of Seoul. ${ }^{8}$ [Figure 28] During an interview I conducted with the artist in 2011, Jeon explained that the idea for the urban research project Drifting Producers was inspired by the socioeconomic and urban changes starting in the 1980s, when Seoul went through a period of radical change. The urban structure was deeply affected by globalization and modernization, especially when the city hosted the Olympic Games in 1988 and old neighbourhoods gave way to business centres, apartment buildings, and highways. As a consequence, residents had to move, and many of Seoul's old shanty towns were demolished. ${ }^{9}$ More than a decade later, a documentary film about a famous revolt against those developments was the incentive for establishing the Flying City collective. ${ }^{10}$

5 Mark Kremer, "Flying City 'Invitation to Drift," in Facing Korea. Dutch-Korean Contemporary Art, exhibition catalogue (Amsterdam: Yellow Sea Publications, 2003), 158.

6 Over the last ten years, Jeon participated, for example, in the 2015 Jakarta Biennial; Public Commotions: 1998-2012 at Art Space Pool, Seoul, in 2013; and Weak Signals, Wild Cards at Tolhuistuin Amsterdam, in 2009.

7 The UNESCO Institute for Lifelong Learning Gwangmyeong aims to provide opportunities of self-development for low-income citizens. See https://uil.unesco.org/city/gwangmyeong (last accessed 26 April 2021).

8 Bearing the motto "Learn to reinterpret urban reality," Jeon Yongseok organizes workshops for children and adults. Jeon is also the theorist and legacy keeper of the project Drifting Producers.

9 Shanty towns are temporary dwellings built from materials at hand, comparable to slums or favelas in other countries.

10 Flying City took its name from a famous watchtower, built by citizens of a shanty town to keep an eye on the police charges. Jeon: "The tower stood there weirdly among the demolished houses, like a spaceship landed among ruins. It was an aesthetic picture, but earthy at the same time. The name flyingCity directly came into my head, and it became our name." Mark Kremer, "See Seoul, Then Die: The flyingCity Experience," published on the flyingCity website in 2005 http://flyingcity.kr/text-eng/text.htm (no longer accessible, but the website has been archived by the Van Abbemuseum). 
Figure 29 Jeon Yongseok visits one of the metal craftsman in Cheonggyecheon district in Seoul, 2011. Photo by the author.

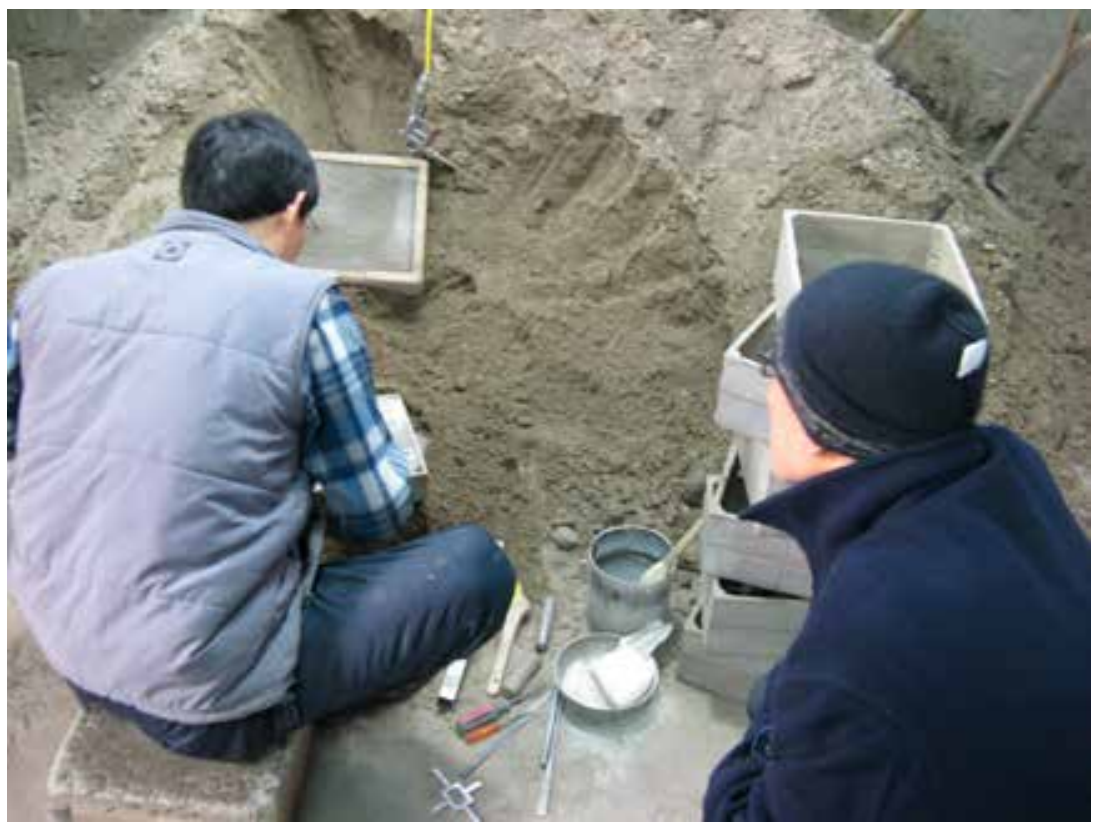

At the beginning, the work of Flying City was experimental, because the artists were still looking for a visual language that could shape the project. One of the earliest actions was visiting the workshops of the metal workers in the Cheonggyecheon district, in Seoul's city centre. [Figure 29] This area along the banks of the rivulet Cheonggye hosted numerous craft workshops and had developed into a flourishing trade area, with economic networks that functioned mainly on barter. In the early 2000s, the mayor issued a decree to move the workshops to a remote location aiming at further development of the area into an economic and tourist centre. The decree posed a serious threat to the well-functioning system of the Cheonggyecheon. For the artists, however, this situation offered an interesting starting point for the project.

One of their favourite strategies was to "spy around" in the workplaces of the metal craftspeople: to observe them at work and to capture the spatial structure of the workplaces in photographs and drawings, eventually leading to a large composite photograph: Power of Cheonggyecheon $\left(35^{8} \times 80 \mathrm{~cm}\right)$. [Figure 30] In exhibitions and installations, we often see Flying City artworks from earlier periods. For example, the composite photograph - one of the key elements of the installation Drifting Producers - was also shown as 
Figure 30 Power of Cheonggyecheon (2003) by Flying City, part of the installation Drifting Producers. Collection Van Abbemuseum, Eindhoven. Photo: Peter Cox. Courtesy photographer and Van Abbemuseum archive, Eindhoven. (c) Flying City.

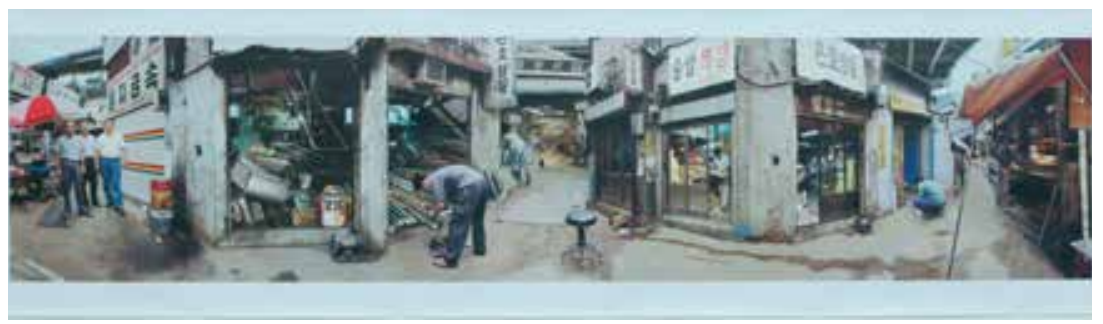

an independent artwork in another exhibition. ${ }^{11}$ Likewise, the art-andcommunity workshops, organized from 2001 onwards, continued until 2009 and became part of the project Drifting Producers. ${ }^{12}$

\section{International Workshops and Cross-Cultural Dialogue}

Around the turn of the twenty-first century, curators Hou Hanru and Charles Esche organized a series of international workshops in Asia with the aim to stimulate a cross-cultural dialogue among artists, curators, and theorists, focusing mainly on institutional frameworks in various countries. ${ }^{13}$ In the heyday of globalization, they recognized a general interest in exploring the activist potential of art in relation to urban structures, both in Asia and Europe; as Esche put it, there was a shared desire among the participants

11 The photograph Power of Cheonggyecheon was shown at the exhibition The Postman is a Genius. Experience and Imagination in Seoul in Amsterdam at De Appel, Foam, Canvas International Art, and the Netherlands Media Art Institute, 29 August-18 October 2003; it was also shown at Seoul-Asia Art Now, Modernization \& Urbanization in Seoul at the Marronnier Art Center, 26 September-19 October 2003. Both exhibitions were cocurated by Mark Kremer and Beck Jee-sook, and resulted from a collaboration between The Netherlands Media Art Institute and the Marronnier Art Center of the Korean Culture and Arts Foundation.

12 Jeon Yongseok kindly provided me with the information on the Drifting Producers project and its forerunners during the interview I conducted with the artist on 20 March 2011.

13 Hou Hanru cocreated, with Hans-Ulrich Obrist, the travelling exhibition Cities on the Move (1997-1998), bringing together various perspectives on modernization of city life and globalization, with a general focus on cities in the Asian hemisphere. At the time, Charles Esche was director of Rooseum Center for Contemporary Art in Malmö. 
to create "conditions where a particular community at particular places in the world can become activated."

Among the participants were Jeon Yongseok and other artists from the Flying City collective, who were inspired by the discussions to investigate the sociogeography of the Cheonggyecheon district. ${ }^{15}$ Simultaneously, Flying City was introduced to the international art scene and participated, for example, in the $4^{\text {th }}$ Gwangju Biennial (2002) and showed its work at exhibitions organized by Mark Kremer and Beck Jee-Sook, as part of an exchange programme between South Korea and the Netherlands (2003). ${ }^{16} \mathrm{~A}$ close professional relationship was established between the Korean artists and curators in the Netherlands, including the curator who became director of the Van Abbemuseum in 2004.

\subsection{The Project and the Installation Drifting Producers}

The incentive for starting the project Drifting Producers was the dire situation of the craftspeople and traders of Cheonggyecheon, who were threatened by a demolishment of the workplaces and disappearance of the economic and social structure of the neighbourhood. Underlying Flying City's artistic approach was their desire to conceive an alternative city, a dream space "where reality returns," as Jeon stated. The artists organized a series of art-and-community workshops for children, students, and citizens, who made drawings and architectural models for an "ideal" urban structure, using simple materials such as cardboard and plywood. ${ }^{17}$

At first, the drawings were rather like abstract expression, but as the projects went on, they revealed the character of an architectural structure

14 Interview with Charles Esche conducted on 24 March 2010. See also the interview with Charles Esche by Laura Vergara in which Esche states that the ultimate goal was to establish an international think tank for new discourses or even new "forms of democracy." Leire Vergara, "Art, Possibility and Democracy, Interview with Charles Esche," Zehar 57 (2005): 28, http://artxibo.arteleku.net/sites/all/libraries/pdfjs/web/viewer.html?file=http\%3A//artxibo. arteleku.net/en/islandora/object/arteleku\%253A5827/datastream/OBJ/view.

15 Both Charles Esche and Jeon Yongseok noted the significance of the meetings for the project Drifting Producers during the respective interviews I conducted in 2010 and 2011.

16 As part of the exchange programme, Flying City participated in the exhibitions The Postman is a Genius: Experience and Imagination in Seoul in Amsterdam and Seoul-Asia Art Now, Modernization \& Urbanization in Seoul. See footnote 11.

17 The workshops took place from 2001 to 2003 and were called Mental Maps and Urban Planning Play. 
and site planning. As a result, a sort of utopic urban planning was developed through this project. ${ }^{18}$

Parallel to the workshops, Flying City organized live performances and tours in the Cheonggyecheon district, and they exhibited their own art and design products in empty spaces in the neighbourhood. [Figure 31] When the project Drifting Producers started, the earlier initiatives were partly continued and some of the elements were reused, such as the workshops and performances, the composite photograph Power of Cheonggyecheon, and some of the drawings and urban models of the workplaces reappeared in the installation.

In 2004, Flying City created the installation artwork Drifting Producers for the Hermes Korea Contest for Contemporary Art, taking place in the Art Sonje Center in Seoul. ${ }^{19}$ The main part of the installation consisted of three large urban models, designed and made by the artists themselves. In the Art Sonje Center, the models were suspended from the ceiling of the gallery space and surrounded by an open framework made of wood. [Figure 32] Various components were attached to the frame, such as posters explaining the project with the help of statistics of manufacturing and trade in the Cheonggyecheon district, drawings of design products and banners created by the artists. [Figure 33] In addition, two monitors were part of the installation: one showing a PowerPoint of (imaginary) tools and industrial design products, the other showing a video of a protest meeting organized by the street vendors.

The display of this installation at the contest marked a new stage in the biography of Drifting Producers, because the installation was not produced by participants in one of the workshops, but by the artists themselves. They built the models as an "echo" of the architectural structure of the Cheonggyecheon workplaces, using wood, plywood, string, and pieces of styrofoam - shaping their own vision of an utopian city, instead of the more intuitive models made in the art-and-community workshops. Visitors could explore the interior spaces of the installation, and from various angles, they

18 Statement by Jeon published on his website. At the time of writing, information about the work of Flying City was collected from the website of flyingCity, offering a rich source of information about events, ideas, and anecdotes, as well as images. Unfortunately, this website no longer exists, but the Van Abbemuseum has captured and stored its content. I furthermore refer to Kremer, "Invitation to Drift" and the Wikipedia page "Public art in South Korea," https:// en.wikipedia.org/wiki/Public_art_in_South_Korea (last accessed 26 April 2021).

19 The Hermes Korea Award for Contemporary Art was organized by the Hermes Foundation Missulsang and took place in the Art Sonje Center, Seoul, 23 October-5 December 2004. 
Figure 31 Poster for a Flying City performance showing the artists and craftspeople in the Cheonggyecheon district, Seoul. Photo by the author. $\odot$ Flying City.

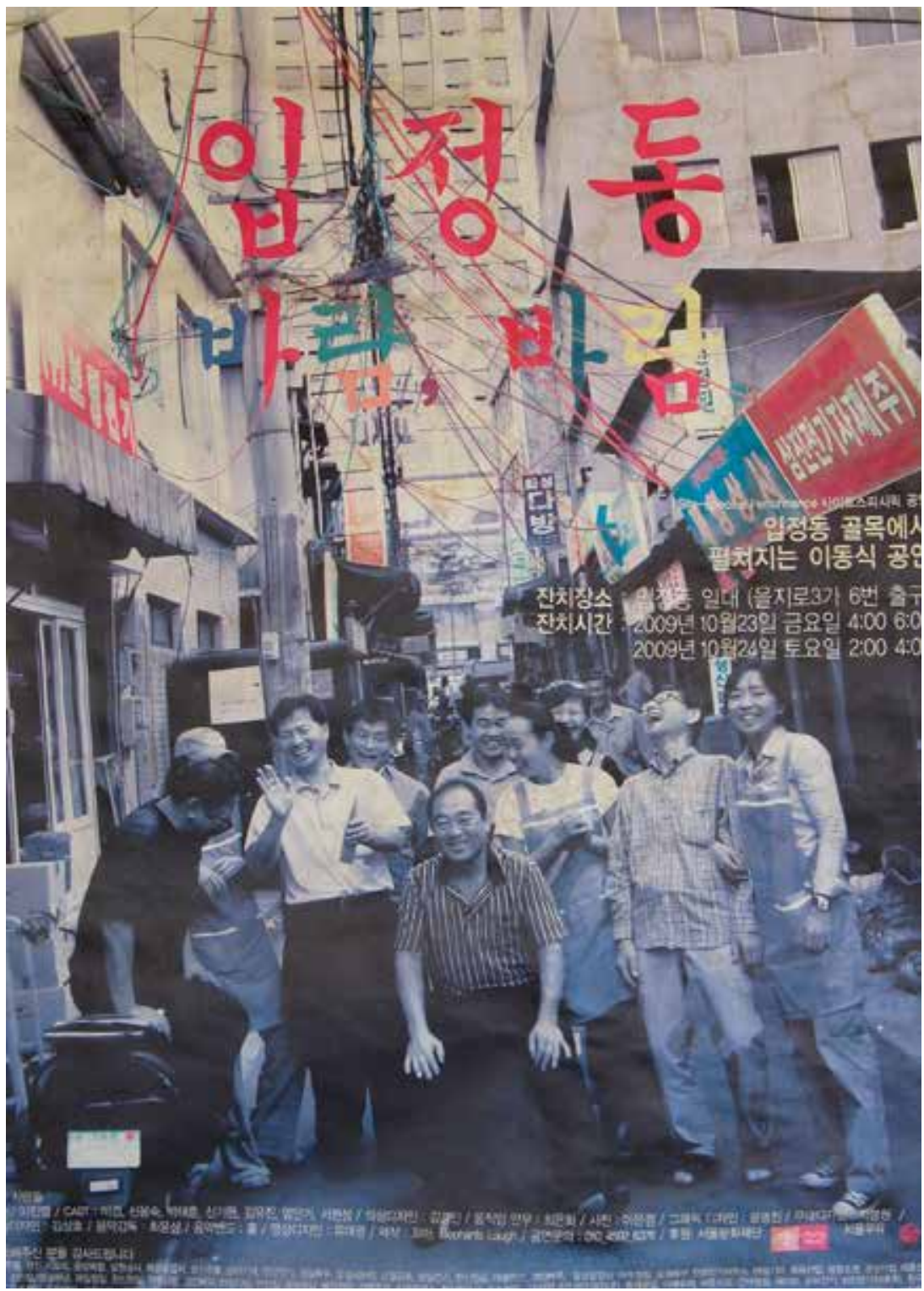


Figure 32 Drifting Producers (2004) by Flying City. Collection Van Abbemuseum, Eindhoven. Installation view in Plugln \#7 in 2006. Photo: Peter Cox. Courtesy photographer and Van Abbemuseum archive, Eindhoven. (c) Flying City.

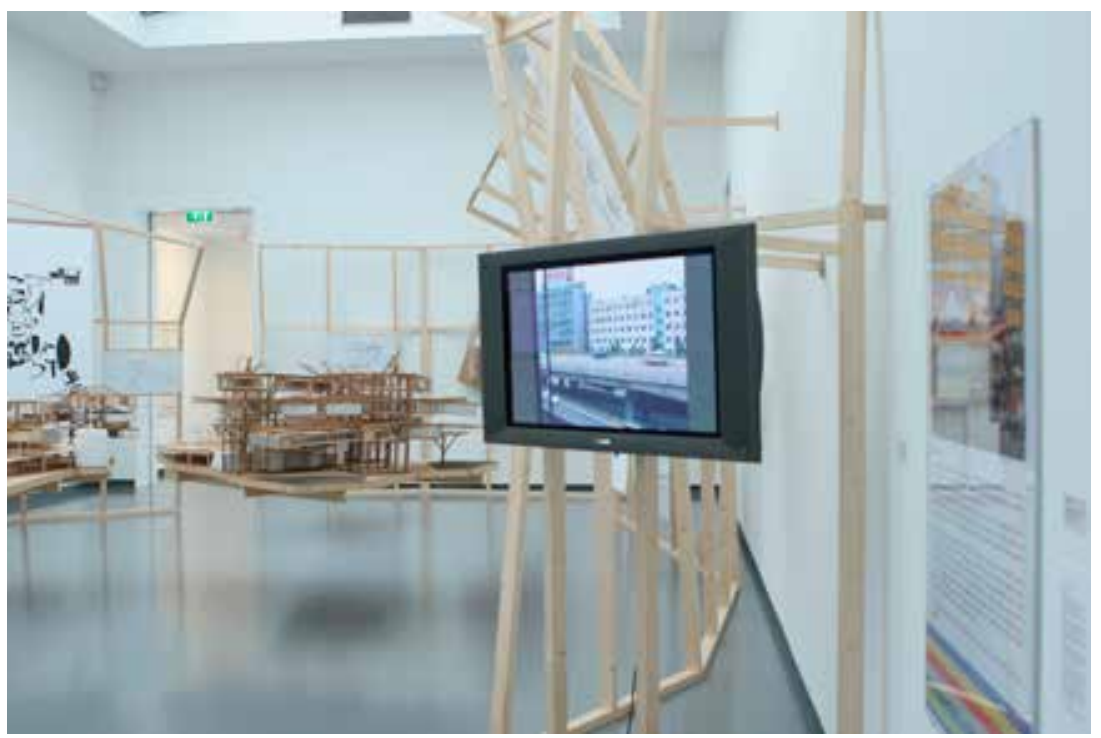

Figure 33 Drawing by Flying City, part of the installation Drifting Producers (2004). Collection Van Abbemuseum, Eindhoven. Photo: Peter Cox. Courtesy photographer and Archieven Van Abbemuseum, Eindhoven. (c) Flying City.

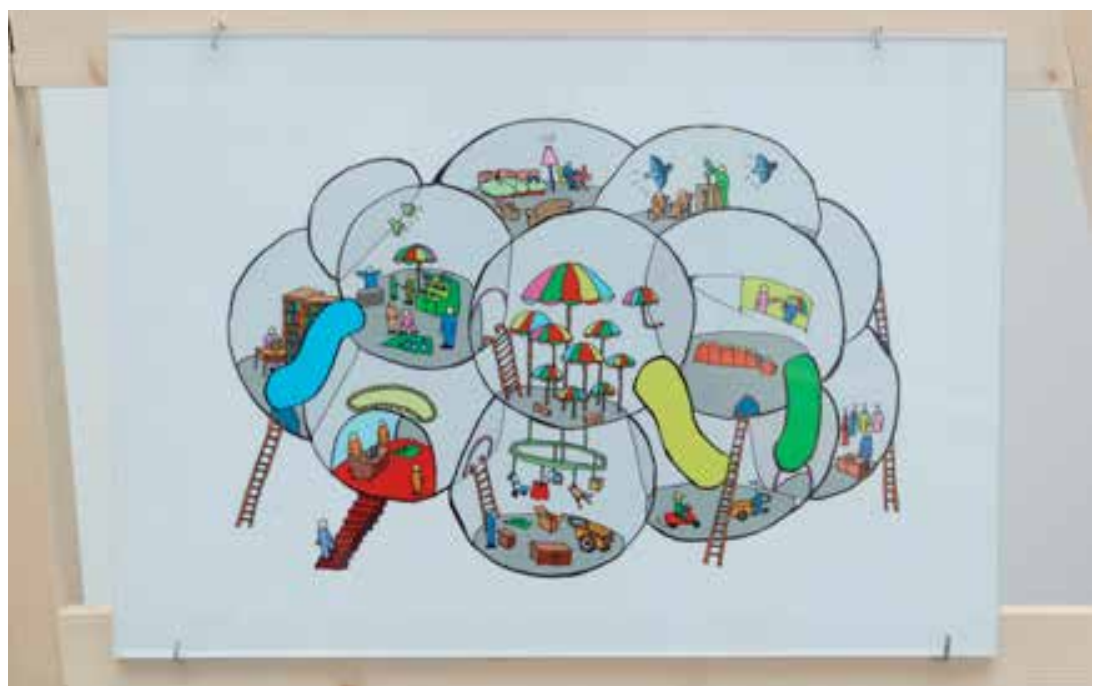


Diagram 12 Drifting Producers: The first staging 2004 and second staging 2005.

(c) The author. Image editing: Arienne Boelens.

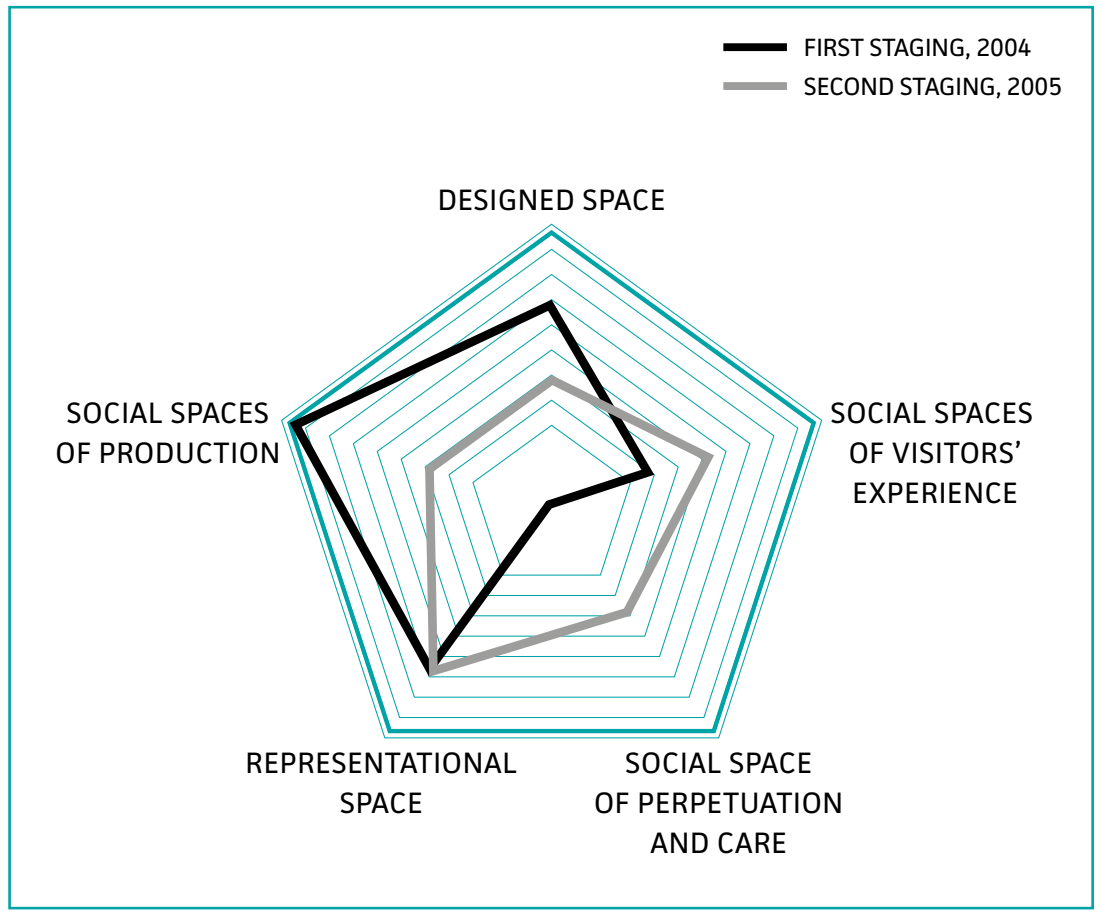

could look at the labyrinthine network of the models' spaces, passageways, and corridors in which tiny figurines were placed.

The installation Drifting Producers was selected as one of the three finalists of the contest and was praised for its artistic qualities and its representation of craftsmanship, which reflected the skills of the metal workers of Cheonggyecheon: "a playful elaboration of ethnographic research."

\subsection{The Spatial Network of the Initial Exhibition at the Art Sonje Center}

At the exhibition of Drifting Producers in the Art Sonje Center, all three spatial functions of the conceptual model can be recognized. [See Diagram 12] Firstly, the "conceived mode" (in Lefebvrian terms) is materialized in

20 See C. Diserens, Young-Ran Park, Yuko Hasegawa, and Mark Kremer, "Jury report," in the exhibition catalogue of Hermès Korea Missulsang (Seoul: Hermès Korea, 2004). 
the spatial design of the models. Inspired by the economic network of craftsmanship and trade, the artists designed an imaginary city plan and shaped their installation according to the spatial structures of the workplaces in the Cheonggyecheon district.

Secondly, the first exhibition of Drifting Producers was still closely connected to the social space of production, because the Art Sonje Centre is located in the immediate vicinity of the Cheonggyecheon. The local communities that had participated in the project in the first place were among the visitors of the exhibition, together with the artists, the general audience, and representatives of the international art scene. Besides, the occasion provided the artists with the opportunity to present the power of Cheonggyecheon to the public and the praise for Drifting Producers implied a recognition of the spatial production practices of the craftspeople and traders. In that sense, the exhibition of Drifting Producers was truly a site-specific event, bringing together the producers (both the craftspeople and the artists) and the recipients, connecting the social space of production with the space of the visitors' experience.

Thirdly, the function of representational space was activated by the exhibition in the Art Sonje Center. To be selected as one of the finalists of the contest was more or less a guarantee that Drifting Producers would be presented at other venues as well and, possibly, to be collected for a museum collection in the future. Although the installation was not originally created as a permanent artwork, the contest offered a serious possibility for Drifting Producers to be distributed to other regions and cultural contexts. Also, from the moment the installation was shown in a prominent art gallery, Drifting Producers had the status of an artwork appreciated for its aesthetics.

In conclusion, a well-balanced network of site-specific functions can be observed during the first staging of the installation in the Art Sonje Center. In the following paragraphs, I will briefly return to the workshops organized by the curators and examine more closely the impact globalization has had on the work of the Flying City artists.

\subsection{Intercultural Exchange in the Production and Reception of Drifting Producers}

During our conversations, both Jeon Yongseok and Charles Esche referred to the intercultural workshops, organized by Esche and Hanru, as a breeding ground for Drifting Producers. And both interviewees mentioned the influence of the European avant-garde of the 196os and 1970s on the art 
production of Flying City. During several workshops, special attention was paid to the Situationist International, an activist movement of the 1950s and 1960 s, and the artists embraced the very same ideas. ${ }^{21}$ To understand the relationship between art produced at the turn of this century in South Korea and the European avant-garde of forty to fifty years earlier, a few words are needed to introduce this movement.

The Situationist movement had a primary focus on the development of modernist urban structures and the role of art in society. Among its leading figures were Guy Debord (1931-1994), a French Marxist theorist, activist, and film-maker, and artist Constant Nieuwenhuys (1920-2012). ${ }^{22}$ In 1957, Debord founded the Situationist movement in Paris, a booming city during the reconstruction period and the ultimate place for a critique on Le Corbusier's modernist architecture. The Situationists responded to the new trends of urban planning and mass consumerism with politically engaged art and with a touch of humour in their films, photography, and Happenings. A typical Situationist method was to explore the urban environment in a playful manner, by "drifting" around and exploring the "psychogeography" of the city. ${ }^{23}$ Debord describes this method of "psychogeography" as follows:

[...] the study of the precise laws and specific effects of the geographical environment, whether consciously organized or not, on the emotions and behavior of individuals. The charmingly vague adjective psychogeographical can be applied to the findings arrived by this type of investigation, to their influence on human feelings, and more generally to any situation or conduct that seems to reflect the same spirit of discovery. ${ }^{24}$

It can be readily understood why the social criticism and methods of the Situationists were appealing to Flying City, who, in their turn, opposed the

21 The Situationist International (SI) was an international organization of social revolutionaries made up of avant-garde artists, intellectuals, and political theorists, prominent in Europe from its formation in 1957 until its dissolution in 1972. For a reconstruction of the movement, see: Simon Ford, The Situationist International: A User's Guide (London: Black Dog Publishing, 2005) and Sadie Plant, The Most Radical Gesture (New York: Routledge, 1992).

22 Guy Debord published, among other writings, two major essays: "The Society of the Spectacle" (1967) and "Comments on the Society of the Spectacle" (1988).

23 These notions are elaborated in Guy Debord's Theory of the Dérive (1958), in essence an instruction manual for the method of "psychogeography" performed through "the act of dériver" (French for "to drift").

24 Guy Debord, "Introduction to a Critique of Urban Geography," Les lèvres nues \#6, trans. Ken Knaub, Situationist International Online, 1995, https://www.cddc.vt.edu/sionline/presitu/ geography.html. 
modernization of the city of Seoul and were "spying around" in the urban environment of Cheonggyecheon. ${ }^{25}$ The artists adopted, for example, the method of psychogeography by creating mental maps during the art-andcommunity workshops. ${ }^{26}$

Apart from being influenced by the Situationist movement, or considering themselves being part of it, Constant's New Babylon was a major source of inspiration for Drifting Producers. Constant joined the Situationist International in 1957, but left a few years later, in 1960, after a fundamental difference of opinion with Guy Debord. He shared the ideals of the movement in a plea for "a liberated architecture that stimulates a creative way of life instead of impeding it," but distanced himself from the radical stance to unleash a revolution "in which the boundaries between art and life are totally dissolved."27 In his urban research project New Babylon (1956-1974), Constant envisioned the utopian city as an urban fabric that would embrace pleasure and "intensify the experience of the people moving through it." ${ }^{28}$ In diverse artistic media and art forms, as well as in writing, his proposition of "unitary urbanism" (a combination of collectivity and play) took shape: sketches, architectural drawings, graphic design, photocollages, manifestos, essays, lectures, and films were all expressions of New Babylon. ${ }^{29}$ In addition to a series of paintings, which made Constant a famous artist, numerous urban models were produced by the artist during the project.

As shown above, a similar heterogeneity of forms and multiplicity of manifestations is present in the project Drifting Producers. The project resembles New Babylon in several respects. For example, in the playful approach of drawing the tools and the banners, and even more so in the skills applied to the models and the choice of commonly used materials (plywood in the case of Drifting Producers, Plexiglas in the case of New

25 Jeon explains that the title Drifting Producers refers to the hybrid production system of the craftspeople in Cheonggyecheon, which could not be determined in an a priori way: "they had to drift to survive in the era of mass production." Jeon Yongseok, "Drifting Producers," 370. Another reference is to "dérive" as introduced by Guy Debord.

26 For further reading on the analogy between Flying City and the Situationist movement, I refer to Birgit Mersmann, "Lacing Places: Situationist Practices and Socio-Political Strategies in Korean Urban Projects," in Situating Global Art: Topologies - Temporalities - Trajectories, ed. Sarah Dornhof, Nanne Buurman, Birgit Hopfener, and Barbara Lutz (Bielefeld: Transcript Verlag, 2018), 91-109.

27 Published by the Constant Foundation, https://stichtingconstant.nl/situationist-international-1958-196o (last accessed 26 April 2021).

28 Mark Wigley, Constant: New Babylon. The Hyper-Architecture of Desire (Rotterdam: naio1o, 1998), 9 .

29 Wigley, Constant: New Babylon, 9. 
Babylon). On a conceptual level, similarities can be discerned in the utopian vision the artists pursued in their art and writing and in their aspirations to bring about change in the urban environments of their own times. This is one of the reasons why head of collections of the Van Abbemuseum, Christiane Berndes, emphasizes the importance of Drifting Producers as an urban research project: "As long as they were engaged with the project, they really considered themselves urban developers, perhaps even more than presenting themselves as artists. ${ }^{30}$

Interlacing art with real-life situations was in accord with the philosophy of the international workshops organized by Esche and Hanru. For the museum, it was an extra stimulus to stay involved with the project after the acquisition of the installation Drifting Producers and to keep it "alive" (in the best possible way) by sustaining the relationship between the installation artwork in the museum and the sociogeographical context from which it emerged.

I will return to the comparison with New Babylon, but first a few more words are spent on the reception of Drifting Producers in a global context.

\section{Intercultural Exchange in the Reception of Drifting Producers}

According to art historian Deborah Cherry, Drifting Producers is a significant contribution to the international art world due to the artists' investigation of "contemporary pressures of globalisation and modernisation on the urban environment." ${ }^{11}$ Conversely, the work is rooted in the local, site-specific context of the Cheonggyecheon district, as the statistics and other documentary material clearly communicate. The sociogeographical content of the work is thus represented in a dual sense: the local signifying as global and, vice versa, the global integrated in the local. As Cherry states, Drifting Producers juxtaposes conceptions of art and reality, of designed spaces and actual "sites," and signifies differently to different audiences, because the appreciation depends on the "skills, family and cultural traditions" of the recipient: ${ }^{22}$

[...] the installation puts forward the concept that space is actual and imaginary, historical and of the present and the future. That space is

30 Interview with Christiane Berndes conducted on 3 March 2010.

31 Deborah Cherry, "Transnational Practices in Collecting," lecture at PlugIn \#7 seminar Becoming Dutch Seminar: Collecting and Identity, Van Abbemuseum, presented on 13 September 2007. A transcript of the lecture is kept in the archive of the Van Abbemuseum.

32 Cherry, "Transnational Practices in Collecting". 
produced, imagined, created by bringing together physical and mental geographies, materials and images. Thinking in this way suggests the kinds of knowledge produced by the object itself, as well as in the framing of its curation. ${ }^{33}$

Extrapolating this view of the exhibition at the Art Sonje Center and the overlapping social networks, as suggested above, one could consider Drifting Producers as "performing" intercultural exchange in optima forma during this first exhibition since the artists, local communities, and international art public were all present at the event. At the same time, not everyone appreciated the transformation of the art-and-community project into an art object and, according to Jeon, some even thought that the metal workers had been exploited by the artists. ${ }^{34}$

It can be argued that, with the production of the installation Drifting Producers, the artists envisioned a script for its ongoing participation in the international art world, eventually leading to the acquisition of the work by a European museum. I will return to this point later when juxtaposing the artists' intention to the aspirations of the custodians during the acquisition process and display of the installation in Van Abbemuseum. First, however, I will follow the trajectory of the installation through the international art world on its way to the next stage of its biography.

\subsection{The Trajectory of Drifting Producers}

After the show in the Art Sonje Center, the installation Drifting Producers travelled to Europe and was shown in the exhibition Kollektive Kreativität / Collective Creativity (2005) in the Kunsthalle Fridericianum, Kassel. ${ }^{35}$ For the second time that year, the installation was shown, this time at the $9^{\text {th }}$ International Istanbul Biennial, curated by Charles Esche and Vasif Kortun. ${ }^{36}$ These successive moments of display marked a new biographical stage, in which the installation caught the attention of the art public, but had not entered a museum collection. In particular, the second show is of interest to the discussion, because the curators of the Istanbul Biennial tried to reactivate

35 The exhibition Kollektive Kreativität / Collective Creativity was curated by What, How, and for Whom?, Kunsthalle Fridericianum, Kassel, 1 May-17 July 2005.

36 The $9^{\text {th }}$ International Istanbul Biennial, curated by Charles Esche and Vasif Kortun, took place from 16 September to 30 October 2005 . 
the initial site specificity of the work by choosing a former tobacco factory as exhibition site. According to Charles Esche, the industrial environment was comparable to the production site of Cheonggycheon and the "narrative of the installation" could be well performed in this environment. Instead of copying the floor plan of the installation in the Art Sonje Center, where the three parts of the models were suspended in space, the models were shown on large, wooden workbenches, emphasizing the spatial production practice of the metal craftspeople. ${ }^{37}$ This way, the audience could observe the creativity and craftsmanship that had gone into the models from nearby and could experience the feeling of a workplace. In the eyes of Christiane Berndes, Drifting Producers was different from projects with a similar content presented at the Istanbul Biennial, because the installation conveyed with simple means, a balance between the aesthetic, visual experience and the subject matter of traditional craftsmanship and urban renewal. ${ }^{38}$ Berndes:

What struck me was that the models were built from small pieces of plywood, giving them a direct energy, but also a natural simplicity. It wasn't slick, not made with contemporary production methods. It matched perfectly with the project, especially with the spontaneity it resembles. ${ }^{39}$

According to the curators, the installations' models were the main agents for conveying the content of the project and it was considered important, by both the artist and the curators, to adjust the spatial design (floor plan) of the installation to the new site. Charles Esche was particularly interested in a dialogue between "sites" and Drifting Producers exemplified this geographical interconnectivity.

I am interested in geography in terms of the specific conditions of a given place and the differences that are established between places. As a cultural intervention, an international biennial can reflect on these specificities, it can raise changes or consider them critically. ${ }^{40}$

38 The curators' press release reads: "The $9^{\text {th }}$ biennial understands itself as a forum for proposing meaning out of the signs of a particular place and time. Those propositions are made in the personal and intimate terms that define the relationship between individual artist and city, as well as the proposed relationship between artwork and viewer." https://bienal.iksv.org/i/assets/ bienal/document/9B_CHARLES-ESCHE-VASIF-KORTUN_EN.pdf(last accessed 26 April 2021). 39 Interview conducted with Christiane Berndes. See footnote 30 of this chapter. 
In brief, drawing on the models as representations of the practices and spatial configuration of the metal workplaces and considering the location of the factory as an agent in the meaning production, the artists and curators together developed a scenario for reinvigorating the sociogeographical site specificity of Drifting Producers in concordance with the new exhibition site. The former tobacco factory created a different - perhaps more direct - context for the visitors to experience the spatial production practices of the Cheonggyecheon workplaces, enhanced by the industrial "look and feel" of the space and by the models being displayed on the workbenches. [See Diagram 12]

After the Istanbul Biennial, Flying City donated Drifting Producers to the Van Abbemuseum, and were compensated for the production costs.

\subsection{Site Specificity of Drifting Producers in the Van Abbemuseum}

Both the Flying City artists and the custodians of Van Abbemuseum welcomed the relocation of Drifting Producers to the Netherlands, not least because the migration would establish an art historical connection with the artworks of Constant's New Babylon project. Constant's models are “just around the corner," noted Charles Esche in the interview conducted for this case study. To Flying City, it was a sign of recognition that the installation would be preserved in the Van Abbemuseum, next to other artworks of the European avant-garde. ${ }^{41}$ However, Esche and Berndes appreciated the installation Drifting Producers primarily for its aesthetic qualities and for the opportunity it offered to remain involved with the urban research project. ${ }^{42}$ The general idea was that the existing relationship between the Flying City artists and the director/curator of the Van Abbemuseum would turn into a long-term partnership by means of the acquisition.

As soon as the installation arrived at the Van Abbemuseum, it entered a regime of conservation and care. Following the usual musealization process, the models and other elements were preserved according to conservation ethics and standard museum practices, including extensive documentation and taking appropriate measures for storage and transport. These are

41 Interviews conducted with Charles Esche on 24 March 2010, and with Jeon Yongseok on 20 March 2011.

42 Christiane Berndes: "We follow how the project evolves. We safeguard the objects, but perhaps more important is the continuation of the project." See footnote 30 of this chapter. 
Figure 34 Tailormade crates and support layers created by the technical staff of Van Abbemuseum for the urban models of Drifting Producers. Photo: Peter Cox. Courtesy photographer and Van Abbemuseum archive, Eindhoven.

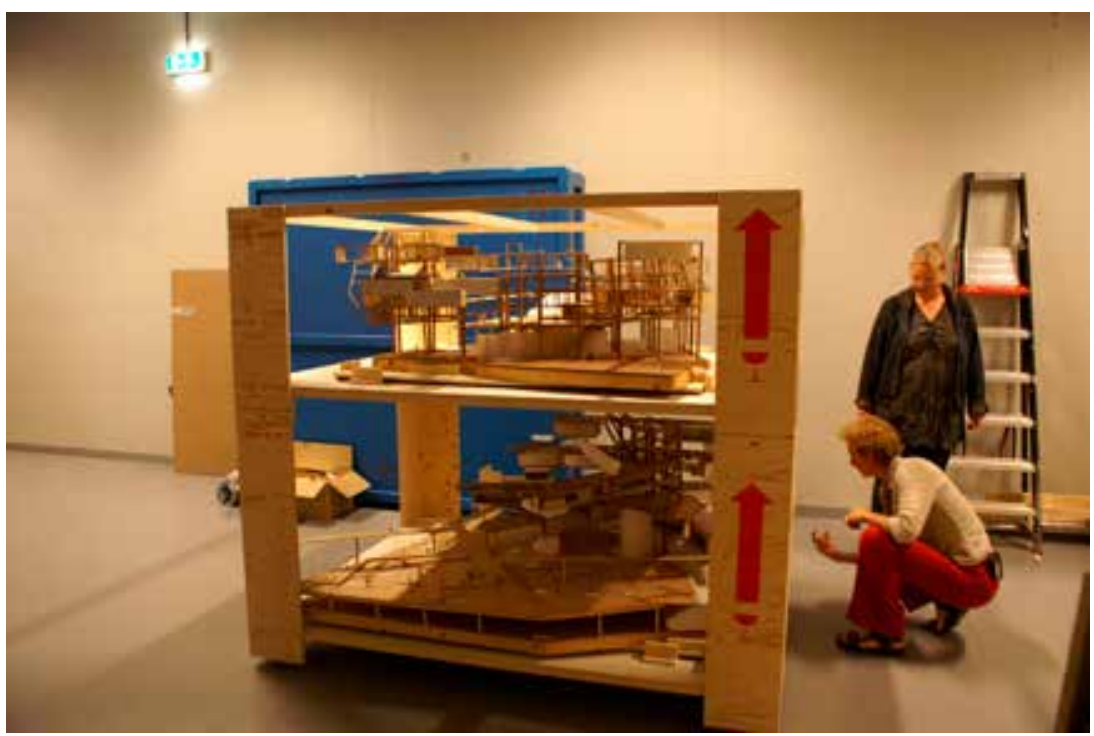

standard procedures for acquisitions, but in the case of Drifting Producers there were a few complicating factors. The models arrived at the museum in a rather poor state, because they had been transported in a normal truck (not equipped for the transportation of art objects). The head of the museum's technical department, Louis Baltussen, recalls: "It was just a mess when they arrived." 43 The artists had not provided any instructions for assembling individual parts of the three large models (some consisted of multiple parts), nor was there any information accompanying additional elements of the installation. Although it was acknowledged that Drifting Producers was not a "standard" work, the staff decided to carry out preventive conservation measures, just as they would normally do: all parts were photographed and registered in the museum information system, and an extensive condition survey was carried out; Baltussen and his colleagues made their own assessments of how the models fitted together, and for each model a wooden base and a tailormade crate were made to ensure proper storage. [Figure 34] 
After Flying City had sent the files of the digital components to Van Abbemuseum, all digital material was stored at the municipality's server, because the museum server had insufficient space for excessive amounts of data (including not only digital components of the installation but also a large collection of photographs used for the condition survey). It was guaranteed that the necessary preventive conservation measures documentation, registration, storage, and transport - were taken and that Drifting Producers was, in that sense, prepared for a long life in a museum environment. ${ }^{44}$

\section{Scenarios for the Perpetuation of Drifting Producers}

The acquisition marked a turning point in the biography of Drifting Producers, because a transition took place when the installation turned into a musealized artwork. For the current research, I will focus on the decision-making process conducted by the custodians and return to the notion of the "script."

In chapter 3 , I elaborated on the script from the perspective of conservation theory, where "script" or "score" is often conceived as a set of instructions defining the artwork and its intended manifestation, thereby facilitating its proper reinstallation. Another notion, introduced by Madeleine Akrich and Bruno Latour, is that of script referring to an implicit set of instructions on the future "use" of the object, which is inscribed by the designer. In Ernesto Neto's Célula Nave, for example, the latter conception of script was recognized in Neto's choice of the haptic, polyamide fabric and construction of the artwork, inciting the visitors' bodily interaction. In the case of Drifting Producers, I would rather use the term "scenario" (instead of script) in reference to the imagined course of action. ${ }^{45}$ Within this context, scenario applies to the deliberations and series of actions intended by the artists and the custodians, resulting in the staging of Drifting Producers as a site-specific installation.

As indicated above, the artists welcomed the hosting of the installation by Van Abbemuseum, because it was a guarantee for the perpetuation of Drifting Producers. The acquisition would fulfil their wish to communicate

44 Louis Baltussen describes in detail the actions taken by staff members after Drifting Producers arrived at the museum. Interview with Louis Baltussen.

45 Merriam-Webster Online defines "scenario" next to "a plot outline of a play," as "an account or synopsis of a possible course of action or events." https:/www.merriam-webster.com/dictionary/ scenario (last accessed 26 April 2021). 
to an international art public the narrative of craftsmanship and the spatial network of Cheonggyecheon. Moreover, it would bring the work in the vicinity of Constant's New Babylon and other works of the European avant-garde. Furthermore, a connection would be re-established between the artists and the Van Abbemuseum, in continuation of the international workshops from the past. In brief, during the successive stages of production and acquisition, the artists imagined a scenario in which a connection would be established between the geographical site of Cheongyyecheon, represented by Flying City's collaboration with the craftspeople and traders, and the international museum site of the Van Abbemuseum.

Looking at an imagined scenario from the viewpoint of the custodians, they, too, envisioned a continuation of the intercultural exchange and a reactivation of the original site specificity of Drifting Producers in a different geographical region: firstly, by hosting the artwork, and secondly, by staying involved in the ongoing project and continuing their relationship with the artists. As we shall see hereafter, part of this scenario was to invite the artists to come to Eindhoven for a programme of discussions about urban planning and local craftsmanship, in connection to a display of the installation.

Although the respective scenarios seem to be more or less congruent, in reality, dilemmas and frictions occurred that were not foreseen at the moment of the agreement to relocate the installation to the museum. On the other hand, an unexpected positive exchange did take place, which contributed to the significance of Drifting Producers for the hosting institution. The encounter was incited by the need for restoration of the models that had suffered from the journey from Istanbul to Eindhoven.

\section{Restoration of the Models and Intercultural Exchange}

Although preventive measures for the three large models had been taken, some elements had suffered severe damage, so they needed restoration treatment. According to Christiane Berndes, normally a conservator would be called upon to perform the restoration; it would probably be considered the best option "to make invisible repairs to the broken junctions of the structure of the models and replace them where necessary, in order to restore the aesthetic appearance. ${ }^{146}$ However, in this case, the approach was attuned to the methods employed by Flying City and to their views on conveying the spatial structures of the workplaces and practices of the Cheonggyecheon district. The artists were invited to come to the Van 
Abbemuseum to perform the restoration treatment themselves. In contrast to what a museum conservator would do, the artists tied broken parts together with visible pieces of rope. In addition, they strutted the most vulnerable parts with extra pieces of plywood, leaving even more visible traces of repair.

According to Berndes, the result of this scenario was, on the one hand, a heated discussion among the staff members, as it caused frictions regarding the ethics of conservation. On the other hand, this was exactly the kind of discussion the director and curator had in mind when they accepted the offer of the acquisition, in other words, to stimulate intercultural exchange, which in this case, revolved around different conservation paradigms: the Western system of conserving art objects - striving for invisible, minimal treatment and reversibility - and restoration practices applied to architectural structures in the poorer areas of Southeast Asia (such as Cheonggyecheon) - leaving visible traces of the intervention and thus transferring craftsmanship from one generation to another. ${ }^{47}$

When staff members questioned the durability of the treatment and future conservation, the artists reassured them that the material authenticity of the models did not need to be a constraint and that a similar treatment could be executed by staff members in the future. In this case, the idea of craftsmanship would be strengthened and the spatial practice of the Cheongyyecheon would find its way into the technical department of the museum. The museum regards this as a feasible scenario for a future restoration of Drifting Producers, if needed..$^{8}$ On the other hand, a more conventional scenario was followed by applying preventive conservation measures (as explained above).

Apart from the consolidation of the models and the crates built for storage and transportation, all digital files are regularly updated to current standards and information about the history and context of the project has been widely collected by the museum registrar, Margo van de Wiel. Part of this effort was a complete download of the Flying City website, which is no longer accessible but has been documented for the museum's archive in this way. ${ }^{49}$ This archival material offers valuable information for research, meaning that not only the physical work is preserved for posterity but also

47 Interview with Christiane Berndes.

48 Interview with Christiane Berndes.

49 The download includes, among other things, descriptions of the project and essays by Jeon Yongseok and Mark Kremer, images, as well as lists of exhibitions and events of the Drifting Producers project and its forerunners. 
the underlying philosophy and contextual references of both the project and the installation.

In museum practices, it is not uncommon to combine diverse strategies, such as in collections of art and culture obtained from indigenous peoples or other cultural communities. Around the turn of this century, museum professionals began to re-examine conservation principles from a similar perspective as the custodians of the Van Abbemuseum; many conservators aim for a continued engagement with the creators of cultural heritage objects (including contemporary art) and their legacy keepers..$^{5}$ In the case of Drifting Producers, the approach followed by the artists and Van Abbemuseum was a "guarantee" for its continued existence, whereas it would otherwise have been destroyed after the Istanbul Biennial. ${ }^{51}$ It proved to be an effective strategy for its perpetuation to relocate the work, but on the other hand, the scenarios imagined by the artists and custodians were not very specific and did not stipulate how exactly the artwork should perform in a museum context.

\section{Staging Drifting Producers in 2006}

In the previous section, I illuminated how the artists and the custodians drafted a scenario for the afterlife of Drifting Producers in terms of an ongoing dialogue between the site of origin and the hosting site. From a more practical perspective, during its staging at the PlugIn \#7 exhibition (2006-2007), there was no script or set of instructions available for assembling the installation..$^{2}$ The technical staff did most of the preparatory work.

The spatial design of Drifting Producers at PlugIn \#7 more or less followed the spatial arrangement of the initial staging at the Art Sonje Center and included the same elements. The centre of the installation consisted of the

$5^{0}$ For more information on the collaboration of conservators with indigenous peoples and other cultural communities, please read, among others: Erica Avrami, Randall Mason, and Marta de la Torre, Values and Heritage Conservation: Research Report (Los Angeles: Getty Conservation Institute, 200o); Miriam Clavir, Preserving What is Valued: Museums, Conservation, and First Nations (Vancouver: University of British Columbia Press, 2002); Glenn Wharton, The Painted King: Art, Activism, \& Authenticity in Hawaii (Honolulu: University of Hawaii Press, 2011). Likewise, in contemporary art conservation, it is a common strategy to collaborate with artists or their representatives, although the artists are seldom invited to execute conservation treatment themselves.

$5^{1}$ Interview with Charles Esche. See footnote 37 of this chapter.

$5^{2}$ Interview with Louis Baltussen. See footnote 43 of this chapter. The exhibition PlugIn \#7 was curated by Charles Esche and Christiane Berndes, Van Abbemuseum, 8 April 2006 to 20 May 2007. 
Diagram 13 Drifting Producers: Staging in the Van Abbemuseum in 2006 and options for future staging. $\odot$ The author. Image editing: Arienne Boelens.

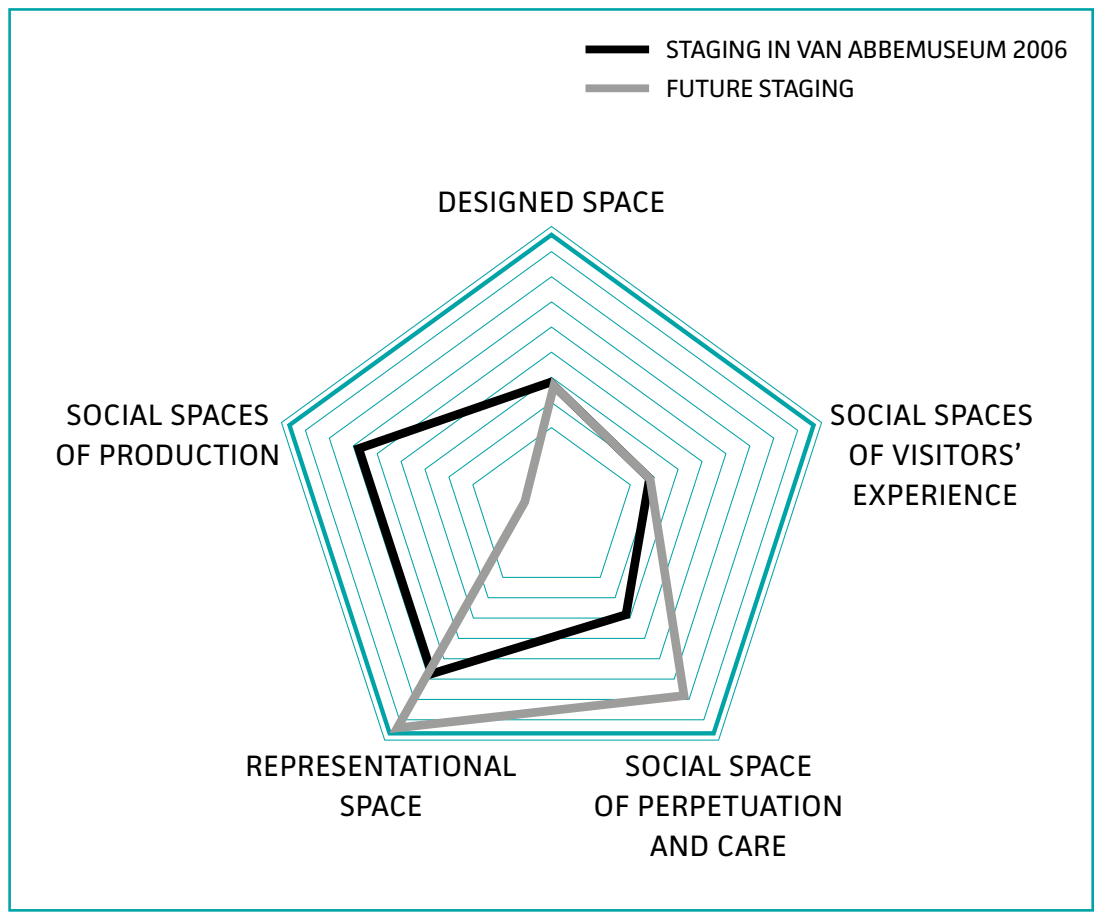

three urban models suspended from the ceiling; the composite photograph Power of Cheongyyecheon, the study drawings and a photograph of the street vendors' protest were displayed along the walls; attached to the frame were statistics of Cheonggyecheon, drawings and banners of the urban research project, as well as two screens (one a PowerPoint presentation of design products, the other one a video of the street vendors' interviews). [Figure 32] Important for the discussion below is the fact that a wooden frame was constructed by the technical staff on the basis of a technical drawing provided by the artists..$^{53}$ The artists themselves were not present during the installation process, but at some point Jeon Yongseok visited and authorized the installation.

The display of Drifting Producers in 2006 was an actualization of the artwork's site specificity. Following Lefebvre's statement that representations of space are "certainly abstract, but also play part in a social and political 
practice" and are therefore "relative and in the process of change," the frame could be considered an element that accommodates the installation to the new site of display. ${ }^{54}$ [See Diagram 13] Whereas the artists had provided the codes for a spatial arrangement of the installation, the technical staff adjusted the design to the dimensions of the room, enabling a presentation of the individual elements and leaving enough space for visitors to "drift" around the models and see them in detail.

One of the staff members recalls her first encounter with the artwork: "It had such an unfinished look, you had to bend your knees in order to look at the figurines. All those tiny details were impressive and yet it had this charming spontaneity."55 Regarding the site specificity of Drifting Producers, the frame is the primary agent for a spatial demarcation of the installation: the dimensions of the floor plan are geared to the exhibition room in the Van Abbemuseum. Moreover, the frame is recorded in a technical drawing, photographs, and a scale model that can be used for future occasions (the frame is destroyed, but can be refabricated in exactly the same way). This brings into focus that, whereas the spatial arrangement was still flexible at previous moments of display (in Seoul, Kassel, and Istanbul), it became "fixed" in Van Abbemuseum; it is likely that the drawing, photos, and scale model will serve as prescriptive agents for the spatial design in future displays.

Furthermore, one of the effects of Drifting Producers's musealization is that the gallery becomes the actual room - representational space - for the public's experience of the work. Like with many site-specific artworks, there is an inherent contradiction in the perpetuation of this installation artwork within a museum context. The temporary liaison between the artwork and the site (as shown in the variation of its display at previous venues) has been replaced by a more permanent spatial design defined by the wooden frame: a fixation of the installation, which is geared to the museum's representational function to show art objects in a finite state. On the other hand, it was part of the custodians' imagined scenario that the dialogue would be continued by means of a cultural programme organized alongside the exhibition.

According to Jeon, the installation Drifting Producers could render its meaning independently from the geographical co-ordinates in which it is presented. But to realize "a performance" in the intended way, he

54 Henri Lefebvre, The Production of Space, trans. Donald Nicholson-Smith (Oxford: Blackwell Publishing, 1991), 41.

55 Interview with Margo van de Wiel conducted on 13 July 2010. 
believed that an exchange with local audiences should be organized. The artists suggested to come over and discuss the project with the public. The custodians of the Van Abbemuseum welcomed this idea and even went one step further by suggesting that some kind of local network should be established around the Drifting Producers project in Eindhoven. A series of events should be organized, with discussions on the topics of city planning and craftsmanship, in which the artist and architectural students, product designers, curators, and the general museum public could participate. The proximity of the Philips Factory and the Design Academy in Eindhoven, and the Master's programme in Architecture, Building and Planning at the Eindhoven University of Technology were considered relevant "substitutes" for the local communities of the Cheonggyecheon. Last but not least, such a programme would serve as a follow-up to the previous relationship between the two main actors in this enterprise Jeon Yonsgeok and Charles Esche - and thereby continue the intended cross-cultural dialogue. ${ }^{6}$

\subsection{The Social Production Space of Drifting Producers}

Examining the function of social space, it is interesting to take a closer look at the production process of Drifting Producers and the network of actors involved. At first, the artists observed the practices of the metal craftspeople and took their inspiration from the spatial structures of the workplaces to create their own "utopian city." Participants of the workshops contributed to the project with their imagination, giving shape to the preliminary models. During the next stage, the artists were the main actors in the process of creating the installation Drifting Producers, and they submitted the artwork to the international contest in the Art Sonje Center. Subsequently, when the artwork entered the museum collection, the museum staff and the artists acted in relation to the conservation of the work by discussing alternative approaches for restoration of the models and the artists executed the treatment. This way, the social production space of Cheonggyecheon was at least shared with the museum's staff members.

Following the imagined scenarios that production practices and social networks of the Cheonggyecheon would be communicated to a wider audience (therewith expanding the social space of the project), the museum had 
the intention to organize a cross-cultural programme, linked to the display of Drifting Producers. However, the reality proved different, and the artwork has only been installed once in the Van Abbemuseum, during PlugIn \#7. Although the display was accompanied with the earlier mentioned lecture by Deborah Cherry, one can hardly speak of a continuation of the social production space of Drifting Producers in the Netherlands. In this sense, the expectations were not fulfilled. Yet, in its own way, the museum did contribute to greater awareness of the project by including an extensive article on Drifting Producers, written by Jeon Yongseok in 2004, into the publication Art and Social Change, edited by Will Bradley and Charles Esche. ${ }^{57}$

\section{Continuation of the Project Drifting Producers}

The Flying City collective continued with the project until 2009, by organizing workshops and performances at various places, including in the Cheonggyecheon district..$^{8}$ Apart from that, they created a second version of the installation Drifting Producers. The location was the Central Tourist Hotel, in the vicinity of the workshops of Cheonggyecheon. This version of the installation was created in commission of Seoul's city council; in terms of its site specificity, it was physically bound to the sociogeographical context of the project. Some of the elements of the initial version, such as the composite photograph Power of Cheonggyecheon, reappeared in the installation. The urban models, however, took a different shape, and the constructions were a combination of plywood, metal, and multicoloured lamps. [Figure 35] Furthermore, objects made by Yongseok out of recycled materials he obtained from the metal craftspeople were additional elements to the installation. Another addition was a series of photographs featuring the metal workers in conversation with the artists, therewith emphasizing their mutual relationship and sociogeographical site specificity

57 The article "Drifting Producers" by Jeon Yongseok (originally published in Mark Kremer et al., Now What? Artists Write!, 2004) was reprinted in: Will Bradley and Charles Esche, Art and Social Change: A Critical Reader (London: Tate Publishing, 2008), 369-377. Apart from other publications, Jeon wrote a book on the project (in Korean language only). Jeon Yongseok, Cheonggye Archive Metal Cloud (Seoul: flyingCity, 2009).

58 Drifting Producers art-and-community workshops and performances were, for example, organized by Flying City for Iron Cloud Machinery (http://historykorea.blogspot.com/20o8/og/ ironcloud-machinery.html? $\mathrm{m}=\mathrm{o}$ (last accessed 26 April 2021) and the Guangzhou Triennial, curated by Hou Hanru and Hans Ulrich Obrist, Guangdong Museum of Art, from 18 November 2005 to 15 January 2006. 
Figure 35 City, Drifting Producers (second version) (2006) by Flying City. Detail of the installation at Central Tourist Hotel, Seoul. Photo by the author. (c) Flying City.

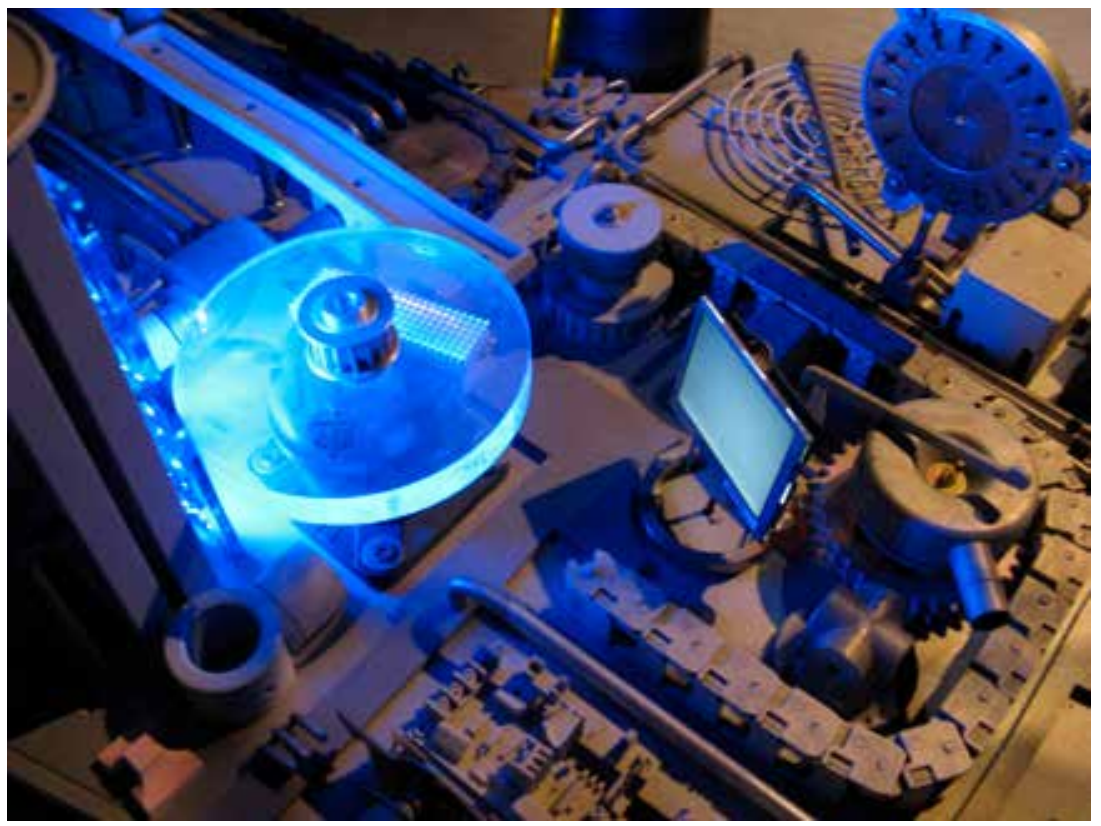

of the work. Unfortunately, the artwork suffered from neglect by the city council (the owner of the work), and the artists were not allowed to carry out repairs themselves. As a result, the second version of Drifting Producers was dismantled a few years after the project ended, meaning that, although the project stays alive in written form, the installation Drifting Producers, hosted by the Van Abbemuseum, is the only materialized form that has survived. 59

To better understand what happened to the social spaces of production and the artwork's perpetuation in a museum context, it is relevant to examine what the expectations were at the moment of the acquisition and how the transition to a musealized artwork took place. During the interview I conducted with the director of the Van Abbemuseum in 2010, he stated that he still wished to follow the dynamics of the project. Drifting Producers

59 This information about the decay and end of the installation Drifting Producers in the Central Tourist Hotel comes from Jeon. Interview with Jeon Yongseok. See footnote 34 of this chapter. 
was regarded as an "open-ended artwork," and new elements, resulting from Flying City's ongoing production practices in the project, could be added.

We are very open to the idea of following their project, but we just haven't done it yet. If we were in Seoul I am sure we would have been much more engaged. The intention has always been that we collect more. ${ }^{60}$

The director acknowledged that the geographical distance had caused a barrier to the ongoing relationship with Jeon Yongseok and his engagement with the installation. Esche is clear in his statement that there is always a "finiteness" to such collaborative processes, which ultimately transformed Drifting Producers into an autonomous work of art. In fact, a process similar to what happened to Constant's New Babylon project, according to Charles Esche.

I like to see it in the same way as Constant's New Babylon. There is a very direct correlation between them. But [Drifting Producers] is made in a particular region. The problem is that art history always tells us to isolate the artist from his social environment, his living. I would like to change that, but probably eventually Drifting Producers will become an aesthetic object too, instead of something that can talk about a particular social moment. ${ }^{61}$

Given the current dormant state of the artwork, one could argue that the social production space has come to an end. Furthermore, as a result of the completion of the project Drifting Producers, a rupture has emerged in the cross-cultural dialogue after the artwork entered the museum - although the restoration activated the social space of perpetuation and care in the museum's conservation department. A final observation in this respect is that it seems inevitable that Drifting Producers turned into a site-generic artwork, because one of its vital spatial functions - the original social production space - has not been reinvigorated. The bigger the time gap, the less likely it is that a cross-cultural exchange on spatial production practices and craftsmanship will take place.

6 o Interview with Charles Esche. See footnote 37 of this chapter. Jeon confided to me that he had discussed with the director the option of adding elements of the metal version of Drifting Producers to the installation in the Van Abbemuseum, "but then he forgot." Interview with Jeon Yongseok. See footnote 34 of this chapter.

61 Interview with Charles Esche. See footnote 37 of this chapter. 
Charles Esche mentions the geographical distance as one of the main reasons for the museum's inability to reactivate this site-specific function. Based on the conceptual model, I would like to make another suggestion, given the artwork's networked relationship with the representational space. Lefebvre's notion that any representational space (including the museum) is a "lived space," clarifies that prevailing value systems of a given space have a profound effect on the spatial production, in this case the meaning production of a site-specific installation in a museum context. Museums adjust their acquisition and display strategies to the actuality of sociocultural circumstances and their own internal policies.

From this perspective, the lack of interest in Drifting Producers could also be explained as a sign of a changed curatorial programme, which shifted its attention from the museum's engagement with cross-cultural dialogue on spatial production practices to collaborative projects in a European context, exemplified by the programme L'Internationale. ${ }^{62}$ From 2009 onwards, the Van Abbemuseum adjusted their acquisition and exhibition policies. Hence, in case Drifting Producers would be put on show again, the intended exchange about production practices in different parts of the world would likely be replaced by other values attributed to the installation. In this respect, I would like to rephrase Esche's statement about the "aestheticized object" as primarily an actualization of the representational function and "lived space" of Drifting Producers - geared to current museum policies and including the "fixation" of the spatial design by means of the wooden frame. [See for a future scenario Diagram 13]

This view was verified by Christiane Berndes during a more recent interview I conducted in 2017. The head of collections sheds light on a possible future staging of Drifting Producers:

If we were to put the installation on display again, the artwork itself would take a central position, but we would see it as a vehicle to connect to the actuality of today, for example the disappearance of craftsmanship

62 On the website of the Van Abbemuseum, the L'Internationale (starting in 2009) is explained as follows: "L'Internationale is a collaborative venture between four museums and two artists' archives in six European countries. It connects these collections in a series of exhibitions that demonstrate how the recent cultural heritage can be independent of national boundaries. The ultimate aim is to create a 'European Collection,' or even a 'Global Collection.' The participating organisations will not amalgamate into an abstract unified entity, but instead gradually create a sense of interconnectedness between, in the first instance, Antwerp, Barcelona, Eindhoven and Ljubljana." https://vanabbemuseum.nl/en/programme/programme/spirits-of-internationalism/ (last accessed 26 April 2021). 
worldwide or how the work connects to different groups of present-day society. The museum is in transition. We invite artists to critically reflect on existing structures inside and outside the museum and to collaborate with academia. By focusing only on the biography of Drifting Producers we would run the risk of an inward view, instead of employing its potential for investigating the issues at stake. ${ }^{63}$

Berndes indicates that a reinvigoration of Drifting Producers within the context of current museum practices could still be accompanied with a programme of events, dedicated to "the issues at stake." The focus would no longer (or not primarily) be on the site specificity of the Drifting Producers project, but on the museum site itself (as a place for critical reflection); the artwork would fulfil the function of evoking discussion and debate - which is not entirely different from the cross-cultural dialogue instigated by the director in the past - focusing on the role of art in society. Furthermore, Berndes remarked that it would not be a primary concern to involve the Flying City artists; in fact, their role as urban researchers could be delegated to others in the discussion. ${ }^{64}$

Those insights made me aware that different modes may coexist for reinvigorating the site specificity of a sociogeographical art project. One mode might consist of referring back to the origin of the artwork and the context in which the work was created (bringing the genesis of the artwork to the fore), while another mode might focus on "using" the artwork for discussions that are considered topical and typical for the museum's position in society. In other words, the artwork could turn into a site-generic art object, appreciated for its aesthetics, and at the same time "perform" as a sitespecific work through its connection with the museum's representational space. However, in this scenario, there is no longer (or not necessarily) a role for Flying City, who represented the metal workers and traders in Cheonggyecheon in their art. And the bigger the time gap, the less plausible it will be that their participation is sought in the discussion. In brief, somewhere during the trajectory, the artists were left out of the perpetuation process and, in accord with its transition into an art object, Drifting Producers was "neutralized" in the museum's space of perpetuation and care.

63 Interview with Christiane Berndes conducted on 2 February 2017. Today, the Van Abbemuseum features a wide range of public programmes, both inside and outside the museum, and has an event manager as a permanent staff member.

64 Interview with Christiane Berndes. 
Drifting Producers has not been on display again. Hence, the arguments discussed above cannot be tested against a realized scenario for the artwork's reinstallation and accompanying curatorial programme. What I will do instead - given the affinity of Flying City with the urban research project of Constant - is examine two different approaches in staging Constant's New Babylon. The exhibitions discussed below took place at the occasion of a retrospective in 2016, organized by the Kunstmuseum in The Hague and Museo Nacional Centro de Arte Reina Sofia in Madrid.

\subsection{Comparative Case Study: Constant's New Babylon Project}

Constant Nieuwenhuys was part of the post-World War II generation, and apart from being a member of the COBRA movement, he also was cofounder of the international Situationist movement. For almost twenty years, Constant worked on the New Babylon project (1956-1974) with the aim to connect art with a new vision on spatial design and urban lifestyle. He imagined that the automation of production would free people from daily work and give them time to devote to creativity and play. During a lecture at Stedelijk Museum Amsterdam (1960), Constant describes his project as follows:

New Babylon is to be a covered city, suspended high above the ground on huge columns. All automobile traffic is isolated on the ground plane, with the trains and fully automated factories buried beneath. Enormous multileveled structures, five to ten hectares in area, are strung together in a chain that spreads across the landscape. This "endless expanse" of interior space is artificially lit and airconditioned. lts inhabitants are given access to "powerful, ambience-creating resources" to construct their own spaces whenever and wherever they desire. The qualities of each space can be adjusted. Light, acoustics, color, ventilation, texture, temperature, and moisture are infinitely variable. Movable floors, partitions, ramps, ladders, bridges, and stairs are used to construct "veritable labyrinths of the most heterogeneous forms" in which desires continuously interact. ${ }^{65}$

65 Lecture given by Constant on 20 December 1960 in Stedelijk Museum Amsterdam. Mark Wigley, Constant:New Babylon. The Hyper-Architecture of Desire (Rotterdam: naio1o, 1998), 9-10. 
In a series of models, Constant created labyrinthian structures of overlapping living spaces, platforms, and terraces rising above the ground. ${ }^{66}$ The "sectors," for which he used Plexiglas as the principal material, were literally floating above the ground, disconnecting the "ideal world" from everyday traffic and city noise. Apart from the models, New Babylon encompassed a wide range of other artworks created by Constant, such as drawings, photographs, oil paintings, watercolours, and documentary films, pamphlets, manifestos, and interviews. In 1974, Hans Locher, then director of the Municipal Museum in The Hague (now Kunstmuseum), organized an exhibition for New Babylon and acquired a number of models directly from the artist. When the curatorial interest was fading, the models were stored in the museum's basement and their condition deteriorated, until the situation changed again in $1991 .{ }^{67}$ The museum's curator of modern art, Hans Janssen, "rediscovered" the models and became interested in the ideas of the New Babylon project. On his initiative, conservation treatment was carried out. In the meantime, Hans Janssen and Constant - who had become a famous painter by that time - built a close relationship.

In the following years, New Babylon gained great popularity with curators, architects, urban planners, and wider audiences. The models were, for example, shown at New Babylon exhibitions in the Kunstmuseum (1997) and at Documenta 11 (Kassel, 2002). In 2016, Laura Stamps and Doede Hardeman cocurated two major exhibitions bearing the same title Constant - New Babylon: one in Centro de Arte Reina Sofia and the other one in the Kunstmuseum. ${ }^{68}$ The analysis hereafter focuses on the perpetuation of the project and the spatial display of the models in a comparison of both exhibitions and the permanent display in Kunstmuseum. Because I was able to visit all three of them, the discussion is partly informed by my own observations.

\section{Staging the Models of New Babylon in the Kunstmuseum}

For Constant, the New Babylon exhibition of 1974, organized by Hans Locher, marked the end of the project. A number of models were acquired for the museum collection in exchange for a monthly compensation, which enabled

66 For an extensive reading on Constant's New Babylon project, I refer to Wigley, New Babylon, 1998.

67 Interview with Hans Janssen conducted on 24 November 2010.

68 The exhibition Constant - New Babylon was cocurated by Laura Stamps and Doede Hardeman, Kunstmuseum Den Haag, 28 May to 25 September 2016; Centro de Arte Reina Sofia, Madrid, 21 October 2015 to 29 February 2016. 
Figure 36 New Babylon (1956-1974) by Constant Nieuwenhuys. Collection Kunstmuseum Den Haag. Installation view in 2012. Photo by the author. ๑) Fondation Constant.

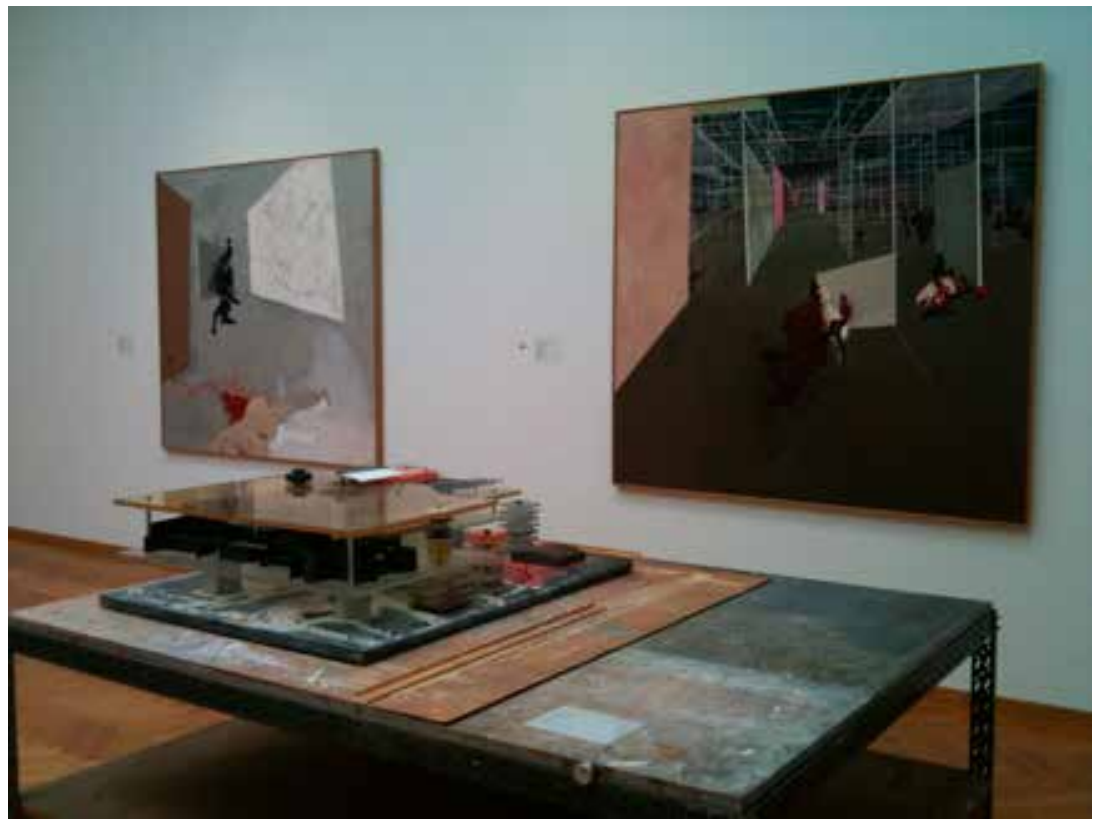

the artist to continue his creation of paintings and other work. ${ }^{69}$ After the period of neglect and then the rediscovery by Hans Janssen, the New Babylon models were put on display in the museum galleries in various ways, but the version I would like to discuss is a "permanent" display (which I was able to see in 2012). [Figure 36]

Some of the models were put on workbenches that had been acquired in the past, directly from the artist, who had used them in his studio for creating the models. Hans Janssen explains that the models were to placed on those tables rather than on pedestals, because of the authenticity of the working practice they resembled:

Constant had made those tables himself or comparable ones came from the construction market. This was a sign that he did not address the models as sculptures. At the time it was a radical gesture, but today we are experiencing the models no different from a sculpture, the aesthetic 
Diagram 14 Two retrospective exhibitions of Constant's New Babylon project in 2016, in Kunstmuseum and Museo Nacional Centro de Arte Reina Sofia. $\odot$ The author. Image editing: Arienne Boelens.

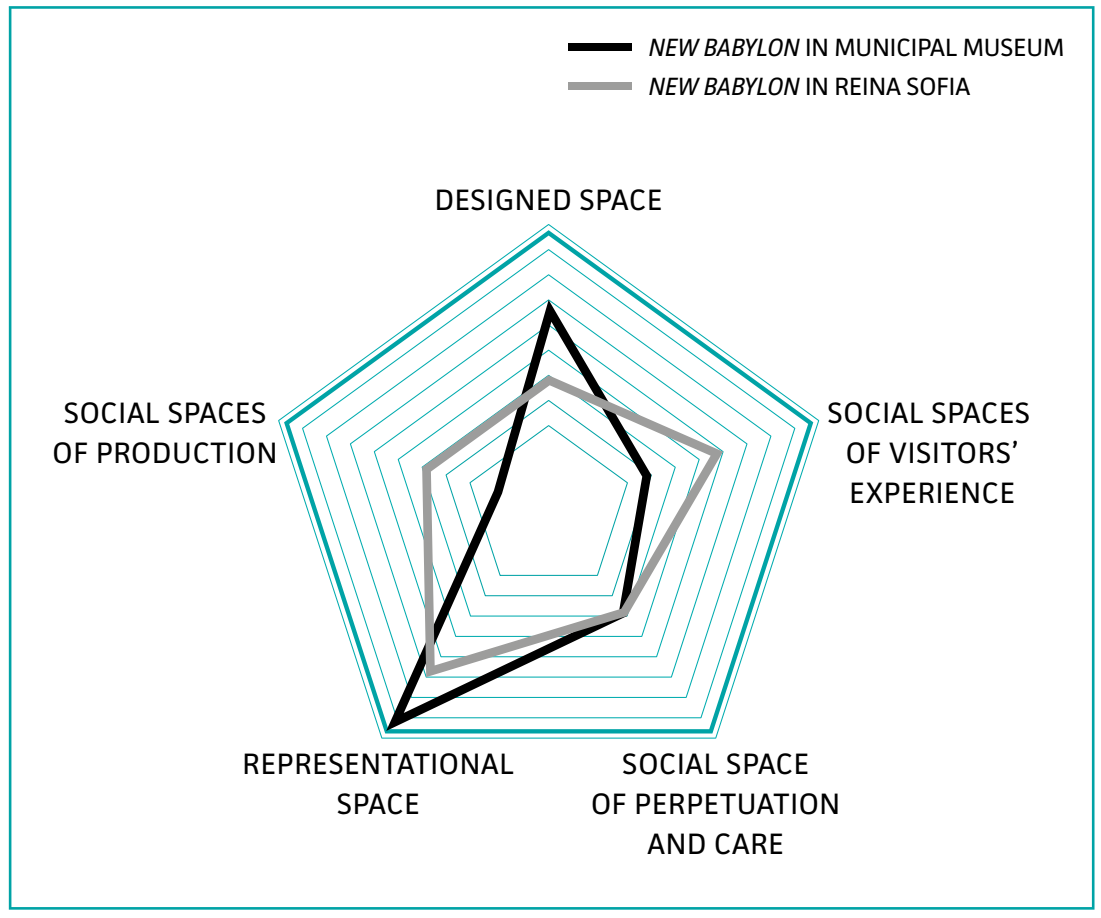

experience is really strong. Otherwise it would have no right to survive in the museum..$^{0}$

Janssen's observation echoes the statements of Charles Esche and Christiane Berndes in relation to the Drifting Producers models: if it was not for their aesthetic quality, there would have been no reason to purchase them for a museum collection. In terms of the conceptual model, these statements can be read as a reference to the aesthetic experience in the representational space of the museum. [See Diagram 14] Simultaneously, however, it seemed important to the curator to display traces of the production process, as an indication that these models were not only art objects but also part of a larger project on spatial production practices at the crossroads of art production, city planning, and architectural design. In that respect, the function of social space was emphasized by displaying the models on the 
Figure 37 New Babylon (1956-1974) by Constant Nieuwenhuys. Collection Kunstmuseum Den Haag. Installation view in Constant - New Babylon in 2016. Photo by the author. $\odot$ Fondation Constant.

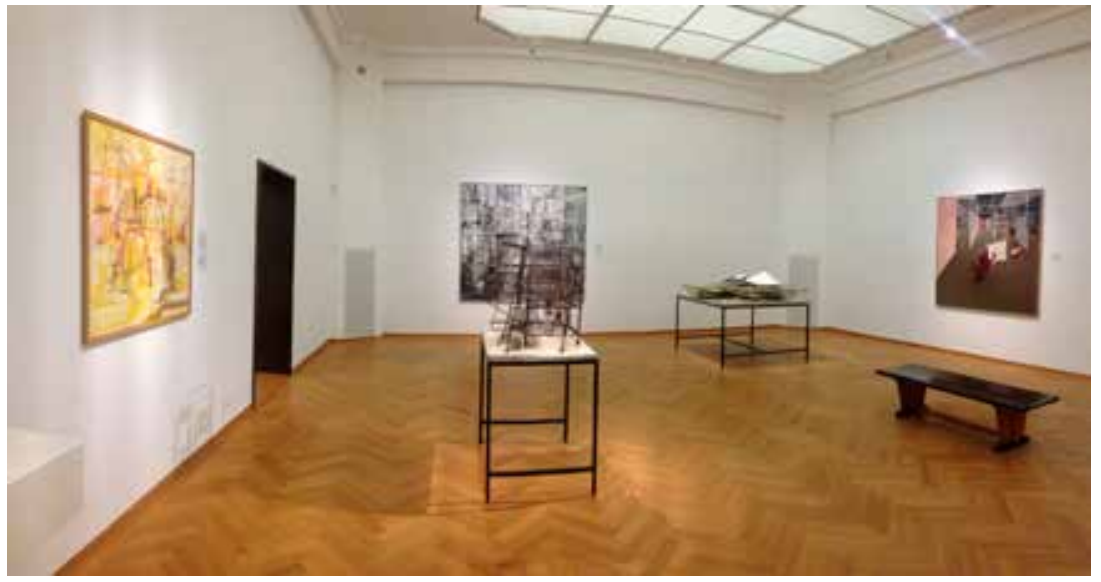

workbenches (comparable to the display of the Drifting Producers models on the workbenches in the tobacco factory). According to Hans Janssen, this approach was in accord with the artist's intent and it has been a guiding principle for future displays, tying the workbenches to the models.

The permanent display, in a relatively small gallery space, showed a few sketches and paintings from New Babylon next to the models. No additional information was provided about the history of the New Babylon project, nor was there any reference to Constant's activism or his underlying philosophy for the project. According to the curator, the exhibition design was prepared in close collaboration with the artist: the focus was on the artist Constant and the creative force of his autonomous works of art. As Janssen explains, visitors could retrieve the information and documentation about the New Babylon project from the museum website and other publications. ${ }^{71}$

For the retrospective of New Babylon in the Kunstmuseum, more or less the same strategy was followed. [Figure 37] The display of the models and paintings, sketches and drawings drew attention to Constant's artistic work, in agreement with the representational space of the museum gallery,

71 The website referred to by Hans Janssen is https:/www.gemeentemuseum.nl/en/collections/ constant-new-babylon (last accessed 26 April 2021). The website presents artworks made by Constant during the New Babylon project, but not the documentary material. An elaborate website on the history and philosophy of the project is published by Fondation Constant: https:// stichtingconstant.nl/new-babylon-1956-1974 (last accessed 26 April 2021). 
whereas only one example of documentary material was presented - a filmed conversation, in which Constant explains his vision on New Babylon. The shooting of the black-and-white film in the crowded streets of Amsterdam illuminated the connection between Constant's project and the sociogeographical context of the city at that time..$^{2}$

In summary, the exhibitions in the Kunstmuseum are manifestations of a curatorial strategy that highlights the significance of Constant's art production for the representational function of the museum space - coded as a universal and timeless white cube - and, at the same time, refers to the artist's studio by presenting the models on the same workbenches Constant had used for their production. In chapter 4, I referred to Julia Noordegraaf's observation that, in the course of the 1980 s, museum spaces became a substitute for the artist's studio, a place where visitors could witness the moment of creation. This goes, too, partly, for the scenario followed by the Kunstmuseum given the cross-reference between the benches and the production practice in the artist's studio. However, I would also argue that the social space of the production - and therewith of Constant's view on urban structures - has become subordinate to the outcomes of the process, because the significance of Constant's artworks is primarily conceived in terms of aesthetic qualities and in terms of their representational function for the museum context. [See Diagram 14]

\section{Staging the Models of New Babylon in Reina Sofia Madrid}

For a number of reasons, the exhibition Constant - New Babylon in Museo Nacional Centro de Arte Reina Sofia was different from the one in The Hague. ${ }^{73}$ Compared to the relatively small rooms of the Kunstmuseum, the architecture of this former hospital in Madrid offered a spacious environment, covering several rooms interconnected in the form of a crucifix. The models were exhibited on tables and workbenches spread out over several gallery spaces (some were the same as the ones used in the Kunstmuseum; some were newly made). Some models were illuminated with coloured spots. Constant had conceptualized this idea, but it had seldom been applied in previous exhibitions. The coloured lights contributed to a theatrical effect,

\footnotetext{
72 "New Babylon, Constant in conversation with writer Simon Vinkenoog" (1962). The film is recorded partly in the artist's studio and partly in the crowded streets of Amsterdam, to which Constant refers as a paradigmatic "automated city." https://stichtingconstant.nl/documentation/ met-simon-vinkenoog-naar-het-new-babylon-van-constant-1962 (last accessed 26 April 2021). 73 Unfortunately, I was not allowed to take pictures, and the catalogue does not provide installation shots of the exhibition.
} 
Figure 38 Ruimte in kleur (1952) by Aldo van Eyck and Constant. Reconstruction made for Constant - New Babylon, Centro de Arte Reina Sofia, Madrid in 2016. Photo by the author. $\odot$ Fondation Constant.

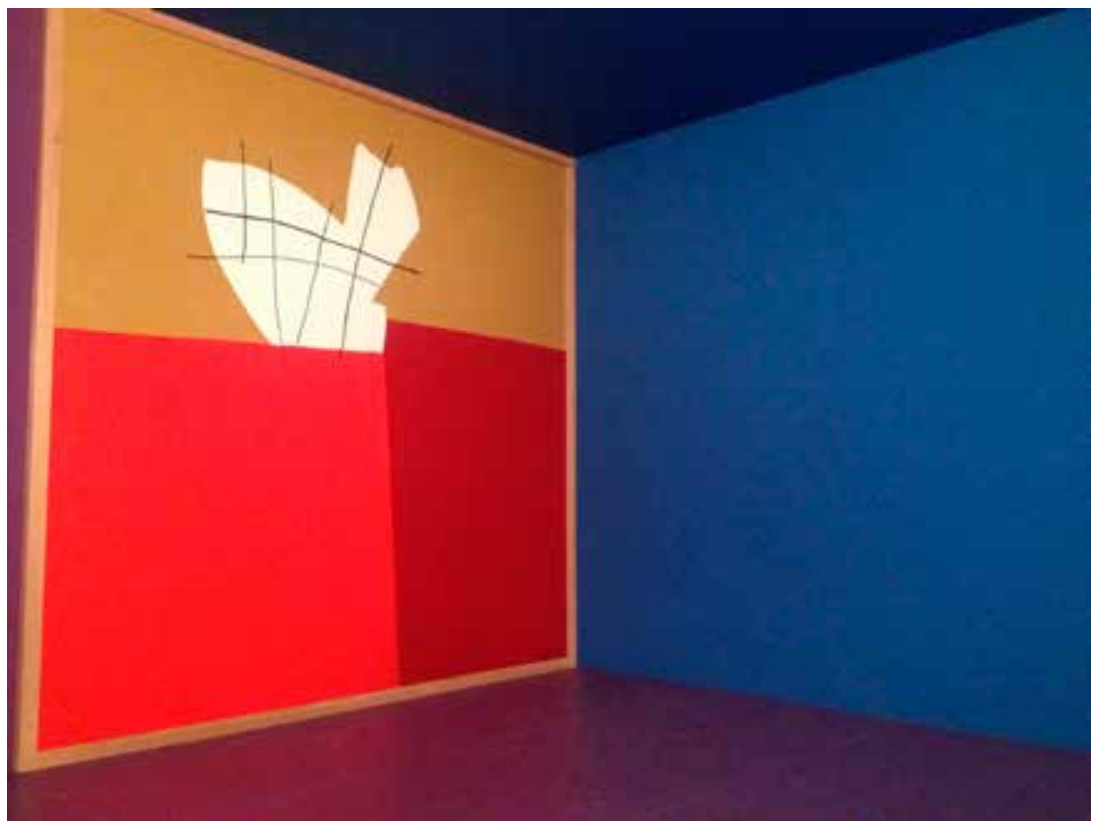

immersing the viewer in a "total experience" of an urban labyrinth. ${ }^{74} \mathrm{~A}$ striking difference was the richness of documentary material on the Situationist movement, as well as personal accounts and references made to the wider sociopolitical context of the New Babylon project. In addition to fragments of historical films and archival material, various anecdotes were shared with the public in texts and screened interviews, emphasizing the social networks in which Constant participated. A number of his larger, interactive spatial structures were refabricated, and a collaborative project between the architect Aldo van Eyck and Constant - Ruimte in kleur / Multicoloured Space - was reconstructed. ${ }^{75}$ [Figure 38] Because Constant had passed away

74 Constant's preference for coloured illumination of the models was mentioned by Hans Janssen during the interview. See footnote 67 of this chapter.

75 Ruimte in kleur / Multi-coloured Space was a source of inspiration for Constant to write his famous manifesto "Voor een spatiaal colorisme" ("A Space in Colour"). The room was exhibited in Stedelijk Museum Amsterdam, $195^{2}$. 
in 2005, his widow and other "legacy keepers" (including Hans Janssen) were closely involved with the exhibition scenario in Reina Sofia..$^{6}$

The reconstructions and documentaries presented in the show highlighted the biography of both the artist and the project, adding multilayered connotations and explanations regarding the underlying concepts. They drew attention to new approaches developed by Constant in reference to the sociogeographical context of his project. The spatial design in the Reina Sofia enabled visitors to wander around the "labyrinth," reinvigorating the social space of the visitors' experience in a way that was rather different from the staging in the Kunstmuseum, not least due to both the interaction with the spatial reconstructions and the alternation of artworks and documentary material. In terms of the conceptual model, I believe that the exhibition reactivated the social spaces of production and of the visitors' experience to a large extent, yet paying tribute to the aesthetics and design of the artworks by means of the spatial arrangement of the exhibition. [See Diagram 14]

The differences in manifestation mentioned above are the result of exhibition scenarios developed by the curators, but I would also like to note the influence of the buildings as well, because the respective gallery spaces were totally different from one another, both in seize and representational function. This diversity once more signals the applicability of Lefebvre's notion that representational space is alive and that manifestations are site-specific, especially when space and site are part of the meaning of the artworks on display.

\subsection{Conclusion}

This chapter was dedicated to an analysis of the musealization process of an installation artwork originating from a sociogeographical project. During the project, several manifestations were realized, varying from temporary events (such as art-and-community workshops and performances) to installation artworks and publications. The installation artwork Drifting Producers is the only physical remainder of the project.

One of my conclusions is that - apart from the passage of time and a disconnection from the initial context - the site specificity of Drifting

76 In 2012, Constant's widow Trudy Nieuwenhuys-Van der Horst gave new impetus to the Fondation Constant. Its main goals are to preserve and promote the art collection and intellectual legacy of the artist. Nieuwenhuys-Van der Horst had a strong voice in the realization of the two New Babylon exhibitions discussed in this chapter. 
Producers was subject to change, due to demands of a museum collection. The "flexible" spatial design of previous stages of the artwork was accommodated to the dimensions of the gallery space by means of the wooden frame; this established a new site specificity, tied to the museum's gallery space. The transition of a site-specific project to an installation artwork and its subsequent transformation into an aesthetic art object with fixed dimensions, is not unusual in a museum context and signals the predominance of representational space over the initial (variable) site specificity of the spatial design at earlier biographical stages. In one important respect, however, a deviation from common museum practices occurred. In the period following the acquisition, the discussion on the restoration of Drifting Producers brought new insights regarding the social space of perpetuation and care, as the restoration technique proposed by the artists (such as leaving visible traces of the restoration treatment) familiarized the professional staff with a conservation practice applied to architectural structures in the Cheonggyecheon, and the artists themselves executed the restoration.

The purpose of the acquisition was to safeguard the artwork and expand its lifespan in a museum context, in order to communicate to wider art audiences the content of the production networks and craftsmanship of Cheonggyecheon. In the exhibition of the installation at PlugIn \# 7 , the focus was on the artwork itself (apart from one accompanying lecture), although the museum imagined an exhibition scenario in which a programme of cultural events would be organized: the Flying City artists would share their insights and experiences gained from the Cheonggyecheon district with urban planners, designers, architects, and general publics in Eindhoven, thus perpetuating the social space of production. From a historical perspective, this intercultural exchange would echo the cross-cultural dialogue that had started in the international workshops attended by both the artists and the director of Van Abbemuseum.

Over time, the personal relationship between the artists and the museum director dampened and the representational space - the "lived space," according to Lefebvre - changed over time. This also implied that the museum's initial focus on the social space of production shifted towards a more general interest in the meaning production of art and craftsmanship in a global context. According to the statements of the director and the curator, an imagined scenario for future staging would mainly focus on Drifting Producers as an aesthetic art object; moreover, its representational function would sooner evoke a discussion on the disappearance of craftsmanship worldwide than refer to the original site specificity of the Cheonggyecheon district. 
The comparative case example of New Babylon showed a variation in exhibition scenarios. The Kunstmuseum foregrounded the merits of the artist Constant and the aesthetics of the models (focusing on the function of their spatial design). An additional element was the presentation of the urban models on the workbenches - a reference to their production in the artist's studio. On the other hand, the exhibition in Reina Sofia communicated the sociogeographical content and the philosophy of the project, emphasizing the social space of production. The wide gallery spaces offered sufficient room to include - apart from the collection of models and other artworks on display - information panels, photographs, and screens conveying information about the project to a contemporary audience. Moreover, the visitor's space of experience was activated by means of the rebuilt spatial constructions and illumination of the models with coloured light. To summarize, I argued that the exhibition in the Reina Sofia came close to reinvigorating the "lived" urban structures of Constant's New Babylon project, whereas the artworks were incorporated into the "universal world" of the white cube in the Kunstmuseum.

My final conclusion is that artworks rooted in a sociogeographical project often transform into aesthetic art objects and reach their final destination in the envelope of the museum system. However, this is not to say that by definition these installations would lose all site-specific functions. Site-specific installation artworks can incorporate specifics of the hosting site sometimes precisely through the accommodation of their spatial dimensions to the gallery space. Furthermore, curatorial scenarios can reinvigorate the "liveliness" of the initial project by additional means, such as documentaries, discussions, and other ways of engaging the audience with the project's history. 



\section{Conclusion and Further Discussion}

Keywords: multivoiced heritage conservation, reiteration, reinterpretation, staging contemporary art, scenography, dramaturg

\subsection{General Conclusion}

The readers of this book have taken note of the history of site-specific installation art and were offered an analytical model for examining the perpetuation of the artworks in a museum context. As the term suggests, site-specific installations are physically tied to the surrounding space and would, strictly speaking, have no afterlives after their initial manifestation. However, as demonstrated with many examples, site-specific installations can have extended lives and are frequently relocated to different contexts and times. Hence, rather than defining site specificity as a "fixed" characteristic, this study took a broader perspective by looking into the biographies of the artworks in relation to the exhibition site, ongoing institutional engagement, the locations of production, and the visitors' interaction in the here and now.

The core of chapter 2 consisted of an art historical summery of sitespecific installation art. From art historians and critics, I learned that, from the 199os onwards, museum policies on site-specific installations developed along two parallel tracks. One track focuses on the acquisition of historical site-specific installations created some decades earlier. The other consists of an active policy encouraging artists to create site-specific installations for museum galleries, which are subsequently acquired and re-exhibited. The research zoomed in on both tracks while examining the artworks' conservation and staging over time. For example, the introductory example of Allan Kaprow's Yard showed a remarkably extended lifespan of a site-specific installation artwork created for a gallery. Even five decades after its first iteration in 1961, the work was

Scholte, T., The Perpetuation of Site-Specific Installation Artworks in Museums. Staging Contemporary Art. Amsterdam: Amsterdam University Press 2022 DOI: 10.5117/9789463723763_CHO7 
(and still is) widely reactivated in various art museums worldwide. Other artworks may have shorter lifespans, or they may have been subjected to a deadlock in the museum's storage rooms for a considerable time, yet continue to exist.

With the purpose to contribute to both the academic discourse and museum practices concerning site-specific installation art, a conceptual model was provided in chapter 3 . This model can be applied by scholars and museum professionals who study the biographies of site-specific artworks and who engage with their perpetuation over long periods of time. The study combined a number of intellectual traditions, including art history, social geography, conservation studies, and museology, leading towards a conceptual model consisting of two main elements (see Diagrams 2-8). One element entails a classification and vocabulary of site-specific installations that is tailored to an analysis independent from art historical periods and trends. Taking the stance that site-specific installations can be conceived as heterogenous networks and following Henri Lefebvre's triad of spatiality, I proposed an ordering principle of three spatial functions constituting the artwork's site-specific network in concrete circumstances. The advantage of this approach is that it considers site specificity as a productive force: as a set of spatial functions set into motion in a particular space and moment in time.

The functions most related to the artwork's s manifestation are the internal spatial arrangement and the artwork's connectivity to the physical surrounding, identified in the model as the spatial design of site-specific installations (equivalent to what Lefebvre indicates as the conceived space). This function is set into motion the moment the artwork is put on display and, in case of a relocation, reinvigorates the spatial design in a different spatial context. Following Lefebvre's view on the spatial network, two other functions are interrelated with the spatial design, namely, the social spaces of production and the representational space.

Social space is incorporated into the model by regarding production practices as an intrinsic part of site specificity, because artists incorporate the specifics of the site in their creative practices and often consider the location of production important for the meaning of the work. I proposed to expand the social space of production into two other directions as well: one relating to the social spaces of visitors who interact, physically or otherwise, with the installation in a given display context; the other addressing the perpetuation of the artwork and the spatial practices employed by the custodians when preserving and staging site-specific installations in museum galleries. What ties these various modes of social space together is that they 
are interconnected with the practices employed in a given space, indicated by Lefebvre as a "perceived space."

The third function of site specificity is the representational space, described here as the museum's organizational principles and philosophies for acquiring and exhibiting site-specific installations. Especially in the case of commissioned installations, site-specific artworks are susceptible to change due to alteration of the museum's physical structure and aspirations of the custodians. Representational space is "alive" and, as many examples in this study show, these artworks evolve in tandem with the value system of the hosting institution and thus frequently stir curatorial intervention, with or without the presence of the artist. By transposing Lefebvre's triad of spatiality to site-specific installation artworks and expanding those notions where needed, I was able to define site specificity as a spatial production practice, which has the potential to be repeated "in the present tense."

The second element of the model provides a methodology for analysing the factors of influence on successive iterations. Taking the view that site specificity is rather an artistic strategy than a fixed characteristic of the artwork, it follows that conservators and curators are challenged to develop strategies for keeping the artworks alive. The artist does not always intend perpetuation nor is the institution always provided with instructions for conservation and reinstallation. Important for the artworks under discussion is that changes of the context - physical, social, or representational - are seldom foreseen at the moment of creation. And last but not least, re-establishing a connection between the artwork and the site is, in theory, something that takes place outside the artist's sphere of influence, unless the artist is present at the moment of staging. The example of Richard Serra's Waxing Arcs in the Museum Boijmans Van Beuningen (discussed in chapter 3 ) demonstrates that artists can make unrealistic demands. Or, as the case studies of SLOTO and Célula Nave show, they may suddenly pass away or lose interest. To understand these influential factors, especially if the artist is disconnected, I proposed to make use of a toolbox supporting both the analysis of past iterations and the development of scenarios for reinvigorating the artwork's site specificity in the present time and future.

To develop this toolbox, I borrowed from art historical and conservation discourses the notion that site-specific installations are performative, like other time-based artworks and installation art at large. This means that each reiteration can be compared to a staging process, which implies a series of actions. Setting the network of spatial functions in motion, these actions can be "followed" in the museum practice and various stages of the artwork's biography can be analysed. In brief, the toolbox borrows 
two familiar concepts from the performance art: the "script," on which the performance is based, and the "actors," who are interpreters of the script and steering factors in the execution of the work.

In theories on contemporary art conservation, a script (or score) usually indicates the core of the artwork and offers guidance for the artwork's performance; either artists themselves provide this information or the installation instructions are developed in collaboration with conservators and curators. I argued that this notion is applicable to site-specific installations, although it does not clarify why curatorial interventions take place, especially when these are not authorized by the artist and/or deviate from the script applied to earlier iterations. The notion of the script defined as an implicit set of instructions for future use of the object (introduced by Madeleine Akrich), sometimes applies to the perpetuation of site-specific installations. I traced this, for example, in Ernesto Neto's Célula Nave, in which the spatial design and the artist's choice of a sensual - as well as vulnerable - type of fabric incited the visitors' physical interaction, eventually leading to dramatic damage of the artwork.

Finally, following a current branch in museology and conservation studies, I drew a parallel with the performance arts to better understand the perpetuation and transformation of site-specific installation artworks in a museum context. I suggested to embrace a broader notion of the script and to incorporate the aspirations of custodians when reinvigorating sitespecific functions. Because connections between the artwork and the site are ephemeral, a radical form of interpretation and curatorial intervention is sometimes needed to redefine the work's site specificity in new places and times.

This observation also relates to a much broader focus area concerning the conservation of contemporary art. In contrast to traditional art conservation, which is primarily dedicated to arresting change in art objects as much as possible, contemporary works incite new approaches to which relationships are key: between people and things, artists and custodians, artworks and publics, and ... between artwork and site. In this respect, I mentioned, for example, the work of Fernando Domínguez Rubio, who makes a distinction between "docile" and "unruly" objects, the latter referring to contemporary artworks with a predisposition for transformation. Throughout their biographies, such artworks transform precisely because of the alterations occurring in the relational network. They enforce, as it were, institutional change in policies and practices, and therefore sometimes demand radical solutions. With this in mind, I argued that the feeling of discontent when historical works are being adapted to new sites is an integral part of their disruptive 
nature and that the new approaches they provoke can play an active role in the production of cultural forms and meanings. By acknowledging the need for reactivation, custodians enable museum visitors and scholars to experience a rich body of art that otherwise might have been lost or would no longer be recognized as a "living art." That said, I also made a plea for providing information to the public more often, especially information on how site-specific installations evolved over time and their relationships with previous sites.

Allied to the notions of the script (or score) are the actors who take conservation decisions and engage with staging site-specific installation artworks. Given the scope of this research, I could only consult a certain number of human actors, and I acknowledge that the analyses of the case studies are partly constructions, based on the available information and access to human sources. An important insight was derived from the conservation discourse that "knowledgeable networks" can play a pivotal role in keeping alive artworks of a temporary nature (like installations or performance artworks), and I suggested to apply this notion to sitespecific installation artworks as well. Sometimes, as in the example of Jason Rhoades's SLOTO in the Van Abbemuseum, the curatorial staff made the decision to perpetuate the spatial functions of the installation on the basis of previous communications with the artist. This raises the question at what point the formation of a knowledgeable network is productive and who should be involved. Although to answer this question in general goes beyond the scope of this study, I presented a number of examples in which the knowledgeable network that has formed between the artist, gallerist, and custodians plays an important role.

\subsection{Site Specificity and the Ongoing Dialogue between Artists and Custodians}

The case studies elucidated that, during the production and perpetuation of site-specific installations, a collaboration between the artists and custodians frequently comes about. Conversely, relationships established during the early stages of site-specific installations are not always continued when the artwork enters a museum collection. Sometimes, such an interruption in the relationship may lead to a deadlock, as in the example of Célula Nave (given the current disinterest of Ernesto Neto in its restoration and reinstallation).

By applying the conceptual model, I was able to clarify, in two case examples, a shift in site-specific functions from the changed relationship 
between the artist and museum professionals. Firstly, Drifting Producers shows the influence of an early collaboration between the Flying City artists and then curator Charles Esche (later director of the Van Abbemuseum). Both the content of the installation and its trajectory through the international art circuit were shaped by this relationship, up to the final moment of the artwork's acquisition. However, the relationship faded over time and Drifting Producers turned into a musealized artwork, no longer representing the sociogeography of the Cheonggyecheon or the cross-cultural dialogue between the two main actors (Jeon Yongseok and Charles Esche) from which it emerged. Instead, the installation attained a site-specific meaning, which was produced by the museum context.

The other example - Jason Rhoades's SLOTO. The Secret Life of the Onion - exposes challenges posed to curators in the unforeseen circumstance that the artist suddenly passes away. The artwork had been produced in close collaboration with the museum professionals of the Van Abbemuseum. Due to the artist's absence and a relocation from the original space to another gallery, the curators developed their own strategy for reactivating the sitespecific functions of the artwork, on the basis of conversations with Jason Rhoades and the agreement that stipulated that the installation could be shown in parts.

From the art historical overview of site-specific installation art, artists frequently created their work in dialogue with museum organizations. As Miwon Kwon and other art historians explain, avant-garde artists of the $1960 \mathrm{~s}$ and 1970 s took an overtly critical stance towards the museum system. This attitude has shifted in more recent periods and site-specific working artists have become used to collaborating with the organizations, employing the expertise of staff members on equal footing. Some site-specific installations, such as Jason Rhoades's $S L O T O$, are the result of such a coproduction and yet they persistently challenge museum organizations in the longer term, especially if the artist is no longer around. In this specific case, the dialogue was continued by "internalizing" the artist's viewpoint in curatorial strategies, and the work was executed "in the spirit of the artist." Domínguez Rubio's notion of unruly objects is beneficial for the stance I would take in this respect to not only focus on a "once-and-for all" meaning of a site-specific installation, but to recognize its force to creating new forms and meanings through continuously re-established relationships between the artist, the artwork, and custodians in a dynamic museum environment. This kind of work evolves in the intermediate zone of conservation, curation, and reinterpretation, and we might allow them a larger degree of interpretation than is usually the case with artworks in museums. At present, however, 
such an approach is not yet generally accepted in museum practices, as conservation and museum scholar Glenn Wharton also observes in his article "Reconfiguring Contemporary Art in the Museum":

Accepting these new collaborative roles in improvisation and interpretation can be difficult for museum staff because of traditions within their professions. ${ }^{1}$

Wharton continues by saying that when time moves on and "artists become less involved in the process, museums gain an institutional understanding of the parameters of improvisation." In view of site-specific installation artworks, it is in the hands of curators and other museum professionals whether, and how, site-specific functions are set into motion when the artwork is staged in a current context. To what extent the artist is involved and what degree of interpretation is considered acceptable will vary from case to case. A reflection on those practices, taking into consideration all elements of the spatial network and conservation issues of the work, will only contribute to a critical dialogue and understanding of new approaches in contemporary art conservation.

\subsection{Museum Practices and the Expanded Performance Analogy}

Reaching the end of this book, I would like to return briefly to the theatrical analogy discussed in chapter 3. The terms "staging" and "performance" were used to indicate processes that are needed for the realization and actual manifestation of a site-specific installation. My suggestion would be to add the term "scenography" to this vocabulary to build an analogy between a theatrical play and the experience of a site-specific installation. In theatre, each performance has its own scenography. The director and scenographer create a scenery in which the actors perform the play, making use of the spatial dimensions of the stage, light and sound, the arrangement of props, the actors' costumes, and the position of the audience vis-à-vis the stage. As the performance scholars Josilin McKinney and Philip Butterworth state, the scenography evolves during the action, when actors

1 Glenn Wharton, "Reconfiguring Contemporary Art in the Museum," in Authenticity in Transition: Changing Practices in Art Making and Conservation, ed. Erma Hermens and Frances Robertson (London: Archetype Publications, 2016), 33.

2 Wharton, "Reconfiguring Contemporary Art," 27. 
are moving around the stage and the spatial functions (such as light and sound) are set into motion. The authors describe the scenography as an "orchestration of the performance environment," which is "defined in its realisation and performance rather than its intentions." I I believe that McKinney and Butterworth's idea that a scenography is an active agent for the performance could be applied to site-specific installations as well, especially with regard to the completion of the artwork "on stage" and the experience by the audience.

As often noted throughout this book, the actual manifestation of the installed artwork may deviate from the planned spatial arrangement, and likewise, the scenography may vary from one iteration to another. Although I have used the term "spatial design," in accord with the triadic set of functions of the conceptual model, there is some overlap with the term "scenography," which is useful for the following argument. Focusing on the role of the interpreters, I suggest that conservators, curators, exhibition designers, and others "design" a scenography for a site-specific installation artwork when putting the work on show. It is often the task of custodians to orchestrate the spatial arrangement of the installation and to establish connections with the spatial environment of the exhibition room (taking into account the lighting, sound, position of the installation in the gallery space, and so on). Compared to a theatrical play, conservators and curators have a relative freedom of interpretation and yet, the distinction made by McKinney and Butterworth, between the plan and actual realization of the scenography, is worth considering. Because just like with a scenography for a theatre play, in staging site-specific installations, too, differences may occur between the concept (realized in the "ideal" moment of the first iteration) and successive iterations.

In the introduction, I posed the question whether a different manifestation of a site-specific installation could still be identified as the same artwork, despite modifications of the "original" to new sites and times. Given the performative nature of the artwork and the involvement of many different actors who contribute to its staging, the answer depends on how the installed artwork resonates with the network of spatial functions of the first iteration - one of those being the spatial design. As shown in the case studies, both the social space and the representational space of a site-specific installation may largely influence the spatial design. In this respect, it is worth noting that, as in theatre, a critical discourse would be needed to

3 Joslin McKinney and Philip Butterworth, The Cambridge Introduction to Scenography (Cambridge: Cambridge University Press, 2009), 4-5. 
assess whether the reinstallation is a successful iteration. In agreement with Tina Fiske, I argued in this book that site-specific installations can be exhibited in different ways, depending on the context. But, as Fiske also observes, "currently there is little critical way of accounting for differences that arise between incarnations of a work, or of the role played in that respect by absence or rupture."4 I have shown that, due to the complexities involved with staging site-specific installations, deadlocks can easily occur, which are often accompanied by long periods of storage. Hence, there is all the more need for a critical awareness of the coherence of all spatial functions of the network, and of functions that are absent or have changed over time.

My final suggestion would be to raise awareness for the role of the custodian who engages with transformative artworks, such as site-specific installations, in dramaturgical terms. As with theatre, a dramaturg would take the role of studying the biographies of individual artworks in which a critical stance could be taken and custodians could act like a dramaturg when developing a strategy for staging the work of art. I borrow this idea from Julia Noordegraaf who, in her publication "Documenting the Analogue Past in Marijke van Warmerdam's Film Installations," points to the dramaturgical perspective when studying different executions or "performances" of time-based media artworks. Applied to curatorial practices, she states, a dramaturg analyses "the composition" of the artwork and studies the history of its performances, on the basis of which the custodians engage with "the actual practical process of structuring the work." ${ }^{\prime \prime}$ Noordegraaf explains that a dramaturgical perspective can help to make distinctions between those elements that belong to the core of the artwork (the structure of the work) and those that may be subject to change (in the actual performance of the work):

Dramaturgy is tied to two different temporalities: the dramaturgy of the play text remains more or less the same and transcends space and time, whereas the dramaturgy of the play in performance is a unique live event that is always situated in space and time. ${ }^{6}$

4 Tina Fiske, "White Walls: Installations, Iteration and Difference," in Conservation: Principles, Dilemmas and Uncomfortable Truths, ed. Alison Richmond and Alison Bracker (Amsterdam: Elsevier, 2009), 231-232.

5 Turner and Behrndt, Dramaturgy and Performance (2008), cited by Julia Noordegraaf, "Documenting the Analogue Past in Marijke van Warmerdam's Film Installations," Revista de História da Arte 4 (2015): 120.

6 Idem. 
Diagram 15 Final model for the analysis of site-specific installation artworks. (c) The author. Image editing: Arienne Boelens/Maxim Hoekmeijer.

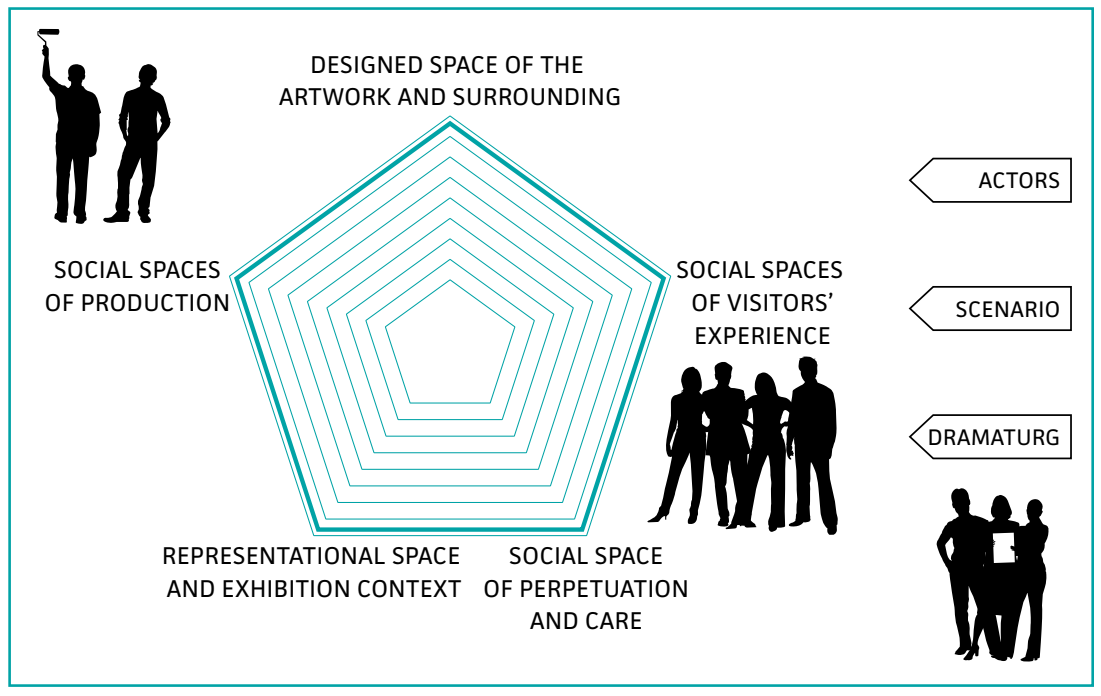

When applied to site-specific installation artworks, an additional note can be made that the structuring force of site-specific installations is their connectedness to a specific place and time. If no connection was established, the artwork would lose its identity as a site-specific artwork. One could even argue that it is at the core of these artworks to re-establish connections through their performance in a given space. The dramaturg could analyse if and how those connections have been realized in the past and, at the same time, engage with the iteration at hand. In other words, the role assigned to custodians when staging a site-specific installation could be compared to the role of a dramaturg. Nonetheless, we have to take into account, as Noordegraaf states, that in theatre, a dramaturg is usually a professionally trained person, whereas in curatorial practices of contemporary art, this role can be adopted by more than one museum professional. Usually, decision-making processes in museums are the result of teamwork, in which professionals of different disciplines collaborate, both from inside and outside the organization. My conclusion is that a team of professionals could play this role and in that sense, the dramaturgical approach could be considered a new way of thinking rather than a plea for a new "position," in addition to the ones already fulfilled by the conservator, curator, technical staff, exhibition designers, or others involved in the perpetuation of site-specific installation artworks. On this final note, I propose to add a last diagram to the conceptual model, to acknowledge 
the role of the dramaturg as a factor of influence on the ongoing lives of site-specific installation artworks. [See Diagram 15]

\section{Concluding Remarks}

With this book, I aimed to contribute to the existing rich body of reflective writing on the conservation and presentation of contemporary art as well as to contemporary policies, strategies, and practices in museums. The focus was on the production and perpetuation of site-specific installation artworks. However, the conceptual framework derived from Lefebvre's theory of space and the toolbox developed in analogy with the performance arts might potentially be useful for other, more traditional heritage objects as well. Wider connections can be made in the future with current scholarship in heritage studies, which challenges the traditional object-centred, "freeze" approach of conservation and which prioritizes, instead, the relationships between people, places, and objects as the primary responsibility of conservation. With art in public space, for example, a "spatial approach" could entail a continued dialogue between the artwork, the spatial context, and local communities who engage with the artwork. With historical interiors, changes of the heritage object could be studied from the perspective of spatial conglomerations and the triadic relationship between the objects, people who inhabit the space, and the (shifts) in representational function of the space. Furthermore, I believe that a connection could be made with technical art history, in particular by putting into focus the study of the places of production and reception, which, as I have shown, are never neutral but imbued with meaning. A reflection on spatial networks that are formed at distinct biographical stage of any heritage object may contribute to a better understanding of their cultural meaning and form.

I was fortunate to be, at times, involved in exciting projects in the relatively new field of contemporary art conservation. I wish researchers of the future an equal openness from the part of the custodians, granting them access to the collections and their minds, and embracing the rapidly evolving scholarship in this field. Only by having access to concrete case studies, documented in the archives as well as in the personal memories of custodians can theories be tested against practice and vice versa. Artists, custodians, and scholars inhabit the same cultural sphere, a space in which dialogues can take place and art continues to gain meaning. 



\section{Acknowledgements}

Over the years, I have been fortunate to work with many colleagues, scholars, and professionals who have inspired me tremendously and who have supported my research. First of all, my sincere gratitude goes to Julia Noordegraaf (University of Amsterdam), Deborah Cherry (University of the Arts London), and Glenn Wharton (University of California, Los Angeles) for sharing their knowledge and supporting me with advice and encouragement. We had so many stimulating conversations and pleasurable moments of friendship. I am also very grateful to Martha Buskirk (Montserrat College of Art), Pip Laurenson (Tate Research/Maastricht University), Ella Hendriks (University of Amsterdam), Erma Hermens (Rijksmuseum/University of Amsterdam), and Margriet Schavemaker (Amsterdam Museum/University of Amsterdam) for sharpening my thoughts in the preparation of this book.

I am most grateful for the generous support of the Dutch cultural heritage agency (Rijksdienst voor het Cultureel Erfgoed), Bauke Zeilstra, Michaela Hanssen, Jan van 't Hof, Janneke Ottens, and Henriette van der Linden, and my colleagues Bart Ankersmit and Klaas Jan van den Berg. Thank you, IJsbrand Hummelen, for your trust and extensive knowledge, and Vivian van Saaze and Renée van de Vall for the many stimulating talks and your constructive criticism on my work. And to Annette Dekker, Angela Matyssek, and Hanna Hölling for our thought-provoking discussions during the New Strategies in the Conservation of Contemporary Art project. The Foundation for the Conservation of Contemporary Art (SBMK) plays a prominent role in my professional life and the collaboration in, for instance, International Network for the Conservation of Contemporary Art (INCCA), Inside Installations, and The Artist Interview has tremendously contributed to developing the content of this research project. Special thanks to Paulien 't Hoen for our years-long friendship and companionship, and to Lydia Beerkens, Sannneke Stigter, and Gaby Wijers for taking me along in your fascinating research. Without the co-operation of many museum professionals, this book would never have seen the light of day. I am deeply indebted to the staff of Van Abbemuseum, Museum Boijmans Van Beuningen, Kunstmuseum Den Haag, Tate London, the Museum of Modern Art, and Hamburger Bahnhof. I also thank the artists for creating highly inspiring artworks and Jeon Yongseok in particular, for his openness and hospitality.

There are many friends and family members I would like to thank, but there are a few to whom I am specifically indebted. Sebastiaan Eliens, Maxim Hoekmeijer, Molly van Gelder, Eelco Vijzelaar, Dos Elshout, Karin 
Klooster, Hanneke Marttin, Farida Laan, Liddie Austin, Arjan Visser, Carla Peters, Patroeska Engel, Julia Sullivan, Natascha Boerkamp, Margo Witte, and Sherida Pengel - many thanks for your patience and support. Gert Peeters and Ton Nederhoed, Lex Moens and Bernadette Jansen, thank you for your hospitality the Greek way. Most of all, I thank Nicolette, who knows from the heart how to give meaning to life and who kept me on track. This book is for you, in anticipation of the journeys still to come. 


\section{List of Interviews Conducted by the Author}

\section{Ernesto Neto's Célula Nave. It happens in the body of time where truth dances}

- Interview with Wout Braber (head of technical department) and Jaqueline Rapmund (registrar of contemporary art), Museum Boijmans Van Beuningen, 28 November 2011.

- Interview with Sjarel Ex (director), Museum Boijmans Van Beuningen, 5 December 2011.

- Interview with Marjolijn de Bakker (technical staff member), Museum Boijmans Van Beuningen, 15 March 2012.

- Interview with Saskia Rijsdijk (independent conservator), 6 May 2012.

- Interview with Eric Meier (exhibition designer and production manager at MoMA) and Margo Delidow (contract conservator for the Whitney Museum and research fellow at MoMA), conservation studio The Bronx, 8 July 2012.

\section{Jason Rhoades's SLOTO. The Secret Life of the Onion}

- Interview with Margo van de Wiel (registrar/documentation), Van Abbemuseum, 13 July 2016.

- Interview Christiane Berndes (head of collections), Van Abbemuseum, 13 July 2016.

\section{Flying City's Drifting Producers}

- Interview with Louis Baltussen (head of technical department), Van Abbemuseum, 13 January 2010.

- Interview with Perry van Duijnhoven (photographer/documentation), Van Abbemuseum, 13 January 2010.

- Interview with Bettine Verkuijlen (registrar/documentation, Van Abbemuseum, 20 January 2010.

- Interview with Margo van de Wiel (registrar/documentation), Van Abbemuseum, 20 January 2010. 
- Interview with Christiane Berndes (head of collections), Van Abbemuseum, 3 March 2010.

- Interview with Charles Esche (director), Van Abbemuseum, 24 March 2010.

- Interview with Jeon Yongseok (artist), Seoul, 20 March 2011.

- Interview with Hans Janssen (curator), Kunstmuseum Den Haag, 24 November 2010.

- Interview with Christiane Berndes (head of collections), Van Abbemuseum, 2 February 2017.

\section{Published interviews consulted for the case studies}

- Skype interview with Ernesto Neto by Museum Boijmans Van Beuningen incorporated in a film by Alexander Goekjian, "Megastructures: Building 'Célula Nave'." Arttube, 7 July 2009. https://vimeo.com/124817865.

- Video recording of Topology: Spaces of Transformation: Edges of the World, panel discussion and presentation by Ernesto Neto. Tate conference (part three), 21 January 2012.

- Interview with Ernesto Neto by Bill Arning, 1 January 2000. https:// bombmagazine.org/articles/ernesto-neto/.

- Interview with Ernesto Neto by Nathan Gülick on the occasion of the installation of Animal Architecture, January 2007. https://www.youtube. com/watch?v=yoMSbpiXsıw-.

- Wilcox, Jess. "Anthropodino: A Conversation with Ernesto Neto." Art in America, 26 May, 2009. https://www.artinamericamagazine.com/newsfeatures/interviews/anthropodino-a-conversation-with-ernesto-neto/.

- Interview with Ernesto Neto by Luiz Camillo Osario. In "Madness is part of life," 7-37. Tokyo: Espace Louis Vuitton, 29 September 2012-6 January 2013 .

- Interview with Jason Rhoades. Heimir Björgúlfsson, "Charisma Catcher," 29 July 2006. Artnet Magazine. http://www.artnet.com/magazineus/ features/bjorgulfsson/bjorgulfsson8-23-06.asp.

- Vergara, Leire, "Art, Possibility and Democracy, Interview with Charles Esche." Zehar 57 (2005).

- http://artxibo.arteleku.net/sites/all/libraries/pdfjs/web/viewer. html?file=http\%3A//artxibo.arteleku.net/en/islandora/object/ arteleku\%253A $5827 /$ datastream/OBJ/view. 


\section{Appendix}

Robert Morris, The Amsterdam Project: Specification for a Piece with Combustible Materials executed at the exhibition Op losse schroeven. Situaties en cryptostructuren, curated by Wim Beeren, Stedelijk Museum Amsterdam, 15 March-27 April, 1969.

Wall text of the instructions to the museum curator by Robert Morris "Amsterdam project: 1 . Collect as many different kinds of combustible materials as are available in Amsterdam - coal, oil, fireplace logs, grass, peat, coke, twigs, magnesium, etc. Assign a curator to thinking of more than I have listed. 2. Divide the number of exhibition days, less one, by the number of exhibition days. 3. Begin with one material and place it in the 9"x 12" space allotted to the work. At each interval obtained by step 2 add another material. Each material must be placed freely in the space - that is, not in containers. If necessary, protect the floor with plastic from the beginning. 4. On the last day of the exhibition remove the entire mass to a designed safe place, outside the museum and ignite - Robert Morris."

From: Christian Rattemeyer, Teresa Gleadowe, Charles Harrison, Harald Szeemann, and Wim Beeren, eds. Exhibiting the New Art. "Op Losse Schroeven" and "When Attitudes Become Form" 1969 (New York: Distributed Art Publishers, 2011), 97. 



\section{Bibliography}

Adamson, Glenn, and Julia Bryan-Wilson. Art in the Making: Artists and their Materials from the Studio to Crowdsourcing. London: Thames \& Hudson, 2016.

Akrich, Madeleine. "The De-scripting of Technological Objects." In Shaping Technology/Building Society, edited by Wiebe E. Bijker and John Law, 205-223. Cambridge, MA: The MIT Press, 1992. Akrich, Madeleine, and Bruno Latour. "A Summary of a Convenient Vocabulary for the Semiotics of Human-Nonhuman Assembles." In Shaping Technology / Building Society, edited by Wiebe E. Bijker and John Law, 259-264. Cambridge, MA: The MIT Press, 1992.

Alexander, Jeffrey C. Performance and Power. Cambridge, UK: Polity Press, 2011.

Appadurai, Arjun. "Introduction: Commodities and the Politics of Value." In The Social Life of Things: Commodities in Cultural Perspective, edited by Arjun Appadurai, 3-63. Cambridge: Cambridge University Press, 2005 [1986].

Appadurai, Arjun. "The Production of Locality." In Modernity at Large: Cultural Dimension of Globalization, 178-199. Minneapolis: University of Minnesota Press, 1996.

Avrami, Erica, Randall Mason, and Marta de la Torre. Values and Heritage Conservation:Research Report. Los Angeles: Getty Conservation Institute, 2000.

Beerkens, Lydia, Paulien 't Hoen, IJsbrand Hummelen, Tatja Scholte, Sanneke Stigter, and Vivian van Saaze, eds. The Artist Interview: Guidelines and Practice for Conservation and Presentation of Contemporary Art. Heijningen: Jap Sam Books, 2012.

Biryukova, Marina. "Reconsidering the Exhibition When Attitudes Become Form Curated by Harald Szeemann: Form versus 'Anti-Form' in Contemporary Art," Journal of Aesthetics \& Culture 9, no. 1 (2017). https://www.tandfonline.com/doi/full/10.1080/20004214.2017.1362309.

Bishop, Claire. Installation Art: A Critical History. London: Tate Publishing, 2005.

Bishop, Claire. "The Social Turn: Collaboration and its Discontents." Artforum International 44 (February 2006): 178-183.

Bismuth, Julien, and David Zwirner.Jason Rhoades: PeaRoeFoam. New York: David Zwirner Books, 2015 .

Buskirk, Martha. Creative Enterprise: Contemporary Art Between Museum and Marketplace (International Texts in Critical Media Aesthetics. Volume 3). New York: The Continuum International Publishing Group, 2012.

Buskirk, Martha. The Contingent Object of Contemporary Art. Cambridge, MA: The MIT Press, 2003.

Buskirk, Martha, and Clara Weyergraf-Serra, eds. The Destruction of Tilted Arc: Documents. Cambridge, MA: The MIT Press, 1991

Butt, Gavin. "Happenings in History, or, The Epistemology of the Memoir." Oxford Art Journal 24, no, 2 (2001): 113-126.

Caianiello, Tiziana, and Renate Buschman, eds. Media Art Installations: Preservation and Presentation. Materializing the Ephemeral. Berlin: Dietrich Reimer Verlag, 2013.

Caianiello, Tiziana. "Between Media: Connections between Performance and Installation Art, and Their Implications for Conservation." VDR Beitrage no. 1 (2018): 104-110.

Cane, Simon. "Why Do We Conserve? Developing Understanding of Conservation as a Cultural Construct." In Conservation Principles, Dilemmas and Uncomfortable Truths, edited by Alison Richmond and Alison Bracker, 163-175. Oxford: Elsevier, 2009.

Carslon, Marvin. Performance: A Critical Introduction. London: Routledge, 2013. 
Chambers, Janet D. “Three Contemporary Korean Artists” Master's thesis, University of Canterbury, 2012. https://ir.canterbury.ac.nz/handle/10092/7822.

Cherry, Deborah. "Altered States: The Social Biographies of Works of Art. She Loved to Breathe Pure Silence (1987-2012) by Zarina Bhimji." In Tra memoria e oblio: percorsinella conservazione dell'arte contemporanea, edited by Paolo Martore, 210-228. Rome: Castelvecchi, 2014.

Cherry, Deborah. "Transnational Practices in Collecting." Transcribed lecture delivered at Becoming Dutch: Seminar Collecting and Identity. Van Abbemuseum, 13 September 2007.

Clavir, Miriam. Preserving What is Valued: Museums, Conservation, and First Nations. Vancouver: University of British Columbia Press, 2002.

Commandeur, Ingrid. "Istanbul, de stad als Biennale." Metropolis M 4 (2005): 17-18.

Crimp, Douglas. On the Museum's Ruins. Cambridge, MA: The MIT Press, 1993.

Crimp, Douglas. "Serra's Public Sculpture: Redefining Site Specificity." In Richard Serra / Sculpture, exhibition catalogue edited by Rosalind Krauss, 40-56. New York: Museum of Modern Art, 27 February-13 May, 1986.

David, Eric. “Jason Rhoades' Brilliant Installations at Hauser \& Wirth Los Angeles." Yatzer Art, 15 April 2017, https://www.yatzer.com/jason-rhoades-installations.

Davidts, Wouter, and Kim Paice. The Fall of the Studio: Artists at Work. Amsterdam: Valiz Publishers, 2009.

De Oliveira, Nicolas, Michael Petry, and Nicola Oxley. Installation Art. London: Thames and Hudson, 1994.

Debord, Guy, "Introduction to a Critique of Urban Geography," Les lèvres nues \#6. Translated by Ken Knaub, Situationist International Online, 1955. https://www.cddc.vt.edu/sionline/ presitu/geography.html.

Dekker, Annet. "Enjoying the Gap: Comparing Contemporary Documentation Strategies.” In Preserving and Exhibiting Media Art:Challenges and Perspectives, edited by Julia Noordegraaf, Cosetta Saba, Barbara Le Maître, and Vinzenz Hediger, 149-169. Chicago: University of Chicago Press, 2013.

Dekker, Annet. "Enabling the Future, or How to Survive FOREVER. A Study of Networks, Processes and Ambiguity in Net Art and the Need for an Expanded Practice of Conservation." PhD diss., University of Amsterdam, 2014.

Depocas, Alain, Jon Ippolito, and Caitlin Jones. Permanence Through Change: The Variable Media Approach. Montreal: Daniel Langlois Foundation for Art, Science, and Technology, 2003. www.variablemedia.net.

Desvallées, André, and François Mairesse. Key Concepts of Museology. Published by Armand Colin, ICOM International Committee for Museology, 2010. http://www.icom-italia.org/ wp-content/uploads/2018/02/ICOMItalia.KeyconceptsofMuseology.Pubblicazioni.2010.pdf.

Doherty, Claire, ed. Situation:Documents of Contemporary Art. Cambridge, MA: The MIT Press, 2009 .

Domínguez Rubio, Fernando. "Preserving the Unpreservable: Docile and Unruly Objects at MoMA.” UC San Diego, 2014. https://escholarship.org/uc/item/9qr4d9qx.

Domínguez Rubio, Fernando. Still Life: Ecologies of the Modern Imagination at the Art Museum. Chicago: The University of Chicago Press, 2020.

"E.C.C.O. Professional Guidelines, Promoted by the European Confederation of ConservatorRestorers' Organization and adopted by the General Assembly," Brussels i March 2002. http:// www.ecco-eu.org/fileadmin/user_upload/ECCO_professional_guidelines_I.pdf.

Ehrlich, Ken, and Brandon Labelle, eds. Surface Tension: Problematics of Site. Downey: Errant Bodies Press, 2003. 
Elden, Stuart. Understanding Henri Lefebvre. Theory and the Possible. London: Continuum, 2004. https://selforganizedseminar.files.wordpress.com/2012/07/elden-stuart-understandinghenri-lefebvre-theory-and-possible.pdf.

Fiske, Tina, "White Walls: Installations, Iteration and Difference." In Conservation: Principles, Dilemmas and Uncomfortable Truths, edited by Alison Richmond and Alison Bracker, 229-240. Amsterdam: Elsevier, 2009.

Fiske, Tina. "Authenticities and the Contemporary Artwork Or Between Stone and Water." VDR Beitrage 2 (2006): 34-39.

Fiske, Tina. "Accessioning Ernesto Neto: Some Recent Installations and Acquisitions Considered." In Postprints of Contemporary Art:Creation, Curation, Collection and Conservation (organized by the Professional Conservators and Restorers Association). Dublin: Irish Museum of Modern Art, 21-22 September, 2001.

Ford, Simon. The Situationist International: A User's Guide. London: Black Dog Publishing, 2005. Foucault, Michel. "Of Other Spaces: Utopias and Heterotopias (1967)." Translated by Jay Miskowiec. Architecture/Mouvement/ Continuité no. 5 (October 1984): 46-49.

Frock, Christian L. "Site-Specific Installation: Some Historic Context." In Unexpected Art: Serendipitous Installations, Site-Specific Works and Surprising Interventions, edited by Jenny Moussa Spring, 8-11. San Francisco: Chronicle Books, 2015.

Gilman, Julie, Liesbeth Jacxens, and Bruno Demeulenaer. "Conservation Strategy for Food-Based Perishable Art: Preservation versus Reconstruction Illustrated by Piece in Ghent by Jason Rhoades." Studies in Conservation 61, no. 1 (2016): 3-12.

Groys, Boris. "The Restoration of Destruction." Witte de With Cahier 4 (March 1996): 155-160.

Grün, Maike. "Coordinates and Plans: Geodetic Measurement of Room Installations." In Inside Installations: Theory and Practice in the Care of Complex Artworks, edited by Tatja Scholte and Glenn Wharton, 185-194. Amsterdam: Amsterdam University Press, 2011.

Harvey, David. Explanation in Geography. New York: St. Martin's Press, 1969.

Hoebink, Dorus. "The Theatre of Heritage. On Museums as Performances of Community Cultures." PhD diss., Erasmus Universiteit Rotterdam, 2016.

Hölling, Hanna. Paik's Virtual Archive: Time, Change, and Materiality in Media Art. Oakland: University of California Press, 2017.

Hölling, Hanna. "The Technique of Conservation: On realms of Theory and Culture Practice." Journal of the Institute of Conservation 40, no. 2 (2017): 87-96.

Hummelen, IJsbrand, and Dionne Sillé, eds. Modern Art: Who Cares? An International Rresearch Project and International Symposium on the Conservation of Modern and Contemporary Art. London: Archetype Publications, 2006 [1999].

Hummelen, IJsbrand, Vivian van Saaze, and Matthijs Versteegh. "Towards a Symmetrical Approach in Conservation." In Preprints ICOM Committee for Conservation, 15 th Triennial Conference, 1041-1047. New Delhi, 22-26 September, 2008.

Hummelen, IJsbrand, and Tatja Scholte. "Collecting and Archiving Information from Living Artists for the Conservation of Contemporary Art." In Conservation of Easel Paintings, edited by Joyce Hill Stoner and Rebecca Rushfield, 39-47, 2nd edition. Oxford: Butterworth-Heinemann, 2012.

Hummelen, IJsbrand, and Tatja Scholte. "Capturing the Ephemeral and Unfinished. Archiving and Documentation as Conservation Strategies of Transient (as Transfinite) Contemporary Art." Technè 24 (2006): $5^{-11 .}$

Hummelen, IJsbrand, and Tatja Scholte. "Sharing Knowledge for the Conservation of Contemporary Art: Changing Roles in a Museum without Walls?” In Modern Art, New Museums, edited 
by Roy Ashok and Perry Smith, 208-210. Bilbao: The International Institute for Conservation of Historic and Artistic Works, 2004.

Huxley, Michael, and Noel Witts. The Twentieth-Century Performance Reader, $2^{\text {nd }}$ edition. New York: Routledge, 2002.

Ippolito, Jon. "Accommodating the Unpredictable: The Variable Media Questionnaire." In Permanence Through Change: The Variable Media Approach, edited by Alain Depocas, 46-53. New York: Solomon Guggenheim Museum, 2003.

Irvin, Shiri. "The Artist's Sanction in Contemporary Art." The Journal of Aesthetics and Art Criticism 63, no 4 (2005): 315-326.

Jeon, Yongseok. Cheonggye Archive Metal Cloud. Seoul: flyingCity (in Korean language only), 2009. Jeon, Yongseok. “Drifting Producers." In Art and Social Change: A Critical Reader, edited by Will Bradley and Charles Esche, 369-377. London: Tate Publishing, 2008.

Jeon, Yongseok. “Seoul Modernity and the Spy Paradigm.” In The Remembrance of a City: The History of Space, an International Symposium on Alternative Space. Seoul: Insa Art Space, 2003.

Kaprow, Allan. 7 Environments, exhibition catalogue. Milan: Fondazione Mudima, 1991 and Naples: Studio Morra, January/February, 1992.

Kaprow, Allan. "Essays on the Blurring of Art and Life." Reprinted by Jeff Kelley. Berkeley: University of California Press, 1993 [1966]. https://monoskop.org/images/3/36/Kaprow_Allan_Essays_on_the_Blurring_of_Art_and_Life_with_Impurity_Experimental_Art_The_Meaning_of_Life_missing.pdf.

Kaprow, Allan. "How to Make a Happening." Lecture recorded on LP in 1966. Transcription http:// primaryinformation.org/files/allan-kaprow-how-to-make-a-happening.pdf.

Kaye, Nick. Site Specific Art: Performance, Place, and Documentation. London: Routledge, 2000. Kera, Denisa. "Psychogeography: City, Utopias and Maps." Umelec online Magazine, 1 (March 2005). Kopytoff, Igor. "The Cultural biography of Things: Commoditization as Process." In The Social Life of Things: Commodities in Cultural Perspective, edited by Arjun Appadurai, 64-91. Cambridge: Cambridge University Press, 2005 [1986].

Krauss, Rosalind E. The Originality of the Avant-Garde and Other Modernist Myths. Cambridge, MA: The MIT Press, 1986.

Krauss, Rosalind E. Richard Serra/sculpture, exhibition catalogue. New York: Museum of Modern Art, 27 February-13 May, 1986. https://assets.moma.org/documents/moma_catalogue_2190_300296038.pdf.

Kremer, Mark. "Flying City 'Invitation to Drift'.” In Facing Korea. Dutch - Korean Contemporary $\mathrm{Art}_{\mathrm{s}}$ exhibition catalogue, 154-173. Amsterdam: Yellow Sea Publications, 2003.

Kwon, Miwon. "One Place after Another: Notes on Site-Specificity." In Space, Site, Intervention: Situating Installation Art, edited by Erika Suderburg, $38-63$. Minneapolis: University of Minnesota Press, 2000.

Kwon, Miwon. One Place After Another: Site-Specific Art and Locational identity. Cambridge, MA: The MIT Press, 2002.

Lagnado, Lisette. "Longing for the Body: Yesterday and Today." In Brazil:Body Nostalgi, 164-169. Tokyo: National Museum of Modern Art, 2004.

Latour, Bruno. Resembling the Social: An Introduction to Actor-Network Theory. Oxford: Oxford University Press, 2005.

Latour, Bruno. "On Actor-Network Theory. A Few Clarifications Plus More Than a Few." Soziale Welt 47 (1996): 1-16. http://www.bruno-latour.fr/sites/default/files/P-67\%20ACTOR-NETWORK.pdf. 
Laurenson, Pip, Vivian van Saaze, and Renée van de Vall. "Bridging the Gaps between Theory and Practice through Cross-Institutional Collaboration in the Conservation of Contemporary Art." In Engaged Humanities: Rethinking Art, Culture, and Public Life edited by Aagje Swinnen, Amanda Kluveld, and Renée van de Vall, 298-329. Amsterdam: Amsterdam University Press, 2022.

Laurenson, Pip, and Vivian van Saaze. "Collecting Performance-Based Art: New Challenges and Shifting Perspectives." In Performativity in the Gallery: Staging Interactive Encounters, edited by Outi Remes, Laura MacCulloch, and Marika Leino, 28-41. Oxford: Peter Lang, 2014.

Laurenson, Pip. "Authenticity, Change and Loss in the Conservation of Time-Based Media." Tate Papers (Autumn 2006). https://www.tate.org.uk/research/publications/tate-papers/o6/ authenticity-change-and-loss-conservation-of-time-based-media-installations.

Laurenson, Pip. “The Management of Display Equipment in Time-Based Media Installations." In Modern Art, New Museums, edited by Roy Ashok and Perry Smith, 49-53. Bilbao: The International Institute for Conservation of Historic and Artistic Works, 2004.

Leary-Owhin, Michael E. ed. "Urban Planning and the Spatial Ideas of Henri Lefebvre." Urban Planning, no. 3 (June 2018). View Issue | Peer-Reviewed Open Access Journal | Cogitatio Press.

Lefebvre, Henri. The Production of Space. Translated by D. Nicholson-Smith. Oxford: Blackwell Publishing, 1991 [1974].

Lefebvre, Henri, Critique of Everyday Life. Translated by John Moore and Gregory Elliott. New York: Verso Books, 2008.

Lippard, Lucy. "Land Art in the Rearview Window." In Surface Tension: Problematics of Site, edited by Ken Ehrlich and Brandon Labelle, 57-66. Downey: Errant Bodies Press, 2003.

Massey, Doreen. "A Global Sense of Place." In Situation (Documents of Contemporary Art), edited by Claire Doherty, 160-169. London: Whitechapel Gallery, 2009 [1991].

Matos, Lucia, Rita Macedo, and Gunnar Heydenreich eds. "Performing Documentation in the Conservation of Contemporary Art."Revista de Historia da Arte 4 (2015). http://revistaharte. fcsh.unl.pt/rhaw4/RHAw4.pdf.

McCall, Vikki, and Clive Gray. "Museums and the 'New Museology': Theory, Practice and Organisational Change." Museum Management and Curatorship 29, no. 1 (2013): 1-17.

McCoy, Richard. "Concepts about Interviewing Artists. A Discussion with Glenn Wharton." Art 21 Magazine, Blog 20 (October 2009). http://blog.art21.org/2009/10/20/concepts-aroundinterviewing-artists-a-discussion-with-glenn-wharton.

McKinney, Joslin, and Philip Butterworth. The Cambridge Introduction to Scenography. Cambridge, UK: Cambridge University Press, 2009.

Melchionne, Kevin. "Rethinking Site-Specificity. Some Critical and Philosophical Problems." Art Criticism 12, no 2 (1998): 36-49.

Mersmann, Birgit. "Lacing Places: Situationist Practices and Socio-Political Strategies in Korean Urban Projects." In Situating Global Art. Topologies - Temporalities - Trajectories, edited by Sarah Dornhof, Nanne Buurman, Birgit Hopfener, and Barbara Lutz, 91-109. Bielefeld: Transcript Verlag, 2018.

Meyer, James. "The Functional Site or The Transformation of Site Specificity." In Space, Site, Intervention: Situating Installation Art, edited by Erika Suderburg, 23-37. Minneapolis: University of Minnesota Press, 2000.

Meyer, Morgan. "Placing and Tracing Absence: A Material Culture of the Immaterial." Journal of Material Culture 17 (2012): 103-110.

Meyer-Hermann, Eva, and Andrew Perchuk. Alan Kaprow - Art as Life. London: Thames and Hudson, 2008.

Morris, Robert. "Notes on Sculpture." Artforum (February and October 1966). 
Morris, Robert. "The Present Tense of Space." Art in America (January-February 1978), reprinted in Continuous Project Altered Daily: The Writings of Robert Morris. Cambridge, MA: The MIT Press, 1994.

Muñoz-Viñas, Salvador. Contemporary Theory of Conservation. Amsterdam: Elsevier, 2005.

Muñoz-Viñas, Salvador. "The Artwork that Became a Symbol of Itself: Reflections on the Conservation of Modern Art." In Theory and Practice in the Conservation of Modern and Contemporary Art: Reflections on the Roots and Perspectives, edited by Urusla Schaedler-Saub and Angela Weyer, 9-20. London: Archetype Publishers, 2010.

Moussa Spring, Jenny, ed. Unexpected Art: Serendipitous Installations, Site-Specific Works and Surprising Interventions. San Francisco: Chronicle Books, 2015.

Noel de Tilly, Ariane. "Scripting Artworks: Studying the Socialization of Editioned Video and Film Installations." PhD diss., University of Amsterdam, 2011.

Noordegraaf, Julia. Strategies of Display. Museum Presentation in Nineteenth- and TwentiethCentury Visual Culture. Rotterdam: NAi Publishers, 2004.

Noordegraaf, Julia, Cosetta G. Saba, Barbara Le Maître, and Vinzenz Hediger, eds. Preserving and Exhibiting Media Art: Challenges and Perspectives. Chicago: University of Chicago Press, 2013.

Noordegraaf, Julia. "Documenting the Analogue Past in Marijke van Warmerdam's Film Installations." Revista de História da Arte 4 (2015):115-123.

O'Doherty, Brian. Inside the White Cube, The Ideology of the Gallery Space (Expanded Edition. Berkeley: University of California Press, 1986.

Osborne, Peter. “Installation, Performance, or What?" Oxford Art Journal 24, no. 2 (2001): 147-154.

Peltomaki, Kirsi. "Affect and Spectatorial Agency: Viewing Institutional Critique in the 1970s." Art Journal 66, no. 4 (2007): 36-51.

Phillips, Joanna, "New Practices of Collecting and Conserving Live Performance Art at the Guggenheim Museum," VDR Beitrage 1 (2018): 124-132.

Plant, Sadie. The Most Radical Gesture: The Situationist International in a Postmodern Age. New York: Routledge, 1992.

Pugliese, Marina, Barabra Ferriani, and Antonio Rava. "Time, Originality and Materiality in Contemporary Art Conservation. The Theory of Restoration by Cesare Brandi, between Tradition and Innovation." Preprints ICOM Committee for Conservation, 15th Triennial Conference, 484-499. New Delhi, 22-26 September, 2008.

Rattemeyer, Christian, Teresa Gleadowe, Charles Harrison, Harald Szeemann, and Wim Beeren, eds. Exhibiting the New Art. "Op Losse Schroeven" and "When Attitudes Become Form" 1969. New York: Distributed Art Publishers, 2011.

Rebentisch, Juliane. Aesthetics of Installation Art. Berlin: Sternberg Press, 2012 [2003].

Reiss, Julie H. From Margin to Center: The Spaces of Installation Art. Cambridge, MA: The MIT Press, 1999 .

Richmond, Alison, and Alison Bracker, eds. Conservation Principles, Dilemmas and Uncomfortable Truths. London: Elsevier, 2009.

Ring Petersen, Anne. Installation Art: Between Image and Stage. Copenhagen: Museum Tusculanum Press, 2015.

Roos, Job, Dorus Hoebink, and Arjan Kok. Metamorphosis: The Transformation of Dutch Museums. Delft: TU Delft - Heritage \& Architecture, 2019.

Rosenthal, Mark. Understanding Installation Art: From Duchamp to Holzer. Munich: Prestel Verlag, 2003. 
Schaffner, Ingrid. "Jason Rhoades. Four Roades. A Case Study of Contemporary Art and Conservation." VoCA Journal 9 (Fall 2015). http://journal.voca.network/jason-rhoades-four-roads/.

Schechner, Richard. Performance Studies: An Introduction (third edition). London: Routledge, 2013.

Schimmel, Paul. "Leap into the Void: Performance and the Object." In Out of Actions: Between Performance and the Object, 1949-1979, exhibition catalogue. New York: Thames and Hudson, 1998.

Schimmel, Paul. “Only Memory Can Carry It into the Future." In Alan Kaprow, Art as Life edited by E. Meyer-Hermann, A. Perchuk, and S. Rosenthal, 8-19. Los Angeles: The Getty Research Institute, 2008.

Scholte, Tatja, and Glenn Wharton, eds. Inside Installations: Theory and Practice in the Care of Complex Artworks. Amsterdam: Amsterdam University Press, 2011.

Scholte, Tatja. "A Comparative Study into the Conservation of Site-Related Works of Art (Ethnographic and Contemporary)". In The Paradigm of Contemporary Art and Ethnographic Objects, edited by Rita Macedo, 47-62. Art History Institute, Universidade Nova de Lisboa, Lisbon, 2011.

Scholte, Tatja, and Paulien 't Hoen, eds. Project Preservation and Presentation of Installation Art. Amsterdam: Instituut Collectie Nederland, 2007.

Serra, Richard. "Introduction." In The Destruction of Tilted Arc: Documents, edited by Clara Weyergraf-Serra and Martha Buskirk, 3-17. Cambridge, MA: The MITT Press, 1991.

Soja, Edward. Postmodern Geographies: The Reassertion of Space in Critical Social Theory. London: Verso, 1989 .

Soja, Edward. Thirdspace:Journeys to Los Angeles and Other Real and Imaginary Spaces. Cambridge, MA: Blackwell, 1996.

Stallabras, Julian. Contemporary Art: A Very Short Introduction. Oxford: Oxford University Press, 2006.

Stamps, Laura, and Mercedes Pina. Constant: New Babylon; To Us Liberty, exhibition catalogue. Gemeentemuseum Den Haag, 28 May-2 October, 2016. Berlin: Hatje Cantz Verlag, 2016.

Stigter, Sanneke. “Co-Producing Conceptual Art: A Conservator's Testimony." Revista de História da Arte 4 (2015): 103-114.

Stigter, Sanneke. “Between Concept and Material. Working with Conceptual Art: A Conservator's Testimony." PhD diss., University of Amsterdam, 2016.

Stigter, Sanneke. "To Replace or Not to Replace? Photographic Material in Site-Specific Conceptual Art." In Preprints ICOM Committee for Conservation, 14 th Triennial Conference, $365-370$. The Hague, 12-16 September, 2005.

Suderburg, Erika, ed. Space, Site, Intervention. Situating Installation Art. Minneapolis: University of Minnesota Press, 2000.

Van Aubel, Carien. "De Ontrafeling van Gebreid Polyamide. Onderzoek naar het ontstaan van mechanische schade bij kunstwerken uit gebreid polyamide.” Master's thesis, University of Amsterdam (Conservation and Restoration), 2014.

Van Aubel, Carien, Suzan de Groot, Henk van Keulen, Tatja Scholte, and Bill Wei. "Stretch in Space. Research into the Mechanical Properties of Installations of Knitted Polyamide under Stress." Postprints Future Talks 015, 29-38. Munich: Pinakothek der Moderne, 28-30 October 2015.

Van Saaze, Vivian. Installation Art and the Museum: Presentation and Conservation of Changing Artworks. Amsterdam: Amsterdam University Press, 2013.

Van de Vall, Renée. "Towards a Theory and Ethics for the Conservation of Contemporary Art." In d'Art aujourd'hui, patrimoine de demain. Conservation et restauration des œuvres contemporaines, edited by Muriel Verbeeck-Boutin, $51-56$. Paris: Institut national du patrimoine (13es journées d'études de la SFIIC), 24-26 June 2009.

Van de Vall, Renée, Hanna Hölling, Tatja Scholte, and Sanneke Stigter. "Reflections on a Biographical Approach to Contemporary Art Conservation." In Preprints ICOM Conservation 
Community 16 th Triennial Conference, 1-8 (only available in electronic version). Lisbon, 19-23 September, 2011.

Van de Vall, Renée. "The Devil and the Details: On the Relevance of Conservation Practice for the Theory of Contemporary Art and Vice Cersa." British Journal of Aesthetics 55, no. 3 (2015): 285-302.

Van Wegen, Rik H. "Between Fetish and Score: The Position of the Curator of Contemporary Art." In Modern Art: Who Cares? An International Research Project and International Symposium on the Conservation of Modern and Contemporary Art, edited by IJsbrand Hummelen and Dionne Sillé, 201-209. London: Archetype Publications, 2006 [1999].

Verbeek, Peter-Paul. What Things Do: Philosophical Reflections on Technology, Agency, and Design. Pennsylvania: The Penn State University Press, 2005.

Weyergraf-Serra, Clara, and Martha Buskirk. The Destruction of Tilted Arc: Documents. Cambridge, MA: The MITT Press, 1991.

Wharton, Glenn. "Reconfiguring Contemporary Art in the Museum." In Authenticity in Transition: Changing Practices in Art Making and Conservation, edited by Erma Hermens and Frances Robertson, 27-36. London: Archetype Publications, 2016.

Wharton, Glenn. The Painted King: Art, Activism, \& Authenticity in Hawaii. Honolulu: University of Hawaii Press, 2011.

Wharton, Glenn, and Harvey Molotch. "The Challenge of Installation Art." In Conservation: Principles, Dilemmas and Uncomfortable Truths, edited by Alison Bracker and Alison Richmond, 210-222. Oxford: Elsevier, 2009.

Wharton, Glenn. "The Challenges of Conserving Contemporary Art." In Collecting the New: Museums and Contemporary Art, edited by Bruce Altshuler, 163-178. Princeton: Princeton University Press, 2005.

Wigley, Mark. Constant:New Babylon. The Hyper-Architecture of Desire. Rotterdam: naio1o, 1998.

Yaneva, Albena. Mapping Controversies in Architecture. London: Ashgate, 2012.

Yaneva, Alabena. "A Building's Trajectory." In Coping with the Past: Creative Perspectives on Conservation and Restoration, edited by Pasquale Gagliardi, Bruno Latour, and Pedro Memelsdorff, 17-45. Florence: Casa Editrice Leo S. Olschki, 2010.

Yaneva, Alabena. "When a Bus Met a Museum: Following Artists, Curators and Workers in Art Installation." Museum and Society 1,3 (2003): 116-131.

Zwirner, David. “Jason Rhoades: Black Pussy (Press Release).” David Zwirner Gallery, 13 November 2007-26 January 2008. 


\section{Index}

\section{Subjects}

actant/actor $36,57,75-76,89,98-107,109-110$, $112,116,124,127,134,172,190,197,222$, 242-244

Actor-Network Theory 98-99

aesthetic appearance see aesthetics

aesthetics $51,55,124-125,135,145,149-15^{2}, 155$, $164,200,208,213-214,217,225,227,230-233$, 235-237

agency/agent $99-100,103-105,155,167,213-214$, 221, 246

allographic and autographic works 94

alteration $186,189,241-242$

architectural space/architectural struc-

ture $37,5^{0}, 81,86,88,103,108,125,203-204$, $210,218,222,231,236$

architecture $35,42,78,80-81,91,103-104,119$, $122,125-126,131,135,209-210,233$

art-and-community project $\quad 195,197-199$, 202-204, 210, 212, 223, 235

art history/art historical 21, 29, 32-35, 41, 51, $53,60,178,214,225,239-241,244,249$ artist

artist intention $19,39,47,57-58,66,92,101$, $104,106,135,188,193,212$

artist opinion $\quad 28$

artist passed away $17,38,112,158,162,234$ communication with the artist 92,155 , 191, 243

artistic strategy $\quad 57,62,72,159,241$

art market $\quad 21,43,5^{2}$

authenticity $92-94,156,219,230,245$

biographical approach/biographical perspective $30-32,93$

biographical stage $\quad 31-32,68,75^{-7} 6,85,89$, 95-96, 103, 105, 109, 111, 116, 131, 136, 162, 192, $212,236,249$

collaboration with artists $53,164,232$, 242-244

connectivity $20-21,33,75,79,103,111,139-240$ construction

construction material $167,169,181,184,216$ construction site 63

material construction $115,119,122,129$, 147,153

spatial construction $\quad 23,27,47,117-118$, 147,237

consumer product/society $\quad 21,158,163-164$, 183-184

continuation and change $\quad 22,29,91,214,217,223$

continued existence $52,187,204,219,244$

continued practice $\quad 53,151,160,162,223$

conversation $50,119,172,176,223,233,254$ coproducer/coproduction $38,125,158,174$, 190, 244

craftsmanship/craftspeople $127,131,148,15^{2}$, 195-197, 201, 203, 207-208, 210, 213, 217-218, 222-223, 225-226, 236

cultivation $38,165,169-170,174,187$

curatorial curatorial decision-making $38,158,162$, $178,186,191,243$

curatorial intervention $187,241-242$

curatorial practice $\quad 47$

curatorial scenario 188,237

curatorial strategy $39,112,183,190,226$, $228,233,244$

deadlock (of the artwork) 29, 117, 136, 152, 240,243

de-scripting the artwork 102-104, 116

designed space 88,126

dialogue ongoing $57,189,219,243$

documentary $26,45,111,200,211,229,232-235$ documentation $17,28,36,56-57,63,65,72,97$, 139-140, 142, 186, 196, 214, 216, 232-233

dramaturg/dramaturgy $\quad 239,247-249$

embodied knowledge $\quad 139$

engagement $57,59,77,131,135,141,174,198$, 219, 225-226, 239

fabrication $116,122,127,131,133,148,152,182$ freeze $162,185^{-189}, 192,248$

geographical site-specific project $\quad 67,69$ globalization $32-33,41,66,69,163,199-200$, 202, 208, 211

heterotopia $\quad 78-79$

imaginary space $\quad 79,164,170$

institution

institutional critique $\quad 42,66,67$

institutional philosophy $\quad 86,190-191$

institutional policies $34,47,80,87,116,15^{8}$ instruction see set of instructions

knowledgeable network 115, 139, 141, 243

life

afterlife of the artwork $19-20,52,219$ extended life of the artwork $17,22,41,48$, $56,152,189,239$

lived space $86-87,107,126,131,190,226,236$ local $33,50,67,69,107,196-198,208,211-212$, $217,222,249$ 
materiality $78,116,122,147,149,156,180$ meaning

meaning of the artwork $20,22-23,34,36$, $59-60,93,95-96,98,133,149,156,174,244$ meaning of the site $33,37,44,59-60,80$, $191,221,235,244$

meaning production $\quad 32,34,98,146,155$, $177,187,190,214,226,236$

symbolic meaning $79,86,126,148,172$ media art $\quad 92-93$

natural process $159,169,172,176,182,213$ food $165,167,185$

network

network of site-specific functions 20,41 , $75,158,177,182,208$

network of spatial functions $35-36,76,81$, $89,96,111,134,144,146,158,174,193,197$, 241, 246

networks of care 35

production network 151

relational network $15,30,34,72,242$

spatial network $39,80,89,110,112,131,136$, $142,186-187,191,198,217,240,245$

open-ended artwork $140,162,177,179,186,225$

PeaRoeFoam $162,167,172-173,178,181-182$, 188-189

performance

performance of the artwork 93, 96-98, $103,105,107,116,135^{-13} 6,15^{8}, 247$

performativity $19,62,72,90-91$

performance art $17-19,56,141-243$

physical interaction $122,124,134,145,150-151$,

$153,177,242$

physical location $38,43,45,48,75,125,131$,

$170,174,176,178,186$

popular culture $157,62-163,169$

process art 47,63

production space $127-128,131,145,148,151,158$,

174-175, 186, 191, 198, 222-223, 225

psychogeography 209-210

public's interaction see visitors' interaction

reconstruction $\quad 17,65-66,109,149,188,209$

refabrication $109,116,146-148,155$

reinterpretation $58,93,190,192,239,244$

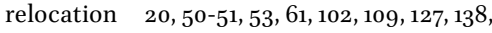
$157,164,198,239$

remake $\quad 37,48,5^{2}, 108,116-117,128-129,145^{-14}$,

$149,151-153,156,158$

representation of space $81-83,86,123,165,220$ routines $85,106,125,175$

scenography $186,190,239,245^{-24} 6$

set of instructions $16,95-96,104-105,129,140$, $216,219,242$

singular/singularity $19,24,56,59,72,115,164$

site-generic $39,189-190,225,227$

Situationist International 195, 209-210, 228, 234

skills $85,131,195,207,210-211$

social space

social space of perpetuation and care ${ }^{155^{-}}$ $156,186-187,191,198,225,236$

social space of production $158,187,208$, $236-237,240$

social space of the visitors' experience 96 , $133,151,153,156,176,235$

sociocultural context $20,48,66,72,75,80,96$, $98,112,183$

sociogeographical $38,71,113,196-198,211,214$, $223,227,233,235,237$

space (according to Henri Lefebvre)

conceived space 81,240

perceived space $83-84,126,241$

spatial design $\quad 20,61,75-113,240,242,246$

triad of spatiality $76,81,100,103,106,109$, $111,116,123,126,165,175,187,197,240-241$ staging

first staging $97,126,130,158,174,176-178$, 191, 208, 219

second staging $117,131,136,140,15^{8}$, $177-178,187-188,191-192$

transformation $31,34,39,53,72,76,80,82,87$, $127,157,197,212,236,242$

transformative (art) $\quad 20,34,87,89,247$

transition $31,38,88,112,116,134,140,197,216$, $224,227,236$

unruly objects $34,38,62,72,75,87,156,175$, 244

urban

urban research $\quad 200,210-211,214,220,228$

urban structure 195-196, 200, 202-203, 209, 233, 237

utopian city $195,198,204,210-211,222$

visitors' interaction $\quad 142,177$

visitors' interaction $116,122,126,131-132$,

134-136, 155, 239

vocabulary $35,42,100,240,245$

white cube gallery $44,88,147,149,182$,

$187-188,190,233,237$

\section{Persons}

Akrich, Madeleine $\quad$ 100-104, 116, 129, 136, 216, 242 Austin, J.L. $\quad$ 96-91

Bakker, Marjolijn de $\quad 122,128,132,136$ Beck, Jee-Sook 202-203 
Beeren, Wim $\quad 46,108,125$

Berndes, Christiane $\quad 164,176-178,179-182,190$, 211, 213-214, 217-219, 226-227, 231

Bismuth, Julien $\quad 162,172,182,188-189$

Björgúlfsson, Heimir 172

Bohlmann, Carolin $\quad$ 161-162

Braber, Wout $127,129-130,153$

Caianiello, Tiziana 97

Cherry, Deborah $\quad 31,211-212,223$

Constant Nieuwenhuys $198,209-210,214,217$, 225, 228-230, 232-235, 237

Debbaut, Jan 164, 179

Debord, Guy 209-210

De Maria, Walter 43,126

Domínguez Rubio, Fernando $\quad 34,62,72,87$, $175,242,244$

Esche, Charles $\quad 178,195,197-198,202-203,208$, 211-214, 219, 222-223, 225-226, 231, 244

Ex, Sjarel 124-126, 130

Flavin, Dan 109

Fletcher, Annie $\quad 178$

Flying City $38,113,195,197-201,203-204$, 208-210, 214, 216-218, 223, 225, 227-228, 236, 244

Foucault, Michel $\quad 78-79$

Gilman, Julie 184-186

Goodman, Nelson 94

Hanru, Hou 202, 208, 211, 223

Jeon, Yongseok 195, 198-200, 202-204, 208, 210, $212,214,218,220-225,244$

Judd, Donald 186-182, 186-187

Kaprow, Allan $\quad 15-18,20-21,24,56,88,97,239$

Kaye, Nick $\quad 41,60-62,72,103,175$

Kortun, Vasif 212

Kremer, Mark 200, 202-204, 207, 218, 223

Kwon, Miwon $32-33,41-45,51-52,55^{-} 56,60$, $62,67,71-72,87,244$

Latour, Bruno $\quad 98-100,102-103,106,116,216$

\section{Artworks discussed}

Aldo van Eyck and Constant, Ruimte in kleur 234

Allan Kaprow, Yard $\quad$ 15, 17-20, 24, 56, 97, 239

Andy Goldsworthy, White Walls 56-58, 247

Constant Nieuwenhuys, New Babylon 195, 198, 210-211, 214, 217, 225, 228-230, 232-235, 237

Dieter Roth, Gartenskulptur $\quad$ 157, 159-162, 192

Donald Judd, Untitled $\quad$ 180-182, 186-187

Ernesto Neto, Leviathan Thot 119

Ernesto Neto, Navedenga $\quad 147^{-152,156}$

Ernesto Neto, Um Sagrado Lugar 118

Ernesto Neto, We Fishing the Time 116, 138-139, $150,15^{2}$

Flying City, Power of Cheonggyecheon 201-202, 204, 223

Jason Rhoades, Costner Complex 172

Jason Rhoades, P.I.G. $\quad$ 157, 164, 183-187, 189, 192
Laurenson, Pip $\quad 35,70,92-95,140-141$

Lefebvre, Henri $\quad 35-36,42,73,75^{-86}, 88-89,96$, $100,103,111,116,125-127,148,165,170,175,187$, 190, 193, 220-221, 226, 235-236, 240-241, 249

Macel, Christine $\quad 118$

Matyssek, Angela 161

Melchionne, Kevin 59, 72

Meyer-Hermann, Eva 17, 164, 167, 169-170, 172,176

Morris, Robert $\quad 46-47,53,63-65,83,189$

Neto, Ernesto $\quad 36-37,112,115-120,122-123$, 126-130, 135-140, 145, 147-153, 155-156, 192, 216, 242-243

Noel de Tilly, Ariane $\quad$ 94, 102-103

Noordegraaf, Julia $94,104,122,125,233$, 247-248

O'Doherty, Brian $\quad 44,46,190$

Rapmund, Jacqueline 122, 127, 145

Rhoades, Jason $\quad 37-38,112,157-159,162-165,167$, 169-170, 172-179, 181-193, 243-244

Rist, Pipilotti $\quad 115,117,137$

Rosenthal, Mark 17, 23, 44, 60-61, 72

Roth, Björn 160, 162

Roth, Dieter $157,159-160,192$

Schaffner, Ingrid 193

Schechner, Richard 19, 91

Sehgal, Tino 140

Serra, Richard $41,46,48,5^{0-51,53-56,61}$, $72-73,83,106-111,125-126,241$

Soja, Edward $\quad 77-78$

Stallabras, Julian 135

Van Aubel, Carien $\quad 117,137,141$

Van de Wiel, Margo $\quad 165,173,218,223$

Van Kampen, Saskia $\quad$ 109-110

Van Saaze, Vivian $\quad 35,92,94,98,140$

Wharton, Glenn $\quad 92,94,219,245$

Yaneva, Albena 103

Zwirner, David $\quad$ 162-164, 172, 181-182

Jason Rhoades, The Black Pussy $163-164,187$ Jason Rhoades, The Purple Penis 164,181 Olafur Eliasson, Life $\quad 25$

Olafur Eliasson, Notion Motion 24-29, 36

Olafur Eliasson, The Weather Project 24

Phil Collins, they shoot horses $\quad 69-71,85,196$

Pipilotti Rist, Let your hair down 153

Richard Serra, Splashing $\quad 48,53,55,61,73$

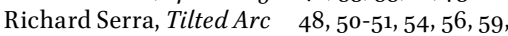
$72,106-108$

Richard Serra, Waxing Arcs $\quad$ 106, 108-111, 125, 241

Robert Morris, Amsterdam Project $\quad 63-66$, 69,189

Robert Morris, Continuous Project $\quad 47,63$

William Pope.L, Yard (to Harrow) 17-18 
